\title{
Exercise and nutrition to support healthy aging
}

Citation for published version (APA):

Leenders, M. (2016). Exercise and nutrition to support healthy aging. [Doctoral Thesis, Maastricht University]. https://doi.org/10.26481/dis.20160623ml

Document status and date:

Published: 01/01/2016

DOI:

10.26481/dis.20160623ml

Document Version:

Publisher's PDF, also known as Version of record

\section{Please check the document version of this publication:}

- A submitted manuscript is the version of the article upon submission and before peer-review. There can be important differences between the submitted version and the official published version of record.

People interested in the research are advised to contact the author for the final version of the publication, or visit the DOI to the publisher's website.

- The final author version and the galley proof are versions of the publication after peer review.

- The final published version features the final layout of the paper including the volume, issue and page numbers.

Link to publication

\footnotetext{
General rights rights.

- You may freely distribute the URL identifying the publication in the public portal. please follow below link for the End User Agreement:

www.umlib.nl/taverne-license

Take down policy

If you believe that this document breaches copyright please contact us at:

repository@maastrichtuniversity.nl

providing details and we will investigate your claim.
}

Copyright and moral rights for the publications made accessible in the public portal are retained by the authors and/or other copyright owners and it is a condition of accessing publications that users recognise and abide by the legal requirements associated with these

- Users may download and print one copy of any publication from the public portal for the purpose of private study or research.

- You may not further distribute the material or use it for any profit-making activity or commercial gain

If the publication is distributed under the terms of Article $25 \mathrm{fa}$ of the Dutch Copyright Act, indicated by the "Taverne" license above, 


\section{Exercise and nutrition to support healthy aging}

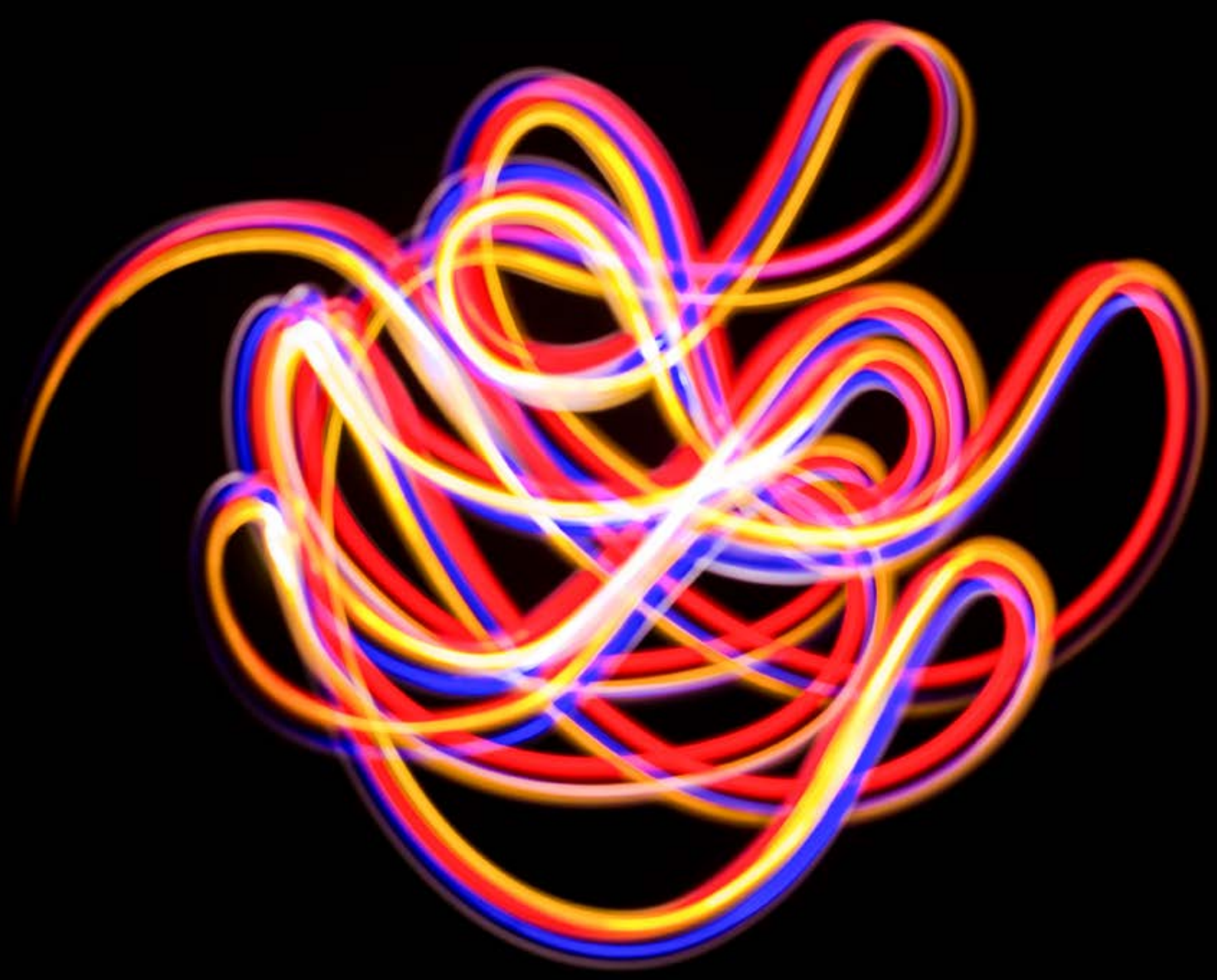

Marika Leenders 


\section{ÖNUTRIM}

The work presented in this thesis was performed within NUTRIM, School for Nutrition and Translational Research in Metabolism, which participates in the Graduate School VLAG (Food Technology, Agrobiotechnology, Nutrition and Health Sciences), accredited by the Royal Netherlands Academy of Arts and Sciences.

Cover design: Marika Leenders \& Lut Geusens

Printed by: Datawyse, Universitaire Pers Maastricht

ISBN 9789461595737

(C) Copyright Marika Leenders, Maastricht 2016

All rights reserved. No part of this thesis may be reproduced or transmitted in any form or by any means electronic, or mechanical, including photocopying, recording or any information storage or retrieval system, without permission from the author in writing, or when appropriate, from the publishers of the publications. 


\title{
Exercise and nutrition to support healthy aging
}

\author{
DISSERTATION \\ to obtain the degree of Doctor at Maastricht University, \\ on the authority of the Rector Magnificus Prof. dr. L.L.G. Soete \\ in accordance with the decision of the Board of Deans, \\ to be defended in public on Thursday, $23^{\text {rd }}$ June 2016 , at 14:00 hours
}

by

\section{Marika Leenders}

Born in Genk, Belgium, 22 October 1982

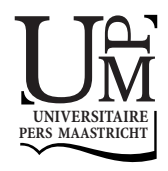


Promotor

Prof. dr. L.J.C. van Loon

\section{Copromotor}

Dr. L.B. Verdijk

\section{Assessment Committee}

Prof. dr. ir. A.M.W.J. Schols (chair)

Prof. dr. ir. C.P.G.M. de Groot (WUR, Wageningen)

Prof. dr. S. Kremers

Prof dr. J.M.G.A. Schols

Dr. M. de van der Schueren (HAN, Arnhem \& Nijmegen) 


\section{CONTENTS}

CHAPTER 1

CHAPTER 2

CHAPTER 3

CHAPTER 4

CHAPTER 5

CHAPTER 6

CHAPTER 7
General Introduction

Leucine as a pharmaconutrient to prevent and/or treat sarcopenia and type 2 diabetes

Prolonged leucine supplementation does not augment 55 muscle mass or affect glycemic control in elderly type 2 diabetic men

Patients with type 2 diabetes show a greater decline in 73 muscle mass, muscle strength, and functional capacity with aging

Protein supplementation during resistance type exercise training in the elderly

Elderly men and women benefit equally from prolonged resistance type exercise training

General Discussion

Summary

Samenvatting

Valorization

Dankwoord

Curriculum Vitae

Publications 

CHAPTER 1

General Introduction 
Skeletal muscle tissue plays an indispensable role in several physiological functions of the human body. Skeletal muscle is primarily responsible for producing the forces that are needed to generate movement of the body. In accordance, muscle mass is a strong predictor for muscle strength and functional performance. Furthermore, skeletal muscle tissue represents a major metabolic organ, accounting for $\sim 70 \%$ of body cell mass. As such, skeletal muscle tissue plays a major role in glucose, fat, and protein metabolism.

Aging is associated with a substantial decrease in skeletal muscle mass and muscle strength. The decrease in muscle mass with aging eventually leads to muscle weakness and major disabilities in day-to-day life. This is accompanied by a decrease in functional capacity and physical performance, and an increased likelihood of developing chronic metabolic diseases like type 2 diabetes, obesity, and osteoporosis. The loss of muscle mass and strength is also referred to as sarcopenia. Sarcopenia is recognized as an important factor in determining the ability of elderly people to live an independent life, and it is associated with a decrease in quality of life (1). Due to greater longevity, the subpopulation of elderly people is presently the fastest growing subpopulation in the developed world. This global aging will have a major impact on our healthcare system and will increasingly become a socio-economic problem. The detrimental consequences of sarcopenia make it essential to improve health in elderly people; reversing and/or attenuating sarcopenia will help elderly people to remain independent and to continue to actively take part in family and community life. Intervention strategies are necessary to improve muscle mass and muscle function in the elderly and, as such, support healthy aging.

In this thesis, the effects of different prolonged intervention strategies are studied on a whole body, limb, and myocellular level in various elderly populations. Specific attention is given to exercise and nutritional interventions to counteract the agerelated loss of skeletal muscle mass and strength. In these intervention programs the focus lies on skeletal muscle mass, strength and functional capacity, and the associated changes in the metabolic profile.

\section{Aging}

In almost every country in the world, the proportion of people aged over 60 years is growing faster than any other age group (2). This is no different from the European region, where the median age is already the highest in the world, and the proportion of people aged 65 and older is estimated to increase to $25 \%$ by 2050 (2). Likewise, in the Netherlands the proportion of elderly ( $>65 \mathrm{y}$ ) in the population is estimated to increase from $\sim 15 \%$ to $\sim 25 \%$ within the next 40 years (3). This global aging will have a major impact on our healthcare system due to increased morbidity and greater need for hospitalization and/or institutionalization (4). The increased morbidity in the elderly is associated with a progressive decline in skeletal muscle mass and strength. The age-related loss of muscle mass has been termed sarcopenia. Sarcopenia has substan- 
tial negative health consequences. It is associated with a decreased metabolic rate, increased body fatness, loss of bone mass and reduced muscle strength and function.

\section{Age related muscle loss}

Between the age of 20 and $30 \mathrm{y}$, skeletal muscle mass peaks in humans, averaging $\sim 42 \%$ of body mass for men and $\sim 34 \%$ for women (5). After the age of 30 , muscle mass gradually decreases by approximately $3-8 \%$ per decade, and this rate of decline is even higher after the age of 60 . Over the lifespan, this accounts for a total decline in wholebody muscle mass of $30-40 \%(5,6)$. For both men and women, the decrease in muscle mass is greatest in the extremities, and mainly in the lower limbs. For example, Lexell et al (6) observed a difference of up to $50 \%$ in the cross-sectional area of the quadriceps muscle between $90-y$ and 20 -y old subjects. Besides the decrease in whole-body and regional lean mass and muscle cross-sectional area, qualitative changes include an increase in connective tissue and fat infiltration into the muscle $(7,8)$.

On the muscle fiber level, Lexell et al (8) showed a decrease in both type I and type II muscle fiber numbers with aging. Additionally, some studies have shown an increased proportion of type I muscle fibers in elderly people, potentially implying the predominant loss of type II muscle fibers $(9,10)$. Interestingly, type I muscle fiber size does not seem to be different between young and elderly individuals. In contrast, type II muscle fiber size is $25-50 \%$ lower in the elderly when compared with the young $(6,8$, $10,11)$. Verdijk et al (11) also showed that type II muscle fiber atrophy in the elderly is accompanied by a type II muscle fiber specific decline in satellite cell content. Furthermore, fiber type grouping (6) and decreased capillarization (12) have been observed in elderly muscle tissue. In a recent study from our research group (13), we report that quadriceps muscle cross-sectional area is $\sim 14 \%$ smaller in healthy elderly men (71 y) when compared with healthy young men (23 y). In addition, type II muscle fiber size was $\sim 30 \%$ smaller in the elderly versus the young. As the calculated number of fibers in the quadriceps muscle did not differ between these younger and older men, these results suggest that at least up to a certain age, specific type II muscle fiber atrophy is likely responsible for the majority of the differences in muscle mass between age groups (13).

Muscle mass represents a major determinant of muscle strength (14). In line with the decrease in skeletal muscle mass, Lindle et al (15) showed an age related decline in knee extensor strength starting in the fourth decade of life, and progressing at a rate of $~ 8-10 \%$ per decade in both men and women. It should be noted that the loss of muscle strength in older men and women is much more rapid than the concomitant decrease in muscle mass. Goodpaster et al (16) even reported an annualized rate of strength decline of $3.6 \%$ in men and $2.8 \%$ in women between the age of 70 and $79 \mathrm{y}$.

Importantly, muscle strength is closely associated with functional performance. The strong correlation between muscle strength and functional performance in elderly is 
depicted in Figure 1, showing that lower leg extension muscle strength is associated with a reduced ability to stand up from a chair. In agreement, Bassey et al (17) reported a significant correlation between leg extensor power and the capacity to rise from a chair, climb the stairs and walking speed. Consequently, the involuntary loss of muscle mass and strength is a fundamental cause of and contributor to functional disability in elderly people. As such, sarcopenia generally increases the risk of falls and vulnerability to injury, culminating in a state of increased functional dependence $(18,19)$, and eventually leading to increased morbidity, institutionalization, and an overall reduction in quality of life (20).

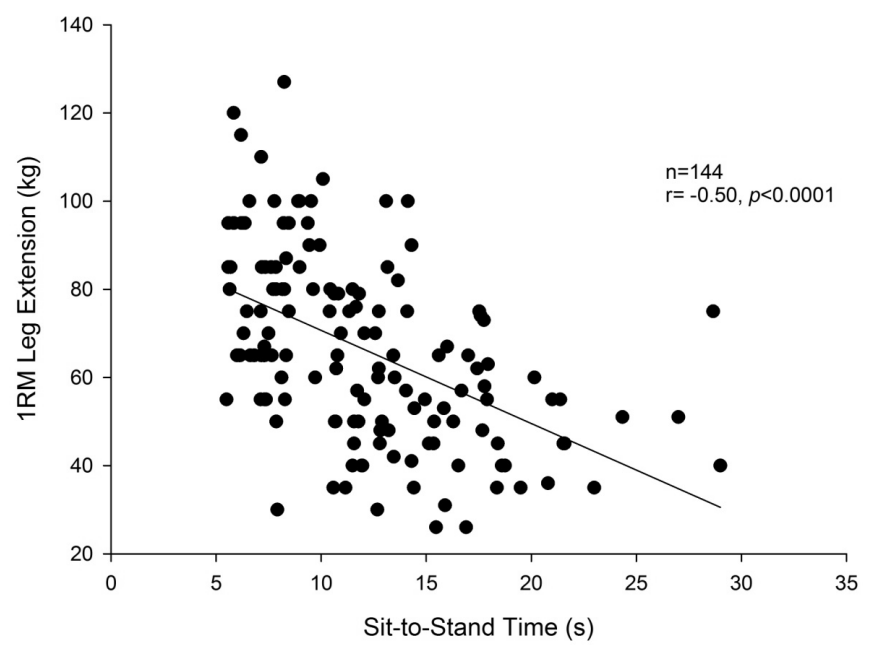

Figure 1: Correlation between sit-to-stand time and one repetition maximum (1RM) leg extension strength (age 65-93y). Leenders et al, (unpublished observations).

Apart from the functional consequences of sarcopenia, it should be taken into account that skeletal muscle tissue is a major metabolic organ. Contributing as much as $70 \%$ of body cell mass, skeletal muscle is responsible for $\sim 30 \%$ of resting energy expenditure and protein turnover, and accounts for $\sim 70-80 \%$ of glucose disposal after a meal. A reduction in muscle mass and physical activity decrease total energy expenditure in the elderly, resulting in enhanced fat accumulation. As a result sarcopenia is associated with an increased risk of developing chronic metabolic diseases, like type 2 diabetes, obesity, osteoporosis, and cardiovascular disease (21). Life-long health promotion is warranted to prevent or delay the onset of these chronic metabolic diseases.

\section{Defining sarcopenia}

The term sarcopenia was first introduced by Rosenberg in 1989 (22) to draw more attention towards the problem of progressive loss of skeletal muscle mass and 
strength with aging. This has undoubtedly helped to direct more research efforts into understanding the epidemiology, as well as the causes and consequences of sarcopenia. Sarcopenia is highly prevalent in older people, has a multifactorial etiology, and is frequently overlapping and associated with decreased physical performance, reduced strength, mobility impairments, disability and poor quality of life (23). It should be noted that sarcopenia is not associated with a specific disease state and is, therefore, distinct from cachexia and/or muscle wasting which is related to an underlying illness such as cancer, kidney disease, chronic obstructive pulmonary disease (COPD), or heart failure $(24,25)$.

Despite the increased attention for the age-related loss of muscle mass and function over the past 25 years, a suitable definition of sarcopenia that can be used in research and clinical practice is still lacking. The most commonly used definition of sarcopenia has been proposed by Baumgartner et al (26) and is based on a skeletal muscle mass index obtained by dividing appendicular skeletal muscle mass (ASM) evaluated by DXA, by body height squared (ASM/ht ${ }^{2}$ ). According to this definition, individuals presenting an ASM $/ \mathrm{ht}^{2}$ ratio between 1 and 2 standard deviations (SD) below the gender-specific average of young controls are categorized as having class I sarcopenia. Individuals with ASM $/ \mathrm{ht}^{2}>2 \mathrm{SD}$ below young controls are categorized as having class II sarcopenia $(5,27,28)$. Using this definition, the prevalence of sarcopenia in a population-based sample of people above the age of 60 years was shown to be $\sim 25 \%$, and up to $50 \%$ in the individuals aged 80 years and over.

In 2010, the European Working Group on Sarcopenia in Older People (EWGSOP) presented a renewed definition of sarcopenia, and introduced several treatment guidelines to counteract sarcopenia. The EWGSOP proposed using both the presence of both low muscle mass, and low muscle strength and/or muscle performance for the diagnosis of sarcopenia. As described by the EWGSOP, a wide range of techniques can be used to measure muscle mass, muscle strength, and physical performance (Table 1). Computed Tomography (CT) and Magnetic Resonance Imaging (MRI) are gold standards for the assessment of muscle mass in research. Dual Energy X-ray Absorptiometry (DXA) is the preferred alternative method for research and clinical use. Compared to muscle mass, there are only a limited amount of well-validated techniques to measure muscle strength. Handgrip strength represents a reliable and simple representation of muscle strength, and has been shown to be strongly related to lower extremity muscle power, and knee extension torque (29). Knee flexion/extension techniques are very suitable in scientific research, however their use in clinical practice is limited due to the need for special equipment and training. To assess physical and/or functional performance, a wide set of tests are available such as the Short Physical Performance Battery (SPPB), the usual gait speed, 6-min walking test, and the stair climb power test. The SPPB, which consists of gait speed, balance, and sit to stand time, is the standard measure for both research and clinical practice. However, it should also be noted that parts of the SPPB can give a good indication of physical performance in the elderly (30). 
Implementation of the measurement of muscle mass, strength and physical performance for the definition and/or diagnosis of sarcopenia is now gradually being incorporated in research settings (31-33). However, epidemiological data on the prevalence of sarcopenia in the general population using the definition of both reduced muscle mass and reduced muscle strength/function are only in an early stage (34).

Table 1: Measurements of muscle mass, strength, and function in research and practice.

(Adapted from Cruz-Jentoft et al, Age and Aging, 2010 (35))

\begin{tabular}{lll}
\hline Variable & Research & Clinical Practice \\
\hline Muscle Mass & Computed tomography (CT) & Dual Energy X-ray Absorptiometry (DXA) \\
& Magnetic Resonance Imaging (MRI) & Bioimpedance Analysis (BIA) \\
& Dual Energy X-ray Absorptiometry (DXA) & \\
& Bioimpedance Analysis (BIA) & Anthropometry \\
& Total or partial body potassium & \\
& per fat free soft tissue & \\
& Handgrip Strength & Handgrip Strength \\
Muscle Strength & Knee flexion/extension & \\
& Peak expiratory flow & \\
Shysical Performance Physical Performance Battery(SPPB) & Short Physical Performance Battery (SPPB) \\
& Usual gait speed & Usual gait speed \\
& Timed get-up-and-go test & Get-up-and-go test \\
& Stair climb power test & \\
\hline
\end{tabular}

\section{Causes of sarcopenia}

The etiology of sarcopenia is a complex, multifactorial process. The decline in skeletal muscle mass with aging must be attributed to a disruption in the regulation of skeletal muscle protein turnover, leading to a structural imbalance between muscle protein synthesis and protein breakdown. Initial studies have suggested an age-related reduction in basal muscle protein synthesis rates (36-40). However, more recent data indicate that basal muscle protein synthesis rates do not differ between young and elderly adults $(19,41-44)$. Similarly, whole-body protein breakdown rates do not seem to differ between healthy young and elderly subjects. As such, it is currently believed that the muscle protein synthetic response to anabolic stimuli may be attenuated in the elderly, thereby explaining the loss of muscle mass over time.

Several factors have been suggested to be involved in the etiology of sarcopenia including immunological, hormonal, neurological, nutritional, and physical activity changes. Several studies have suggested a subtle increase in circulating concentrations of inflammatory cytokines in elderly people. A higher inflammatory state could be the cause of increased muscle protein catabolism in the elderly (45). Roubenoff et al (46) reported an increase of IL- 6 and IL-1Ra (IL-1 receptor antagonist) production in the 
elderly compared to healthy young subjects. This increase in IL-6 was also correlated with an increased production of C-reactive protein (CRP), a marker for inflammation. Several more recent studies $(47,48)$ indicate that high levels of IL-6 and/or CRP may contribute to the loss of muscle strength in elderly people. In a recent study by Schaap et al (49), higher levels of IL-6, CRP and TNF- $\alpha$ were shown to be associated with a larger reduction in thigh muscle area in an elderly population as measured over a period of 5 years. An increase in TNF- $\alpha$ was also shown to be associated with a decline in muscle strength.

Hormonal changes have also been implicated as contributing factors to the development of sarcopenia. During aging decreased concentrations of testosterone, estrogen, growth hormone $(\mathrm{GH})$ and/or insulin like growth factor-1 (IGF-1) have been observed $(50,51)$. There are epidemiological data supporting the relationship between the fall in testosterone and the decline in muscle mass, strength and functional status $(52,53)$. In a part of the elderly male population, hypogonadism, also known as testosterone deficiency, could also play a role in the development of sarcopenia, because one of the clinical implications of hypogonadism is a decrease in muscle mass and muscle strength (54). The decline in estrogen, associated with menopause in women, may also have net catabolic effects on the muscle (55). In women, hormone replacement therapy can significantly increase serum steroid hormone binding globulin, which leads to a significant decrease in serum free testosterone levels in women (56). Low serum free testosterone is associated with a lower muscle mass in women. Therefore, hormone replacement therapy may play a role in a further reduction of muscle mass in older women (19).

Neurological changes also play an important role in the onset of sarcopenia, with motor unit loss and/or remodeling clearly attributing to some of the effects observed at the muscle fiber level including fiber loss and fiber atrophy $(6,10,23)$. Furthermore, we observed that the decrease in type II muscle fiber size is accompanied by a specific decline in type II muscle fiber satellite cell content (11). The age-related reduction in muscle fiber satellite cell number and/or function may also play a key role in the loss of muscle mass with aging (57-59). Although the loss of type II fibers contributes to the loss of muscle mass, it may also directly contribute to the accelerated loss of muscle strength, given the larger specific force in type II vs type I muscle fibers (60). Similarly, neurological impairments in the recruitment/activation of muscle tissue likely contributes to the finding that muscle strength is lost at an even faster rate than muscle mass. Therefore, intervention studies need to target muscle strength and muscle performance as well as muscle mass.

Two important factors in the etiology of sarcopenia are related to changes in lifestyle. A less than optimal nutrition and physical inactivity are considered two key factors that contribute to the age-related loss of muscle mass and function. It is well known that aging is associated with a decrease in food intake, due to decreased energy expenditure, early satiety and/or social isolation (61). The recommended daily allowance (RDA) for protein intake is set at $0.8 \mathrm{~g} / \mathrm{kg} / \mathrm{d}$. However, the adequacy of the RDA 
has been under discussion for many years. It has been shown by Houston et al (62), that lower dietary protein intake is associated with a greater decrease in lean mass in older community dwelling men and women. Although specific guidelines still need to be established for the elderly population, it seems evident that habitual protein undernutrition contributes to the loss of muscle mass with aging. Furthermore, recent studies suggest that the muscle protein synthetic response to the ingestion of a small amount of essential amino acids (EAA) is attenuated in the elderly $(41,43)$. Katsanos et al (43) reported an attenuated postprandial muscle protein synthetic response following the ingestion of a small meal like amount of EAA $(6.9 \mathrm{~g})$ in the elderly versus the young. Cuthbertson et al (41) assessed the muscle protein synthetic response to the ingestion of different amounts of EAA in both young and elderly men. They showed that even a very large ( $40 \mathrm{~g}$ ) dose of EAA is not sufficient to restore the rate of muscle protein synthesis in older adults. The mechanisms responsible for this "anabolic resistance" to protein/AA intake still need to be further elucidated. Data from Cuthbertson et al (41) and Guillet et al (63) suggest that anabolic signaling is impaired in skeletal muscle of older compared to younger subjects. Another mechanism that could contribute to the anabolic resistance is the impairment in dietary protein digestion and/or absorption (64). However, evidence to support such impairments in elderly humans is still lacking.

Physical inactivity is another significant factor in the development of sarcopenia. Physical activity is an important anabolic stimulus which increases protein synthesis to a large extent. Aging is generally associated with the adoption of a more sedentary lifestyle. This will lead to a reduced muscle mass, resulting in an even further decline in habitual physical activity levels. Epidemiological data have shown that low levels of physical activity are related to an accelerated decline in muscle mass, strength and physical performance (65-67). The effect of physical inactivity can be illustrated by the loss of muscle mass due to prolonged bed rest, which results in a substantial decline in muscle mass in a very short period (68). Physical inactivity and as such muscle inactivity due to prolonged immobility or bed rest will induce muscle atrophy and loss of strength and power as shown in several studies (69-71). This clearly shows that an inactive lifestyle can reduce muscle mass, muscle strength and functional capacity. In addition, special attention needs to be given to periods of "catabolic crisis". Bed rest or acute inactivity associated with disease or hospitalization will lead in to accelerated muscle loss, accompanied with a decrease in muscle strength and functional capacity (72). All of these factors can have detrimental consequences when protein intake, muscle mass, strength and functional capacity are already decreased in the elderly.

To better understand skeletal muscle wasting in healthy elderly, researchers have started to focus on the muscle protein synthetic response to anabolic stimuli such as physical activity and food intake. Recent studies suggest that the muscle protein synthetic response to amino acids/protein $(63,73)$ and physical activity $(74)$ are diminished in the elderly when compared with young controls. This appears to be one of the key factors accountable for the decrease in muscle mass with aging. The importance of 
each factor may show a large inter-individual variability and it remains to be determined whether anabolic resistance is merely a consequence of a more sedentary lifestyle or a consequence of aging per se.

\section{Interventions to counteract sarcopenia}

Several interventions have been performed in an attempt to slow down or reverse the process of sarcopenia. Most of the intervention studies focus on some of the proposed etiological factors of sarcopenia to increase muscle mass, strength and functional capacity: e.g. hormonal interventions, nutritional supplements and exercise. Although hormonal interventions, (i.e. mainly testosterone administration) have been shown effective to increase muscle mass and strength in the elderly (75-77), the long-term safety and efficacy of such interventions remain to be established. On the other hand, both nutritional and exercise interventions may represent much more applicable strategies, inducing less side effects. Promising results have been reported showing improvements in muscle mass and strength in response to prolonged exercise and/or nutritional interventions.

\section{Nutritional interventions}

Protein turnover in skeletal muscle is highly responsive to food intake (78). It has been shown in several studies that the ingestion of amino acids (AA) and/or protein strongly stimulates muscle protein synthesis rates (78-83). It has been shown by Volpi et al (84) that the essential amino acids (EAA) are primarily responsible for the increase in muscle protein synthesis following protein administration. Leucine in particular seems to represent the main anabolic signal responsible for the post-prandial increase in muscle protein synthesis $(85,86)$.

In view of the above, nutritional intervention studies have mainly focused on increasing dietary protein intake and/or on the ingestion of specific protein or (essential) amino acid mixtures thought to augment muscle anabolism. However, evidence from long-term intervention studies still shows many inconsistencies in the apparent benefits of prolonged dietary protein supplementation on skeletal muscle mass in the elderly population. Bonnefoy et al (87) observed a significant increase in muscle mass and power after 3 months of protein supplementation (protein rich supplement, twice daily) in frail elderly people (aged 83 y on average). Borsheim et al (88) studied the effects of 16 wks of essential amino acid supplementation $(11 \mathrm{~g})$ twice daily on muscle mass and strength in elderly subjects (approximately $67 \mathrm{y}$ of age). They reported a 22.2 $\pm 6.1 \%$ increase in muscle strength but no changes in muscle mass. A recent study by Tieland et al (89) showed that 24 wks of dietary supplementation (15 g provided twice daily) did not augment muscle mass in frail elderly people. However, they did observe an improvement in physical performance following protein supplementation. In con- 
trast, others have failed to report any measureable impact of long-term dietary protein supplementation on muscle mass, strength and function in healthy elderly subjects (90-93). Several parameters can influence the effect of protein supplementation on muscle strength and physical performance. The effect of dietary supplementation can be dependent on the amount of proteins used, timing of the protein supplementation, the type of amino acid(s), the duration of the supplementation and the composition of the proteins. As such, it still remains to be determined which approach for dietary supplementation will be most successful to support increases in muscle strength and improve physical performance.

Some researchers believe that the attenuated response to food intake in the elderly can be, at least partly, compensated for by increasing the leucine content of a meal $(42,94)$. Wall et al $(95)$ showed that leucine co-ingestion with a bolus of dietary protein further augments post-prandial muscle protein synthesis in elderly men. We previously investigated the effects of 3 months of leucine supplementation with each main meal $(7.5 \mathrm{~g} / \mathrm{d})$ on skeletal muscle mass and strength in healthy elderly men (96). We did not observe any effect of leucine supplementation on skeletal muscle mass and strength. We concluded that long term leucine supplementation in healthy elderly men does not augment skeletal muscle mass or strength (96). It could be speculated that long-term leucine supplementation is of greater clinical relevance in frail and/or malnourished elderly or in specific clinical subpopulations. In elderly patients with type 2 diabetes, a more rapid decline in muscle mass has been observed with aging. Because of its insulinotropic properties, leucine might be even more relevant as a pharmaconutrient in elderly patients with type 2 diabetes.

\section{Resistance type exercise training}

There is substantial evidence that older adults who are less active are more likely to have lower skeletal muscle mass and strength and are at increased risk of developing sarcopenia $(65,66,68,97)$. As such, it seems reasonable to argue that a physically active lifestyle should be protective for sarcopenia. In line, specific physical activity and/or exercise interventions likely represent valuable strategies in the treatment of muscle loss with aging. In general, resistance type exercise training has been shown to be the most potent stimulus to increase muscle mass and strength. Frontera et al (98) were amongst the first to show that elderly are still capable of increasing skeletal muscle mass and strength in response to resistance type exercise training. They showed in 12 healthy untrained male volunteers, between the age 60 and 72, that a progressive resistance type exercise training program increased leg extension strength by $107 \%$ and quadriceps area by $9 \%$. Since that study, several subsequent studies have confirmed these findings (99-104). Fiatarone et al (101) reported strength gains of up to $174 \%$ and an increase of midthigh muscle area of 9\% after 8 wks of high-intensity resistance type exercise training in ten frail elderly aged $90 \pm 1$ years. At almost the same time, Charette et al performed a 12 week resistance type exercise training pro- 


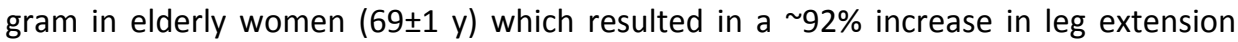
strength. Lexell et al (102) studied both the short and long term effects of heavy resistance type exercise training in elderly men and women aged 70-77 years. They also showed a significant increase in muscle strength after 11 wks as well as a further strength increase when training was continued after that time.

More recently, Kosek et al (100) performed a resistance type exercise training study, where elderly men and women (60-75 y) trained 3 times a week for 16 wks. They observed a $41 \%$ increase in leg extension strength after 16 wks, and they observed no differences between genders (100). Verdijk et al (99) reported comparable results after $12 \mathrm{wks}$ of resistance type exercise training in 13 healthy elderly men $(72 \pm 2$ y) with a $26 \%$ increase in leg extension strength and $9 \%$ increase in quadriceps crosssectional area. Resistance type exercise training has several benefits which include an increase in whole-body lean mass, greater cross-sectional area of the trained muscle, muscle fiber hypertrophy, and substantial gains in muscle strength. Some studies also assessed functional outcomes, showing improvements in walking speed, chair rising and stair climbing $(91,101,105)$. For example, Fiatarone et al (101) reported a $48 \%$ improvement in mean tandem gait speed after $8 \mathrm{wks}$ of high intensity resistance type exercise training in frail elderly ( $90 \pm 1$ y). More recently, Capodaglio et al (105) showed a significant improvement in chair rise, bed rise, 6-min walking test, stair climbing, get up and go and one-legged standing balance after 1 year of resistance type exercise training. Importantly, the increase in muscle mass, strength and function are accompanied by improvements in other (metabolic) health parameters, such as blood pressure, insulin sensitivity and body weight $(106,107)$. As a result, resistance type exercise training is currently the only effective intervention strategy to counteract and/or prevent muscle loss with aging.

The above studies indicate that skeletal muscle tissue in the elderly is still able to respond to resistance type exercise training. However, despite the overwhelming evidence showing the efficacy of resistance type exercise training to increase muscle mass and strength in the elderly, there is still a lot of disparity on the proposed benefits of resistance type exercise training in elderly women vs elderly men. Some studies showed similar $(108,109)$ or smaller $(110-112)$ muscle mass and strength gains in older women compared with older men. On the other hand, Hakkinen et al (113) showed a larger increase in muscle mass and strength in elderly women compared to men after 6 months of resistance type exercise training. It remains unclear whether women benefit to the same extent from prolonged resistance type exercise training as men, and there is still no consensus whether resistance type exercise training programs should be specifically tailored for either gender.

\section{Resistance type exercise training and protein supplementation}

It has been well-established that protein ingestion before, during and/or after a single session of resistance type exercise further stimulates muscle protein synthesis and 
reduces muscle protein degradation in both younger and older individuals (114-116). Surprisingly though, there is little evidence that dietary interventions can further augment the adaptive response to prolonged resistance type exercise training in the elderly. The requirement of sufficient dietary protein consumption in affecting the longterm adaptive response to exercise training has been a topic of recurrent debate (117120). Some researchers recommend that the current RDA for habitual protein intake of $0.8 \mathrm{~g} / \mathrm{kg}$ per day is enough to allow lean mass accretion following resistance type exercise training. Iglay et al (121) reported that when protein intake is standardized at 0.9 $\mathrm{g} / \mathrm{kg}$ per day during a period of resistance type exercise training, no additional benefits are observed when the amount of protein intake per day is further increased (121). Verdijk et al (33) compared increases in skeletal muscle mass and strength following 3 months of resistance type exercise training with or without protein supplementation prior to and immediately after each training session in elderly males. In agreement with previous suggestions (33), protein supplementation did not further augment skeletal muscle hypertrophy in healthy elderly males who habitually consumed $1.0 \mathrm{~g}$ protein/kg bodyweight per day. Taken together, these data suggest that resistance type exercise training will result in substantial gains in muscle mass and strength even when habitual protein intake is maintained and no additional protein is supplemented However, a meta-analysis from our group by Cermak et al (122) has recently shown that protein supplementation can further increase muscle mass and strength gains during prolonged resistance type exercise training in older subjects. This systematic analysis showed that when studies were examined individually, only very few studies reported significant benefits of protein supplementation. However, once the data were pooled it became clear that protein supplementation during resistance type exercise training increases lean mass gains by an additional $38 \%$ when compared to a placebo. In line, a $33 \%$ greater increase in 1RM leg press strength was also reported following protein supplementation during prolonged resistance type exercise training.

There is an ongoing debate on the optimal intervention to increase muscle mass and strength and to improve functional capacity. It has been shown that resistance type exercise training plays a significant role in increasing muscle mass, strength and physical performance. However, a combination of both resistance type exercise training and nutritional intervention seems most promising. However, a specific program to optimize the synergy between the effects of nutrition and exercise remains to be further explored. The amount and type of protein, the intensity/type of training and the timing of the protein ingestion all seem to play a key role. Therefore, in the present thesis we aim to gain further insight in the potential of different nutritional and/or exercise interventions to augment muscle mass and function in the elderly population. 


\section{Outline of thesis}

This thesis describes a series of studies in which we investigate the effects of protein supplementation and resistance type exercise training on muscle mass, strength and functional capacity in the elderly population. In chapter 2, an overview is given of current literature on the potential anabolic properties of leucine. It has been proposed in several studies that leucine is the key amino acid stimulating muscle protein synthesis. As such, long-term leucine supplementation may have the potential to increase muscle mass. More specifically, it has been suggested that increasing the leucine content of a meal represents an effective strategy to augment the muscle protein synthetic response to food intake in the elderly. Therefore, the effects of long term leucine supplementation on muscle mass and function is presented in chapter 3 . In this project, 60 elderly type 2 diabetes patients were randomized to receive 24 wks of leucine or placebo supplementation. In chapter 4 , we present a comparison between elderly type 2 diabetes patients and age matched normoglycemic controls. The aim of this comparison is to evaluate the impact of type 2 diabetes on body composition, muscle strength, functional capacity, and reaction time performance in the elderly.

Chapters 5 and 6 further focus on healthy elderly. Although it has been suggested that dietary protein supplementation can further augment the increase in muscle mass and strength during prolonged resistance type exercise training, most intervention studies have applied relative short intervention periods between 6-12 wks. Chapter 5 presents the outcome of a study in which we performed a 24 week intervention program in which we determined whether protein supplementation can augment the increase in muscle mass and strength in response to prolonged resistance type exercise training in healthy elderly. Subsequently, Chapter 6 extends on the study described in chapter 5 and compares structural, functional as well as metabolic adaptations to prolonged resistance type exercise training between elderly men and women on a whole body, muscle and muscle fiber level. Finally, in chapter $\mathbf{7}$ we discuss the results from the studies above and provide an overview of the main conclusions. Based on these conclusions the practical considerations are discussed and subsequent aims for future research are provided in the light of the studies described in this thesis as well as current knowledge in the field. 


\section{References}

1. Lamberts SW, van den Beld AW, van der Lely AJ: The endocrinology of aging. Science 1997, 278(5337):419-424.

2. WHO. Ageing (Online). http://www.who.int/topics/ageing/en/, 2012.

3. CBS. Prognose bevolking; geslacht en leeftijd, 2016-2060. http:// tatline.cbs.nl/Statweb/publication/?DM=SLNL\&PA=83225ned\&D1=0\&D2=a\&D3=0,131-133\&D4=0,4,9,14,19,24,29,34,39,I\&VW=T: 2016.

4. Saltman RB, Dubois HF, Chawla M: The impact of aging on long-term care in Europe and some potential policy responses. Int J Health Serv 2006, 36(4):719-746.

5. Janssen I, Heymsfield SB, Wang ZM, Ross R: Skeletal muscle mass and distribution in 468 men and women aged 18-88 yr. J Appl Physiol 2000, 89(1):81-88.

6. Lexell J, Taylor CC, Sjostrom M: What is the cause of the ageing atrophy? Total number, size and proportion of different fiber types studied in whole vastus lateralis muscle from 15- to 83-year-old men. J Neurol Sci 1988, 84(2-3):275-294.

7. Goodpaster BH, Carlson CL, Visser M, Kelley DE, Scherzinger A, Harris TB, Stamm E, Newman AB: Attenuation of skeletal muscle and strength in the elderly: The Health ABC Study. J Appl Physiol 2001, 90(6):2157-2165.

8. Lexell J: Human aging, muscle mass, and fiber type composition. J Gerontol A Biol Sci Med Sci 1995, 50 Spec No:11-16.

9. Dreyer HC, Blanco CE, Sattler FR, Schroeder ET, Wiswell RA: Satellite cell numbers in young and older men 24 hours after eccentric exercise. Muscle Nerve 2006, 33(2):242-253.

10. Larsson L, Sjodin B, Karlsson J: Histochemical and biochemical changes in human skeletal muscle with age in sedentary males, age 22--65 years. Acta Physiol Scand 1978, 103(1):31-39.

11. Verdijk LB, Koopman R, Schaart G, Meijer K, Savelberg HH, van Loon L: Satellite cell content is specifically reduced in type II skeletal muscle fibers in the elderly. Am J Physiol Endocrinol Metab 2007, 292(1):E151-157.

12. Frontera WR, Hughes VA, Fielding RA, Fiatarone MA, Evans WJ, Roubenoff R: Aging of skeletal muscle: a 12-yr longitudinal study. J Appl Physiol 2000, 88(4):1321-1326.

13. Nilwik R, Snijders T, Leenders M, Groen BB, van Kranenburg J, Verdijk LB, van Loon LJ: The decline in skeletal muscle mass with aging is mainly attributed to a reduction in type II muscle fiber size. Exp Gerontol 2013, 48(5):292-298.

14. Frontera WR, Hughes VA, Lutz KJ, Evans WJ: A cross-sectional study of muscle strength and mass in 45to 78-yr-old men and women. J Appl Physiol 1991, 71(2):644-650.

15. Lindle RS, Metter EJ, Lynch NA, Fleg JL, Fozard JL, Tobin J, Roy TA, Hurley BF: Age and gender comparisons of muscle strength in 654 women and men aged 20-93 yr. J Appl Physiol 1997, 83(5):15811587.

16. Goodpaster BH, Park SW, Harris TB, Kritchevsky SB, Nevitt M, Schwartz AV, Simonsick EM, Tylavsky FA, Visser $M$, Newman $A B$ : The loss of skeletal muscle strength, mass, and quality in older adults: the health, aging and body composition study. J Gerontol A Biol Sci Med Sci 2006, 61(10):1059-1064.

17. Bassey EJ, Fiatarone MA, O'Neill EF, Kelly M, Evans WJ, Lipsitz LA: Leg extensor power and functional performance in very old men and women. Clin Sci (Lond) 1992, 82(3):321-327.

18. Wolfson L, Judge J, Whipple R, King M: Strength is a major factor in balance, gait, and the occurrence of falls. J Gerontol A Biol Sci Med Sci 1995, 50 Spec No:64-67.

19. Volpi E, Nazemi R, Fujita S: Muscle tissue changes with aging. Curr Opin Clin Nutr Metab Care 2004, $7(4): 405-410$.

20. Abellan Van Kan G: Epidemiology and consequences of sarcopenia. The Journal of Nutrition, Health and Aging 2009, 13(8):708-712.

21. Nair KS: Aging muscle. Am J Clin Nutr 2005, 81(5):953-963.

22. Rosenberg IH: Summary comments. Am J Clin Nutr 1989, 50(5):1231-1233.

23. Cruz-Jentoft AJ, Landi F, Topinkova E, Michel JP: Understanding sarcopenia as a geriatric syndrome. Curr Opin Clin Nutr Metab Care 2010, 13(1):1-7. 
24. Evans WJ, Morley JE, Argiles J, Bales C, Baracos V, Guttridge D, Jatoi A, Kalantar-Zadeh K, Lochs H, Mantovani G et al: Cachexia: a new definition. Clin Nutr 2008, 27(6):793-799.

25. Muscaritoli M, Anker SD, Argiles J, Aversa Z, Bauer JM, Biolo G, Boirie Y, Bosaeus I, Cederholm T, Costelli $\mathrm{P}$ et al: Consensus definition of sarcopenia, cachexia and pre-cachexia: joint document elaborated by Special Interest Groups (SIG) "cachexia-anorexia in chronic wasting diseases" and "nutrition in geriatrics". Clin Nutr 2010, 29(2):154-159.

26. Baumgartner RN, Koehler KM, Gallagher D, Romero L, Heymsfield SB, Ross RR, Garry PJ, Lindeman RD: Epidemiology of Sarcopenia among the Elderly in New Mexico. Am J Epidemiol 1998, 147(8):755-763.

27. Janssen I, Heymsfield SB, Ross R: Low Relative Skeletal Muscle Mass (Sarcopenia) in Older Persons Is Associated with Functional Impairment and Physical Disability. Journal of the American Geriatrics Society 2002, 50(5):889-896.

28. Narici MV, Maffulli N: Sarcopenia: characteristics, mechanisms and functional significance. Br Med Bull 2010, 95:139-159.

29. Lauretani F, Russo CR, Bandinelli S, Bartali B, Cavazzini C, Di lorio A, Corsi AM, Rantanen T, Guralnik JM, Ferrucci L: Age-associated changes in skeletal muscles and their effect on mobility: an operational diagnosis of sarcopenia. J Appl Physiol 2003, 95(5):1851-1860.

30. Cesari M, Kritchevsky SB, Newman AB, Simonsick EM, Harris TB, Penninx BW, Brach JS, Tylavsky FA, Satterfield S, Bauer DC et al: Added value of physical performance measures in predicting adverse health-related events: results from the Health, Aging And Body Composition Study. J Am Geriatr Soc 2009, 57(2):251-259.

31. Verdijk LB, van Loon L, Meijer K, Savelberg HH: One-repetition maximum strength test represents a valid means to assess leg strength in vivo in humans. J Sports Sci 2009, 27(1):59-68.

32. Sarti S, Ruggiero E, Coin A, Toffanello ED, Perissinotto E, Miotto F, Pintore G, Inelmen EM, Manzato E, Sergi G: Dietary intake and physical performance in healthy elderly women: a 3-year follow-up. Exp Gerontol 2013, 48(2):250-254.

33. Verdijk LB, Jonkers RA, Gleeson BG, Beelen M, Meijer K, Savelberg HH, Wodzig WK, Dendale P, van Loon LJ: Protein supplementation before and after exercise does not further augment skeletal muscle hypertrophy after resistance training in elderly men. Am J Clin Nutr 2009, 89(2):608-616.

34. Dodds RM, Roberts HC, Cooper C, Sayer AA: The Epidemiology of Sarcopenia. J Clin Densitom 2015, 12Jun2015(Epub).

35. Cruz-Jentoft AJ, Baeyens JP, Bauer JM, Boirie Y, Cederholm T, Landi F, Martin FC, Michel JP, Rolland Y, Schneider SM et al: Sarcopenia: European consensus on definition and diagnosis: Report of the European Working Group on Sarcopenia in Older People. Age Ageing 2010, 39(4):412-423.

36. Short KR, Vittone JL, Bigelow ML, Proctor DN, Nair KS: Age and aerobic exercise training effects on whole body and muscle protein metabolism. Am J Physiol Endocrinol Metab 2004, 286(1):E92-101.

37. Welle S, Thornton C, Jozefowicz R, Statt M: Myofibrillar protein synthesis in young and old men. Am J Physiol 1993, 264(5 Pt 1):E693-698.

38. Welle S, Thornton C, Statt M: Myofibrillar protein synthesis in young and old human subjects after three months of resistance training. Am J Physiol 1995, 268(3 Pt 1):E422-427.

39. Yarasheski KE, Welle S, Nair KS: Muscle protein synthesis in younger and older men. JAMA 2002, 287(3):317-318.

40. Yarasheski KE, Zachwieja JJ, Bier DM: Acute effects of resistance exercise on muscle protein synthesis rate in young and elderly men and women. Am J Physiol 1993, 265(2 Pt 1):E210-214.

41. Cuthbertson D, Smith K, Babraj J, Leese G, Waddell T, Atherton P, Wackerhage H, Taylor PM, Rennie MJ: Anabolic signaling deficits underlie amino acid resistance of wasting, aging muscle. FASEB J 2005, 19(3):422-424.

42. Katsanos CS, Kobayashi H, Sheffield-Moore M, Aarsland A, Wolfe RR: A high proportion of leucine is required for optimal stimulation of the rate of muscle protein synthesis by essential amino acids in the elderly. Am J Physiol Endocrinol Metab 2006, 291(2):E381-387.

43. Katsanos CS, Kobayashi H, Sheffield-Moore M, Aarsland A, Wolfe RR: Aging is associated with diminished accretion of muscle proteins after the ingestion of a small bolus of essential amino acids. Am J Clin Nutr 2005, 82(5):1065-1073. 
44. Volpi E, Sheffield Moore M, Rasmussen BB, Wolfe RR: Basal muscle amino acid kinetics and protein synthesis in healthy young and older men. JAMA 2001, 286(10):1206-1212.

45. Roubenoff R: Catabolism of aging: is it an inflammatory process? Curr Opin Clin Nutr Metab Care 2003, 6(3):295-299.

46. Roubenoff R, Harris TB, Abad LW, Wilson PW, Dallal GE, Dinarello CA: Monocyte cytokine production in an elderly population: effect of age and inflammation. J Gerontol A Biol Sci Med Sci 1998, 53(1):M20-26.

47. Pereira LS, Narciso FM, Oliveira DM, Coelho FM, Souza Dda G, Dias RC: Correlation between manual muscle strength and interleukin-6 (IL-6) plasma levels in elderly community-dwelling women. Arch Gerontol Geriatr 2009, 48(3):313-316.

48. Schaap LA, Pluijm SM, Deeg DJ, Visser M: Inflammatory markers and loss of muscle mass (sarcopenia) and strength. Am J Med 2006, 119(6):526 e529-517.

49. Schaap LA, Pluijm SM, Deeg DJ, Harris TB, Kritchevsky SB, Newman AB, Colbert LH, Pahor M, Rubin SM, Tylavsky FA et al: Higher inflammatory marker levels in older persons: associations with 5-year change in muscle mass and muscle strength. J Gerontol A Biol Sci Med Sci 2009, 64(11):1183-1189.

50. Kamel HK, Maas D, Duthie EH, Jr.: Role of hormones in the pathogenesis and management of sarcopenia. Drugs Aging 2002, 19(11):865-877.

51. Short KR, Nair KS: Mechanisms of sarcopenia of aging. J Endocrinol Invest 1999, 22(5 Suppl):95-105.

52. Perry HM, 3rd, Miller DK, Patrick P, Morley JE: Testosterone and leptin in older African-American men: relationship to age, strength, function, and season. Metabolism 2000, 49(8):1085-1091.

53. Baumgartner RN, Waters DL, Gallagher D, Morley JE, Garry PJ: Predictors of skeletal muscle mass in elderly men and women. Mech Ageing Dev 1999, 107(2):123-136.

54. Traish AM, Miner MM, Morgentaler A, Zitzmann M: Testosterone deficiency. Am J Med 2011, 124(7):578-587.

55. Roubenoff R, Hughes VA: Sarcopenia: Current Concepts. J Gerontol A Biol Sci Med Sci 2000, 55(12):M716-724.

56. Gower BA, Nyman L: Associations among oral estrogen use, free testosterone concentration, and lean body mass among postmenopausal women. J Clin Endocrinol Metab 2000, 85(12):4476-4480.

57. Snijders T, Verdijk LB, van Loon LJ: The impact of sarcopenia and exercise training on skeletal muscle satellite cells. Ageing Res Rev 2009, 8(4):328-338.

58. Snijders T, Verdijk LB, Smeets JS, McKay BR, Senden JM, Hartgens F, Parise G, Greenhaff P, van Loon L: The skeletal muscle satellite cell response to a single bout of resistance-type exercise is delayed with aging in men. Age (Dordr) 2014, 36(4):9699.

59. Verdijk LB, Snijders T, Drost M, Delhaas T, Kadi F, van Loon LJ: Satellite cells in human skeletal muscle; from birth to old age. Age (Dordr) 2014, 36(2):545-547.

60. Clark BC, Manini TM: What is dynapenia? Nutrition 2012, 28(5):495-503.

61. Doherty TJ: Invited Review: Aging and sarcopenia. J Appl Physiol 2003, 95(4):1717-1727.

62. Houston DK, Nicklas BJ, Ding J, Harris TB, Tylavsky FA, Newman AB, Lee JS, Sahyoun NR, Visser M, Kritchevsky SB: Dietary protein intake is associated with lean mass change in older, communitydwelling adults: the Health, Aging, and Body Composition (Health ABC) Study. Am J Clin Nutr 2008, 87(1):150-155.

63. Guillet C, Prod'homme M, Balage M, Gachon P, Giraudet C, Morin L, Grizard J, Boirie Y: Impaired anabolic response of muscle protein synthesis is associated with S6K1 dysregulation in elderly humans. FASEB J 2004:03-1341fje.

64. Boirie $Y$, Dangin M, Gachon P, Vasson MP, Maubois JL, Beaufrere B: Slow and fast dietary proteins differently modulate postprandial protein accretion. Proc Natl Acad Sci U S A 1997, 94(26):1493014935.

65. Liu CJ, Latham NK: Progressive resistance strength training for improving physical function in older adults. Cochrane Database Syst Rev 2009, 8(3):Cd002759.

66. Puthoff $\mathrm{ML}$, Janz KF, Nielson $\mathrm{D}$ : The relationship between lower extremity strength and power to everday walking behaviors in older adults with functional limitations. J Geriatr Phys Ther 2008, 31(1):24-31. 
67. Chale-Rush A, Guralnik JM, Walkup MP, Miller ME, Rejeski WJ, Katula JA, King AC, Glynn NW, Manini TM, Blair SN et al: Relationship between physical functioning and physical activity in the lifestyle interventions and independence for elders pilot. J Am Geriatr Soc 2010, 58(10):1918-1924.

68. Kortebein P, Ferrando A, Lombeida J, Wolfe R, Evans WJ: Effect of 10 days of bed rest on skeletal muscle in healthy older adults. JAMA 2007, 297(16):1772-1774.

69. Creditor MC: Hazards of hospitalization of the elderly. Ann Intern Med 1993, 118(3):219-223.

70. Ferrando AA, Lane HW, Stuart CA, Davis-Street J, Wolfe RR: Prolonged bed rest decreases skeletal muscle and whole body protein synthesis. Am J Physiol 1996, 270(4 Pt 1):E627-633.

71. Deutz NE, Pereira SL, Hays NP, Oliver JS, Edens NK, Evans CM, Wolfe RR: Effect of beta-hydroxy-betamethylbutyrate (HMB) on lean body mass during 10 days of bed rest in older adults. Clin Nutr 2013, 32(5):704-712.

72. English KL, Paddon-Jones D: Protecting muscle mass and function in older adults during bed rest. Curr Opin Clin Nutr Metab Care 2010, 13(1):34-39.

73. Volpi E, Mittendorfer B, Rasmussen BB, Wolfe RR: The Response of Muscle Protein Anabolism to Combined Hyperaminoacidemia and Glucose-Induced Hyperinsulinemia Is Impaired in the Elderly. J Clin Endocrinol Metab 2000, 85(12):4481-4490.

74. Kumar V, Selby A, Rankin D, Patel R, Atherton P, Hildebrandt W, Williams J, Smith K, Seynnes O, Hiscock $\mathrm{N}$ et al: Age-related differences in the dose-response relationship of muscle protein synthesis to resistance exercise in young and old men. J Physiol 2009, 587(Pt 1):211-217.

75. Kamel HK: Sarcopenia and aging. Nutr Rev 2003, 61(5 Pt 1):157-167.

76. Sinha-Hikim I, Cornford M, Gaytan H, Lee ML, Bhasin S: Effects of testosterone supplementation on skeletal muscle fiber hypertrophy and satellite cells in community-dwelling older men. J Clin Endocrinol Metab 2006, 91(8):3024-3033.

77. Bhasin S, Woodhouse L, Casaburi R, Singh AB, Mac RP, Lee M, Yarasheski KE, Sinha-Hikim I, Dzekov C, Dzekov $\mathrm{J}$ et al: Older men are as responsive as young men to the anabolic effects of graded doses of testosterone on the skeletal muscle. J Clin Endocrinol Metab 2005, 90(2):678-688.

78. Rennie MJ, Edwards RH, Halliday D, Matthews DE, Wolman SL, Millward DJ: Muscle protein synthesis measured by stable isotope techniques in man: the effects of feeding and fasting. Clin Sci (Lond) 1982, 63(6):519-523.

79. Koopman R, Verdijk L, Manders RJ, Gijsen AP, Gorselink M, Pijpers E, Wagenmakers AJ, van Loon LJ: Coingestion of protein and leucine stimulates muscle protein synthesis rates to the same extent in young and elderly lean men. Am J Clin Nutr 2006, 84(3):623-632.

80. Paddon-Jones D, Sheffield-Moore M, Katsanos CS, Zhang XJ, Wolfe RR: Differential stimulation of muscle protein synthesis in elderly humans following isocaloric ingestion of amino acids or whey protein. Exp Gerontol 2006, 41(2):215-219.

81. Paddon-Jones D, Sheffield-Moore M, Zhang XJ, Volpi E, Wolf SE, Aarsland A, Ferrando AA, Wolfe RR: Amino acid ingestion improves muscle protein synthesis in the young and elderly. Am J Physiol Endocrinol Metab 2004, 286(3):E321-328.

82. Volpi E, Ferrando AA, Yeckel CW, Tipton KD, Wolfe RR: Exogenous amino acids stimulate net muscle protein synthesis in the elderly. J Clin Invest 1998, 101(9):2000-2007.

83. Volpi E, Mittendorfer B, Wolf SE, Wolfe RR: Oral amino acids stimulate muscle protein anabolism in the elderly despite higher first-pass splanchnic extraction. Am J Physiol Endocrinol Metab 1999, 277(3):E513-520.

84. Volpi E, Kobayashi H, Sheffield-Moore M, Mittendorfer B, Wolfe RR: Essential amino acids are primarily responsible for the amino acid stimulation of muscle protein anabolism in healthy elderly adults. $A m \mathrm{~J}$ Clin Nutr 2003, 78(2):250-258.

85. Smith K, Barua JM, Watt PW, Scrimgeour CM, Rennie MJ: Flooding with L-[1-13C]leucine stimulates human muscle protein incorporation of continuously infused L-[1-13C]valine. Am J Physiol 1992, 262(3 Pt 1):E372-376.

86. Norton LE, Layman DK: Leucine regulates translation initiation of protein synthesis in skeletal muscle after exercise. J Nutr 2006, 136(2):533S-537S. 
87. Bonnefoy M, Cornu C, Normand S, Boutitie F, Bugnard F, Rahmani A, Lacour JR, Laville M: The effects of exercise and protein-energy supplements on body composition and muscle function in frail elderly individuals: a long-term controlled randomised study. Br J Nutr 2003, 89(5):731-739.

88. Borsheim E, Bui QU, Tissier S, Kobayashi H, Ferrando AA, Wolfe RR: Effect of amino acid supplementation on muscle mass, strength and physical function in elderly. Clin Nutr 2008, 27(2):189-195.

89. Tieland M, van de Rest O, Dirks ML, van der Zwaluw N, Mensink M, van Loon L, de Groot LC: Protein supplementation improves physical performance in frail elderly people: a randomized, double-blind, placebo-controlled trial. J Am Med Dir Assoc 2012, 13(8):720-726.

90. Carlsson M, Littbrand H, Gustafson Y, Lundin-Olsson L, Lindelof N, Rosendahl E, Haglin L: Effects of highintensity exercise and protein supplement on muscle mass in ADL dependent older people with and without malnutrition: a randomized controlled trial. J Nutr Health Aging 2011, 15(7):554-560.

91. Fiatarone MA, O'Neill EF, Ryan ND, Clements KM, Solares GR, Nelson ME, Roberts SB, Kehayias JJ, Lipsitz LA, Evans WJ: Exercise training and nutritional supplementation for physical frailty in very elderly people. N Engl J Med 1994, 330(25):1769-1775.

92. Meredith CN, Frontera WR, O'Reilly KP, Evans WJ: Body composition in elderly men: effect of dietary modification during strength training. J Am Geriatr Soc 1992, 40(2):155-162.

93. Rosendahl E, Lindelof N, Littbrand H, Yifter-Lindgren E, Lundin-Olsson L, Haglin L, Gustafson Y, Nyberg L: High-intensity functional exercise program and protein-enriched energy supplement for older persons dependent in activities of daily living: a randomised controlled trial. Aust J Physiother 2006, 52(2):105-113.

94. Rieu I, Balage M, Sornet C, Giraudet C, Pujos E, Grizard J, Mosoni L, Dardevet D: Leucine supplementation improves muscle protein synthesis in elderly men independently of hyperaminoacidaemia. J Physiol 2006, 575(Pt 1):305-315.

95. Wall BT, Hamer HM, de Lange A, Kiskini A, Groen BB, Senden JM, Gijsen AP, Verdijk LB, van Loon L: Leucine co-ingestion improves post-prandial muscle protein accretion in elderly men. Clin Nutr 2013, 32(3):412-419.

96. Verhoeven S, Vanschoonbeek K, Verdijk LB, Koopman R, Wodzig WK, Dendale P, van Loon LJ: Longterm leucine supplementation does not increase muscle mass or strength in healthy elderly men. $\mathrm{Am} \mathrm{J}$ Clin Nutr 2009, 89(5):1468-1475.

97. Landi F, Abbatecola AM, Provinciali M, Corsonello A, Bustacchini S, Manigrasso L, Cherubini A, Bernabei R, Lattanzio F: Moving against frailty: does physical activity matter? Biogerontology 2010, 11(5):537545.

98. Frontera WR, Meredith CN, O'Reilly KP, Knuttgen HG, Evans WJ: Strength conditioning in older men: skeletal muscle hypertrophy and improved function. J Appl Physiol 1988, 64(3):1038-1044.

99. Verdijk LB, Gleeson BG, Jonkers RA, Meijer K, Savelberg HH, Dendale P, van Loon LJ: Skeletal muscle hypertrophy following resistance training is accompanied by a fiber type-specific increase in satellite cell content in elderly men. J Gerontol A Biol Sci Med Sci 2009, 64(3):332-339.

100. Kosek DJ, Kim JS, Petrella JK, Cross JM, Bamman MM: Efficacy of 3 days/wk resistance training on myofiber hypertrophy and myogenic mechanisms in young vs. older adults. J Appl Physiol 2006, 101(2):531-544.

101. Fiatarone MA, Marks EC, Ryan ND, Meredith CN, Lipsitz LA, Evans WJ: High-intensity strength training in nonagenarians. Effects on skeletal muscle. JAMA 1990, 263(22):3029-3034.

102. Lexell J, Downham DY, Larsson Y, Bruhn E, Morsing B: Heavy-resistance training in older Scandinavian men and women: short- and long-term effects on arm and leg muscles. Scand J Med Sci Sports 1995, 5(6):329-341.

103. Charette SL, McEvoy L, Pyka G, Snow-Harter C, Guido D, Wiswell RA, Marcus R: Muscle hypertrophy response to resistance training in older women. J Appl Physiol 1991, 70(5):1912-1916.

104. Frontera WR, Hughes VA, Krivickas LS, Kim SK, Foldvari M, Roubenoff R: Strength training in older women: early and late changes in whole muscle and single cells. Muscle Nerve 2003, 28(5):601-608.

105. Capodaglio P, Capodaglio Edda M, Facioli M, Saibene F: Long-term strength training for communitydwelling people over 75: impact on muscle function, functional ability and life style. Eur J Appl Physiol 2007, 100(5):535-542. 
106. Hunter GR, McCarthy JP, Bamman MM: Effects of resistance training on older adults. Sports Med 2004, 34(5):329-348.

107. Winett RA, Carpinelli RN: Potential health-related benefits of resistance training. Prev Med 2001, 33(5):503-513.

108. Ivey FM, Tracy BL, Lemmer JT, NessAiver M, Metter EJ, Fozard JL, Hurley BF: Effects of strength training and detraining on muscle quality: age and gender comparisons. J Gerontol A Biol Sci Med Sci 2000, 55(3):B152-157; discussion B158-159.

109. Roth SM, Ivey FM, Martel GF, Lemmer JT, Hurlbut DE, Siegel EL, Metter EJ, Fleg JL, Fozard JL, Kostek MC et al: Muscle size responses to strength training in young and older men and women. J Am Geriatr Soc 2001, 49(11):1428-1433.

110. Bamman MM, Hill VJ, Adams GR, Haddad F, Wetzstein CJ, Gower BA, Ahmed A, Hunter GR: Gender differences in resistance-training-induced myofiber hypertrophy among older adults. J Gerontol A Biol Sci Med Sci 2003, 58(2):108-116.

111. Ivey FM, Roth SM, Ferrell RE, Tracy BL, Lemmer JT, Hurlbut DE, Martel GF, Siegel EL, Fozard JL, Jeffrey Metter $E$ et al: Effects of age, gender, and myostatin genotype on the hypertrophic response to heavy resistance strength training. J Gerontol A Biol Sci Med Sci 2000, 55(11):M641-648.

112. Tracy BL, Ivey FM, Hurlbut D, Martel GF, Lemmer JT, Siegel EL, Metter EJ, Fozard JL, Fleg JL, Hurley BF: Muscle quality. II. Effects Of strength training in 65- to 75-yr-old men and women. J Appl Physiol 1999, 86(1):195-201.

113. Hakkinen $K$, Kallinen $M$, Izquierdo $M$, Jokelainen $K$, Lassila $H$, Malkia E, Kraemer WJ, Newton RU, Alen $\mathrm{M}$ : Changes in agonist-antagonist EMG, muscle CSA, and force during strength training in middle-aged and older people. J Appl Physiol 1998, 84(4):1341-1349.

114. Biolo G, Maggi SP, Williams BD, Tipton KD, Wolfe RR: Increased rates of muscle protein turnover and amino acid transport after resistance exercise in humans. Am J Physiol 1995, 268(3 Pt 1):E514-520.

115. Phillips SM, Tipton KD, Aarsland A, Wolf SE, Wolfe RR: Mixed muscle protein synthesis and breakdown after resistance exercise in humans. Am J Physiol 1997, 273(1 Pt 1):E99-107.

116. Tipton KD, Ferrando AA, Phillips SM, Doyle D, Jr., Wolfe RR: Postexercise net protein synthesis in human muscle from orally administered amino acids. Am J Physiol 1999, 276(4 Pt 1):E628-634.

117. Campbell WW, Evans WJ: Protein requirements of elderly people. Eur J Clin Nutr 1996, 50 Suppl 1:S180183; discussion S183-185.

118. Campbell WW, Leidy HJ: Dietary protein and resistance training effects on muscle and body composition in older persons. J Am Coll Nutr 2007, 26(6):696S-703S.

119. Morais JA, Chevalier S, Gougeon R: Protein turnover and requirements in the healthy and frail elderly. $J$ Nutr Health Aging 2006, 10(4):272-283.

120. Paddon-Jones D, Short KR, Campbell WW, Volpi E, Wolfe RR: Role of dietary protein in the sarcopenia of aging. Am J Clin Nutr 2008, 87(5):1562S-1566.

121. Iglay HB, Thyfault JP, Apolzan JW, Campbell WW: Resistance training and dietary protein: effects on glucose tolerance and contents of skeletal muscle insulin signaling proteins in older persons. Am J Clin Nutr 2007, 85(4):1005-1013.

122. Cermak NM, Res PT, de Groot LC, Saris WH, van Loon LJ: Protein supplementation augments the adaptive response of skeletal muscle to resistance-type exercise training: a meta-analysis. Am J Clin Nutr 2012, 96(6):1454-1464. 

CHAPTER 2

\section{Leucine as a pharmaconutrient to prevent and/or treat sarcopenia and type 2 diabetes}




\section{Abstract}

Amino acids function as precursors for de novo protein synthesis. In addition, however, they play a key role as nutritional signals regulating multiple cellular processes. There is ample in vitro and in vivo evidence showing that muscle tissue responds to increases in amino acid availability via signal transduction pathways that are also regulated by insulin, glucagon, growth hormone, and insulin growth factor 1 . The increased amino acid availability results in the upregulation of mRNA translation, thereby increasing muscle protein synthesis, which, in turn, leads to greater net muscle protein accretion. These findings have been particularly pronounced for the amino acid leucine. Furthermore, leucine has the ability to act as a strong insulin secretagogue. Consequently, it has been suggested that leucine represents an effective pharmaconutrient for the prevention and treatment of sarcopenia and type 2 diabetes. In accordance, recent in vivo studies in humans show that free leucine ingestion can reverse the blunted response of muscle protein synthesis to amino acid/protein intake in the elderly.

Although short-term studies suggest that leucine supplementation can stimulate muscle mass accretion in the elderly, there are no long-term nutritional intervention studies to confirm this or the other proposed benefits of leucine as a pharmaconutrient. 


\section{Introduction}

Besides their function as precursors for de novo protein synthesis, amino acids are also involved in regulating numerous cellular processes. The essential amino acids seem to play a key role in regulating the synthesis and breakdown of skeletal muscle protein. In vitro studies show that the branched-chain amino acids (BCAAs), i.e., leucine, isoleucine, and valine, act as potent nutritional signaling molecules that regulate the rate of protein synthesis and degradation. Leucine seems to represent a unique amino acid in this regard (1-4) as it can stimulate mRNA translation initiation via insulin dependent and independent pathways, thereby stimulating muscle protein synthesis (5). As a consequence, leucine has been identified as a pharmaconutrient with the potential to promote muscle hypertrophy. More detailed information on the impact of leucine on the activation of the mammalian target of rapamycin (mTOR) signaling pathway and the subsequent mRNA translation is provided later in this review.

Aging is accompanied by a progressive decline in muscle mass and strength, or sarcopenia. This loss of muscle mass and strength results in a decline in functional capacity and predisposes to the development of chronic metabolic diseases such as obesity and type 2 diabetes (6). Recent work suggests that the elderly show a blunted response of muscle protein synthesis to food ingestion (7-9). It has been suggested that the blunted response of muscle protein synthesis to food intake can be compensated for by increasing the leucine content of a meal $(8,10)$. Consequently, leucine supplementation might represent an interesting approach to prevent or reverse the progressive loss of muscle mass that occurs with aging. Furthermore, leucine has also been identified as a potent insulin secretagogue when administered in combination with carbohydrate and protein. Co-ingestion of additional leucine increases postprandial insulin release and stimulates blood glucose disposal. Several studies support the hypothesis that administration of protein and additional leucine represents an effective dietary strategy to improve glycemic control in type 2 diabetes patients (11-16). This review evaluates whether leucine represents an effective pharmaconutrient in the prevention and treatment of sarcopenia and type 2 diabetes. The impact of the BCAAs, and of leucine in particular, on muscle protein metabolism and endogenous insulin release are addressed with regard to the existing literature.

\section{In vitro evidence for the anabolic properties of leucine}

Amino acids function not only as building blocks for de novo protein synthesis; they also play a key role as nutritional signals that regulate multiple cellular processes (17). In the 1970s, several laboratories performed in vitro studies to investigate the potential of amino acids to regulate muscle protein metabolism. Since then, numerous studies have reported that amino acids can stimulate muscle protein synthesis (18-21) and inhibit proteolysis $(20,22)$. Other studies further investigated the proposed anabolic properties of amino acids, and observed that the BCAAs are mainly responsible for 
stimulating muscle protein synthesis and inhibiting protein degradation $(1,23)$. Classic studies by Buse and Reid (4) describe the incorporation of lysine into muscle protein in isolated rat diaphragms following administration of BCAAs. Rates of muscle protein synthesis were $20 \%$ greater in muscle tissue incubated with the BCAAs. After testing each of the BCAAs separately, it became evident that leucine was solely responsible for stimulating protein synthesis and reducing proteolysis. This has since been confirmed by several other groups $(1,4,23)$.

Much of the work in this area has focused on the molecular mechanisms that might be responsible for the leucine-induced stimulation of muscle protein synthesis. Acute changes in muscle protein synthesis generally occur well before increases in mRNA content become evident (24). As such, activation of muscle protein synthesis must be controlled by a post-transcriptional mechanism (25). The post-transcriptional regulation of protein synthesis involves mRNA translation, elongation, termination and posttranslational modification. The initiation of mRNA translation is thought to represent one of the more important levels of control of muscle protein synthesis $(26,27)$. The mTOR signal transduction pathway plays a major role in regulating the initiation of mRNA translation $(27,28)$. Leucine stimulates the initiation of mRNA translation via activation of $\operatorname{mTOR}(27,29)$, and the subsequent phosphorylation and activation of eukaryotic initiation factor 4E-binding protein 1 (4E-BP1), ribosomal protein S6 kinase 1 (S6K1), and ribosomal protein S6, thereby increasing the rates of muscle protein synthesis (Figure 1). MTOR is thought to serve as a convergence point for leucinemediated effects on the initiation of mRNA translation $(27,30)$.

Recent studies reveal that a small subfamily of GTPases, i.e. Rags play an important role in the regulation of mTOR activation $(31,32)$. Rag GTP levels are upregulated by leucine stimulation, suggesting that the Rag complex may function as a sensor for nutrients to modulate mTOR activity $(31,32)$. In addition to Rags, it is postulated that Vps34 (a PI3 kinase) and MAP4K3 (a germinal center kinase-related kinase) are involved in the regulation of mTOR activation in response to amino acids (33-35). MacKenzie et al (36) recently reported that mVps34 (a PI3 kinase) becomes phosphorylated when intramuscular leucine levels increase, which is followed by the phosphorylation and activation of mTOR (36). Furthermore, in vitro work has identified MAP4K3 as a regulator of $\mathrm{S} 6 \mathrm{~K}$ and $4 \mathrm{E}-\mathrm{BP} 1$ activity in response to leucine (34). In addition to increased signaling through mTOR, an increase in essential amino acid availability results in a decreased phosphorylation state of the eukaryotic initiation factor 2 (37). This cascade also results in increased activation of translation initiation. An overview of the signaling pathways and the (un)known signaling properties of leucine are illustrated in Figure 1. Recently published reviews provide a more detailed description of the molecular pathways regulating muscle protein synthesis (37-39). However, it should be acknowledged that a close association between the activation status of signaling proteins regulating mRNA translation initiation and the rates of muscle protein synthesis is not always evident in vivo (40). Consequently, based on the proposed properties of leucine to stimulate protein synthesis in vitro, many research groups have since started 
to assess the impact of leucine administration on in vivo muscle protein synthesis and breakdown.

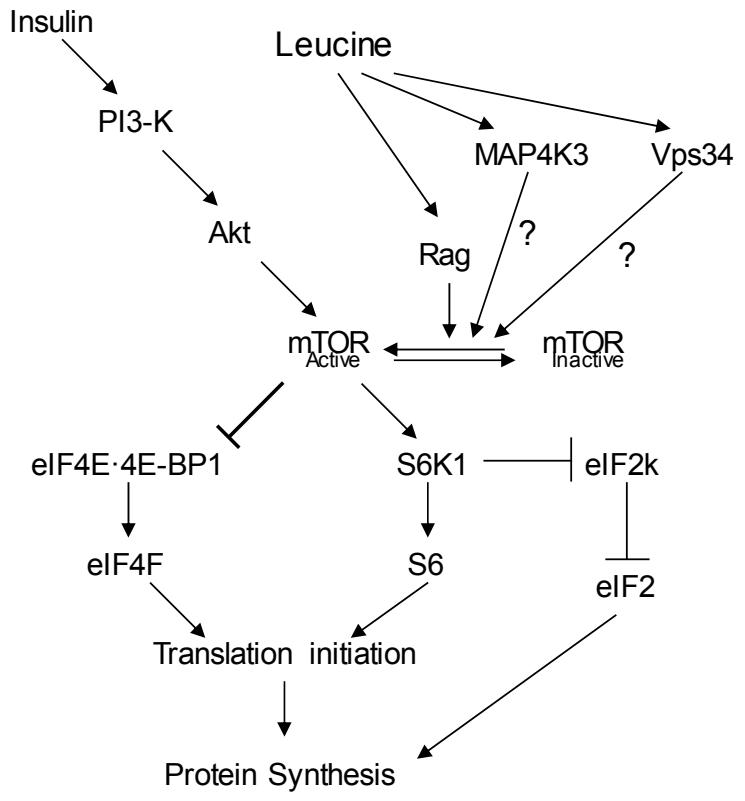

Figure 1: An overview on the proposed mechanisms by which insulin and leucine can regulate protein metabolism by modulating the signal transduction pathways that regulate mRNA translation. Besides the insulin mediated signaling cascade that leads to the activation of the mammalian target of rapamycin (mTOR) signal transduction pathway, leucine activates mTOR in an insulin-independent manner through Ras-related GTPase (Rag), Vps34 and MAP4K3. Activation of mTOR leads to an increase in phosphorylation of ribosomal protein S6 kinase (S6K1) and the eukaryotic initiation factor 4E-binding protein (elF4E-BP). Phosphorylation of elF4E-BP1 prevents binding with elF4E, thereby enhancing the assembly of the elF4F complex. Both these processes initiate translation and stimulate protein synthesis. Leucine also has the potential to regulate mRNA translation through the phosphorylation of the eukaryotic initiation factor 2 (elF2). PI3K, Phosphoinositide 3-kinase; AMPK, AMP-activated protein kinase; eEF2k, eukaryotic elongation factor 2 kinase.

\section{In vivo effects of leucine administration in rodents}

Administration of BCAAs or leucine has the ability to stimulate protein synthesis and inhibit myocellular protein degradation in vitro $(1,3,23)$. So far, most in vivo animal models seem to confirm these findings (18, 41-45). Garlick and Grant (18) studied the effects of intravenous infusions with various combinations of insulin and amino acids on rates of muscle protein synthesis in rodents. They showed that infusing food deprived rats with an amino acid mixture for 1 hour increased rates of muscle protein synthesis by $15 \%$. A similar increase in rates of protein synthesis was observed when these food deprived rats were infused with merely the amount of BCAAs present in the same amino acid mixture $(9 \mathrm{mg}$ leucine, $7.5 \mathrm{mg}$ isoleucine and $7.3 \mathrm{mg}$ valine over 1 hour) (18). The specific relevance of the stimulating properties of leucine became evi- 
dent when Anthony et al. reported that oral free leucine administration directly stimulates skeletal muscle protein synthesis during post-exercise recovery in rats (41). Exercised rats were fed leucine $(270 \mathrm{mg}$ ) immediately after exercise, which resulted in a steep approximately $18 \%$ rise in the rates of muscle protein synthesis. In a subsequent study (46), they tried to determine whether leucine is unique among the BCAAs to stimulate skeletal muscle protein synthesis. In this follow-up experiment, fooddeprived rats received $1.35 \mathrm{~g} / \mathrm{kg}$ body weight valine, isoleucine or leucine (providing approximately $270 \mathrm{mg}$ of amino acid). Leucine was the only BCAA that stimulated in vivo skeletal muscle protein synthesis. Consequently, it was concluded that leucine is of key importance in regulating skeletal muscle protein synthesis (46).

To establish the minimal dose of leucine required to stimulate muscle protein synthesis, Crozier et al (42) measured the incorporation rate of [3H] labeled phenylalanine into muscle protein 30 minutes after oral administration of saline or leucine with doses ranging from 0.068 to $1.35 \mathrm{~g}$ of leucine/ $\mathrm{kg}$ body weight (providing 14 to up to $270 \mathrm{mg}$ ). Even relative small amounts of leucine (i.e. $0.135 \mathrm{~g} / \mathrm{kg}$ body weight or $27 \mathrm{mg}$ ) were shown to increase muscle protein synthesis rates by as much as $30 \%$ (42). Whereas some investigated the impact of the administration of free leucine, others tried to assess the anabolic properties of leucine when provided in combination with mixed meals. Dardevet et al (43) reported that the addition of $445 \mathrm{mg}$ leucine with a mixed meal further increased in vivo post-prandial muscle protein synthesis rates by as much as $19 \%$ in older rats. In an effort to examine whether the acute benefits of leucine supplementation on post-prandial muscle protein anabolism persist when leucine is supplemented for more prolonged periods, Rieu et al (44) provided these older rats with similar leucine-enriched meals over a 10-day period. Again, rates of muscle protein synthesis were considerably higher $(+24 \%)$ in the rats fed the leucine supplemented meals (providing $445 \mathrm{mg}$ leucine per day). Moreover, the higher rates of postprandial muscle protein synthesis following ingestion of the leucine-enriched meals persisted over the subsequent 10 days. Thereafter, the same research group continued their work by assessing the anabolic properties of various dietary protein sources that differed in leucine content (providing 250 up to $300 \mathrm{mg}$ per day) supplemented over a prolonged intervention period, i.e. a 30-day period (45). In accordance with the results of free leucine feeding (44), rates of postprandial muscle protein synthesis were approximately $25 \%$ greater following ingestion of the protein sources with the greater leucine content (i.e. $300 \mathrm{mg} /$ day vs $250 \mathrm{mg} /$ day). Furthermore, the greater response of protein synthesis persisted even after 30 days of intervention (45). These studies by Rieu et al $(44,45)$ strongly suggest that the stimulatory properties of leucine ingestion, provided either as free leucine or via dietary protein with a higher leucine content, on postprandial muscle protein synthesis persist over time. As a consequence, it was speculated that leucine supplementation with each main meal over a prolonged period of time represents an effective nutritional intervention strategy to stimulate net muscle protein accretion and to counteract muscle loss with aging. However, despite the observed increase in the rates of postprandial muscle protein synthesis, none of the 
studies detected increases in muscle mass or muscle strength $(44,45)$. This apparent discrepancy might be attributed to the relative short timeline of these nutritional intervention studies, but it might also be due to the fact that the acute response of postprandial muscle protein synthesis does not necessarily translate into net muscle protein accretion. Other factors, such as changes in hormonal milieu (47), satellite cells (48), and neuromuscular alternations (49), may all play an important role in regulating the more long-term increases in muscle mass accretion.

In short, there is ample evidence to support the claim that leucine administration represents an effective strategy to stimulate postprandial muscle protein synthesis in vivo in rodents. However, it is still unknown whether prolonged leucine supplementation can be applied effectively to augment skeletal muscle mass and strength. Evidence of this augmentation would further strengthen the proposal of leucine as an effective pharmaconutrient and could set the stage for leucine intervention studies in vivo in humans.

\section{Anabolic properties of leucine in vivo in humans}

Although leucine administration has been shown to stimulate muscle protein synthesis and inhibit protein breakdown in in vitro $(1,3,23)$ and in vivo rodent studies $(18,41$ 46), in vivo studies in humans generally report inhibition of muscle protein breakdown following intravenous leucine administration, with no apparent effect on the rates of muscle protein synthesis $(50,51)$. Louard et al $(50)$ studied the impact of continuous intravenous BCAA administration on whole-body and skeletal muscle amino acid kinetics in healthy, young subjects $(23 \pm 1 \mathrm{y}$ ). Combining the use of the arteriovenous (AV) balance model across the forearm with the application of stable isotope tracers, i.e. labeled phenylalanine and leucine, they assessed the acute effects of BCAA infusion (providing $0.035 \mathrm{~g}$ valine, $0.040 \mathrm{~g}$ leucine, and $0.040 \mathrm{~g}$ isoleucine per $\mathrm{kg}$ body weight, within a $3 \mathrm{~h}$ period) on rates of muscle protein synthesis and breakdown. Whole-body phenylalanine flux, used as an index of proteolysis, was suppressed by approximately $40 \%$ following intravenous administration of BCAAs. However, administration of BCAA did not increase rates of muscle protein synthesis $(50,52)$. Furthermore, Nair et al $(51)$ studied the impact of intravenous leucine infusion $(0.14 \mathrm{~g} / \mathrm{kg}$ body weight over a $7 \mathrm{~h}$ period) on rates of muscle protein synthesis and breakdown in postabsorptive, healthy subjects $(25 \pm 2 \mathrm{y}$ ). Arteriovenous differences across the leg showed that valine release and phenylalanine release were reduced, suggesting an approximately $35 \%$ decline in protein degradation following leucine administration. However, in accordance with Louard et al (50) intravenous administration of leucine did not seem to elevate the rates of muscle protein synthesis $(51)$. Collectively, these studies $(50,51)$ do not report any effect of BCAA or leucine administration on rates of muscle protein synthesis in vivo in humans. 
In contrast, other groups reported substantial increases (between 35 and 50\%) in rates of muscle protein synthesis following intravenous administration of amino acid in vivo in humans (53-55). An overview of some of these studies is provided in Figure 2.

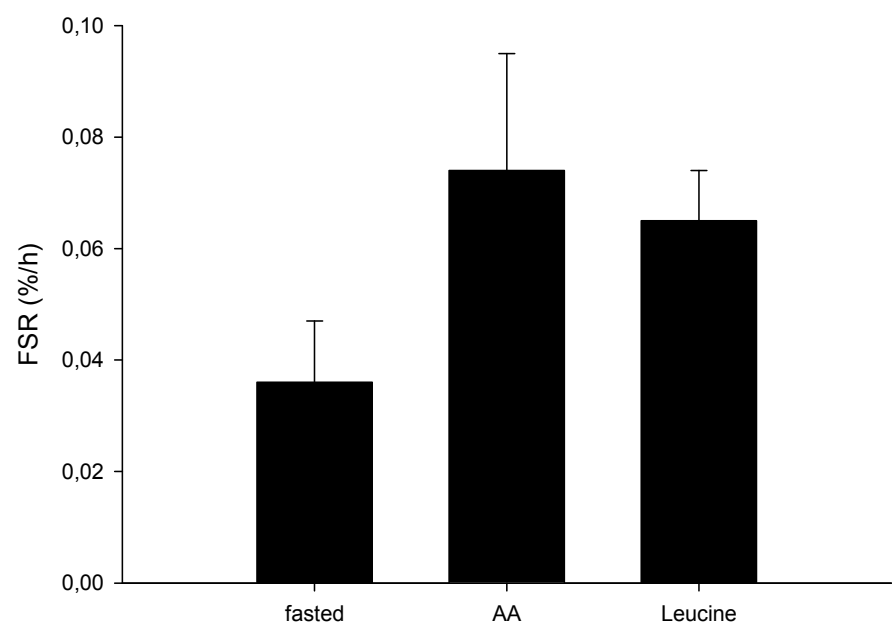

Figure 2: Muscle protein synthesis rates in healthy subjects assessed under various conditions by Rennie and co-workers (53-55). Fasted: muscle protein synthesis rates in the overnight fasted state (54). AA: muscle protein synthesis rates following continuous infusion of $0.33 \mathrm{~g} / \mathrm{kg}$ mixed amino acids (53). Leucine: muscle protein synthesis rates following intravenous infusion of a flooding dose of $0.05 \mathrm{~g} / \mathrm{kg}$ leucine (55). Data expressed as means $\pm \mathrm{SD}$.

Bennet et al (53) measured rates of muscle protein synthesis following continuous infusion of $0.33 \mathrm{~g}$ mixed amino acids $/ \mathrm{kg}$ body weight, providing $0.032 \mathrm{~g}$ leucine $/ \mathrm{kg}$ body weight. Rates of mixed muscle protein synthesis averaged $0.055 \pm 0.008 \% / \mathrm{h}$ in the fasted state and increased by more than $35 \%$ during administration of amino acid (up to $0.074 \pm 0.021 \% / \mathrm{h}$ ). During administration of amino acid, the rates of whole-body protein synthesis increased by approximately $13 \%$, and rates of whole-body protein breakdown declined by approximately $12 \%$. These findings show that an increase in plasma amino acid availability can reverse whole-body protein balance from negative to positive (53). In line with the in vivo rodent data (41-45), leucine seems to represent the essential amino acid with the greatest anabolic properties. Smith et al (55) observed an approximate $50 \%$ increase in rates of muscle protein synthesis following administration of a large flooding dose of leucine $(0.05 \mathrm{~g} / \mathrm{kg}$ body weight). In fact, this response was not much different from the approximately $35 \%$ greater response of muscle protein synthetic after administration of $0.33 \mathrm{~g}$ mixed amino acids per kilogram body weight (providing $0.032 \mathrm{~g}$ leucine/kg body weight) (53). However, it should be noted that similar increases in rates of muscle protein synthesis were also reported following flooding doses $(0.05 \mathrm{~g} / \mathrm{kg}$ body weight) of other essential amino acids (54). A 
more complete and detailed assessment of the stimulating properties of various other amino acids on muscle protein synthesis is still lacking. The apparent discrepancy between the studies that did and did not observe the proposed stimulatory effects of intravenous leucine administration on the rates of muscle protein synthesis in vivo in humans might be attributable to the relatively large bolus of leucine that was administered over a short period time (55) as opposed to the other studies that applied a more continuous infusion protocol over time $(50,51)$. More work is warranted to establish the specific relevance of a (more) rapid increase in free leucine concentration in plasma or tissue as an anabolic stimulus.

Besides studies that investigated the effects of intravenous administration of amino acid, numerous other studies have reported the stimulatory properties of ingestion of amino acid and protein on postprandial muscle protein synthesis $(8,10,15,19,20,50$, $51,56-59)$. Volpi et al (60) reported an approximate $80 \%$ increase in the rates of muscle protein synthesis in vivo following ingestion of $40 \mathrm{~g}$ mixed amino acids (60). They continued their work by studying the impact of ingesting a single bolus essential amino acids (18 g) with or without an additional $22 \mathrm{~g}$ nonessential amino acids on postprandial muscle protein synthesis (56). As there were no differences in the anabolic response between treatments, the authors concluded that the essential amino acids are responsible for the observed increase in postprandial muscle protein synthesis (56). These earlier findings show that the essential amino acids play a key role in the regulation and, more specifically, in the stimulation of postprandial muscle protein synthesis (Table 1).

Besides amino acid administration, muscle contraction, i.e. physical activity, strongly stimulates muscle protein synthesis (61-65). Many studies addressed the impact of amino acid/protein administration as a nutritional strategy to further increase muscle protein accretion during and after exercise (66-70). Physical activity and exercise not only increase rates of muscle protein synthesis but also increase rates of muscle protein breakdown, although the latter occurs to a lesser extent $(61,71)$. As a consequence, net muscle protein balance improves, but in the absence of nutrient intake muscle protein balance will remain negative (61). Protein and amino acid administration with and without carbohydrate strongly increases rates of mixed muscle protein synthesis (ranging between 35 and 65\%) and improves net muscle protein balance both at rest $(19,57,58)$ and during postexercise recovery $(72)$. The improved protein balance has been associated with an increase in intra- and extracellular leucine concentrations, now believed to form the main stimulus driving the postprandial response of muscle protein synthesis (27). It has been speculated that ingestion of additional leucine during postexercise recovery could further accelerate postexercise rates of muscle protein synthesis rates. In accordance, Dreyer et al (67) recently reported that ingestion of a leucine-enriched essential amino acid and carbohydrate mixture (providing $7 \mathrm{~g}$ leucine, $20 \mathrm{~g}$ essential amino acids, and $35 \mathrm{~g}$ carbohydrate) enhances mTOR signaling and increases muscle protein synthesis during postexercise recovery in vivo in humans. However, previous observations showed no additional value of additional 
leucine supplementation $(0.18 \mathrm{~g}$ of leucine/ $\mathrm{kg}$ body weight or approximately $12.6 \mathrm{~g}$ over a $6 \mathrm{~h}$ period) on the acute postexercise response of muscle protein synthesis in both young $(20 \pm 1$ y) $(57)$ and elderly $(74 \pm 1$ y) $(57,58)$ subjects when ample amounts of dietary protein were already ingested ( $72 \mathrm{~g}$ protein, providing $13.5 \mathrm{~g}$ protein-bound leucine: see Table 1). It may be speculated that additional leucine does not further increase post-exercise muscle protein synthesis when ample amounts of leucine $(>10$ g) are already ingested. Furthermore, it is not unlikely that the stimulating properties of physical activity, including muscle contraction and increased muscle perfusion, sensitize the muscle to such an extent that the anabolic stimulus of leucine is no longer of any additional value.

In summary, intravenous as well as oral administration of essential amino acids, and leucine in particular, strongly stimulates postprandial rates of muscle protein synthesis in vivo in humans. Although the essential amino acids, and leucine in particular, seem essential in maximizing the postprandial response of muscle protein synthesis, there seems to be a limit to the surplus benefits of leucine when supplemented above a certain level or when additional leucine is provided during the initial stages of postexercise recovery.

\section{Leucine as a pharmaconutrient in the elderly}

One of the factors playing an important role in the loss of functional performance and, therefore, the capacity to maintain a healthy, active lifestyle is the progressive loss of skeletal muscle mass with aging. Lean muscle mass generally contributes up to approximately $50 \%$ of total bodyweight in young adults but declines to approximately $25 \%$ when the age of $75-80 y$ is reached $(73,74)$. The loss of muscle mass is typically offset by gains in fat mass. The loss of muscle mass is most notable in the lower limb muscle groups, with the cross-sectional area of the vastus lateralis being reduced by as much as $40 \%$ between the age of 20 and 80 years (75). The age-related loss of skeletal muscle mass is facilitated by a combination of factors that include a less-than-optimal diet (76-78) and a sedentary lifestyle (79). The decline in muscle tissue with aging must be attributed to a disruption in the regulation of skeletal muscle protein turnover, leading to a structural imbalance between muscle protein synthesis and protein degradation. Though some studies suggest that this is at least partly attributable to lower basal rates of muscle protein synthesis in senescent muscle $(64,74,80-82)$, other studies do not show any differences in basal rates of muscle protein synthesis between the young and elderly $(7-9,19,60,83,84)$. As a consequence, many research groups have started to focus on potential age-related differences in the response of muscle protein synthesis to the main anabolic stimuli, i.e. dietary protein intake and physical activity. It has been hypothesized that skeletal muscle tissue is less responsive to the anabolic properties of dietary protein intake $(9,85)$ and physical activity $(86)$ in the elderly.

Cuthbertson et al (9) assessed the response of muscle protein synthesis to the

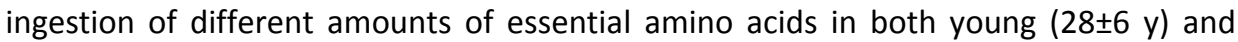


elderly $(70 \pm 6$ y) men under conditions in which insulin was clamped at approximately $10 \mathrm{mIU} / \mathrm{L}$ following intravenous infusion of both (the somatostatin analog) octreotide and exogenous insulin. The elderly showed a blunted response of muscle protein synthesis to the ingestion of 10-20 g essential amino acids when compared with their younger controls. Rates of postprandial muscle protein synthesis increased threefold when compared with basal fasting levels in the young, whereas the increase was only twofold in the elderly. The latter finding implies the presence of some level of anabolic resistance to amino acid/protein intake in senescent muscle. However, these findings seem to be at odds with previous work in which similar amounts of amino acids were provided in a more physiological setting without modulating the postprandial endocrine response (56). Volpi et al (56) reported similar increments (circa 100\% increase)

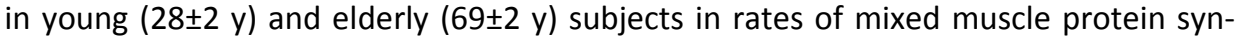
thesis following ingestion of $40 \mathrm{~g}$ mixed amino acids or $18 \mathrm{~g}$ essential amino acids. In agreement, Paddon-Jones et al (19) observed no significant differences between young $(34 \pm 4$ y) and elderly ( $67 \pm 2$ y) subjects in rates of postprandial muscle protein synthesis following ingestion of $15 \mathrm{~g}$ essential amino acids (providing approximately $2.8 \mathrm{~g}$ leucine) $(0.103 \pm 0.011 \%$ per hour in young vs $0.088 \pm 0.011 \%$ per hour in elderly subjects). More recently, no differences were observed in the postprandial response of muscle protein synthesis following the ingestion of $20 \mathrm{~g}$ or $35 \mathrm{~g}$ intrinsically labeled casein (providing approximately 1.7 or $2.8 \mathrm{~g}$ leucine) between healthy young ( $<24 \mathrm{y}$ ) and elderly $(>65$ y) males $(0.062 \pm 0.007 \%$ per hour vs $0.056 \pm 0.004 \%$ per hour and $0.063 \pm 0.006 \%$ per hour vs $0.054 \pm 0.004 \% / h$, respectively) $(87,88)$. 


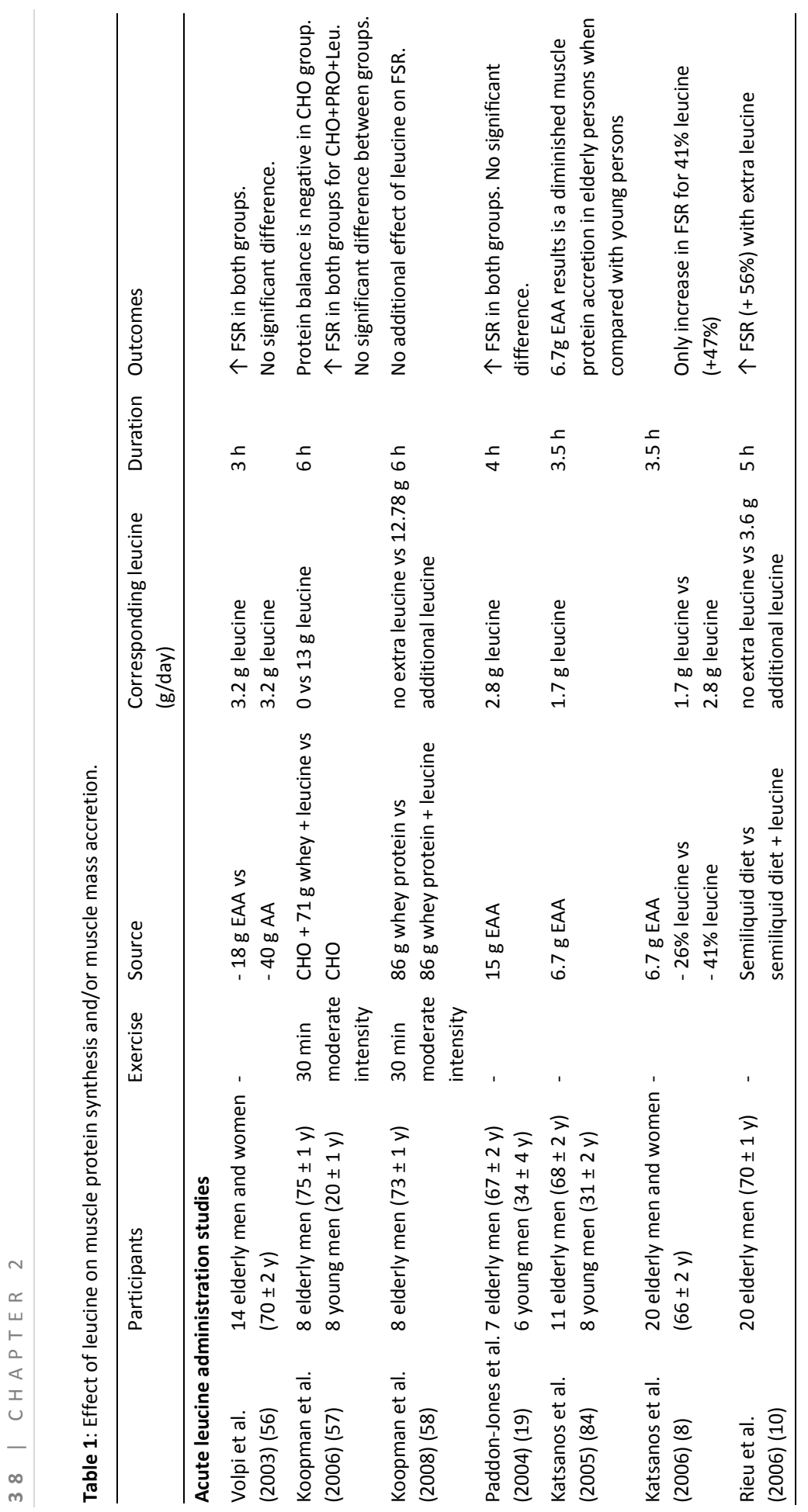




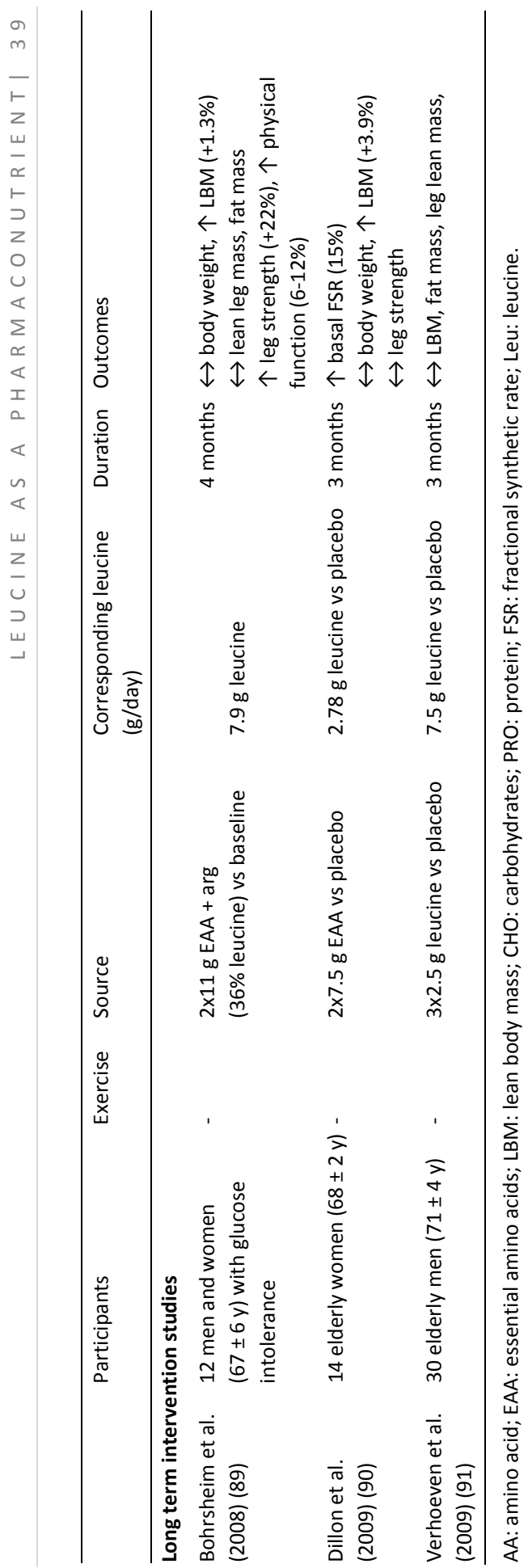


So far, there is only one study that reports an impaired postprandial response of muscle protein synthesis in the elderly versus the young, without modulating the associated endocrine response (84). Katsanos et al (84) reported an attenuated postprandial response of muscle protein synthesis following the ingestion of a small, meal like amount of essential amino acids (6.7 g with a $26 \%$ leucine content, providing $1.7 \mathrm{~g}$ leucine) in the elderly ( $68 \pm 2$ y) versus the young ( $31 \pm 2$ y). As a consequence, it is now speculated that anabolic resistance in the elderly becomes relevant when small, meal like amounts of protein are ingested. Interestingly, with leucine being of particular relevance to the stimulation of muscle protein synthesis, Katsanos and co-workers (8) demonstrated that the blunted response to amino acid ingestion in the elderly could be compensated for by increasing the leucine content of the amino acid mixture from 26 to $41 \%$ (from 1.7 to $2.8 \mathrm{~g}$ leucine). The higher content stimulated postprandial muscle protein synthesis by approximately $20 \%$ in the elderly (66 22 y) when compared with the postprandial response to the ingestion of the $26 \%$ leucine mixture, resulting in a response that no longer differed from that observed in the young $(30 \pm 2 \mathrm{y})$. The authors proposed that increasing the leucine content of a meal might represent an effective dietary strategy to normalize the response of muscle protein synthesis in the elderly. These observations are supported by Rieu et al (10), who evaluated the impact of meals enriched with leucine on muscle protein synthesis in the elderly $(70 \pm 1 \mathrm{y})$. Subjects received semi-liquid meals administered over a 5 hour period, with $50 \mathrm{~mL}$ provided every $20 \mathrm{~min}$. The leucine diet was supplemented with $0.052 \mathrm{~g}$ leucine per $\mathrm{kg}$ body weight (providing an additional $\sim 3.6 \mathrm{~g}$ leucine compared with $2.2 \mathrm{~g}$ protein bound leucine). Leucine supplementation increased the muscle protein fractional synthetic rate, measured at the end of the feeding period from $0.053 \pm 0.009 \%$ per hour in the control group to $0.083 \pm 0.008 \%$ per hour in the leucine-supplemented group. The proposed anabolic properties of the leucine supplemented diet were attributed to the approximately $130 \%$ increase in the leucine concentration in plasma, as only plasmafree leucine concentrations differed between groups (10). These recent studies in humans strongly suggest that leucine supplementation with each main meal might represent an effective nutritional strategy to improve skeletal muscle mass and function in the elderly (91). However, such an effect will depend on the amount of leucine that is provided by the meal and the extent of additional supplementation. So far, there are no dose-effect studies that have particularly addressed the postprandial response of synthesis to the ingestion of various amounts of leucine. However, the abovereported data suggest that approximately $3 \mathrm{~g}$ leucine is sufficient to maximize the postprandial response of muscle protein synthesis in the elderly. For an overview of the amounts of leucine that were provided in the key studies mentioned, see Table 1.

Long-term studies of leucine supplementation are warranted to address whether the proposed anabolic properties of leucine co-ingestion will translate into clinically relevant gains in muscle mass and strength in the elderly. So far, only a few studies have addressed the potential impact of prolonged leucine supplementation in the elderly (89-92). Borsheim et al (89) studied the effects of 16 weeks of essential amino 
acid supplementation (11 g essential amino acids containing $2.8 \mathrm{~g}$ leucine, twice daily) on muscle mass and strength in elderly subjects (approximately 67 years of age). They reported a $22.2 \pm 6.1 \%$ increase in muscle strength. Dillon et al (90) performed a similar study over 12 weeks, during which they supplemented healthy elderly women (approximately 68 years of age) with $15 \mathrm{~g}$ essential amino acids per day (providing $4.0 \mathrm{~g}$ leucine per day). After 12 weeks lean mass had increased by approximately 4\% (representing $1.7 \mathrm{~kg}$ lean tissue). As neither studies reported data on total energy intake and/or habitual diet, it can only be speculated whether the benefits of essential amino acid supplementation were attributed to an increase in total amino acid/protein intake or to the anabolic properties of leucine or other specific essential amino acids.

A recent study investigated the impact of 3 months leucine supplementation with each main meal on muscle mass and strength in healthy, elderly males (71 \pm 4 y) (91). Thirty healthy men were randomly assigned to either placebo or leucine supplementation for a 12-week intervention period. Subjects were administered $2.5 \mathrm{~g}$ leucine (or placebo) with each main meal (3 times $2.5 \mathrm{~g}$ [7.5 g] leucine or placebo per day). No changes in skeletal muscle mass or strength were observed over time in either the leucine-supplemented or the placebo group. Extrapolation of the acute stimulating properties of leucine ingestion ( $2.8 \mathrm{~g}$ ) on postprandial muscle protein synthesis reported by Katsanos et al (8) towards the impact of prolonged leucine supplementation with each main meal should translate into a gain of at least $1.7 \mathrm{~kg}$ lean muscle mass over a 3 month intervention period. However, no such changes in body composition and lean tissue mass were detected (91). There is no clear explanation for the apparent discrepancy between the acute and more prolonged effects of leucine supplementation on muscle protein metabolism. It might be speculated that 3 months leucine supplementation is insufficient to maximize the proposed benefits of prolonged leucine supplementation on muscle mass accretion. Furthermore, healthy elderly men who habitually consumed ample amounts of protein in their diet (approximately $1.0 \mathrm{~g} / \mathrm{kg} / \mathrm{day}$, resulting in a leucine intake of $8-15 \mathrm{~g}$ per day) were selected. This might explain why a further increase in leucine intake did not result in net muscle mass accretion. However, in line with the in vivo studies in rodents, it should also be considered that a greater postprandial response of muscle protein synthesis does not necessarily translate into structural skeletal muscle hypertrophy during more prolonged intervention, as many other factors contribute to regulate muscle mass maintenance (47-49). It could be speculated that long-term leucine supplementation is of greater clinical relevance in frail and malnourished elderly or in specific clinical subpopulations. In elderly patients with type 2 diabetes, a more rapid decline in muscle mass has been observed with aging. Because of its insulinotropic properties, leucine might be of even more relevant as a pharmaconutrient in elderly patients with type 2 diabetes. 


\section{Leucine as a pharmaconutrient in type 2 diabetes}

Epidemiological studies and preliminary intervention studies showed that postprandial hyperglycaemia represents a direct and independent risk factor for the development of cardiovascular disease (93). Importantly, the rapid postprandial increase in blood glucose concentrations or 'hyperglycemic spikes' seem to be even more relevant to the onset of cardiovascular complications than merely elevated fasting plasma glucose levels (94). The glycemic instability is a severely underestimated problem in patients with type 2 diabetes. Even in patients whose type 2 diabetes is well controlled with oral blood-glucose-lowering medication, hyperglycemia is still prevalent throughout the greater part of the day $(95,96)$. The capacity to maintain good glycemic control is generally evaluated based on the basis of the glycemic and insulinemic response to the ingestion of a single bolus of carbohydrate (97). However, it should be noted that carbohydrate is not the only macronutrient that strongly increases endogenous insulin release following food intake. Dietary protein and free amino acids can have strong insulinotropic effects, especially when co-ingested with carbohydrate (98-100). In accordance, co-ingestion of protein plus leucine represents an effective nutritional strategy to strongly stimulate postprandial insulin release, augment blood glucose disposal, and attenuate the post-prandial rise in blood glucose concentration in patients with type 2 diabetes $(11,13,15)$. These findings imply that the insulin secretory capacity of the compromised $\beta$-cell remains highly functional when responding to stimuli other than glucose, like amino acids.

From both in vitro and in vivo studies in humans, it has become evident that leucine functions as a strong insulin secretagogue. Recent in vivo observations show a two- to four-fold increase in endogenous insulin release following ingestion of relatively small amounts of free leucine $(3.75 \mathrm{~g})$ with carbohydrate and protein $(72,101)$. Leucine stimulates insulin release in the pancreas via its mitochondrial oxidative decarboxylation as well as by allosterically activating glutamate dehydrogenase in the $\beta$-cell (102104) (Figure 3). Besides the acute effects of leucine co-ingestion on $\beta$-cell function, $X u$ et al (102) suggested that a more prolonged exposure to leucine might also contribute to enhanced $\beta$-cell function through improved maintenance of $\beta$-cell mass. In accordance, Zhang et al (105) reported improvements in glycemic control by increases in insulin sensitivity (homeostasis model of insulin resistance [HOMA-IR] index was 50\% lower) and approximately 50\% lower glucagon levels following 14 weeks of leucine supplementation (via drinking water containing $1.5 \%$ leucine) in mice fed a high-fat diet. These findings supports the hypothesis that leucine co-ingestion with each main meal, containing both carbohydrate and protein, might represent an effective nutritional strategy to increase postprandial insulin release and, as such, improve glycemic control. 


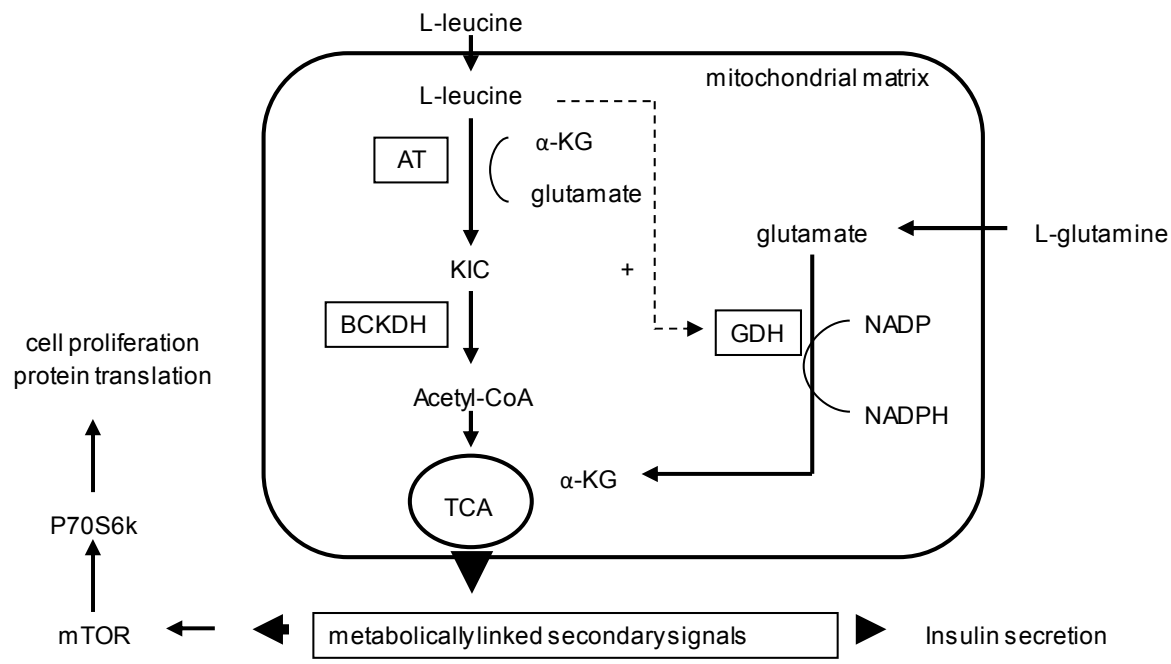

Figure 3: Simplified overview on the mechanisms by which leucine stimulates insulin secretion in the pancreatic $\boldsymbol{\beta}$-cell. Leucine-induced insulin secretion is mediated by leucine's oxidative decarboxylation as well as by allosteric activation of glutamate dehydrogenase. Both the generation of acetyl-coenzyme $A$ (Acetyl-CoA) and $\alpha$-ketoglutarate $(\alpha-K G)$ are needed for leucine to fully stimulate mitochondrial activity in the pancreatic $\beta$-cell. The metabolically linked secondary signals that subsequently lead to insulin exocytosis have yet to be established and seem responsible for the leucine-induced activation of the mammalian target

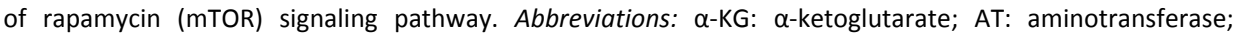
BCKDH: branched-chain $\alpha$-keto-acid dehydryogenase; GDH: glutamate dehydrogenase; KIC: $\alpha$ ketoisocaproate; P70S6k: P70S6 kinase; TCA: tricarboxylic acid cycle (adapted from van Loon et al (106))

Generally, improvements in postprandial blood glucose homeostasis are accompanied by improvements in blood lipid profile (105). Besides the improvements in glycemic control, Zhang et al (105) reported a $27 \%$ decrease in plasma total cholesterol concentration and a 53\% lower level of low-density lipoprotein cholesterol following 14 weeks of leucine supplementation in mice fed a high-fat diet (105). Their data imply that leucine supplementation protects against the harmful effects of a high-fat diet, providing further support for leucine as a promising pharmaconutrient in the prevention and treatment of chronic metabolic disease. The proposed clinical benefits of leucine supplementation in reducing both hyperglycemia and hypercholesterolemia remain to be investigated in an in vivo setting in humans.

Besides disturbances in glucose homeostasis, there is a two- to three-fold greater risk of injurious falls (107) and physical disability (108-111) in elderly adults with type 2 diabetes. In accordance, elderly patients with type 2 diabetes generally show a more pronounced decline in skeletal muscle mass and strength when compared with agematched, normoglycemic controls (6). In accordance, Park et al (6) showed that muscle quality, defined as muscle strength per unit of regional muscle mass, is consistently lower in elderly adults with type 2 diabetes. In fact, leg muscle quality was reported to be approximately $8 \%$ lower in the elderly with diabetes compared with the normoglycemic elderly (14 \pm 3 versus $15 \pm 3 \mathrm{Nm} / \mathrm{kg}$, respectively). In another study by Park et al, a 
more rapid decline in skeletal muscle mass was reported in patients with previously undiagnosed type 2 diabetes (112). The mechanisms responsible for the accelerated loss of skeletal muscle mass in elderly patients with type 2 diabetes remain to be elucidated. It is likely that the metabolic abnormalities associated with the type 2 diabetic state impair muscle protein metabolism (113). It could be speculated that the anabolic resistance of muscle protein synthesis to response to food intake $(114,115)$, is even more pronounced in elderly patients with type 2 diabetes. Although it has been proposed that circulating insulin levels (above $15 \mathrm{uU} / \mathrm{ml}$ ) are rather permissive instead of modulatory to allow muscle protein synthesis to be increased $(9,116)$, it seems evident that this might not be the case in an insulin-resistant state. Postprandial insulin release is severely blunted in patients with longstanding type 2 diabetes (117) and, combined with peripheral insulin resistance, might impair the postprandial response of muscle protein synthesis. This possible impairment of the postprandial response of muscle protein synthesis can be attributed to a reduced capacity of insulin to stimulate post-prandial muscle perfusion $(118,119)$, thereby lowering amino acid delivery to the muscle (120-122) and attenuating myocellular anabolic signaling $(9,85,123)$. Consequently, increasing postprandial insulin release, e.g., by ingesting leucine (2-4 g) with a mixed meal, might represent an effective nutritional strategy to improve postprandial muscle protein synthesis and counteract the anabolic resistance to feeding in insulin resistant muscle. Furthermore, the impact of greater postprandial insulin release might also inhibit muscle protein breakdown in the type 2 diabetic state. Though more research is warranted, it seems evident that nutritional strategies could be defined that will improve postprandial muscle protein synthesis in elderly patients with longstanding type 2 diabetes. Such an improvement might attenuate or reverse the accelerated loss of muscle mass and function in aging type 2 diabetes patients.

\section{Concerns of using leucine}

Despite the proposed benefits of leucine supplementation on muscle hypertrophy and glycemic control, the potential concerns about the use of leucine as a nutritional supplement must be considered. Leucine supplementation generally induces a decline in the plasma concentration of the other BCAAs, i.e., valine and isoleucine (52). It has been suggested that such a decline might negate the anabolic properties of leucine administration (124). However, it should be noted that lower plasma concentrations of valine and isoleucine are observed only in a postabsorptive resting condition and not in a postprandial situation, when large increases in the plasma concentrations of virtually all amino acids become apparent. Therefore, the stimulatory properties of the ingestion of leucine (2-3 g) with a mixed meal are unlikely to be attenuated by a relative lowering of the basal plasma concentration of valine or isoleucine. Furthermore, despite the observed decreases in basal fasting plasma valine (approximately 10-20\%) and isoleucine concentrations (approximately 0-10\%), plasma levels still fall well within the normal physiological range. Consequently, there do not seem to be any major 
concerns associated with the lowering of the basal plasma concentration of valine or isoleucine following leucine supplementation with the main meals.

As leucine stimulates muscle hypertrophy, it has been questioned whether leucine could also have an unwanted impact on tumor growth. This is supported by the findings of Vogt (125), who showed that signaling through the PI3-kinase and mTOR pathway is increased in some forms of cancer. In accordance, McNurlan et al (126), reported a similar increase in the rates of fractional protein synthesis in both muscle and tumor tissue following amino acid infusion prior to colorectal tumor surgery. However, further increasing the fraction of BCAAs in the amino acid mixture did not result in a further increase in rates of protein synthesis. This suggests that further increasing the leucine content in the diet does not necessarily affect tumor growth.

The potential safety limits for (free) amino acid supplementation are subject to speculation. De Lorenzo et al (127) provided 10 healthy males with $14.4 \mathrm{~g} / \mathrm{d}$ BCAAs for 30 days, without reporting any side effects or adverse reactions. In agreement, Marchesini et al (128) treated 20 chronic hepatic encephalopathy patients for 6 months with an enteral supplement that provided $240 \mathrm{mg} / \mathrm{kg} / \mathrm{d}$ BCAAs, without reporting any side effects or adverse reactions. Furthermore, patients with sepsis, stress, or injury have been treated with parenteral solutions containing up to $50 \%$ of the AA nitrogen as BCAA, without apparent side effects (129). It seems that large dietary excess intake of an individual BCAA ( $>8 \mathrm{~g} /$ day) is well tolerated when consumed in a diet containing surfeit levels of protein and, therefore, the other BCAAs (130). In agreement, based on the work to date, Matthews (52) concludes that leucine and the other BCAAs can be safely consumed in large amounts relative to the other amino acids in protein. Finally, it should be noted that the addition of free leucine in consumer food products can severely affect taste. Though this generally does not preclude the use of leucinecontaining sports nutrition supplements in athletes seeking ergogenic benefits, it might affect satiety and impair food intake in more compromised clinical subpopulations, where sufficient food intake generally forms a major problem.

\section{Future research}

Over the past decade, there has been an enormous gain in insight into the role of essential amino acids in regulating skeletal muscle protein synthesis and breakdown. However, there are still discrepancies between the results obtained in vivo in rodents and humans. In the in vivo rodent studies, an increase in the rates of postprandial muscle protein synthesis was observed, but not one of the studies referenced was able to detect increases in muscle mass or muscle strength $(44,45)$. So far, one human intervention study (90) has reported an increase in muscle mass (from $43.5 \pm 2.8$ to $45.2 \pm 3.0 \mathrm{~kg}$ lean body mass), whereas another study (89) reported an increase in leg strength (from $127 \pm 21$ to $146 \pm 19 \mathrm{~kg}$ sum of individual knee extensors en flexors) following prolonged essential amino acid supplementation. It seems imperative to use 
the human model to explore the true functional role of leucine in the regulation of muscle metabolism in the elderly. There is ample evidence to support the ability of leucine to stimulate protein synthesis in rodents $(18,41-45)$. In accordance, there are also strong indications that leucine plays a key role in regulating muscle protein synthesis in vivo in humans $(8,10,55)$. However, apart from the observed increase in muscle protein synthesis following the use of the flooding dose technique with labeled amino acids (55), there is limited evidence on the differential anabolic properties of the various amino acids in vivo in humans. Comparisons of leucine versus other (essential) amino acids using established methods for measuring muscle protein synthesis and breakdown are required to elucidate the acute anabolic effects of amino acid administration on muscle protein turnover. Furthermore, the use of leucine coingestion as a means to improve net muscle protein balance should be assessed in a more practical, postprandial condition.

Besides studying the acute effects of leucine administration on muscle protein metabolism, it is imperative to assess whether these proposed acute effects are maintained during more prolonged leucine supplementation protocols in vivo in humans. Furthermore, more long-term intervention studies are warranted to investigate whether the acute effects of leucine administration on muscle protein synthesis can be translated into measurable and clinically relevant increases in muscle mass, strength, and functional capacity. So far, there is little evidence to support the proposed clinical benefits of prolonged leucine supplementation in healthy elderly subjects (91). It could be speculated that clinical benefits of leucine supplementation are more relevant in more compromised elderly subpopulations. Research is warranted to assess whether leucine co-ingestion can promote postprandial muscle protein accretion under conditions in which food intake is suboptimal, i.e., in malnourished and/or frail elderly. Assessing the clinical benefits of prolonged leucine supplementation on preventing or attenuating the greater loss of muscle mass and strength in these clinical subpopulations could be of greater clinical relevance.

Due to its insulinotropic properties, leucine might represent an even more interesting pharmaconutrient for elderly patients with type 2 diabetes $(11,13,15)$. The greater post-prandial insulin release would likely augment the protein synthesis response in insulin-resistant muscle $(119,131)$ and also improve postprandial glucose and lipid handling. So far, there is little evidence to support the proposed beneficial effects of prolonged leucine supplementation on blood glucose and lipid profile in rodents (105). Both short- and long-term intervention studies are warranted to assess the efficacy of leucine as an effective pharmaconutrient in the prevention and treatment of type 2 diabetes in vivo in humans. Other clinical subpopulations that might benefit from leucine administration include patients with accelerated muscle wasting and cachexia, as occurs in cancer, chronic obstructive pulmonary disease, and intensive care unit (ICU) patients (132). Whether acute leucine administration can effectively modulate muscle protein synthesis and proteolysis in these conditions remains to be established in vivo in humans. Subsequently, prolonged leucine supplementation studies should be per- 
formed to confirm the proposed anabolic properties of leucine in muscle wasting disease and cachexia.

\section{Conclusions}

Leucine administration stimulates muscle protein synthesis and inhibits protein degradation via insulin-dependent and insulin-independent pathways. Recent studies report that increasing the leucine content of a meal to a level exceeding $3 \mathrm{~g}$ increases rates of postprandial muscle protein synthesis in vivo in elderly men, thereby normalizing the blunted response of muscle protein synthesis to food ingestion. Furthermore, due to its insulinotropic properties, free leucine (2-5 g) ingested with a mixed meal stimulates endogenous insulin release and attenuates the rise in postprandial blood glucose concentrations in patients with type 2 diabetes. Consequently, leucine supplementation has been suggested to represent an effective nutritional strategy to prevent and treat the loss of muscle mass with aging as well as to improve postprandial glycemic control in patients with type 2 diabetes. Though promising, there is no evidence that dietary supplementation with leucine can augment muscle mass or strength or improve glycemic control. More prolonged nutritional intervention studies in vivo are warranted to assess these proposed clinical benefits of leucine supplementation in elderly individuals or in patients with chronic metabolic disease or muscle wasting conditions. 


\section{References}

1. Li JB, Jefferson LS: Influence of amino acid availability on protein turnover in perfused skeletal muscle. Biochim Biophys Acta 1978, 544(2):351-359.

2. Anthony JC, Anthony TG, Kimball SR, Vary TC, Jefferson LS: Orally administered leucine stimulates protein synthesis in skeletal muscle of postabsorptive rats in association with increased elF4F formation. J Nutr 2000, 130(2):139-145.

3. Buse MG, Atwell R, Mancusi V: In vitro effect of branched chain amino acids on the ribosomal cycle in muscles of fasted rats. Horm Metab Res 1979, 11(4):289-292.

4. Buse MG, Reid SS: Leucine. A possible regulator of protein turnover in muscle. J Clin Invest 1975, 56(5):1250-1261.

5. Norton LE, Layman DK: Leucine regulates translation initiation of protein synthesis in skeletal muscle after exercise. J Nutr 2006, 136(2):533S-537S.

6. Park SW, Goodpaster BH, Strotmeyer ES, de Rekeneire N, Harris TB, Schwartz AV, Tylavsky FA, Newman $A B$ : Decreased muscle strength and quality in older adults with type 2 diabetes: the health, aging, and body composition study. Diabetes 2006, 55(6):1813-1818.

7. Volpi E, Mittendorfer B, Rasmussen BB, Wolfe RR: The response of muscle protein anabolism to combined hyperaminoacidemia and glucose-induced hyperinsulinemia is impaired in the elderly. $J$ Clin Endocrinol Metab 2000, 85(12):4481-4490.

8. Katsanos CS, Kobayashi H, Sheffield-Moore M, Aarsland A, Wolfe RR: A high proportion of leucine is required for optimal stimulation of the rate of muscle protein synthesis by essential amino acids in the elderly. Am J Physiol Endocrinol Metab 2006, 291(2):E381-387.

9. Cuthbertson D, Smith K, Babraj J, Leese G, Waddell T, Atherton P, Wackerhage H, Taylor PM, Rennie MJ: Anabolic signaling deficits underlie amino acid resistance of wasting, aging muscle. FASEB J 2005, 19(3):422-424.

10. Rieu I, Balage M, Sornet C, Giraudet C, Pujos E, Grizard J, Mosoni L, Dardevet D: Leucine supplementation improves muscle protein synthesis in elderly men independently of hyperaminoacidaemia. $J$ Physiol 2006, 575(Pt 1):305-315.

11. Manders RJ, Wagenmakers AJ, Koopman R, Zorenc AH, Menheere PP, Schaper NC, Saris WH, van Loon $\sqcup$ : Co-ingestion of a protein hydrolysate and amino acid mixture with carbohydrate improves plasma glucose disposal in patients with type 2 diabetes. Am J Clin Nutr 2005, 82(1):76-83.

12. Manders RJ, Praet SF, Meex RC, Koopman R, de Roos AL, Wagenmakers AJ, Saris WH, van Loon LJ: Protein hydrolysate/leucine co-ingestion reduces the prevalence of hyperglycemia in type 2 diabetic patients. Diabetes Care 2006, 29(12):2721-2722.

13. van Loon LJ, Kruijshoop M, Menheere PP, Wagenmakers AJ, Saris WH, Keizer HA: Amino acid ingestion strongly enhances insulin secretion in patients with long-term type 2 diabetes. Diabetes Care 2003, 26(3):625-630.

14. Manders RJ, Koopman R, Beelen M, Gijsen AP, Wodzig WK, Saris WH, van Loon LJ: The muscle protein synthetic response to carbohydrate and protein ingestion is not impaired in men with longstanding type 2 diabetes. J Nutr 2008, 138(6):1079-1085.

15. Manders RJ, Koopman R, Sluijsmans WE, van den Berg R, Verbeek K, Saris WH, Wagenmakers AJ, van Loon $\mathrm{L}$ : Co-ingestion of a protein hydrolysate with or without additional leucine effectively reduces postprandial blood glucose excursions in Type 2 diabetic men. J Nutr 2006, 136(5):1294-1299.

16. Manders RJ, Praet SF, Vikstrom MH, Saris WH, van Loon LJ: Protein hydrolysate co-ingestion does not modulate $24 \mathrm{~h}$ glycemic control in long-standing type 2 diabetes patients. Eur J Clin Nutr 2009, 63(1):121-126.

17. Kimball SR, Jefferson LS: Regulation of protein synthesis by branched-chain amino acids. Curr Opin Clin Nutr Metab Care 2001, 4(1):39-43.

18. Garlick PJ, Grant I: Amino acid infusion increases the sensitivity of muscle protein synthesis in vivo to insulin. Effect of branched-chain amino acids. Biochem J 1988, 254(2):579-584. 
19. Paddon-Jones D, Sheffield-Moore M, Zhang XJ, Volpi E, Wolf SE, Aarsland A, Ferrando AA, Wolfe RR: Amino acid ingestion improves muscle protein synthesis in the young and elderly. Am J Physiol Endocrinol Metab 2004, 286(3):E321-328.

20. Volpi E, Lucidi P, Cruciani G, Monacchia F, Reboldi G, Brunetti P, Bolli GB, De Feo P: Contribution of amino acids and insulin to protein anabolism during meal absorption. Diabetes 1996, 45(9):1245-1252.

21. Kimball SR, Jefferson LS: Control of protein synthesis by amino acid availability. Curr Opin Clin Nutr Metab Care 2002, 5(1):63-67.

22. Guillet C, Zangarelli A, Gachon P, Morio B, Giraudet C, Rousset P, Boirie Y: Whole body protein breakdown is less inhibited by insulin, but still responsive to amino acid, in nondiabetic elderly subjects. J Clin Endocrinol Metab 2004, 89(12):6017-6024.

23. Fulks RM, Li JB, Goldberg AL: Effects of insulin, glucose, and amino acids on protein turnover in rat diaphragm. J Biol Chem 1975, 250(1):290-298.

24. Welle S, Bhatt K, Thornton CA: Stimulation of myofibrillar synthesis by exercise is mediated by more efficient translation of mRNA. J Appl Physiol 1999, 86(4):1220-1225.

25. Laurent GJ, Sparrow MP, Millward DJ: Turnover of muscle protein in the fowl. Changes in rates of protein synthesis and breakdown during hypertrophy of the anterior and posterior latissimus dorsi muscles. Biochem J 1978, 176(2):407-417.

26. Kimball SR: Regulation of global and specific mRNA translation by amino acids. J Nutr 2002, 132(5):883886.

27. Kimball SR, Jefferson LS: Regulation of global and specific mRNA translation by oral administration of branched-chain amino acids. Biochem Biophys Res Commun 2004, 313(2):423-427.

28. Pain VM: Initiation of protein synthesis in eukaryotic cells. Eur J Biochem 1996, 236(3):747-771.

29. Koopman R, Saris WH, Wagenmakers AJ, van Loon LJ: Nutritional interventions to promote postexercise muscle protein synthesis. Sports Med 2007, 37(10):895-906.

30. Proud CG: mTOR-mediated regulation of translation factors by amino acids. Biochem Biophys Res Commun 2004, 313(2):429-436.

31. Kim E, Goraksha-Hicks P, Li L, Neufeld TP, Guan KL: Regulation of TORC1 by Rag GTPases in nutrient response. Nat Cell Biol 2008, 10(8):935-945

32. Sancak Y, Peterson TR, Shaul YD, Lindquist RA, Thoreen CC, Bar-Peled L, Sabatini DM: The Rag GTPases bind raptor and mediate amino acid signaling to mTORC1. Science 2008, 320(5882):1496-1501.

33. Byfield MP, Murray JT, Backer JM: hVps34 is a nutrient-regulated lipid kinase required for activation of p70 S6 kinase. J Biol Chem 2005, 280(38):33076-33082.

34. Findlay GM, Yan L, Procter J, Mieulet V, Lamb RF: A MAP4 kinase related to Ste20 is a nutrient-sensitive regulator of mTOR signalling. Biochem $J$ 2007, 403(1):13-20.

35. Nobukuni T, Joaquin M, Roccio M, Dann SG, Kim SY, Gulati P, Byfield MP, Backer JM, Natt F, Bos JL et al: Amino acids mediate $\mathrm{mTOR} /$ raptor signaling through activation of class 3 phosphatidylinositol $3 \mathrm{OH}$ kinase. Proc Natl Acad Sci U S A 2005, 102(40):14238-14243.

36. MacKenzie MG, Hamilton DL, Murray JT, Taylor PM, Baar K: mVps34 is activated following highresistance contractions. J Physiol 2009, 587(Pt 1):253-260.

37. Stipanuk MH: Leucine and protein synthesis: mTOR and beyond. Nutrition reviews 2007, 65(3):122-129.

38. Kimball SR, Jefferson LS: Signaling pathways and molecular mechanisms through which branched-chain amino acids mediate translational control of protein synthesis. The Journal of nutrition 2006, 136(1 Suppl):227S-231S.

39. Layman DK, Baum Jl: Dietary protein impact on glycemic control during weight loss. The Journal of nutrition 2004, 134(4):968S-973S.

40. Greenhaff PL, Karagounis LG, Peirce N, Simpson EJ, Hazell M, Layfield R, Wackerhage H, Smith K, Atherton P, Selby A et al: Disassociation between the effects of amino acids and insulin on signaling, ubiquitin ligases, and protein turnover in human muscle. Am J Physiol Endocrinol Metab 2008, 295(3):E595-604.

41. Anthony JC, Anthony TG, Layman DK: Leucine supplementation enhances skeletal muscle recovery in rats following exercise. J Nutr 1999, 129(6):1102-1106. 
42. Crozier SJ, Kimball SR, Emmert SW, Anthony JC, Jefferson LS: Oral leucine administration stimulates protein synthesis in rat skeletal muscle. J Nutr 2005, 135(3):376-382.

43. Dardevet D, Sornet C, Bayle G, Prugnaud J, Pouyet C, Grizard J: Postprandial stimulation of muscle protein synthesis in old rats can be restored by a leucine-supplemented meal. J Nutr 2002, 132(1):95-100.

44. Rieu I, Sornet C, Bayle G, Prugnaud J, Pouyet C, Balage M, Papet I, Grizard J, Dardevet D: Leucinesupplemented meal feeding for ten days beneficially affects postprandial muscle protein synthesis in old rats. J Nutr 2003, 133(4):1198-1205.

45. Rieu I, Balage M, Sornet C, Debras E, Ripes S, Rochon-Bonhomme C, Pouyet C, Grizard J, Dardevet D: Increased availability of leucine with leucine-rich whey proteins improves postprandial muscle protein synthesis in aging rats. Nutrition 2007, 23(4):323-331.

46. Anthony JC, Yoshizawa F, Anthony TG, Vary TC, Jefferson LS, Kimball SR: Leucine stimulates translation initiation in skeletal muscle of postabsorptive rats via a rapamycin-sensitive pathway. J Nutr 2000, 130(10):2413-2419.

47. Proctor DN, Balagopal P, Nair KS: Age-Related Sarcopenia in Humans Is Associated with Reduced Synthetic Rates of Specific Muscle Proteins. J Nutr 1998, 128(2):351S-.

48. Snijders T, Verdijk LB, van Loon LJ: The impact of sarcopenia and exercise training on skeletal muscle satellite cells. Ageing Res Rev 2009, 8(4):328-338.

49. Lexell J, Taylor CC, Sjöström M: What is the cause of the ageing atrophy?: Total number, size and proportion of different fiber types studied in whole vastus lateralis muscle from 15- to 83-year-old men. Journal of the Neurological Sciences 1988, 84(2-3):275-294.

50. Louard RJ, Barrett EJ, Gelfand RA: Effect of infused branched-chain amino acids on muscle and wholebody amino acid metabolism in man. Clin Sci (Lond) 1990, 79(5):457-466.

51. Nair KS, Schwartz RG, Welle S: Leucine as a regulator of whole body and skeletal muscle protein metabolism in humans. Am J Physiol 1992, 263(5 Pt 1):E928-934.

52. Matthews DE: Observations of branched-chain amino acid administration in humans. J Nutr 2005, 135(6 Suppl):1580S-1584S.

53. Bennet WM, Connacher AA, Scrimgeour CM, Smith K, Rennie MJ: Increase in anterior tibialis muscle protein synthesis in healthy man during mixed amino acid infusion: studies of incorporation of [113C]leucine. Clin Sci (Lond) 1989, 76(4):447-454.

54. Smith K, Reynolds N, Downie S, Patel A, Rennie MJ: Effects of flooding amino acids on incorporation of labeled amino acids into human muscle protein. Am J Physiol 1998, 275(1 Pt 1):E73-78.

55. Smith K, Barua JM, Watt PW, Scrimgeour CM, Rennie MJ: Flooding with L-[1-13C]leucine stimulates human muscle protein incorporation of continuously infused L-[1-13C]valine. Am J Physiol 1992, 262(3 Pt 1):E372-376.

56. Volpi E, Kobayashi H, Sheffield-Moore M, Mittendorfer B, Wolfe RR: Essential amino acids are primarily responsible for the amino acid stimulation of muscle protein anabolism in healthy elderly adults. $\mathrm{Am} \mathrm{J}$ Clin Nutr 2003, 78(2):250-258.

57. Koopman R, Verdijk L, Manders RJ, Gijsen AP, Gorselink M, Pijpers E, Wagenmakers AJ, van Loon LJ: Coingestion of protein and leucine stimulates muscle protein synthesis rates to the same extent in young and elderly lean men. Am J Clin Nutr 2006, 84(3):623-632.

58. Koopman R, Verdijk LB, Beelen M, Gorselink M, Kruseman AN, Wagenmakers AJ, Kuipers H, van Loon : Co-ingestion of leucine with protein does not further augment post-exercise muscle protein synthesis rates in elderly men. Br J Nutr 2008, 99(3):571-580.

59. Louard RJ, Barrett EJ, Gelfand RA: Overnight branched-chain amino acid infusion causes sustained suppression of muscle proteolysis. Metabolism 1995, 44(4):424-429.

60. Volpi E, Mittendorfer B, Wolf SE, Wolfe RR: Oral amino acids stimulate muscle protein anabolism in the elderly despite higher first-pass splanchnic extraction. Am J Physiol 1999, 277(3 Pt 1):E513-520.

61. Phillips SM, Tipton KD, Aarsland A, Wolf SE, Wolfe RR: Mixed muscle protein synthesis and breakdown after resistance exercise in humans. Am J Physiol 1997, 273(1 Pt 1):E99-107.

62. Tang JE, Perco JG, Moore DR, Wilkinson SB, Phillips SM: Resistance training alters the response of fed state mixed muscle protein synthesis in young men. Am J Physiol Regul Integr Comp Physiol 2008, 294(1):R172-178. 
63. Chesley A, MacDougall JD, Tarnopolsky MA, Atkinson SA, Smith K: Changes in human muscle protein synthesis after resistance exercise. J Appl Physiol 1992, 73(4):1383-1388.

64. Welle S, Thornton C, Statt M: Myofibrillar protein synthesis in young and old human subjects after three months of resistance training. Am J Physiol 1995, 268(3 Pt 1):E422-427.

65. Yarasheski KE, Zachwieja JJ, Bier DM: Acute effects of resistance exercise on muscle protein synthesis rate in young and elderly men and women. Am J Physiol 1993, 265(2 Pt 1):E210-214.

66. Borsheim E, Tipton KD, Wolf SE, Wolfe RR: Essential amino acids and muscle protein recovery from resistance exercise. Am J Physiol Endocrinol Metab 2002, 283(4):E648-657.

67. Dreyer HC, Drummond MJ, Pennings B, Fujita S, Glynn EL, Chinkes DL, Dhanani S, Volpi E, Rasmussen BB: Leucine-enriched essential amino acid and carbohydrate ingestion following resistance exercise enhances mTOR signaling and protein synthesis in human muscle. Am J Physiol Endocrinol Metab 2008, 294(2):E392-400.

68. Drummond MJ, Bell JA, Fujita S, Dreyer HC, Glynn EL, Volpi E, Rasmussen BB: Amino acids are necessary for the insulin-induced activation of mTOR/S6K1 signaling and protein synthesis in healthy and insulin resistant human skeletal muscle. Clin Nutr 2008, 27(3):447-456.

69. Miller SL, Tipton KD, Chinkes DL, Wolf SE, Wolfe RR: Independent and combined effects of amino acids and glucose after resistance exercise. Med Sci Sports Exerc 2003, 35(3):449-455.

70. Rasmussen BB, Tipton KD, Miller SL, Wolf SE, Wolfe RR: An oral essential amino acid-carbohydrate supplement enhances muscle protein anabolism after resistance exercise. J Appl Physiol 2000, 88(2):386-392.

71. Biolo G, Maggi SP, Williams BD, Tipton KD, Wolfe RR: Increased rates of muscle protein turnover and amino acid transport after resistance exercise in humans. Am J Physiol 1995, 268(3 Pt 1):E514-520.

72. Koopman R, Wagenmakers AJ, Manders RJ, Zorenc AH, Senden JM, Gorselink M, Keizer HA, van Loon LJ: Combined ingestion of protein and free leucine with carbohydrate increases postexercise muscle protein synthesis in vivo in male subjects. Am J Physiol Endocrinol Metab 2005, 288(4):E645-653.

73. Short KR, Nair KS: The effect of age on protein metabolism. Curr Opin Clin Nutr Metab Care 2000, 3(1):39-44.

74. Short KR, Vittone JL, Bigelow ML, Proctor DN, Nair KS: Age and aerobic exercise training effects on whole body and muscle protein metabolism. Am J Physiol Endocrinol Metab 2004, 286(1):E92-101.

75. Lexell J: Human aging, muscle mass, and fiber type composition. J Gerontol A Biol Sci Med Sci 1995, 50 Spec No:11-16.

76. Campbell WW, Evans WJ: Protein requirements of elderly people. Eur J Clin Nutr 1996, 50 Suppl 1:S180183; discussion S183-185.

77. Campbell WW, Trappe TA, Wolfe RR, Evans WJ: The recommended dietary allowance for protein may not be adequate for older people to maintain skeletal muscle. J Gerontol A Biol Sci Med Sci 2001, 56(6):M373-380.

78. Campbell WW, Leidy HJ: Dietary protein and resistance training effects on muscle and body composition in older persons. J Am Coll Nutr 2007, 26(6):696S-703S.

79. Nair KS: Aging muscle. Am J Clin Nutr 2005, 81(5):953-963.

80. Balagopal P, Rooyackers OE, Adey DB, Ades PA, Nair KS: Effects of aging on in vivo synthesis of skeletal muscle myosin heavy-chain and sarcoplasmic protein in humans. Am J Physiol 1997, 273(4 Pt 1):E790-800.

81. Rooyackers OE, Adey DB, Ades PA, Nair KS: Effect of age on in vivo rates of mitochondrial protein synthesis in human skeletal muscle. Proc Natl Acad Sci U S A 1996, 93(26):15364-15369.

82. Welle S, Thornton C, Jozefowicz R, Statt M: Myofibrillar protein synthesis in young and old men. Am J Physiol 1993, 264(5 Pt 1):E693-698.

83. Volpi E, Sheffield-Moore M, Rasmussen BB, Wolfe RR: Basal muscle amino acid kinetics and protein synthesis in healthy young and older men. JAMA 2001, 286(10):1206-1212.

84. Katsanos CS, Kobayashi H, Sheffield-Moore M, Aarsland A, Wolfe RR: Aging is associated with diminished accretion of muscle proteins after the ingestion of a small bolus of essential amino acids. Am J Clin Nutr 2005, 82(5):1065-1073. 
85. Guillet C, Prod'homme M, Balage M, Gachon P, Giraudet C, Morin L, Grizard J, Boirie Y: Impaired anabolic response of muscle protein synthesis is associated with $\mathrm{S} 6 \mathrm{~K} 1$ dysregulation in elderly humans. FASEB J 2004, 18(13):1586-1587.

86. Kumar V, Selby A, Rankin D, Patel R, Atherton P, Hildebrandt W, Williams J, Smith K, Seynnes O, Hiscock $\mathrm{N}$ et al: Age-related differences in the dose-response relationship of muscle protein synthesis to resistance exercise in young and old men. J Physiol 2009, 587(Pt 1):211-217.

87. Koopman R, Walrand S, Beelen M, Gijsen AP, Kies AK, Boirie Y, Saris WH, van Loon LJ: Dietary protein digestion and absorption rates and the subsequent postprandial muscle protein synthetic response do not differ between young and elderly men. J Nutr 2009, 139(9):1707-1713. Epub 2009 Jul 1722.

88. Pennings B, Koopman R, Beelen M, Senden JM, Saris WH, van Loon L: Exercising before protein intake allows for greater use of dietary protein-derived amino acids for de novo muscle protein synthesis in both young and elderly men. Am J Clin Nutr 2011, 93(2):322-331.

89. Borsheim E, Bui QU, Tissier S, Kobayashi H, Ferrando AA, Wolfe RR: Effect of amino acid supplementation on muscle mass, strength and physical function in elderly. Clin Nutr 2008, 27(2):189-195.

90. Dillon EL, Sheffield-Moore M, Paddon-Jones D, Gilkison C, Sanford AP, Casperson SL, Jiang J, Chinkes DL, Urban RJ: Amino acid supplementation increases lean body mass, basal muscle protein synthesis, and insulin-like growth factor-I expression in older women. J Clin Endocrinol Metab 2009, 94(5):1630-1637.

91. Verhoeven S, Vanschoonbeek K, Verdijk LB, Koopman R, Wodzig WK, Dendale P, van Loon LJ: Longterm leucine supplementation does not increase muscle mass or strength in healthy elderly men. $\mathrm{Am} \mathrm{J}$ Clin Nutr 2009, 89(5):1468-1475.

92. Borsheim E, Bui QU, Tissier S, Cree MG, Ronsen O, Morio B, Ferrando AA, Kobayashi H, Newcomer BR, Wolfe RR: Amino acid supplementation decreases plasma and liver triacylglycerols in elderly. Nutrition 2009, 25(3):281-288.

93. Wautier MP, Massin P, Guillausseau PJ, Huijberts M, Levy B, Boulanger E, Laloi-Michelin M, Wautier JL: $\mathrm{N}$ (carboxymethyl)lysine as a biomarker for microvascular complications in type 2 diabetic patients. Diabetes Metab 2003, 29(1):44-52.

94. Ceriello A: Postprandial hyperglycemia and diabetes complications: is it time to treat? Diabetes 2005, 54(1):1-7.

95. Praet SF, Manders RJ, Meex RC, Lieverse AG, Stehouwer CD, Kuipers H, Keizer HA, van Loon LJ: Glycaemic instability is an underestimated problem in Type II diabetes. Clin Sci (Lond) 2006, 111(2):119-126.

96. Manders RJ, Pennings B, Beckers CP, Aipassa TI, van Loon $\mathrm{U}$ : Prevalence of daily hyperglycemia in obese type 2 diabetic men compared with that in lean and obese normoglycemic men: effect of consumption of a sucrose-containing beverage. Am J Clin Nutr 2009, 90(3):511-518.

97. Diagnosis and classification of diabetes mellitus. Diabetes Care 2006, 29 Suppl 1:S43-48.

98. van Loon $\mathrm{L}$, Kruijshoop M, Verhagen H, Saris WH, Wagenmakers AJ: Ingestion of protein hydrolysate and amino acid-carbohydrate mixtures increases postexercise plasma insulin responses in men. $J$ Nutr 2000, 130(10):2508-2513.

99. van Loon LJ, Saris WH, Kruijshoop M, Wagenmakers AJ: Maximizing postexercise muscle glycogen synthesis: carbohydrate supplementation and the application of amino acid or protein hydrolysate mixtures. Am J Clin Nutr 2000, 72(1):106-111.

100. van Loon LJ, Saris WH, Verhagen H, Wagenmakers AJ: Plasma insulin responses after ingestion of different amino acid or protein mixtures with carbohydrate. Am J Clin Nutr 2000, 72(1):96-105.

101. Kaastra B, Manders RJ, Van Breda E, Kies A, Jeukendrup AE, Keizer HA, Kuipers H, Van Loon LJ: Effects of increasing insulin secretion on acute postexercise blood glucose disposal. Med Sci Sports Exerc 2006, 38(2):268-275.

102. Xu G, Kwon G, Cruz WS, Marshall CA, McDaniel ML: Metabolic regulation by leucine of translation initiation through the mTOR-signaling pathway by pancreatic beta-cells. Diabetes 2001, 50(2):353-360.

103. Sener A, Malaisse WJ: L-leucine and a nonmetabolized analogue activate pancreatic islet glutamate dehydrogenase. Nature 1980, 288(5787):187-189.

104. Fahien LA, MacDonald MJ, Kmiotek EH, Mertz RJ, Fahien CM: Regulation of insulin release by factors that also modify glutamate dehydrogenase. J Biol Chem 1988, 263(27):13610-13614. 
105. Zhang Y, Guo K, LeBlanc RE, Loh D, Schwartz GJ, Yu YH: Increasing dietary leucine intake reduces dietinduced obesity and improves glucose and cholesterol metabolism in mice via multimechanisms. Diabetes 2007, 56(6):1647-1654.

106. van Loon L: Amino acids as pharmaco-nutrients for the treatment of type2 diabetes. Immun Endoc \& Metab Agents in Med Chem 2007:39-48.

107. Miller DK, Lui LY, Perry HM, 3rd, Kaiser FE, Morley JE: Reported and measured physical functioning in older inner-city diabetic African Americans. J Gerontol A Biol Sci Med Sci 1999, 54(5):M230-236.

108. De Rekeneire N, Resnick HE, Schwartz AV, Shorr RI, Kuller LH, Simonsick EM, Vellas B, Harris TB: Diabetes is associated with subclinical functional limitation in nondisabled older individuals: the Health, Aging, and Body Composition study. Diabetes Care 2003, 26(12):3257-3263.

109. Gregg EW, Beckles GL, Williamson DF, Leveille SG, Langlois JA, Engelgau MM, Narayan KM: Diabetes and physical disability among older U.S. adults. Diabetes Care 2000, 23(9):1272-1277.

110. Gregg EW, Mangione CM, Cauley JA, Thompson TJ, Schwartz AV, Ensrud KE, Nevitt MC: Diabetes and incidence of functional disability in older women. Diabetes Care 2002, 25(1):61-67.

111. Ryerson B, Tierney EF, Thompson TJ, Engelgau MM, Wang J, Gregg EW, Geiss LS: Excess physical limitations among adults with diabetes in the U.S. population, 1997-1999. Diabetes Care 2003, 26(1):206-210.

112. Park SW, Goodpaster BH, Lee JS, Kuller LH, Boudreau R, de Rekeneire N, Harris TB, Kritchevsky S, Tylavsky FA, Nevitt $\mathrm{M}$ et al: Excessive loss of skeletal muscle mass in older adults with type 2 diabetes. Diabetes Care 2009, 32(11):1993-1997.

113. Gougeon R, Morais JA, Chevalier S, Pereira S, Lamarche M, Marliss EB: Determinants of whole-body protein metabolism in subjects with and without type 2 diabetes. Diabetes Care 2008, 31(1):128-133.

114. Guillet C, Boirie Y: Insulin resistance: a contributing factor to age-related muscle mass loss? Diabetes Metab 2005, 31 Spec No 2:5S20-25S26.

115. Pereira S, Marliss EB, Morais JA, Chevalier S, Gougeon R: Insulin resistance of protein metabolism in type 2 diabetes. Diabetes 2008, 57(1):56-63.

116. Bohe J, Low A, Wolfe RR, Rennie MJ: Human muscle protein synthesis is modulated by extracellular, not intramuscular amino acid availability: a dose-response study. J Physiol 2003, 552(Pt 1):315-324.

117. Polonsky KS, Sturis J, Bell GI: Seminars in Medicine of the Beth Israel Hospital, Boston. Non-insulindependent diabetes mellitus - a genetically programmed failure of the beta cell to compensate for insulin resistance. N Engl J Med 1996, 334(12):777-783.

118. Wilkes EA, Selby AL, Atherton PJ, Patel R, Rankin D, Smith K, Rennie MJ: Blunting of insulin inhibition of proteolysis in legs of older subjects may contribute to age-related sarcopenia. Am J Clin Nutr 2009, 90(5):1343-1350.

119. Fujita S, Rasmussen BB, Cadenas JG, Grady JJ, Volpi E: Effect of insulin on human skeletal muscle protein synthesis is modulated by insulin-induced changes in muscle blood flow and amino acid availability. Am J Physiol Endocrinol Metab 2006, 291(4):E745-754.

120. Fryburg DA, Jahn LA, Hill SA, Oliveras DM, Barrett EJ: Insulin and insulin-like growth factor-I enhance human skeletal muscle protein anabolism during hyperaminoacidemia by different mechanisms. J Clin Invest 1995, 96(4):1722-1729.

121. Hillier TA, Fryburg DA, Jahn LA, Barrett EJ: Extreme hyperinsulinemia unmasks insulin's effect to stimulate protein synthesis in the human forearm. Am J Physiol 1998, 274(6 Pt 1):E1067-1074.

122. Bennet WM, Connacher AA, Scrimgeour CM, Jung RT, Rennie MJ: Euglycemic hyperinsulinemia augments amino acid uptake by human leg tissues during hyperaminoacidemia. Am J Physiol 1990, 259(2 Pt 1):E185-194.

123. Rattan SI: Synthesis, modifications, and turnover of proteins during aging. Exp Gerontol 1996, 31(12):33-47.

124. Balage M, Dardevet D: Long-term effects of leucine supplementation on body composition. Curr Opin Clin Nutr Metab Care 2010, 13(3):265-270.

125. Vogt PK: PI 3-kinase, mTOR, protein synthesis and cancer. Trends Mol Med 2001, 7(11):482-484. 
126. McNurlan MA, Heys SD, Park KG, Broom J, Brown DS, Eremin O, Garlick PJ: Tumour and host tissue responses to branched-chain amino acid supplementation of patients with cancer. Clin Sci (Lond) 1994, 86(3):339-345.

127. De Lorenzo A, Petroni ML, Masala S, Melchiorri G, Pietrantuono M, Perriello G, Andreoli A: Effect of acute and chronic branched-chain amino acids on energy metabolism and muscle performance. Diabetes Nutr Metab 2003, 16(5-6):291-297.

128. Marchesini G, Dioguardi FS, Bianchi GP, Zoli M, Bellati G, Roffi L, Martines D, Abbiati R: Long-term oral branched-chain amino acid treatment in chronic hepatic encephalopathy. A randomized double-blind casein-controlled trial. The Italian Multicenter Study Group. J Hepatol 1990, 11(1):92-101.

129. Brennan MF, Cerra F, Daly JM, Fischer JE, Moldawer LL, Smith RJ, Vinnars E, Wannemacher R, Young VR: Report of a research workshop: branched-chain amino acids in stress and injury. JPEN J Parenter Enteral Nutr 1986, 10(5):446-452.

130. Baker DH: Tolerance for branched-chain amino acids in experimental animals and humans. J Nutr 2005, 135(6 Suppl):1585S-1590S.

131. Gelfand RA, Barrett EJ: Effect of physiologic hyperinsulinemia on skeletal muscle protein synthesis and breakdown in man. J Clin Invest 1987, 80(1):1-6.

132. Siddiqui R, Pandya D, Harvey K, Zaloga GP: Nutrition modulation of cachexia/proteolysis. Nutr Clin Pract 2006, 21(2):155-167. 
CHAPTER 3

\section{Prolonged leucine supplementation does not augment muscle mass or affect glycemic control in elderly type 2 diabetic men}

Marika Leenders Lex B Verdijk Letty van der Hoeven Janneau van Kranenburg

Fred Hartgens Will KWH Wodzig Wim HM Saris

Luc JC van Loon 


\section{Abstract}

The loss of muscle mass with aging has been, at least partly, attributed to a blunted muscle protein synthetic response to food intake. Leucine co-ingestion has been reported to stimulate postprandial insulin release and augment postprandial muscle protein accretion. We assessed the clinical benefits of 6 mo of leucine supplementation in elderly, type 2 diabetes patients. Sixty elderly males with type 2 diabetes (age, $\left.71 \pm 1 \mathrm{y} ; \mathrm{BMI}, 27.3 \pm 0.4 \mathrm{~kg} / \mathrm{m}^{2}\right)$ were administered $2.5 \mathrm{~g}$ L-leucine $(n=30)$ or a placebo $(n=30)$ with each main meal during 6 mo of nutritional intervention $(7.5 \mathrm{~g} / \mathrm{d}$ leucine or placebo). Body composition, muscle fiber characteristics, muscle strength, glucose homeostasis, and basal plasma amino acid and lipid concentrations were assessed prior to, during, and after intervention. Lean tissue mass did not change or differ between groups at 0,3 , and 6 mo and were $61.9 \pm 1.1,62.2 \pm 1.1$, and $62.0 \pm 1.0 \mathrm{~kg}$, respectively, in the leucine group and $62.2 \pm 1.3,62.2 \pm 1.3$, and $62.2 \pm 1.3 \mathrm{~kg}$ in the placebo group. There also were no changes in body fat percentage, muscle strength, and muscle fiber type characteristics. Blood glycosylated hemoglobin did not change or differ between groups and was $7.1 \pm 0.1 \%$ in the leucine group and $7.2 \%$ in the placebo group. Consistent with this, oral glucose insulin sensitivity and plasma lipid concentrations did not change or differ between groups. We conclude that prolonged leucine supplementation $(7.5 \mathrm{~g} / \mathrm{d})$ does not modulate body composition, muscle mass, strength, glycemic control, and/or lipidemia in elderly, type 2 diabetes patients who habitually consume adequate dietary protein. 


\section{Introduction}

Aging is accompanied by a progressive decline in skeletal muscle mass and strength, termed sarcopenia (1). The progressive loss of skeletal muscle mass and strength results in a decline in functional capacity and predisposes to the development of chronic metabolic diseases, like obesity and type 2 diabetes (2). One of the major causes of sarcopenia seems to be the disruption in the regulation of muscle protein turnover. Recent work indicates that the elderly are less sensitive to the main anabolic stimuli, such as physical activity and/or food intake $(3,4)$. It has been suggested that increasing the leucine content of a meal can effectively compensate for the blunted muscle protein synthetic response to food intake in the elderly $(5,6)$. Recently, Katsanos et al (5) reported that increasing the leucine content of an amino acid mixture (from 26 to 41\%) normalizes the muscle protein synthetic response in the elderly when compared with the young. These findings were supported by Rieu et al (6) who observed considerably higher postprandial muscle protein synthetic rates in elderly men after they consumed leucine-enriched meals. As a consequence, it has been suggested that increasing the leucine content of a meal represents an effective dietary strategy to augment the muscle protein synthetic response to food intake in the elderly.

So far only a single placebo-controlled study has been performed to evaluate the proposed clinical relevance of prolonged leucine supplementation in the elderly. We recently reported the impact of 3 mo of leucine supplementation with each main meal on muscle mass and strength in healthy, elderly males (7). No changes in skeletal muscle mass or strength were observed over the 3 mo intervention period. In response, some suggested that the absence of any impact of leucine supplementation on muscle mass and strength could be attributed to the relative short intervention period and/or to the specific inclusion of healthy, elderly males. As such, we concluded that the impact of prolonged leucine supplementation should be assessed in more compromised elderly subpopulations over a more extensive intervention period (7).

It has been well-established that elderly, type 2 diabetic patients generally have a more pronounced decline in skeletal muscle mass and/or strength compared with agematched, normoglycemic controls (2). Because of this accelerated loss of muscle mass (8), it would be of particular interest to study the impact of leucine supplementation on muscle mass in this specific elderly subpopulation. Furthermore, amino acids (and leucine in particular) act as strong stimuli for endogenous insulin release by the pancreatic $\beta$-cell $(9,10)$. Leucine co-ingestion has been reported to effectively increase postprandial insulin release, stimulate glucose disposal, and subsequently improve glycemic control in type 2 diabetes patients (11-13). In addition, recent work in rodents reported substantial improvements in blood lipid profiles following prolonged leucine supplementation (14). Consequently, prolonged leucine supplementation may represent an even more effective nutritional strategy to increase muscle mass and improve glycemia and lipidemia in type 2 diabetes patients. 
Prolonged intervention studies investigating the clinical benefits of leucine supplementation in elderly and/or type 2 diabetes patients are thus far lacking. Therefore, we assessed the impact of 6 mo of leucine supplementation with each main meal $(7.5 \mathrm{~g} / \mathrm{d})$ on muscle mass and strength, body composition, insulin sensitivity, glycemia, and lipidemia in a large group of elderly, type 2 diabetes patients (71 $\pm 1 \mathrm{y}$ ). This is the first study to assess the clinical relevance of such prolonged leucine supplementation in vivo in humans.

\section{Materials and methods}

\section{Participants}

A total of 60 elderly men with type 2 diabetes were selected to participate in a 6 mo (24 wk) nutritional intervention program. For all participants medical history was evaluated and an oral glucose tolerance test (OGTT) was performed prior to inclusion. An electrocardiogram was performed at rest and during submaximal exercise. Exclusion criteria included (silent) cardiac or peripheral vascular disease, orthopedic limitations, and/or impaired renal function. Participants were treated with either dietary recommendation only ( $n=6$ ) or oral blood glucose lowering medication: metformin combined with sulfonylurea derivatives and/or thiazolidinediones $(n=21)$, metformin only ( $n=28$ ) or sulfonylurea derivates only $(n=5)$. All participants were receiving stable medication and/or dietary prescriptions for at least 3 mo before the intervention. All eligible men were randomly assigned to either the leucine- or placebo-supplemented group. Three participants dropped out for medical reasons not related to the study. Participants' characteristics are provided in Table 1. All participants were informed about the nature and possible risks of the experimental procedures before their written informed consent were obtained. The study was performed according to the principles of the Declaration of Helsinki and was approved by the local Medical Ethical Committee.

\section{Study design}

Participants ingested either 2.5 g leucine or a placebo after each main meal (breakfast, lunch, and dinner) during the entire 24-wk intervention period. Anthropometrics (height, body weight, waist:hip ratio), muscle strength [one repetition maximum; 1RM)], and body composition (DXA), were assessed and muscle biopsies, blood samples, and dietary intake and physical activity records were collected before, after 12 wk, and after cessation of the nutrition intervention program. 
Table 1: Baseline characteristics of diabetic men in the placebo group and leucine group ${ }^{1}$

\begin{tabular}{lcc}
\hline & Placebo, $n=28$ & Leucine, $n=29$ \\
\hline Age, $y$ & $71 \pm 1$ & $71 \pm 1$ \\
Body weight, $k g$ & $84.4 \pm 2.0$ & $83.4 \pm 1.8$ \\
Height, $m$ & $1.76 \pm 0.01$ & $1.75 \pm 0.01$ \\
Waist-Hip Ratio & $1.01 \pm 0.01$ & $1.02 \pm 0.01$ \\
BMI, $\mathrm{kg} / \mathrm{m}^{2}$ & $27.2 \pm 0.6$ & $27.4 \pm 0.6$ \\
Basal plasma glucose, $\mathrm{mmol} / \mathrm{L}$ & $7.60 \pm 0.26$ & $7.99 \pm 0.23$ \\
$\mathrm{HbA}_{1 c} \%$ & $7.2 \pm 0.2$ & $7.1 \pm 0.1$ \\
Lean Mass, $\mathrm{kg}$ & $62.2 \pm 1.3$ & $61.9 \pm 1.1$ \\
Fat, $\%$ & $22.9 \pm 0.8$ & $22.5 \pm 0.6$ \\
\hline
\end{tabular}

${ }^{1}$ Values are mean $\pm \mathrm{SEM}$.

\section{Diet and physical activity}

Standardized meals were provided to all participants the evening prior to each test day. The participants were instructed to refrain from strenuous physical activity for at least $3 \mathrm{~d}$ prior to testing. On all test days, participants arrived at the laboratory by car or public transportation following an overnight fast. To assess potential changes in habitual daily food intake and physical activity during the 6 mo intervention period, the participants recorded 3-d weighted dietary intake records and 2-d physical activity records. Dietary intake was recorded before, after 3, 7, 11, 15, 19, and 23 wk of intervention (Komeet, 4.059 BaS Nutrition Software). Habitual physical activity was recorded before and after 11 and 23 wk of intervention. For every type of activity, a mean equivalent task (MET)-score was assigned as previously defined (15). Energy expenditure was calculated as mean MET-h/d (16).

\section{Supplementation}

All participants were studied over a 24-wk intervention period during which they were supplemented with either $7.5 \mathrm{~g} / \mathrm{d}$ L-leucine (Frutarom NV) or a placebo (wheat flour; Verstegen). The participants ingested 5 capsules (500 mg each) after each main meal (breakfast, lunch, and dinner). The supplements were provided in a double-blind manner and the different capsules could not be distinguished by scent, color, or taste.

\section{Muscle strength}

Maximal strength was assessed by 1RM strength tests on leg-press and leg-extension machines (Technogym). During a familiarization trial, the proper lifting technique was demonstrated and practiced, after which maximal strength was estimated by using the multiple repetitions testing procedure (17). In an additional session, at least 1 wk prior 
to muscle biopsy collection, each participant's 1 RM was determined as previously described (18). The $1 \mathrm{RM}$ test was repeated after $12 \mathrm{wk}$ and after the cessation of the intervention program.

\section{Body composition}

Body composition and bone mineral content were measured with DXA (Hologic, Discovery A, QDR Series). Anthropometrics were measured by trained observers using standard techniques (19).

\section{Blood samples}

Before, and after $4,8,12,16,20$, and 24 wk of intervention, blood samples were collected from fasting subjects to determine basal plasma glucose and insulin concentrations, plasma amino acid and lipid profiles, serum creatinine, and blood glycolysated hemoglobin (HbA1c) content. Blood $(10 \mathrm{~mL})$ was collected into EDTA-containing and serum tubes. EDTA tubes were immediately centrifuged at $1000 \mathrm{Xg}$ for $10 \mathrm{~min}$ at $4^{\circ} \mathrm{C}$ (plasma) and the serum tubes were centrifuged at $1000 \mathrm{Xg}$ for $15 \mathrm{~min}$ at $21^{\circ} \mathrm{C}$ (serum) after allowing the blood to clot for $90 \mathrm{~min}$ at $21^{\circ} \mathrm{C}$. Aliquots of plasma and serum were immediately frozen in liquid nitrogen and stored at $-80^{\circ} \mathrm{C}$ until further analysis. Plasma glucose concentrations were analyzed with a COBAS FARA analyzer (Uni Kit III; Roche). Plasma insulin concentrations were determined by using an Insulin RIA Kit (LINCO Research Inc). Plasma free amino acid concentrations were analyzed with a dedicated amino acid analyzer (LCA10; Shimadzu Benelux) as previously described (7). Reagents to determine plasma TG, total cholesterol and HDL-cholesterol were from ABX Diagnostics. Plasma FFA concentrations were analyzed with the NEFA C test kit from Wako Chemicals. Because plasma TG concentrations were $<4.5 \mathrm{mmol} / \mathrm{L}$, LDL-cholesterol could be calculated by LDL cholesterol = total cholesterol $-\mathrm{HDL}$ cholesterol $-\mathrm{TG} / 2.2$ (in $\mathrm{mmol} / \mathrm{L}$ ). Serum creatinine concentrations were determined using the Jaffe rate method on a Synchron LX Systems analyzer with Synchron creatinine reagent kit (Beckmann Coulter Inc). Blood HbA1c content was analyzed by HPLC (Bio-Rad Variant II 4).

\section{Whole-body insulin sensitivity}

Whole-body insulin sensitivity and/or oral glucose tolerance were assessed by fasting blood glucose and insulin concentrations using the homeostasis model assessment of insulin resistance (HOMA-IR) (20). Furthermore, the oral glucose insulin sensitivity (OGIS) index (21) and the insulin sensitivity index (ISI) (22) were calculated from the data derived from the OGTT. 


\section{Muscle biopsies}

Three days prior to the onset of nutritional intervention, after 12 wk of intervention and immediately after cessation of the nutritional intervention, skeletal muscle biopsies were taken from the right leg of each participant. After local anesthesia was induced, percutaneous needle biopsy samples $(50-80 \mathrm{mg}$ ) were collected from the vastus lateralis muscle, $\sim 15 \mathrm{~cm}$ above the patella (23). Any visible non-muscle tissue was removed immediately, and biopsy samples were embedded in Tissue-Tek (Sakura Finetek), frozen in liquid nitrogen-cooled isopentane, and stored at $-80^{\circ} \mathrm{C}$ until analyses.

\section{Muscle tissue analysis}

From all biopsies, $5 \mu \mathrm{m}$ thick cryosections were cut at $-20^{\circ} \mathrm{C}$. All samples from each participant were mounted together on uncoated glass slides. Cross-sections were stained for muscle fiber typing using the analytical procedures previously described (24). In short, muscle fiber typing (type I vs Ila vs IIx) was determined based on staining with antibodies against MHC-I and MHC-Ila, and anti-laminin was used to visualize the basement membrane. After staining, all images were digitally captured by using fluorescence microscopy (Nikon Instruments Europe). Image processing and quantitative analyses were performed as described previously (25). Within each image, the number of fibers and the muscle fiber cross-sectional area (CSA) were measured for the type I, Ila, and IIx fibers separately.

\section{4-h Urine collection}

To determine urinary nitrogen and creatinine excretion, $24 \mathrm{~h}$ urine was collected over the last day of the 3-d dietary intake assessment, as previously described (25). Nitrogen content was analyzed with an elemental analyzer (model CHN-ORAPID, Heraeus). Total nitrogen excretion was calculated from total urinary nitrogen excretion and an estimated $0.031 \mathrm{~g} / \mathrm{kg}$ body mass for miscellaneous nitrogen loss (26). Nitrogen balance was calculated as the difference between nitrogen intake [protein intake (g)/6.25] and total nitrogen excretion before and after 4,12 , and $24 \mathrm{wk}$ of intervention. As a measure of renal function, creatinine clearance was calculated from urinary excretion and its serum concentration and corrected for body surface area, yielding the amount of blood (in $\mathrm{mL}$ ) cleared from creatinine per min per $1.73 \mathrm{~m}^{2}$ of total body surface area (27).

\section{Statistical Analysis}

Data are expressed as means \pm SEM. Baseline characteristics between groups were compared by means of an independent samples $t$-test. Pre- vs. 3 mo vs. post-interven- 
tion data were analyzed using repeated-measures ANOVA with time as within-subjects factor and treatment as between-subjects factor. For muscle fiber type analyses, a second within-subjects factor (type I vs. type II fibers) was included. In case of significant main effects or interactions, post hoc testing with Bonferroni correction and/or separate analyses within groups were performed when appropriate. Statistical significance was set at $P<0.05$. All calculations were performed using SPSS 15.0.

\section{Results}

\section{Participants}

A total of 57 men completed the intervention study, 28 in the placebo group and 29 in the leucine group. Baseline variables did not differ between groups (Table 1). Participants had been diagnosed with type 2 diabetes for $3 \pm 1 \mathrm{y}$. Except for one patient in the leucine group, no changes in medication dose occurred during the 6-mo intervention period.

\section{Diet and physical activity}

Analysis of the 3-d dietary intake records collected before, during, and after 24 wk of intervention did not differ in total daily energy intake between groups or change over time (Supplemental Table 1). In addition, the macronutrient composition of the diet did not change over time and did not differ between groups (Supplemental Table 1). Daily protein intake prior to the supplementation period did not differ between the placebo (0.94 $\pm 0.04 \mathrm{~g} / \mathrm{kg}$ body weight) and leucine $(1.04 \pm 0.05 \mathrm{~g} / \mathrm{kg}$ body weight) groups and did not change throughout the supplementation period (Supplemental Table 1). Habitual physical activity levels and mean energy expenditure at baseline were similar between the placebo $(1.55 \pm 0.03 \mathrm{MET}-\mathrm{h} / \mathrm{d})$ and leucine $(1.55 \pm 0.04 \mathrm{MET}$ $\mathrm{h} / \mathrm{d}$ ) groups and did not change over time.

\section{Muscle strength}

At baseline, 1RM for leg press and leg extension did not differ between groups (Table 2). After 24 wk of intervention, muscle strength had increased significantly in both the placebo and leucine group for leg press $(P<0.001)$ and leg extension $(P<0.001)$, with no differences between groups. 
Table 2: Body composition and muscle strength during 24 wk of leucine or placebo intervention in diabetic men $^{1}$

\begin{tabular}{|c|c|c|c|c|c|c|}
\hline & \multicolumn{3}{|c|}{ Placebo, $n=28$} & \multicolumn{3}{|c|}{ Leucine, $n=29$} \\
\hline & wk 0 & wk 12 & wk 24 & wk 0 & wk 12 & wk 24 \\
\hline \multicolumn{7}{|l|}{ Body composition } \\
\hline Body weight, $\mathrm{kg}$ & $84.6 \pm 2.0$ & $85.0 \pm 2.0$ & $85.1 \pm 2.1$ & $83.6 \pm 1.8$ & $84.0 \pm 1.8$ & $83.9 \pm 1.7$ \\
\hline Lean mass, $\mathrm{kg}$ & $62.2 \pm 1.3$ & $62.2 \pm 1.3$ & $62.2 \pm 1.3$ & $61.9 \pm 1.1$ & $62.2 \pm 1.1$ & $62.0 \pm 1.0$ \\
\hline Fat mass, $\mathrm{kg}$ & $19.6 \pm 1.0$ & $20.0 \pm 1.1$ & $20.2 \pm 1.1$ & $19.0 \pm 0.8$ & $19.1 \pm 0.9$ & $19.2 \pm 0.9$ \\
\hline Fat, $\%$ & $22.9 \pm 0.8$ & $23.3 \pm 0.9$ & $23.4 \pm 0.9$ & $22.5 \pm 0.6$ & $22.4 \pm 0.6$ & $22.6 \pm 0.6$ \\
\hline $\mathrm{BMC}, \mathrm{kg}$ & $2.7 \pm 0.1$ & $2.7 \pm 0.1$ & $2.7 \pm 0.1$ & $2.7 \pm 0.1$ & $2.7 \pm 0.1$ & $2.7 \pm 0.1$ \\
\hline Leg lean mass, $k g$ & $19.3 \pm 0.5$ & $19.4 \pm 0.5$ & $19.4 \pm 0.4$ & $19.0 \pm 0.4$ & $19.1 \pm 0.4$ & $19.0 \pm 0.4$ \\
\hline Leg fat mass, $k g$ & $5.0 \pm 0.3$ & $5.1 \pm 0.3$ & $5.2 \pm 0.3$ & $4.8 \pm 0.2$ & $4.9 \pm 0.2$ & $4.9 \pm 0.2$ \\
\hline \multicolumn{7}{|l|}{ Muscle strength } \\
\hline Leg press, kg & $205 \pm 7$ & $210 \pm 8^{*}$ & $218 \pm 8^{*}, \#$ & $202 \pm 7$ & $208 \pm 8^{*}$ & $217 \pm 8^{*}$ \\
\hline Leg extension, $k g$ & $88 \pm 3$ & $91 \pm 3^{*}$ & $94 \pm 4^{*, \#}$ & $80 \pm 2$ & $84 \pm 3^{*}$ & $84 \pm 3^{*}$ \\
\hline
\end{tabular}

${ }^{1}$ Values are mean \pm SEM. ${ }^{*}$ Different from wk $0, P<0.05 .{ }^{*}$ Different from wk $12, P<0.05$.

\section{Body composition}

Whole-body and leg fat mass and fat-free mass did not differ between the groups prior to the intervention (Table 2). Throughout the intervention, body composition, fat mass and lean mass did not change over time or differ between groups.

\section{Glycemic control}

Measures of glycemic control did not differ between the placebo and the leucine groups prior to intervention (Table 3). After 24 wk of intervention, the basal fasting insulin concentration increased in both groups. In accordance, insulin resistance significantly increased over time as assessed by HOMA-IR and ISI. However, blood HbA1C values remained stable throughout the intervention period. Fasting blood glucose concentrations and the OGIS index did not change over time or differ between groups (Table 3). 
Table 3: Glycemic control during 24 wk of leucine or placebo intervention in diabetic men ${ }^{1}$

\begin{tabular}{|c|c|c|c|c|c|c|}
\hline & \multicolumn{3}{|c|}{ Placebo, $n=28$} & \multicolumn{3}{|c|}{ Leucine, $n=29$} \\
\hline & wk 0 & wk 12 & wk 24 & wk 0 & wk 12 & wk 24 \\
\hline Plasma glucose, $\mathrm{mmol} / \mathrm{L}$ & $7.5 \pm 0.2$ & $7.3 \pm 0.2$ & $7.6 \pm 0.3$ & $8.0 \pm 0.2$ & $7.8 \pm 0.2$ & $7.5 \pm 0.2$ \\
\hline Glucose $_{120 \mathrm{~min}}$ OGTT, $\mathrm{mmol} / \mathrm{L}$ & $13.9 \pm 0.8$ & $14.1 \pm 0.9$ & $14.5 \pm 0.8$ & $13.7 \pm 0.8$ & $13.8 \pm 0.7$ & $13.4 \pm 0.7$ \\
\hline $\mathrm{HbA} 1 \mathrm{c}, \%$ & $7.2 \pm 0.2$ & $7.2 \pm 0.2$ & $7.2 \pm 0.1$ & $7.1 \pm 0.1$ & $7.1 \pm 0.1$ & $7.1 \pm 0.1$ \\
\hline Plasma insulin, $\mathrm{pmol} / \mathrm{L}$ & $103 \pm 7$ & $113 \pm 15$ & $144 \pm 18^{*}, \#$ & $95 \pm 6$ & $100 \pm 8$ & $121 \pm 12^{*}$ \\
\hline Insulin $120 \mathrm{~min}$ OGTT, $\mathrm{pmol} / \mathrm{L}$ & $465 \pm 60$ & $495 \pm 76$ & $596 \pm 82^{*, \#}$ & $383 \pm 72$ & $382 \pm 49$ & $425 \pm 53^{*}$ \\
\hline Insulin peak, $\mathrm{pmol} / \mathrm{L}$ & $641 \pm 99$ & $634 \pm 102$ & $775 \pm 101^{*}$,\# & $486 \pm 72$ & $524 \pm 56$ & $665 \pm 77^{*}$,\# \\
\hline HOMA-IR & $4.8 \pm 0.4$ & $5.1 \pm 0.7$ & $6.8 \pm 0.9^{*, \#}$ & $4.7 \pm 0.3$ & $4.9 \pm 0.4$ & $5.6 \pm 0.6^{*, \#}$ \\
\hline ISI & $2.5 \pm 0.2$ & $2.7 \pm 0.3$ & $2.0 \pm 0.2^{*, \#}$ & $2.8 \pm 0.3$ & $2.8 \pm 0.3$ & $2.6 \pm 0.4^{*}, \#$ \\
\hline OGIS & $350 \pm 9$ & $352 \pm 8$ & $345 \pm 8$ & $336 \pm 8$ & $338 \pm 8$ & $351 \pm 8$ \\
\hline
\end{tabular}

${ }^{1}$ Values are mean \pm SEM. ${ }^{*}$ Different from wk $0, P<0.05$. " Different from wk $12, P<0.05$.

\section{Plasma lipids and urine analyses}

Plasma lipid concentrations did not differ between groups prior to the intervention and did not change over time in either group (Supplemental Table 2).

Serum creatinine concentrations were within the normal range prior to intervention and did not change over time in either the placebo (from $99.0 \pm 5.3$ to $84.0 \pm 5.3$ $\mu \mathrm{mol} / \mathrm{L}$ ) or leucine (from $99.0 \pm 3.5$ to $94.6 \pm 4.4 \mu \mathrm{mol} / \mathrm{L}$ ) group, and the groups did not differ. Creatinine clearance at baseline did not differ between the placebo (75.8 \pm 3.2 $\left[\mathrm{mL} / \mathrm{min}\right.$ per $\left.\left.1.73 \mathrm{~m}^{2}\right]\right)$ and leucine $\left(82.2 \pm 3.7\left[\mathrm{~mL} / \mathrm{min}\right.\right.$ per $\left.\left.1.73 \mathrm{~m}^{2}\right]\right)$ groups and did not change in either group. Prior to intervention, 24-h nitrogen balance was $-1.20 \pm$ $0.62 \mathrm{~g} / \mathrm{d}$ in the placebo group and $-0.52 \pm 0.54 \mathrm{~g} / \mathrm{d}$ in the leucine group and did not change in either group.

\section{Amino acid profiles}

Plasma total amino acid (TAA), non-essential amino acid (NEAA), and essential amino acid (EAA) concentrations in fasting men did not differ between groups at baseline and did not change in either group (Table 4). For the plasma BCAA, there were significant time $X$ treatment interactions. Basal plasma leucine concentrations increased in the leucine group by $13 \pm 3 \%$ within 12 wk of supplementation $(P<0.05)$, after which concentrations remained elevated. The 2 other BCAA, valine and isoleucine, decrease over time in the leucine group. Basal plasma valine concentrations declined by $23 \pm 2 \%$ within 4 wk of supplementation $(P<0.05)$, after which concentrations remained stable. Basal plasma isoleucine concentrations declined by $16 \pm 2 \%$ within 4 wk of supplementation $(P<0.05)$, after which concentrations remained stable. Plasma BCAA concentrations did not change in the placebo group (Table 4). 
Table 4: Basal plasma amino acid concentrations 24 wk of leucine or placebo intervention in diabetic men ${ }^{1}$

\begin{tabular}{|c|c|c|c|c|c|c|c|c|}
\hline & \multicolumn{4}{|c|}{ Placebo, $n=28$} & \multicolumn{4}{|c|}{ Leucine, $n=29$} \\
\hline & wk 0 & wk 4 & wk 12 & wk 24 & wk 0 & wk 4 & wk 12 & wk 24 \\
\hline Leucine, $\mu \mathrm{mol} / \mathrm{L}$ & $149 \pm 4$ & $155 \pm 7$ & $153 \pm 4$ & $147 \pm 4$ & $143 \pm 4$ & $154 \pm 5$ & $161 \pm 5^{*}, \#$ & $155 \pm 5^{*}, \#$ \\
\hline Valine, $\mu \mathrm{mol} / \mathrm{L}$ & $254 \pm 7$ & $265 \pm 10$ & $262 \pm 7$ & $253 \pm 8$ & $239 \pm 6$ & $185 \pm 5^{* \#}$ & $195 \pm 7^{*}, \#$ & $196 \pm 7^{*}$ \\
\hline Isoleucine, $\mu \mathrm{mol} / \mathrm{L}$ & $85 \pm 3$ & $89 \pm 4$ & $88 \pm 3$ & $86 \pm 3$ & $79 \pm 3$ & $66 \pm 2^{*}$ & $69 \pm 2^{*}$ & $69 \pm 2^{*}$ \\
\hline $\mathrm{EAA}, \mu \mathrm{mol} / \mathrm{L}$ & $970 \pm 18$ & $996 \pm 32$ & $999 \pm 18$ & $956 \pm 22$ & $939 \pm 20$ & $913 \pm 28$ & $910 \pm 22$ & $902 \pm 20$ \\
\hline NEAA, $\mu \mathrm{mol} / \mathrm{L}$ & $1673 \pm 32$ & $1694 \pm 36$ & $1722 \pm 27$ & $1694 \pm 30$ & $1719 \pm 34$ & $1707 \pm 35$ & $1738 \pm 38$ & $1751 \pm 39$ \\
\hline $\mathrm{TAA}, \mu \mathrm{mol} / \mathrm{L}$ & $2645 \pm 46$ & $2691 \pm 59$ & $2721 \pm 41$ & $2651 \pm 45$ & $2658 \pm 50$ & $2619 \pm 47$ & $2648 \pm 53$ & $2653 \pm 56$ \\
\hline
\end{tabular}

${ }^{1}$ Values are mean \pm SEM. ${ }^{*}$ Different from wk $0, P<0.05$. ${ }^{\#}$ Different from the placebo at that time, $P<0.05$.

\section{Muscle tissue analysis}

Type I and II muscle fiber percentage did not differ between both groups prior to the intervention (Supplemental Table 3). Type I muscle fiber percentage was $43 \pm 2,43 \pm$ 2 , and $48 \pm 2 \%$ at 0,3 , and 6 mo for the entire group, with no changes over time. Muscle fiber CSA at baseline did not differ between the placebo and leucine groups for the type I, type Ila, and type IIx fibers and the values did not change during the intervention in the entire group. Notably, type II muscle fiber CSA was significantly smaller compared with type I muscle fiber CSA at all time points and in both groups (Supplemental Table 3).

\section{Discussion}

The present study shows that 6 mo of leucine supplementation (a total of $7.5 \mathrm{~g} / \mathrm{d}$ ) with each main meal does not augment skeletal muscle mass and strength, modulate body composition, or improve glycemic control and blood lipid profile in elderly men with type 2 diabetes, who habitually consume sufficient protein.

Aging is associated with the gradual but progressive loss of skeletal muscle mass and function, resulting from an imbalance between muscle protein synthesis and breakdown. Recent work from Katsanos et al (5) and Rieu et al (6) shows that increasing the leucine content of a meal increases the postprandial muscle protein synthetic response in healthy elderly men. Consequently, it has been suggested that long-term leucine supplementation with each main meal represents an effective nutritional intervention strategy to stimulate postprandial net muscle protein accretion and, as such, increase muscle mass and strength in the elderly (28). Katsanos et al (5) reported a substantial $0.008 \% / \mathrm{h}$ increase in postprandial muscle protein synthesis rate for up to $2.5 \mathrm{~h}$ after increasing the leucine content of an oral amino acid mixture. Extrapolation of these data towards the impact of prolonged leucine supplementation with each main meal should theoretically result in an enormous $3.4 \mathrm{~kg}$ (range $2.8-4.2 \mathrm{~kg}$ ) gain in 
muscle mass over a 6 mo intervention period. Consequently, such a $\sim 4-6 \%$ increase in whole-body lean tissue mass could be expected in the leucine supplemented group. The latter would easily be detected by DXA scanning as applied in the present study (with a CV for lean tissue mass $<0.5 \%$ ). However, even after 6 mo of leucine supplementation, we did not observe any effect on muscle mass (Table 2) and/or muscle fiber size (Supplemental Table 3). It seems evident that the suggested increase in muscle protein synthesis in the postprandial phase following leucine supplementation cannot be translated into muscle mass accrual during a more prolonged dietary intervention. This appears to be in line with previous findings from our group in which leucine supplementation did not affect body composition in healthy elderly males over a 3 mo intervention period (7). It was suggested that the duration of the latter study might have been insufficient to detect any clinically relevant improvements. In addition, it was suggested that leucine co-ingestion with each main meal would be of more benefit to more compromised elderly subpopulations, as opposed to healthy elderly men (7). Therefore, in the present study, we implemented 6 mo of dietary supplementation in elderly, type 2 diabetes patients. The peripheral insulin resistance observed in type 2 diabetes patients is likely to further attenuate the postprandial muscle protein synthetic response to food intake (29), and could be largely responsible for the accelerated loss of muscle mass with aging in these patients (8). Nonetheless, we did not observe any increase in muscle mass and/or function after 3 and 6 mo of nutritional intervention in these elderly type 2 diabetes patients (Table 2). As such, we must conclude that even such long-term leucine supplementation does not represent an effective nutritional strategy to increase muscle mass and function.

Apart from its proposed role in regulating postprandial muscle protein synthesis, leucine also acts as a strong insulin secretagogue (30-32). The latter has since been applied as an effective nutritional strategy to augment postprandial insulin release, increase blood glucose disposal and, as such, improve glycemic control in type 2 diabetes patients $(11-13,33)$. Furthermore, Zhang et al (14) also reported a reduction in diet-induced obesity, hyperglycemia, and hypercholesterolemia following prolonged leucine supplementation in mice fed a high-fat diet. In the present study, we assessed the impact of prolonged leucine co-ingestion with each main meal on oral glucose tolerance and various derived parameters of whole-body insulin sensitivity (Table 3 ). However, no changes were observed in fasting blood glucose concentrations, HbA1c levels, and OGIS in either group. However, we did observe significant increases in fasting plasma insulin concentrations and the HOMA-IR index, and a decline in the ISI after 24 wk of intervention in both groups. The changes in these indices over time did not differ between groups and merely represent the gradual increase in insulin resistance that is associated with the progression of the disease. Generally, changes in glycemic control are often accompanied by changes in lipid profile. In the study by Zhang et al (14), an attenuated rise in plasma total cholesterol and LDL-concentrations was observed after leucine supplementation in mice fed a high-fat diet. However, in line with the data on glycemic control we did not detect any significant changes in the plasma 
FFA. TG, or LDL- and HDL-cholesterol levels in either group (Supplemental Table 2). Clearly, 6 months of leucine co-ingestion with each main meal did not improve glycemia and/or lipidemia in elderly type 2 diabetes patients.

Both leucine and the placebo were provided in identical capsules and 5 capsules were taken at every main meal. Compliance was verified by counting the number of surplus capsules that were left after each 4 wk period. In the leucine supplemented group, we observed a $13 \pm 3 \%$ increase in basal plasma leucine concentrations within 12 wk of intervention (Table 4). This increase in basal plasma leucine concentration resulted in a rapid decline in fasting plasma valine $(-23 \pm 2 \%)$ and isoleucine $(-16 \pm 2 \%)$ concentrations within the first 4 wk of intervention. Thereafter, plasma valine and isoleucine concentrations remained stable. These data tend to be consistent with previous observations (34) and confirm that leucine supplementation reduces basal levels of the other BCAA. However, basal valine $(196 \pm 7 \mu \mathrm{mol} / \mathrm{L})$ and isoleucine $(69 \pm 2$ $\mu \mathrm{mol} / \mathrm{L}$ ) concentrations remained well within their normal physiological range and, as such, are unlikely to negatively affect muscle protein metabolism. Moreover, with the ingestion of ample meal derived dietary protein, postprandial plasma valine and isoleucine availability could not have prevented the postprandial rise in muscle protein synthesis rates. Basal TAA, EAA and the NEAA concentrations did not change over time in either group.

To evaluate any potential impact of leucine co-ingestion after each main meal on daily food intake, we obtained dietary intake records throughout the intervention period (Supplemental Table 1). The latter showed no changes in daily energy intake and/or macronutrient composition of the diet during the intervention period in either the placebo and leucine supplemented group. Mean habitual dietary protein intake was $0.94 \pm 0.04 \mathrm{~g} \mathrm{~kg}^{-1} \mathrm{~d}^{-1}$ and $1.04 \pm 0.05 \mathrm{~g} \mathrm{~kg}^{-1} \mathrm{~d}^{-1}$ in the placebo and leucine supplemented groups and remained stable throughout the intervention. Daily protein intake values are in line with dietary guidelines (35-38) and indicate that the diabetes patients ingested sufficient dietary protein. It could be speculated that habitual dietary protein consumption may have provided sufficient leucine to optimize postprandial muscle protein synthesis, making the impact of additional leucine supplementation with each main meal of no surplus benefit. The habitual physical activity level did not change over time or between groups. With a mean energy expenditure of $1.5 \mathrm{MET}-\mathrm{h} / \mathrm{d}$ these elderly patients seem to be more active compared with diabetes patients in the US (16), but less active compared with patients in Canada (16). Whether different leucine supplementation intervention strategies, e.g. different timing of leucine ingestion around the main meals and/or in combination with an exercise/physical activity regimen, result in greater clinical benefits remains to be established. Prolonged supplementation with relative large amounts of leucine did not seem to be accompanied by any negative side effects. Supplements were well tolerated and there were no complaints of gastro-intestinal discomfort reported. Because excess dietary protein intake has been associated with an increased risk of developing renal failure, we also measured serum creatinine and urinary creatinine excretion to assess potential changes in 
kidney function. Because no changes were observed in serum creatinine levels and 24 $\mathrm{h}$ creatinine clearance in either group, prolonged leucine supplementation $(7.5 \mathrm{~g} / \mathrm{d})$ does not seem to have any negative impact on renal function.

In this study, we show that the proposed stimulating properties of co-ingesting leucine on postprandial muscle protein synthesis rates do not translate into muscle mass accrual during more prolonged nutritional intervention. Six months of leucine supplementation $(7.5 \mathrm{~g} / \mathrm{d})$ does not augment muscle mass and strength, improve blood glucose homeostasis, and/or lipid profile in elderly type 2 diabetes patients. In conclusion, leucine supplementation after each main meal does not represent an effective nutritional strategy to increase muscle mass or strength or to improve glycemic control or circulating lipids in elderly, type 2 diabetic men who habitually consume adequate dietary protein. 


\section{References}

1. Evans W: Functional and metabolic consequences of sarcopenia. J Nutr 1997, 127(5 Suppl):998S-1003S.

2. Park SW, Goodpaster BH, Strotmeyer ES, de Rekeneire N, Harris TB, Schwartz AV, Tylavsky FA, Newman $A B$ : Decreased muscle strength and quality in older adults with type 2 diabetes: the health, aging, and body composition study. Diabetes 2006, 55(6):1813-1818.

3. Cuthbertson D, Smith K, Babraj J, Leese G, Waddell T, Atherton P, Wackerhage H, Taylor PM, Rennie MJ: Anabolic signaling deficits underlie amino acid resistance of wasting, aging muscle. FASEB J 2005, 19(3):422-424.

4. Volpi E, Mittendorfer B, Rasmussen BB, Wolfe RR: The response of muscle protein anabolism to combined hyperaminoacidemia and glucose-induced hyperinsulinemia is impaired in the elderly. $J$ Clin Endocrinol Metab 2000, 85(12):4481-4490.

5. Katsanos CS, Kobayashi H, Sheffield-Moore M, Aarsland A, Wolfe RR: A high proportion of leucine is required for optimal stimulation of the rate of muscle protein synthesis by essential amino acids in the elderly. Am J Physiol Endocrinol Metab 2006, 291(2):E381-387.

6. Rieu I, Balage M, Sornet C, Giraudet C, Pujos E, Grizard J, Mosoni L, Dardevet D: Leucine supplementation improves muscle protein synthesis in elderly men independently of hyperaminoacidaemia. $J$ Physiol 2006, 575(Pt 1):305-315.

7. Verhoeven S, Vanschoonbeek K, Verdijk LB, Koopman R, Wodzig WK, Dendale P, van Loon LJ: Longterm leucine supplementation does not increase muscle mass or strength in healthy elderly men. $A m \mathrm{~J}$ Clin Nutr 2009, 89(5):1468-1475.

8. Park SW, Goodpaster BH, Lee JS, Kuller LH, Boudreau R, de Rekeneire N, Harris TB, Kritchevsky S, Tylavsky FA, Nevitt $\mathrm{M}$ et al: Excessive loss of skeletal muscle mass in older adults with type 2 diabetes. Diabetes Care 2009, 32(11):1993-1997.

9. Newsholme P, Brennan L, Rubi B, Maechler P: New insights into amino acid metabolism, beta-cell function and diabetes. Clin Sci (Lond) 2005, 108(3):185-194.

10. Manders RJ, Koopman R, Sluijsmans WE, van den Berg R, Verbeek K, Saris WH, Wagenmakers AJ, van Loon $\mathrm{U}$ : Co-ingestion of a protein hydrolysate with or without additional leucine effectively reduces postprandial blood glucose excursions in Type 2 diabetic men. J Nutr 2006, 136(5):1294-1299.

11. Manders RJ, Wagenmakers AJ, Koopman R, Zorenc AH, Menheere PP, Schaper NC, Saris WH, van Loon $\sqcup$ : Co-ingestion of a protein hydrolysate and amino acid mixture with carbohydrate improves plasma glucose disposal in patients with type 2 diabetes. Am J Clin Nutr 2005, 82(1):76-83.

12. van Loon L, Kruijshoop M, Menheere PP, Wagenmakers AJ, Saris WH, Keizer HA: Amino acid ingestion strongly enhances insulin secretion in patients with long-term type 2 diabetes. Diabetes Care 2003, 26(3):625-630.

13. Manders RJ, Praet SF, Meex RC, Koopman R, de Roos AL, Wagenmakers AJ, Saris WH, van Loon LJ: Protein hydrolysate/leucine co-ingestion reduces the prevalence of hyperglycemia in type 2 diabetic patients. Diabetes Care 2006, 29(12):2721-2722.

14. Zhang Y, Guo K, LeBlanc RE, Loh D, Schwartz GJ, Yu YH: Increasing dietary leucine intake reduces dietinduced obesity and improves glucose and cholesterol metabolism in mice via multimechanisms. Diabetes 2007, 56(6):1647-1654.

15. Ainsworth BE, Haskell WL, Whitt MC, Irwin ML, Swartz AM, Strath SJ, O'Brien WL, Bassett DR, Jr., Schmitz KH, Emplaincourt PO et al: Compendium of physical activities: an update of activity codes and MET intensities. Med Sci Sports Exerc 2000, 32(9 Suppl):S498-504.

16. Zhang X, Geiss LS, Caspersen CJ, Cheng YJ, Engelgau MM, Johnson JA, Plotnikoff RC, Gregg EW: Physical activity levels and differences in the prevalence of diabetes between the United States and Canada. Prev Med 2010, 50(5-6):241-245.

17. Mayhew JL, Prinster JL, Ware JS, Zimmer DL, Arabas JR, Bemben MG: Muscular endurance repetitions to predict bench press strength in men of different training levels. J Sports Med Phys Fitness 1995, 35(2):108-113.

18. Verdijk LB, van Loon L, Meijer K, Savelberg HH: One-repetition maximum strength test represents a valid means to assess leg strength in vivo in humans. J Sports Sci 2009, 27(1):59-68. 
19. Lean ME, Han TS, Morrison CE: Waist circumference as a measure for indicating need for weight management. BMJ 1995, 311(6998):158-161.

20. Matthews DR, Hosker JP, Rudenski AS, Naylor BA, Treacher DF, Turner RC: Homeostasis model assessment: insulin resistance and beta-cell function from fasting plasma glucose and insulin concentrations in man. Diabetologia 1985, 28(7):412-419.

21. Alberti KG, Zimmet PZ: Definition, diagnosis and classification of diabetes mellitus and its complications. Part 1: diagnosis and classification of diabetes mellitus provisional report of a WHO consultation. Diabet Med 1998, 15(7):539-553.

22. Gutt M, Davis CL, Spitzer SB, Llabre MM, Kumar M, Czarnecki EM, Schneiderman N, Skyler JS, Marks JB: Validation of the insulin sensitivity index $(I S I(0,120))$ : comparison with other measures. Diabetes Res Clin Pract 2000, 47(3):177-184.

23. Bergstrom J: Percutaneous needle biopsy of skeletal muscle in physiological and clinical research. Scand J Clin Lab Invest 1975, 35(7):609-616.

24. Verdijk LB, Gleeson BG, Jonkers RA, Meijer K, Savelberg HH, Dendale P, van Loon LJ: Skeletal muscle hypertrophy following resistance training is accompanied by a fiber type-specific increase in satellite cell content in elderly men. J Gerontol A Biol Sci Med Sci 2009, 64(3):332-339.

25. Verdijk LB, Jonkers RA, Gleeson BG, Beelen M, Meijer K, Savelberg HH, Wodzig WK, Dendale P, van Loon LJ: Protein supplementation before and after exercise does not further augment skeletal muscle hypertrophy after resistance training in elderly men. Am J Clin Nutr 2009, 89(2):608-616.

26. Maroni BJ, Steinman TI, Mitch WE: A method for estimating nitrogen intake of patients with chronic renal failure. Kidney Int 1985, 27(1):58-65.

27. Levey AS, Bosch JP, Lewis JB, Greene T, Rogers N, Roth D: A more accurate method to estimate glomerular filtration rate from serum creatinine: a new prediction equation. Modification of Diet in Renal Disease Study Group. Ann Intern Med 1999, 130(6):461-470.

28. Dardevet D, Sornet C, Bayle G, Prugnaud J, Pouyet C, Grizard J: Postprandial stimulation of muscle protein synthesis in old rats can be restored by a leucine-supplemented meal. J Nutr 2002, 132(1):95-100.

29. van Loon LJ: Amino acids as pharmaco-nutrients for the treament of type 2 diabetes. Immunology, Endocrine \& Metabolic Agents in Medicinal Chemistry 2007, 7(1):39-48.

30. Xu G, Kwon G, Cruz WS, Marshall CA, McDaniel ML: Metabolic regulation by leucine of translation initiation through the mTOR-signaling pathway by pancreatic -cells. Diabetes 2001, 50:353-360.

31. Sener A, Malaisse WJ: L-leucine and a nonmetabolized analogue activate pancreatic islet glutamate dehydrogenase. Nature 1980, 288(5787):187-189.

32. Fahien LA, MacDonald MJ, Kmiotek EH, Mertz RJ, Fahien CM: Regulation of insulin release by factors that also modify glutamate dehydrogenase. J Biol Chem 1988, 263(27):13610-13614.

33. Layman DK, Walker DA: Potential importance of leucine in treatment of obesity and the metabolic syndrome. J Nutr 2006, 136(1 Suppl):319S-323S.

34. Matthews DE: Observations of branched-chain amino acid administration in humans. J Nutr 2005, 135(6 Suppl):1580S-1584S.

35. Campbell WW, Trappe TA, Wolfe RR, Evans WJ: The recommended dietary allowance for protein may not be adequate for older people to maintain skeletal muscle. J Gerontol A Biol Sci Med Sci 2001, 56(6):M373-380.

36. Campbell WW, Crim MC, Dallai GE, Young VR, Evans WJ: Increased protein requirements in elderly people: New data and retrospective reassessments. American Journal of Clinical Nutrition 1994, 60(4):501-509.

37. Campbell WW, Evans WJ: Protein requirements of elderly people. Eur J Clin Nutr 1996, 50 Suppl 1:S180183; discussion S183-185.

38. Campbell WW, Johnson CA, McCabe GP, Carnell NS: Dietary protein requirements of younger and older adults. Am J Clin Nutr 2008, 88(5):1322-1329. 


\section{Supplemental Tables}

Supplemental Table 1: Habitual energy intake and macronutrient composition of the diet during 24 wk of leucine or placebo intervention in diabetic men ${ }^{1}$

\begin{tabular}{|c|c|c|c|c|c|c|}
\hline & \multicolumn{3}{|c|}{ Placebo group, $n=28$} & \multicolumn{3}{|c|}{ Leucine group, $n=29$} \\
\hline & wk 0 & wk 12 & wk 24 & wk 0 & wk 12 & wk 24 \\
\hline Energy intake, $M J / d$ & $8.5 \pm 0.2$ & $8.8 \pm 0.3$ & $8.5 \pm 0.3$ & $8.9 \pm 0.2$ & $9.0 \pm 0.2$ & $8.9 \pm 0.2$ \\
\hline Carbohydrate, En\% & $46 \pm 1$ & $45 \pm 1$ & $45 \pm 1$ & $45 \pm 1$ & $46 \pm 1$ & $46 \pm 1$ \\
\hline Fat, En\% & $35 \pm 1$ & $34 \pm 1$ & $35 \pm 1$ & $35 \pm 1$ & $34 \pm 1$ & $34 \pm 1$ \\
\hline Protein, En\% & $15 \pm 1$ & $15 \pm 1$ & $16 \pm 1$ & $16 \pm 1$ & $16 \pm 1$ & $16 \pm 1$ \\
\hline Alcohol, En\% & $4 \pm 1$ & $6 \pm 1$ & $4 \pm 1$ & $4 \pm 0$ & $4 \pm 0$ & $4 \pm 0$ \\
\hline Carbohydrate, $g k g^{-1} d^{-1}$ & $2.79 \pm 0.14$ & $2.81 \pm 0.14$ & $2.71 \pm 0.15$ & $2.91 \pm 0.14$ & $2.93 \pm 0.13$ & $2.99 \pm 0.12$ \\
\hline Fat, $g k g^{-1} \cdot d^{-1}$ & $0.95 \pm 0.04$ & $0.99 \pm 0.05$ & $0.94 \pm 0.05$ & $1.01 \pm 0.04$ & $1.00 \pm 0.05$ & $1.00 \pm 0.04$ \\
\hline Protein, $g k g^{-1} d^{-1}$ & $0.94 \pm 0.04$ & $0.98 \pm 0.05$ & $0.96 \pm 0.04$ & $1.04 \pm 0.05$ & $1.00 \pm 0.05$ & $0.99 \pm 0.04$ \\
\hline
\end{tabular}

${ }^{1}$ Values are mean \pm SEM. No differences between groups prior to the intervention. No differences over time.

Supplemental Table 2: Plasma metabolite concentrations $24 \mathrm{wk}$ of leucine or placebo intervention in diabetic men ${ }^{1}$

\begin{tabular}{lccccccc}
\hline & \multicolumn{3}{c}{ Placebo, $n=28$} & & \multicolumn{3}{c}{ Leucine, $n=29$} \\
\cline { 2 - 3 } & wk 0 & wk 12 & wk 24 & & wk 0 & wk 12 & wk 24 \\
\hline FFA, $\mu \mathrm{mol} / \mathrm{L}$ & $393 \pm 26$ & $362 \pm 31$ & $332 \pm 20$ & & $397 \pm 34$ & $314 \pm 25$ & $373 \pm 30$ \\
Triglycerides, $\mathrm{mmol} / \mathrm{L}$ & $1.8 \pm 0.2$ & $1.7 \pm 0.2$ & $1.7 \pm 0.2$ & & $1.4 \pm 0.2$ & $1.4 \pm 0.1$ & $1.5 \pm 0.1$ \\
Total Cholesterol, $\mathrm{mmol} / \mathrm{L}$ & $4.82 \pm 0.21$ & $4.67 \pm 0.22$ & $4.57 \pm 0.20$ & & $4.54 \pm 0.17$ & $4.42 \pm 0.17$ & $4.38 \pm 0.17$ \\
$\mathrm{HDL}, \mathrm{mmol} / \mathrm{L}$ & $1.32 \pm 0.08$ & $1.27 \pm 0.07$ & $1.29 \pm 0.07$ & & $1.36 \pm 0.07$ & $1.22 \pm 0.06$ & $1.24 \pm 0.06$ \\
LDL, $\mathrm{mmol} / \mathrm{L}$ & $2.73 \pm 0.17$ & $2.68 \pm 0.17$ & $2.56 \pm 0.15$ & $2.58 \pm 0.14$ & $2.60 \pm 0.15$ & $2.50 \pm 0.15$ \\
Glycerol, $\mu \mathrm{mol} / \mathrm{L}$ & $91 \pm 6$ & $102 \pm 8$ & $88 \pm 8$ & & $102 \pm 9$ & $83 \pm 5$ & $90 \pm 7$ \\
Lactate, $\mathrm{mmol} / \mathrm{L}$ & $1.50 \pm 0.14$ & $1.64 \pm 0.14$ & $1.72 \pm 0.14$ & & $1.43 \pm 0.12$ & $1.43 \pm 0.13$ & $1.50 \pm 0.11$ \\
\hline
\end{tabular}

\footnotetext{
${ }^{1}$ Values are mean \pm SEM. No significant differences were observed between groups prior to intervention. No time $x$ group interaction was observed for any of the variables. No significant main effects of group and/or time were observed for any of the variables
} 
Supplemental Table 3: Muscle fiber type characteristics during 24 wk of leucine or placebo intervention in diabetic men ${ }^{1}$

\begin{tabular}{|c|c|c|c|c|c|c|}
\hline & \multicolumn{3}{|c|}{ Placebo, $n=28$} & \multicolumn{3}{|c|}{ Leucine, $n=29$} \\
\hline & wk 0 & wk 12 & wk 24 & wk 0 & wk 12 & wk 24 \\
\hline \multicolumn{7}{|l|}{ Fiber , \% } \\
\hline Type I & $41 \pm 4$ & $46 \pm 3$ & $46 \pm 3$ & $42 \pm 2$ & $40 \pm 3$ & $50 \pm 3$ \\
\hline Type Ila & $48 \pm 4$ & $43 \pm 3$ & $43 \pm 3$ & $47 \pm 2$ & $45 \pm 2$ & $42 \pm 2$ \\
\hline Type IIx & $10 \pm 8$ & $11 \pm 2$ & $11 \pm 2$ & $11 \pm 3$ & $14 \pm 3$ & $8 \pm 2$ \\
\hline \multicolumn{7}{|l|}{$\mathrm{CSA}, \mu \mathrm{m}^{2}$} \\
\hline Type I & $5745 \pm 316$ & $5983 \pm 363$ & $6334 \pm 358$ & $6043 \pm 399$ & $5190 \pm 270$ & $5879 \pm 393$ \\
\hline Type Ila* & $5557 \pm 273$ & $5564 \pm 352$ & $5710 \pm 360$ & $5197 \pm 275$ & $4979 \pm 279$ & $5339 \pm 408$ \\
\hline Type IIx ${ }^{*}$ & $4272 \pm 357$ & $4037 \pm 279$ & $4450 \pm 381$ & $4525 \pm 365$ & $4028 \pm 255$ & $4054 \pm 270$ \\
\hline
\end{tabular}

${ }^{1}$ Data represent mean \pm SEM. ${ }^{*}$ significantly different from type I fibers at all time points $(P<0.05)$. 
CHAPTER 4

\title{
Patients with type 2 diabetes show a greater decline in muscle mass, muscle strength, and functional capacity with aging
}

\author{
Marika Leenders \\ Lex B Verdijk \\ Letty van der Hoeven \\ Jos J Adam \\ Janneau van Kranenburg \\ Rachel Nilwik \\ Luc JC van Loon
}




\section{Abstract}

Background: The loss of muscle mass with aging reduces muscle strength, impairs functional capacity, and increases the risk of developing chronic metabolic disease. It has been suggested that the development of type 2 diabetes results in a more rapid decline in muscle mass, strength, and functional capacity.

Objective: To investigate the impact of type 2 diabetes on muscle mass, strength and functional capacity in an older population.

Methods: Muscle mass (DXA and muscle biopsies), strength (1-repetition maximum), functional capacity (sit-to-stand test and handgrip strength), and reaction time performance (computer task) were compared between 60 older men with type 2 diabetes (71 $\pm 1 \mathrm{y}$ ) and 32 age-matched normoglycemic controls (70 $\pm 1 \mathrm{y}$ ). Data were analyzed using ANCOVA to adjust for several potential confounders.

Results: Leg lean mass and appendicular skeletal muscle mass were significantly lower in older men with type 2 diabetes (19.1 \pm 0.3 and $25.9 \pm 0.4 \mathrm{~kg}$, respectively) compared with normoglycemic controls (19.7 \pm 0.3 and $26.7 \pm 0.5 \mathrm{~kg}$, respectively). Additionally, leg extension strength was significantly lower in the group with type 2 diabetes ( $84 \pm 2$ vs $91 \pm 2 \mathrm{~kg}$, respectively). In agreement, functional performance was impaired in the men with type 2 diabetes, with longer sit-to-stand time ( $9.1 \pm 0.4$ vs 7.8 $\pm 0.3 \mathrm{~s})$ and lower handgrip strength ( $39.5 \pm 5.8$ vs $44.6 \pm 6.1 \mathrm{~kg}$ ) when compared with normoglycemic controls. However, muscle fiber size and reaction time performance did not differ between groups.

Conclusion: Older patients with type 2 diabetes show an accelerated decline in leg lean mass, muscle strength, and functional capacity when compared with normoglycemic controls. Exercise intervention programs should be individualized to specifically target muscle mass, strength and functional capacity in the older population with type 2 diabetes. 


\section{Introduction}

Aging is associated with a progressive loss of skeletal muscle mass and strength, commonly termed sarcopenia. This age-related decline in skeletal muscle mass and strength impairs functional performance, leading to a decreased level of independence and greater morbidity (1). The loss of independence imposes a major burden on our healthcare system because of the greater need for hospitalization and/or institutionalization. Furthermore, the loss of skeletal muscle mass also predisposes to the development of chronic metabolic disease. The latter is not surprising considering the fact that skeletal muscle tissue is responsible for up to $80 \%$ of glucose uptake following food intake. Thus, the preservation of muscle mass is fundamental to allow glucose homeostasis and to negate the development of chronic metabolic disease (2).

Recent data indicate that the loss of muscle mass is not only a cause but can also be a consequence of type 2 diabetes. The Health $A B C$ study has previously reported a more pronounced decline in skeletal muscle mass in elderly type 2 diabetes patients when compared with age-matched normoglycemic controls (3). It has been suggested that the postprandial muscle protein synthetic response may be blunted in an insulinresistant state $(4,5)$, thereby contributing to a more rapid loss of muscle mass in the older patient with type 2 diabetes. We hypothesize that muscle mass is reduced to a greater extent in older patient with type 2 diabetes when compared with agematched, normoglycemic controls.

The loss of muscle mass, and specific type II muscle fiber atrophy, leads to the loss of muscle strength $(6,7)$. In accordance, Park et al $(2,8)$ have reported a greater decline in muscle strength in elderly patients with type 2 diabetes when compared with normoglycemic controls. These findings imply that age-related loss of muscle mass and strength is accelerated in a type 2 diabetes state. It could be speculated that greater type II muscle fiber atrophy in the diabetic elderly could predispose to a greater loss of strength. Therefore, we hypothesize that a greater decline in skeletal muscle mass and strength in a type 2 diabetic state is associated with greater type II muscle fiber specific atrophy.

So far, it remains unclear whether these proposed differences in muscle mass and strength predispose to a reduced level of functional performance in the elderly type 2 diabetes patient. With aging, the rate of decline in muscle strength generally exceeds the loss of muscle mass (9). The latter clearly shows that impairments in neuromuscular function contribute to the rapid loss of strength and functional capacity with aging (9-11). There are ample indications that neuromuscular function and even cognitive function are compromised in the type 2 diabetic state (12-14). It has been well established that hyperglycemic events culminate into nerve damage, eventually resulting in neuropathic alterations (15). These neuropathic alterations likely contribute to the loss of muscle strength and function in the older patient with type 2 diabetes. We hypothesize that muscle function and reaction time performance are reduced to a greater 
extent in older patients with type 2 diabetes when compared with age-matched, normoglycemic controls.

As recently pointed out by Sinclair et al (16), diabetes is a highly prevalent metabolic condition in ageing societies and most international clinical guidelines have ignored the unique issues of frailty, functional limitations, changes in mental health, and increasing dependency in this population. The aim of present study was to assess the impact of type 2 diabetes on body composition, muscle strength, functional capacity, and reaction time performance. Consequently, we selected a large group of older patients with type 2 diabetes ( $n=60$, age: $71 \pm 1$ y) and a group of age-matched normoglycemic controls ( $n=32$, age: $70 \pm 1$ y) to compare skeletal muscle mass, muscle strength, functional capacity, and reaction time performance between groups. Furthermore, we collected muscle biopsy samples in all subjects to define whether differences in muscle mass, strength and/or function could be attributed to differences in fiber type specific muscle atrophy. The present study shows that leg muscle mass, muscle strength, and functional capacity are more compromised in older patients with type 2 diabetes when compared with age-matched normoglycemic controls.

\section{Methods}

\section{Subjects}

Ninety-two older men were included in the present study, 60 with type 2 diabetes (71 \pm 1 y) and 32 age-matched normoglycemic controls (70 \pm 1 y). All subjects were community dwelling and still living independently. All subjects were recruited through advertisements in local newspapers. Medical history of all subjects was evaluated and an oral glucose tolerance test and resting and exercise electrocardiogram were performed before inclusion. Exclusion criteria included a recent history or current state of cardiovascular disease, chronic obstructive pulmonary disease, Parkinson, rheumatoid arthritis, musculoskeletal/orthopedic disorders, and cognitive impairment. None of the men reported any problems with normal activities of daily living (e.g., walking, climbing stairs, rising from a chair) and did not need any assistive equipment (e.g., using a cane) while walking. In addition, none of the men reported cognitive and/or psychosocial problems. In the normoglycemic control group, individuals were treated with cholesterol- or lipid-lowering medication $(n=6)$, anticoagulant medication ( $n=6)$, antihypertensive medication $(n=6)$, medication for prostate problems $(n=3)$ and antidysrhythmia medication $(n=1)$. Individuals with type 2 diabetes were treated with dietary recommendations only $(n=6)$ or oral blood-glucose lowering medication: metformin combined with sulfonylurea derivates and/or thiazolidinediones ( $n=21)$, metformin only $(n=28)$, or sulfonylurea derivates only $(n=5)$. Additionally, subjects in the type 2 diabetes group were treated with cholesterol- or lipid-lowering medication ( $n=$ $31)$, anticoagulant medication $(n=22)$, antihypertensive medication $(n=30)$ and anti- 
dysrhythmia medication $(n=5)$. All participants had been receiving the same medication and/ or dietary prescriptions for at least 3 months before the measurements. Individuals with more severe medical problems (treatment by a medical specialist more than twice a year) were excluded. All subjects were informed of the nature and possible risks of the experimental procedures before their written informed consent was obtained. This study was part of a greater project investigating the impact of combined dietary and exercise interventions to increase muscle mass and strength in different elderly populations and has been approved by the Medical Ethics Committee of the Maastricht University Medical Centre ${ }^{+}$.

\section{Dietary intake and physical activity}

Dietary intake was recorded with 4-d weighted dietary intake records. Dietary records were analyzed with Komeet (Komeet, 4.059 BaS Nutrition Software, Arnhem, Netherlands) to determine habitual daily energy intake, and absolute and relative intakes of carbohydrates, protein, fat, and alcohol. Habitual physical activity was recorded with a 2-d physical activity record. For every type of activity, a mean equivalent task (MET) score was assigned to express the intensity of a specific activity as previously defined (17). One MET unit equals resting energy expenditure (i.e. $1 \mathrm{kcal}$ per kg body weight per hour (17)). Energy expenditure was calculated as mean MET-h/d (18).

\section{Body composition}

Body composition and bone mineral content were measured with dual-energy $x$-ray absorptiometry (DXA) (Hologic, Discovery A, QDR Series, Bradford, MA, USA). Wholebody and regional lean mass, fat mass, and bone mineral content were determined by using the software package Apex version 2.3 (Hologic, Bradford, MA). DXA scans were performed in a fasting state after participants had voided. Appendicular skeletal muscle mass (ASM) was calculated as the sum of lean mass of the arms and legs (19). Body mass was measured to the nearest $0.1 \mathrm{~kg}$ using an electronic balance scale, height was measured to the nearest $0.5 \mathrm{~cm}$ using a wall-mounted stadiometer, circumferences to within $1 \mathrm{~mm}$ using a measuring tape, with waist midway between the lowest rib and the iliac crest with the subject standing at the end of gentle expiration and hips at the greater trochanters (16). Leg volume was assessed according to the method described by Jones and Pearson as an estimate of leg muscle mass (20).

\section{Strength assessment}

Maximum strength was assessed by 1-repetition maximum (1RM) strength tests on leg press and leg extension machines (Technogym, Rotterdam, The Netherlands). During a familiarization trial, proper lifting technique was demonstrated and practiced and 
maximum strength was estimated using the multiple repetitions testing procedure (21). In an additional session, at least one week prior to muscle biopsy collection, each subject's 1RM was determined as described previously (22). The 1RM strength assessment has previously been validated against dynamometry-based measurements (23).

\section{Physical performance measures}

To assess lower and upper extremity physical performance, a sit-to-stand test and a handgrip test were performed. For the sit-to-stand test (24), the participants were instructed to fold their arms across their chest and to stand up/sit down 5 times, as fast as possible, from a seat at $0.42 \mathrm{~m}$ from the floor. Patients were timed from the initial sitting to the final standing position. The fastest out of 2 rises was recorded (24). Data on maximal grip strength were obtained using a JAMAR handheld dynamometer (model BK-7498, Fred Sammons, Inc., Burr Ridge, IL). Grip strength was measured 3 times with each hand. The best measure in the stronger hand is reported (25). Tests were conducted seated in a chair, hips and knees flexed at $90^{\circ}$ and a $90^{\circ}$ angle between upper and lower arm.

\section{Reaction time performance}

Reaction time performance was measured by means of the finger-precuing task, which represents a 4-choice reaction time task (26). In short, the index and middle fingers of both hands are placed on 4 response keys: (Z), (X), (.), and (/) of a computer keyboard. Responses are made by pressing one of these keys as quickly as possible when a visual target signal appears (a single "+" sign presented on a computer monitor). Two seconds before the presentation of the target signal, a precue signal appears, which specifies a subset of 2 possible responses (for instance, the 2 fingers on the left hand, or the 2 index fingers). The function of the precue is to reduce the number of possible responses from 4 to 2, thereby facilitating reaction time. Participants performed 160 trials, with a 1-min break halfway. Dependent measures were mean reaction time (in $\mathrm{ms}$ ) and mean percentage of errors (i.e., pressing the wrong key).

\section{Muscle biopsy sampling}

Skeletal muscle biopsies were taken from the vastus lateralis muscle in the right leg of each subject, in the morning following an overnight fast. After local anesthesia was induced, percutaneous needle biopsy samples $(50-80 \mathrm{mg})$ were collected from the vastus lateralis muscle, approximately $15 \mathrm{~cm}$ above the patella (27). Any visible nonmuscle tissue was removed immediately, and biopsy samples were embedded in Tissue-Tek (Sakura Finetek, Zoeterwoude, The Netherlands), frozen in liquid nitrogencooled isopentane, and stored at $-80^{\circ} \mathrm{C}$ until further analyses. 


\section{Immunohistochemistry}

From all biopsies, $5 \mu \mathrm{m}$ thick cryosections were cut at $-20^{\circ} \mathrm{C}$. Care was taken to properly align the samples for cross-sectional fiber analyses. Muscle biopsies were stained for muscle fiber typing as described in detail previously (28). In short, the slides were incubated with primary antibodies against MHC-I (A4.840, Developmental Studies Hybridoma Bank, lowa City, IA) and laminin (polyclonal laminin, Sigma, Zwijndrecht, the Netherlands). After washing, appropriate secondary antibodies were applied (goat anti-mouse (Ig)M AlexaFluor555 and goat anti-rabbit IgG AlexaFluor647, respectively; Molecular Probes, Invitrogen, Breda, the Netherlands). Images were visualized and automatically captured at $\times 10$ magnification with a fluorescent microscope equipped with an automatic stage (IX81 motorized inverted microscope, Olympus, Hamburg, Germany). Muscle fiber type (fiber \%), fiber cross-sectional area (CSA), and the number of myonuclei, were measured for each separate muscle fiber. As such, mean muscle fiber size was calculated for the type I and type II muscle fibers separately. As a measure of fiber circularity, form factors were calculated by using the following formula: $(4 \pi \cdot \mathrm{CSA}) /(\text { perimeter })^{2}$. All image recordings and analyses were performed by an investigator blinded to subject coding. No differences in fiber circularity were observed between groups.

\section{Blood samples}

Fasting blood samples were collected to determine basal plasma glucose and insulin concentrations, plasma amino acid, and blood glycated hemoglobin (HbA1c) content. Blood (10 mL) was collected into EDTA-containing tubes. EDTA tubes were immediately centrifuged at $1000 \mathrm{~g}$ for $10 \mathrm{~min}$ at $4^{\circ} \mathrm{C}$. Aliquots of plasma were immediately frozen in liquid nitrogen and stored at $-80^{\circ} \mathrm{C}$ until further analysis. Plasma glucose concentrations were analyzed with a COBAS FARA analyzer (Uni Kit III; Roche, Basel, Switzerland). Plasma insulin concentrations were determined by using an Insulin RIA Kit (LINCO Research Inc, St Charles, MO). For the amino acid analyses, plasma was deproteinized on ice with $100 \mu \mathrm{L} \mathrm{24 \%} \mathrm{(wt:vol)} \mathrm{5-sulfosalicylic} \mathrm{acid} \mathrm{and} \mathrm{mixed,} \mathrm{and} \mathrm{the} \mathrm{clear} \mathrm{su-}$ pernatant fluid was collected after centrifugation. Plasma amino acid concentrations were analyzed with a dedicated amino acid analyzer (LCA10; Shimadzu Benelux, Den Bosch, The Netherlands) by using an automated precolumn derivatization procedure and a ternary solvent system. To determine blood HbA1c content, $3 \mathrm{~mL}$ blood was collected in EDTA containing tubes and analyzed by high-performance liquid chromatography (Bio-Rad Variant II 4, Munich, Germany). 


\section{Statistics}

Data are expressed as means \pm SEM. Descriptive characteristics for healthy individuals and those with type 2 diabetes were compared by independent samples t-tests. In addition, differences in muscle mass, muscle strength, functional capacity, and reaction time performance between healthy individuals and those with type 2 diabetes were analyzed by using analysis of covariance (ANCOVA) to adjust for potential confounders. A set of 7 potential confounders was selected: age, body mass index (BMI), fasting glucose, high-density lipoprotein-cholesterol, branched-chain amino acid (BCAA) concentration, habitual protein intake (in grams per kilogram body weight per day), and physical activity level. Selection of these variables was based on a) an established or expected relation with the outcome variables; b) a significant difference (or tendency) between healthy individuals and those with type 2 diabetes; c) collinearity diagnostics: in case of multicollinearity between related variables, only 1 covariate was selected. For example, multicollinearity was observed between fasting blood glucose, glycated hemoglobin (HbA1c), homeostasis model assessment of insulin resistance (HOMA), and insulin sensitivity (ISI); as such only fasting blood glucose was included as covariate to adjust for "glucose homeostasis". Apart from the ANCOVA, mixed model analysis of variance (ANOVA) with fiber type (type I vs II) as within subjects factor and group (healthy vs diabetes) as between-subjects factor was performed to determine differences between type I and II muscle fiber size in both groups. Pearson correlation coefficients were calculated to determine the relation between different variables. Significance was set at $P<0.05$. All calculations were performed using SPSS 19.0 (SPSS Inc, Chicago, IL).

\section{Results}

\section{Subjects}

Subjects' characteristics are provided in Table 1. In total, 60 elderly men with type 2 diabetes and 32 normoglycemic age-matched controls were included in the study. Both groups showed no differences for age, body weight, height, BMI, HOMA and ISI. The group with type 2 diabetes presented significantly higher basal plasma glucose, and $\mathrm{HbA} 1 \mathrm{C}$ values and lower basal plasma insulin concentrations when compared with the normoglycemic group.

\section{Dietary intake and physical activity}

A significant difference was observed in total energy intake between the healthy and the type 2 diabetes group $(9.8 \pm 0.4$ vs $8.9 \pm 0.2 \mathrm{MJ} / \mathrm{d}$, respectively; $P=0.018)$. No 
significant differences were observed in the macronutrient composition of the diet between the normoglycemic and the type 2 diabetes group. Daily protein intake averaged $1.0 \pm 0.1 \mathrm{~g} / \mathrm{kg} / \mathrm{d}$ in the normoglycemic group and $1.0 \pm 0.1 \mathrm{~g} / \mathrm{kg} / \mathrm{d}$ in the type 2 diabetes group. Energy percentage from alcohol intake was $6 \pm 1 \%$ in the normoglycemic group and $4 \pm 1 \%$ in the type 2 diabetes group, with no differences between groups. No significant differences were observed in habitual physical activity level of the healthy and the type 2 diabetes group $(1.49 \pm 0.04$ vs $1.47 \pm 0.05 \mathrm{MET}-\mathrm{h} / \mathrm{d}$, respectively).

Table 1: Subjects' characteristics

\begin{tabular}{|c|c|c|c|}
\hline & $\begin{array}{c}\text { Normoglycemic } \\
(n=32)\end{array}$ & $\begin{array}{c}\text { Type } 2 \text { diabetes } \\
\qquad(n=60)\end{array}$ & $P$-value \\
\hline Age (y) & $70 \pm 1$ & $71 \pm 1$ & 0.646 \\
\hline Body weight (kg) & $83.8 \pm 1.7$ & $83.9 \pm 1.3$ & 0.991 \\
\hline Height (m) & $1.77 \pm 0.01$ & $1.75 \pm 0.01$ & 0.284 \\
\hline BMI $\left(\mathrm{kg} / \mathrm{m}^{2}\right)$ & $26.9 \pm 0.5$ & $27.3 \pm 0.4$ & 0.608 \\
\hline Basal plasma glucose (mmol/L) & $5.6 \pm 0.1$ & $7.8 \pm 0.2^{*}$ & 0.000 \\
\hline Basal plasma insulin (mU/L) & $18.2 \pm 1.5$ & $13.6 \pm 0.6^{*}$ & 0.008 \\
\hline HbA1c (\%) & $5.5 \pm 0.1$ & $7.2 \pm 0.1^{*}$ & 0.000 \\
\hline HOMA & $4.3 \pm 0.3$ & $4.7 \pm 0.2$ & 0.277 \\
\hline ISI & $3.1 \pm 0.3$ & $2.7 \pm 0.2$ & 0.197 \\
\hline
\end{tabular}

HbA1c: glycated hemoglobin; HOMA: homeostasis model assessment of insulin resistance; ISI: Insulin sensitivity index.

Data represent mean \pm SEM. Data were analyzed by using independent samples $t$-test.

* Different from normoglycemic group.

\section{Body composition}

At a whole body level, no significant differences were observed between the normoglycemic and the type 2 diabetes group for body mass ( $83.8 \pm 1.7$ vs $83.9 \pm 1.3 \mathrm{~kg}$ ) and fat mass (19.2 \pm 0.9 vs $19.2 \pm 0.6 \mathrm{~kg}$, respectively). Although absolute values for wholebody lean mass were similar between groups $(61.8 \pm 1.1$ vs $62.0 \pm 0.8 \mathrm{~kg}$ in normoglycemic vs those with type 2 diabetes), the ANCOVA analyses showed borderline significant lower lean mass in the individuals with type 2 diabetes $(P=0.051)$. In accordance, lean mass was shown to be significantly lower in individuals with type 2 diabetes compared with healthy controls when expressed both as ASM ( $25.9 \pm 0.4$ vs $26.7 \pm 0.5 \mathrm{~kg}$, respectively; $\mathrm{P}=0.005$; Table 2 ) and expressed as leg lean mass (19.1 \pm 0.3 vs $19.7 \pm$ $0.3 \mathrm{~kg}$, respectively; $\mathrm{P}=0.013$ ). 
Table 2: Body composition and muscle strength

\begin{tabular}{|c|c|c|c|}
\hline & $\begin{array}{c}\text { Normoglycemic } \\
\qquad(n=32)\end{array}$ & $\begin{array}{c}\text { Type } 2 \text { diabetes } \\
(n=60)\end{array}$ & $P$-value \\
\hline \multicolumn{4}{|l|}{ Body composition } \\
\hline Body mass (kg) & $83.8 \pm 1.7$ & $83.9 \pm 1.3$ & 0.097 \\
\hline Lean mass (kg) & $61.8 \pm 1.1$ & $62.0 \pm 0.8$ & 0.051 \\
\hline Leg lean mass (kg) & $19.7 \pm 0.3$ & $19.1 \pm 0.3^{*}$ & 0.013 \\
\hline Fat mass (kg) & $19.2 \pm 0.9$ & $19.2 \pm 0.6$ & 0.949 \\
\hline Fat $\%$ & $22.7 \pm 0.8$ & $22.6 \pm 0.5$ & 0.534 \\
\hline ASM (kg) & $26.7 \pm 0.5$ & $25.9 \pm 0.4^{*}$ & 0.005 \\
\hline \multicolumn{4}{|l|}{ Strength } \\
\hline Leg press (kg) & $204 \pm 2$ & $202 \pm 2$ & 0.201 \\
\hline Leg extension (kg) & $91 \pm 2$ & $84 \pm 2^{*}$ & 0.024 \\
\hline
\end{tabular}

ASM: appendicular skeletal muscle mass.

Data represent mean \pm SEM. Data were analyzed using ANCOVA.

*Significantly different from normoglycemic group.

\section{Muscle strength}

In line with the findings for lean mass, leg extension strength was significantly lower in the group with type 2 diabetes compared with the normoglycemic control group (84 \pm 2 vs $91 \pm 2 \mathrm{~kg}$, respectively; $P=0.013$ )(Figure $1 \mathrm{~A}$ ). In contrast, no differences were observed in leg press strength between groups (202 \pm 2 vs $204 \pm 2 \mathrm{~kg}$, respectively; $P=$ 0.201 )(Figure $1 B$ ). Leg extension strength was significantly correlated with lean mass, leg lean mass (Figure 2A), and ASM, with $r$ values of $0.37,0.49$ and 0.53 , respectively $(P$ $<0.001)$. Leg press strength correlated significantly with lean mass, leg lean mass, and ASM with $r$ values of $0.22,0.27$ and 0.31 , respectively $(P<0.05)$.

\section{Functional capacity}

Sit-to-stand time and handgrip strength are presented in Figure 1. A significantly longer sit-to-stand time was observed in the group with type 2 diabetes versus the normoglycemic group (9.1 \pm 0.4 vs $7.8 \pm 0.3 \mathrm{~s}$, respectively; $P=0.001$ ). In addition, handgrip strength was significantly lower in the group with type 2 diabetes when compared with the normoglycemic controls ( $39.5 \pm 5.8$ vs $44.6 \pm 6.1 \mathrm{~kg}$, respectively; $P<0.001$ ). Sit-tostand time was significantly correlated with handgrip strength, and leg extension (Figure 2B) and leg press strength with $r$ values of $-0.24,-0.34$ and -0.40 , respectively $(P<$ $0.05)$. Handgrip strength correlated significantly with leg extension (Figure $\mathbf{2 C}$ ) and leg press strength, lean mass, lean mass in the legs and ASM with $r$ values of: 0.61, 0.45, $0.37,0.46$, and 0.51 , respectively $(P<0.01)$. Furthermore, blood HbA1c content showed a significant negative correlation with functional performance as evidenced by 
a slower sit-to-stand time $(r=0.24 ; P=0.042)$ and a lower handgrip strength $(r=-0.32$; $P=0.005)$.
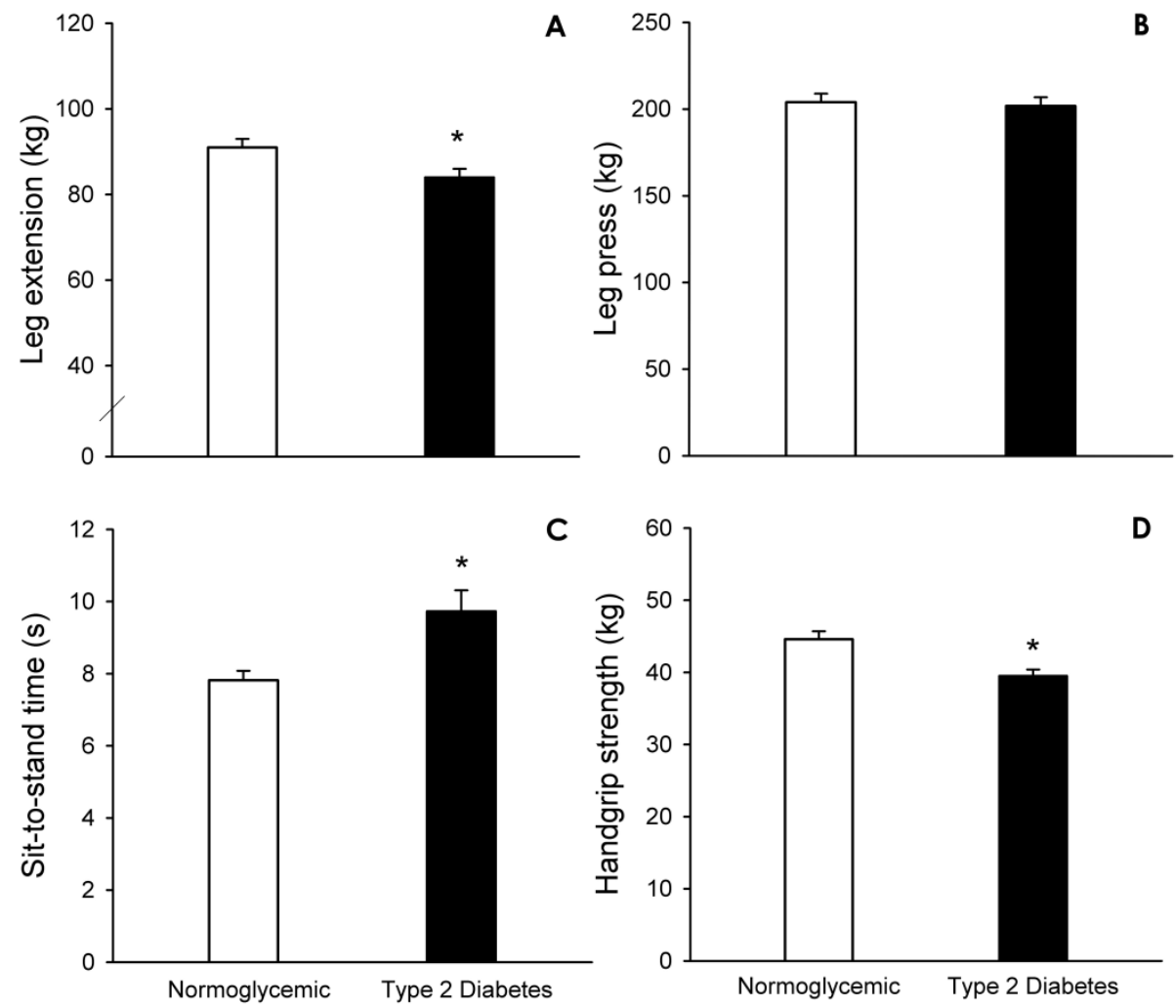

Figure 1: Functional performance

A) Mean $( \pm S E M) 1 R M$ leg extension in normoglycemic (white bar) and type 2 diabetic (black bar) elderly subjects. B) Mean ( \pm SEM) 1RM leg press in normoglycemic (white bar) and type 2 diabetic (black bar) older subjects. C) Mean ( \pm SEM) sit-to-stand time in normoglycemic older (white bar) and type 2 diabetic (black bar) older subjects. D) Mean ( \pm SEM) hand-grip strength in normoglycemic (white bar) and type 2 diabetic (black bar) older subjects. Data were analyzed using an ANCOVA. *Significantly different from normoglycemic subjects, $P<0.001$. 

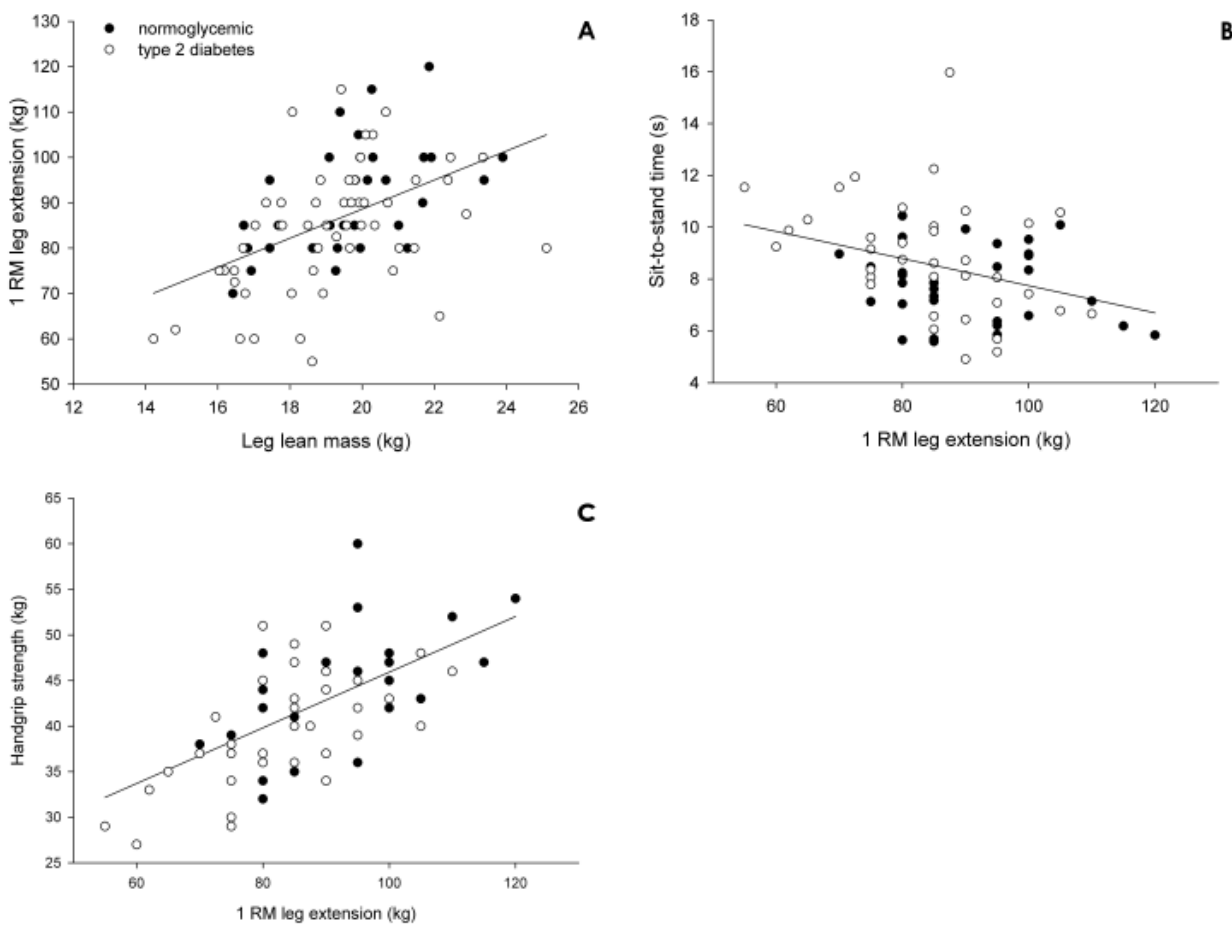

Figure 2: Scatter plots of relationships between muscle mass, strength, and functional capacity.

A) Scatter plot for correlation of leg lean mass with 1RM leg extension strength in normoglycemic (filled circles) and type 2 diabetic (open circles) older subjects. Line represents the fitted regression. Pearson correlation coefficient was $0.49(P<0.001)$. B) Scatter plot for correlation of 1RM leg extension with sit-tostand time in normoglycemic (filled circles) and type 2 diabetic older subjects (open circles). Line represents the fitted regression. Pearson correlation coefficient was $-0.34(P<0.005)$, respectively. C) Scatter plot for correlation of 1 RM leg extension with handgrip strength in normoglycemic (filled circles) and type 2 diabetic older subjects (open circles). Line represents fitted regression. Pearson correlation coefficient was $0.61(P<$ 0.0001).

\section{Muscle characteristics}

At the myocellular level, type I muscle fiber CSA averaged $5862 \pm 234$ and $5704 \pm 202$ $\mu \mathrm{m}^{2}$ in the individuals with type 2 diabetes and normoglycemic individuals, respectively. Type II muscle fiber CSA averaged $5159 \pm 179$ and $5005 \pm 187 \mu \mathrm{m}^{2}$, respectively, with no significant differences between groups. For both groups, type II muscle fiber CSA was significantly smaller than type I muscle fiber CSA $(P<0.001)$. However, no differences were observed between groups for either type I or type II muscle fiber CSA. In agreement, muscle fiber type composition was not significantly different between groups (43 \pm 2 vs $53 \pm 3 \%$ type I muscle fibers in type 2 diabetes and normoglycemic subjects, respectively). Similar findings were observed when muscle fiber type composition was expressed as a percentage of muscle area occupied by type I and II fibers (46 
\pm 2 vs $56 \pm 3 \%$ of muscle area occupied by type I muscle fibers in individuals with type 2 diabetes and those who are normoglycemic, respectively). Type II muscle fiber CSA significantly correlated with lean mass, leg lean mass, ASM, leg extension and leg press strength with $r$ values of $0.23,0.26,0.25,0.35$ and 0.38 , respectively $(P<0.05)$.

\section{Plasma amino acid profile}

Fasting plasma amino acid profiles are presented in Table 3. Plasma BCAA concentrations were significantly different between groups, with higher values observed in the group with type 2 diabetes versus normoglycemic control group for valine (9\%), isoleucine (13\%), and leucine (18\%). Furthermore, significantly higher concentrations for glutamic acid and alanine were observed in the group with diabetes compared with the normoglycemic control group $(P<0.05)$. Plasma arginine, tyrosine, tryptophan, phenylalanine and methionine concentrations were significantly lower in the diabetic versus the normoglycemic group $(P<0.05)$. Blood HbA1c contents were strongly correlated with fasting plasma glutamic acid, leucine, isoleucine, valine and methionine concentrations with $r$ values of $0.68,0.57,0.46,0.44$ and -0.59 , respectively $(P<$ $0.001)$. Fasting plasma glucose concentrations correlated significantly with the same amino acids with $r$ values of $0.51,0.47,0.36,0.32$ and -0.45 , respectively $(P<0.001)$. Fasting insulin concentrations correlated significantly with citrulline, phenylalanine, arginine, and methionine with $r$ values of $0.22,0.22,0.23,0.29$, respectively $(P<0.05)$. ISI correlated negatively with plasma isoleucine, phenylalanine, valine, leucine and glutamic acid concentrations with $r$ ranging from -0.27 to $-0.39(P<0.05)$.

\section{Reaction time performance}

Although absolute values differed substantially, the ANCOVA analysis showed no significant differences for reaction time performance between the group with type 2 diabetes and the normoglycemic control group (724 \pm 24 vs $641 \pm 25 \mathrm{~ms}$, respectively; $P=0.195)$. In addition, error rates did not differ significantly between groups (1.6 \pm 0.2 vs $1.5 \pm 0.3 \%$, respectively, $P=0.62$ ). Interestingly though, reaction time was negatively correlated with handgrip strength and leg extension strength with $r$ values of -0.36 and -0.31 , respectively $(P<0.005)$. 
Table 3: Amino acid profiles

\begin{tabular}{|c|c|c|c|}
\hline Amino acids $(\mu \mathrm{mol} / \mathrm{L})$ & $\begin{array}{c}\text { Normoglycemic } \\
(n=32)\end{array}$ & $\begin{array}{c}\text { Type } 2 \text { diabetes } \\
(n=60)\end{array}$ & $P$-value \\
\hline Glutamic acid & $56 \pm 2$ & $117 \pm 27^{*}$ & 0.000 \\
\hline Asparagine & $51 \pm 1$ & $49 \pm 1$ & 0.183 \\
\hline Serine & $100 \pm 3$ & $106 \pm 3$ & 0.143 \\
\hline Glutamine & $627 \pm 10$ & $622 \pm 10$ & 0.770 \\
\hline Histidine & $89 \pm 2$ & $88 \pm 1$ & 0.636 \\
\hline Glycine & $240 \pm 7$ & $240 \pm 5$ & 0.972 \\
\hline Threonine & $135 \pm 4$ & $139 \pm 3$ & 0.410 \\
\hline Citrulline & $44 \pm 2$ & $40 \pm 1$ & 0.055 \\
\hline Arginine & $109 \pm 4$ & $91 \pm 3^{*}$ & 0.000 \\
\hline Alanine & $409 \pm 17$ & $458 \pm 12^{*}$ & 0.017 \\
\hline Taurine & $111 \pm 5$ & $106 \pm 4$ & 0.424 \\
\hline Tyrosine & $73 \pm 2$ & $67 \pm 2 *$ & 0.037 \\
\hline Tryptophan & $52 \pm 1$ & $43 \pm 1 *$ & 0.000 \\
\hline Ornitine & $61 \pm 2$ & $61 \pm 3$ & 0.945 \\
\hline Lysine & $208 \pm 7$ & $212 \pm 5$ & 0.672 \\
\hline Phenylalanine & $62 \pm 1$ & $58 \pm 1^{*}$ & 0.013 \\
\hline Methionine & $38 \pm 1$ & $27 \pm 1^{*}$ & 0.000 \\
\hline Leucine & $123 \pm 2$ & $145 \pm 3^{*}$ & 0.000 \\
\hline Isoleucine & $72 \pm 2$ & $81 \pm 2^{*}$ & 0.000 \\
\hline Valine & $223 \pm 5$ & $245 \pm 4^{*}$ & 0.002 \\
\hline
\end{tabular}

Data represent mean \pm SEM. Data were analyzed using independent samples $t$-test.

*Significantly different from normoglycemic group.

\section{Discussion}

The present study shows that both leg lean mass and ASM are lower in older patients with type 2 diabetes when compared with age-matched normoglycemic controls. Additionally, leg muscle strength and functional capacity are reduced in older individuals suffering from type 2 diabetes. Reduced muscle strength and impairments in functional capacity are strongly correlated with type II muscle fiber atrophy in both normoglycemic elderly and those with type 2 diabetes.

Aging is accompanied by a progressive decline in skeletal muscle mass, referred to as sarcopenia. It has been suggested that the loss of muscle mass with aging is, at least partly, attributed to a reduction in the muscle protein synthetic response to the main anabolic stimuli, i.e. food intake and physical activity $(29,30)$. It could be speculated that the blunting of the muscle protein synthetic response to food intake is even more pronounced in an insulin resistant state, resulting in a more rapid decline in skeletal 
muscle mass in older patients with type 2 diabetes $(4,5)$. Previous findings from the Health $A B C$ study were somewhat inconclusive, showing only lower muscle strength (2) or lower muscle mass and strength in older patients with diabetes (8). More recently however, Park et al (3) clearly confirmed the presence of accelerated sarcopenia in older patients with type 2 diabetes compared with age-matched normoglycemic controls (3). In line with these findings, we observed an approximately $3 \%$ lower leg lean mass in the patients with type 2 diabetes compared with their age-matched controls, despite similar body mass between groups. Likewise, diabetes was associated with 3\% lower ASM in our elderly population (Table 2).

In addition to significant differences in lean mass, we observed significant differences in muscle strength between the group with type 2 diabetes and the normoglycemic control group. Knee extensor strength was approximately $8 \%$ lower in the older diabetes patients when compared with their age-matched controls (Figure 1A). These findings are comparable to observations from Park et al (2) and Andersen et al (31) who observed a lower knee extension strength in the patients with type 2 diabetes ranging between $4 \%$ and $7 \%$ compared to subjects without diabetes. In contrast with leg extension strength, no differences were observed in leg press strength between diabetic and healthy elderly. This is likely explained by the open-chain nature of the leg extension exercise which may be more difficult to perform than the closed-chain movement in the leg press exercise and, as such, is affected to a larger extent by neuropathic alterations associated with diabetes. Given the isolated nature of the leg extension exercise (purely quadriceps activation), compensation by more proximal muscles is impossible. In contrast, lower quadriceps strength may be partly compensated for by increased hip extensor force production in the leg press exercise. A similar finding has previously been observed in elderly versus young individuals during gait analyses (32).

As muscle strength is an important factor determining the level of functional (dis)ability in the elderly population (33-35), we also assessed whether differences in muscle mass and/or strength would translate to differences in functional capacity between both groups. In accordance with the decline in leg extension, we also report substantial longer sit-to-stand times in the older patients with type 2 diabetes when compared with the normoglycemic controls $(9.1 \pm 0.4$ vs $7.8 \pm 0.3 \mathrm{~s}$, respectively; $P<$ 0.005). In addition of previous work in this area (2), we show that handgrip strength was approximately $13 \%$ lower in the elderly individuals with diabetes when compared with the normoglycemic controls $(P<0.001)$. Clearly, our data confirm our hypothesis that leg lean mass, ASM, muscle strength and functional capacity are diminished in older patients with type 2 diabetes when compared with age-matched normoglycemic controls. In addition, we observed a substantial difference in absolute values for reaction time, though this difference did not reach statistical significance $(P=0.20)$. It could be speculated that other neural changes take place in the diabetic group, but we were not able to pick up differences in reaction time task performance between groups. 
Further research is necessary to determine to what extent cognitive deterioration is related to functional changes in elderly patients with type 2 diabetes.

As the loss of muscle mass and strength with aging is generally attributed to a type II muscle fiber type specific atrophy in senescent muscle (22), we also collected muscle biopsy samples to assess potential differences in type I and type II muscle fiber size in senescent muscle in patients with type 2 diabetes and healthy controls. In agreement with previous work, we observed a smaller type II versus type I muscle fiber size in these older populations ( $5721 \pm 166$ vs $4999 \pm 131 \mu \mathrm{m}^{2}$, for the type I vs II muscle fiber size, respectively: $P<0.001)$. No differences were observed in muscle fiber size and percentage of fiber type between groups. As such, we were unable to detect any differences at the myocellular level that could be directly related to the observed differences in muscle mass and strength associated with diabetes. It appears that the level of type II muscle fiber atrophy is not further increased in the older type diabetic patient and, as such, does not seem to contribute to the greater loss of leg lean mass, muscle strength and functional capacity in the older type 2 diabetes patients.

Leg lean mass, appendicular skeletal muscle mass, muscle strength and functional capacity were lower in patients with type 2 diabetes when compared with normoglycemic controls. Interestingly, we observed significant correlations between the levels of glycemic control ( $\mathrm{HbA} 1 \mathrm{c}$ content) and functional capacity (handgrip strength $r=$ $0.32, P<0.01$; sit-to-stand time $r=0.24, P<0.05)$. In other words, these data seem to suggest that patients with less well-controlled type 2 diabetes have more problems with maintaining functional capacity. Clearly, these data also imply that the lower muscle strength and reduced functional capacity in the older patients with type 2 diabetes are, at least partly, attributed to the status of the disease. In agreement, the loss of muscle strength and function ( $10 \%)$ was relatively large when compared with the reduction in lean mass ( $3 \%)$, which may indicate that some level of diabetic polyneuropathy may already impair the capacity to generate strength and/or power. Of course, it has been well established that diabetic neuropathy results in impaired mobility and loss of muscle strength (36). Earlier studies have reported an increased muscle weakness in lower extremities in patients with diabetes with $(31,37)$ or without severe polyneuropathy $(38,39)$. Although the selected subjects had no clinical signs of neuropathy, we speculate that some minor level of neuromuscular dysfunction due to glycosylation may already result in a greater loss of muscle strength and functional capacity in the older patients with type 2 diabetes. Disturbances in glucose metabolism induce the generation of advanced glycation end products (AGE), and increases exposure to reactive oxygen species (ROS) in almost any organ system (40-42). The chronic exposure to AGE and ROS plays an important role in the development of neuropathy and neuromuscular dysfunction (43). The latter underlines the requirement to screen early for an age-related decline in muscle mass, strength, and function, as the older patient with diabetes will likely encounter major limitations in physical function at a much earlier stage in life when compared with normoglycemic counterparts. 
In the present study, we determined body composition, muscle strength, functional capacity, reaction time performance, and muscle fiber characteristics in 32 healthy elderly patients and 60 elderly patients with type 2 diabetes. Although only a limited number of subjects participated in the current study, we were still able to detect significant and clinically relevant differences between groups. This is likely explained by performing all testing in a highly standardized manner, using well-established, reliable, and valid techniques, which is of major importance when the number of subjects that can be included is limited. The rapid loss of muscle mass, strength, and functional capacity with aging impairs functional capacity and increases the risk of developing chronic metabolic diseases, and reduces quality of life. The present study clearly shows that the older patients with type 2 diabetes are even more at risk of skeletal muscle loss than their normoglycemic counterparts. Therefore, effective interventional strategies to counteract the loss of muscle mass and strength are of even greater relevance in the older diabetic population and, as such, should be implemented at an earlier stage. As older patients type 2 diabetes experience greater impairments in leg lean mass, muscle strength, and functional capacity, it is evident that generic exercise, nutritional and/or pharmacological intervention programs designed to prevent and/or treat sarcopenia should be tailored for the elderly patients with type 2 diabetes.

In conclusion, older patients with type 2 diabetes show an accelerated decline in leg lean mass, muscle strength, and functional capacity when compared with normoglycemic controls. It is evident that resistance type exercise intervention programs designed to prevent and/or treat sarcopenia should be tailored for elderly type 2 diabetes patients. 


\section{References}

1. Evans W: Functional and metabolic consequences of sarcopenia. J Nutr 1997, 127(5 Suppl):998S-1003S.

2. Park SW, Goodpaster BH, Strotmeyer ES, de Rekeneire N, Harris TB, Schwartz AV, Tylavsky FA, Newman $A B$ : Decreased muscle strength and quality in older adults with type 2 diabetes: the health, aging, and body composition study. Diabetes 2006, 55(6):1813-1818.

3. Park SW, Goodpaster BH, Lee JS, Kuller LH, Boudreau R, de Rekeneire N, Harris TB, Kritchevsky S, Tylavsky FA, Nevitt $\mathrm{M}$ et al: Excessive loss of skeletal muscle mass in older adults with type 2 diabetes. Diabetes Care 2009, 32(11):1993-1997.

4. Guillet C, Boirie Y: Insulin resistance: a contributing factor to age-related muscle mass loss? Diabetes Metab 2005, 31 Spec No 2:5S20-25S26.

5. Pereira S, Marliss EB, Morais JA, Chevalier S, Gougeon R: Insulin resistance of protein metabolism in type 2 diabetes. Diabetes 2008, 57(1):56-63.

6. Larsson L, Grimby G, Karlsson J: Muscle strength and speed of movement in relation to age and muscle morphology. J Appl Physiol 1979, 46(3):451-456.

7. Lindle RS, Metter EJ, Lynch NA, Fleg JL, Fozard JL, Tobin J, Roy TA, Hurley BF: Age and gender comparisons of muscle strength in 654 women and men aged 20-93 yr. J Appl Physiol 1997, 83(5):1581-1587.

8. Park SW, Goodpaster BH, Strotmeyer ES, Kuller LH, Broudeau R, Kammerer C, de Rekeneire N, Harris TB, Schwartz AV, Tylavsky FA et al: Accelerated loss of skeletal muscle strength in older adults with type 2 diabetes: the health, aging, and body composition study. Diabetes Care 2007, 30(6):1507-1512.

9. Clark BC, Manini TM: What is dynapenia? Nutrition 2012, 28(5):495-503.

10. Delmonico MJ, Harris TB, Visser M, Park SW, Conroy MB, Velasquez-Mieyer P, Boudreau R, Manini TM, Nevitt $M$, Newman $A B$ et al: Longitudinal study of muscle strength, quality, and adipose tissue infiltration. Am J Clin Nutr 2009, 90(6):1579-1585.

11. Clark BC, Manini TM: Functional consequences of sarcopenia and dynapenia in the elderly. Curr Opin Clin Nutr Metab Care 2010, 13(3):271-276.

12. de Groot PC, Borghouts LB, Adam JJ, Keizer HA: Diminished performance on response-selection tasks in Type 2 diabetes. Percept Mot Skills 2003, 96(1):257-266.

13. Cosway R, Strachan MW, Dougall A, Frier BM, Deary IJ: Cognitive function and information processing in type 2 diabetes. Diabet Med 2001, 18(10):803-810.

14. Awad N, Gagnon M, Messier C: The relationship between impaired glucose tolerance, type 2 diabetes, and cognitive function. J Clin Exp Neuropsychol 2004, 26(8):1044-1080.

15. Dobretsov M, Romanovsky D, Stimers JR: Early diabetic neuropathy: triggers and mechanisms. World J Gastroenterol 2007, 13(2):175-191.

16. Sinclair A, Morley JE, Rodriguez-Manas L, Paolisso G, Bayer T, Zeyfang A, Bourdel-Marchasson I, Vischer U, Woo J, Chapman I et al: Diabetes Mellitus in Older People: Position Statement on behalf of the International Association of Gerontology and Geriatrics (IAGG), the European Diabetes Working Party for Older People (EDWPOP), and the International Task Force of Experts in Diabetes. J Am Med Dir Assoc 2012, 13(6):497-502.

17. Ainsworth BE, Haskell WL, Whitt MC, Irwin ML, Swartz AM, Strath SJ, O'Brien WL, Bassett DR, Jr., Schmitz KH, Emplaincourt PO et al: Compendium of physical activities: an update of activity codes and MET intensities. Med Sci Sports Exerc 2000, 32(9 Suppl):S498-504.

18. Zhang X, Geiss LS, Caspersen CJ, Cheng YJ, Engelgau MM, Johnson JA, Plotnikoff RC, Gregg EW: Physical activity levels and differences in the prevalence of diabetes between the United States and Canada. Prev Med 2010, 50(5-6):241-245.

19. Baumgartner RN, Stauber PM, McHugh D, Koehler KM, Garry PJ: Cross-sectional age differences in body composition in persons 60+ years of age. J Gerontol A Biol Sci Med Sci 1995, 50(6):M307-316.

20. Jones PR, Pearson J: Anthropometric determination of leg fat and muscle plus bone volumes in young male and female adults. J Physiol 1969, 204(2):63P-66P.

21. Mayhew JL, Prinster JL, Ware JS, Zimmer DL, Arabas JR, Bemben MG: Muscular endurance repetitions to predict bench press strength in men of different training levels. J Sports Med Phys Fitness 1995, 35(2):108-113. 
22. Verdijk LB, Koopman R, Schaart G, Meijer K, Savelberg HH, van Loon L: Satellite cell content is specifically reduced in type II skeletal muscle fibers in the elderly. Am J Physiol Endocrinol Metab 2007, 292(1):E151-157.

23. Verdijk LB, van Loon L, Meijer K, Savelberg HH: One-repetition maximum strength test represents a valid means to assess leg strength in vivo in humans. J Sports Sci 2009, 27(1):59-68.

24. Guralnik JM, Simonsick EM, Ferrucci L, Glynn RJ, Berkman LF, Blazer DG, Scherr PA, Wallace RB: A short physical performance battery assessing lower extremity function: association with self-reported disability and prediction of mortality and nursing home admission. J Gerontol 1994, 49(2):M85-94.

25. Cappola AR, Bandeen-Roche K, Wand GS, Volpato S, Fried LP: Association of IGF-I levels with muscle strength and mobility in older women. J Clin Endocrinol Metab 2001, 86(9):4139-4146.

26. Adam JJ, Hommel B, Umilta C: Preparing for perception and action (I): the role of grouping in the response-cuing paradigm. Cogn Psychol 2003, 46(3):302-358.

27. Bergstrom J: Percutaneous needle biopsy of skeletal muscle in physiological and clinical research. Scand J Clin Lab Invest 1975, 35(7):609-616.

28. Verdijk LB, Jonkers RA, Gleeson BG, Beelen M, Meijer K, Savelberg HH, Wodzig WK, Dendale P, van Loon LJ: Protein supplementation before and after exercise does not further augment skeletal muscle hypertrophy after resistance training in elderly men. Am J Clin Nutr 2009, 89(2):608-616.

29. Guillet C, Prod'homme M, Balage M, Gachon P, Giraudet C, Morin L, Grizard J, Boirie Y: Impaired anabolic response of muscle protein synthesis is associated with $\mathrm{S} 6 \mathrm{~K} 1$ dysregulation in elderly humans. FASEB J 2004:03-1341fje.

30. Kumar V, Selby A, Rankin D, Patel R, Atherton P, Hildebrandt W, Williams J, Smith K, Seynnes O, Hiscock $\mathrm{N}$ et al: Age-related differences in the dose-response relationship of muscle protein synthesis to resistance exercise in young and old men. J Physiol 2009, 587(Pt 1):211-217.

31. Andersen H, Nielsen S, Mogensen CE, Jakobsen J: Muscle strength in type 2 diabetes. Diabetes 2004, 53(6):1543-1548.

32. Savelberg HH, Verdijk LB, Willems PJ, Meijer K: The robustness of age-related gait adaptations: can running counterbalance the consequences of ageing? Gait Posture 2007, 25(2):259-266.

33. Rantanen T, Guralnik JM, Foley D, Masaki K, Leveille S, Curb JD, White L: Midlife hand grip strength as a predictor of old age disability. JAMA 1999, 281(6):558-560.

34. Rantanen T, Avlund K, Suominen H, Schroll M, Frandin K, Pertti E: Muscle strength as a predictor of onset of ADL dependence in people aged 75 years. Aging Clin Exp Res 2002, 14(3 Suppl):10-15.

35. Visser M, Goodpaster BH, Kritchevsky SB, Newman AB, Nevitt M, Rubin SM, Simonsick EM, Harris TB: Muscle mass, muscle strength, and muscle fat infiltration as predictors of incident mobility limitations in well-functioning older persons. J Gerontol A Biol Sci Med Sci 2005, 60(3):324-333.

36. van Schie $\mathrm{CH}$ : Neuropathy: mobility and quality of life. Diabetes Metab Res Rev 2008, 24 Suppl 1:S45-51.

37. Andersen $\mathrm{H}$, Poulsen $\mathrm{PL}$, Mogensen $\mathrm{CE}$, Jakobsen J: Isokinetic muscle strength in long-term IDDM patients in relation to diabetic complications. Diabetes 1996, 45(4):440-445.

38. IJzerman TH, Schaper NC, Melai T, Meijer K, Willems PJ, Savelberg HH: Lower extremity muscle strength is reduced in people with type 2 diabetes, with and without polyneuropathy, and is associated with impaired mobility and reduced quality of life. Diabetes Res Clin Pract 2011, 95(3):345-351.

39. Andreassen CS, Jakobsen J, Ringgaard S, Ejskjaer N, Andersen H: Accelerated atrophy of lower leg and foot muscles--a follow-up study of long-term diabetic polyneuropathy using magnetic resonance imaging (MRI). Diabetologia 2009, 52(6):1182-1191.

40. Schalkwijk CG, Lieuw-a-Fa M, van Hinsbergh VW, Stehouwer CD: Pathophysiological role of Amadoriglycated proteins in diabetic microangiopathy. Semin Vasc Med 2002, 2(2):191-197.

41. Goldin A, Beckman JA, Schmidt AM, Creager MA: Advanced glycation end products: sparking the development of diabetic vascular injury. Circulation 2006, 114(6):597-605.

42. Brownlee M: Biochemistry and molecular cell biology of diabetic complications. Nature 2001, 414(6865):813-820.

43. Wada R, Yagihashi S: Role of advanced glycation end products and their receptors in development of diabetic neuropathy. Ann N Y Acad Sci 2005, 1043:598-604. 

CHAPTER 5

\section{Protein supplementation during resistance type exercise training in the elderly}

Marika Leenders

Lex B Verdijk Letty van der Hoeven Janneau van Kranenburg Rachel Nilwik Will KWH Wodzig Joan MG Senden

Hans A Keizer Luc JC van Loon 


\section{Abstract}

Introduction: Resistance training has been well established as an effective treatment strategy to increase skeletal muscle mass and strength in the elderly.

We assessed whether dietary protein supplementation can further augment the adaptive response to prolonged resistance type exercise training in healthy elderly men and women.

Methods: Healthy, elderly men $(n=31: 70 \pm 1 \mathrm{y})$ and women $(n=29: 70 \pm 1 \mathrm{y})$ were randomly assigned to a progressive, 24-wk resistance type exercise training program with or without additional protein supplementation (15 g/d). Muscle hypertrophy was assessed on a whole-body (DXA), limb (computed tomography), and muscle fiber (biopsy) level. Strength was assessed regularly by 1-repetition maximum (1RM) strength testing. Functional capacity was assessed with a sit-to-stand and handgrip test.

Results: 1 RM strength increased by $45 \pm 6$ vs $40 \pm 3 \%$ (women) and $41 \pm 4$ vs $44 \pm$ $3 \%$ (men) in the placebo vs protein group, respectively $(P<0.001)$, with no differences between groups. Leg muscle mass (women: $4 \pm 1$ vs $3 \pm 1 \%$, men: $3 \pm 1$ vs $3 \pm 1 \%$ ) and quadriceps cross-sectional area (women: $9 \pm 1$ vs $9 \pm 1 \%$, men: $9 \pm 1$ vs $10 \pm 1 \%$ ) increased similarly in the placebo versus protein groups $(P<0.001)$. Type II muscle fiber size increased over time in both placebo and protein groups ( $25 \pm 13$ vs $30 \pm 9$ and $23 \pm$ 12 vs $22 \pm 10 \%$ in the women and men, respectively). Sit-to-stand improved by $18 \pm 2$ and $19 \pm 2 \%$ in women and men, respectively $(P<0.001)$.

Conclusion: Prolonged resistance type exercise training increases skeletal muscle mass and strength, augments functional capacity, improves glycemia and lipidemia, and reduces blood pressure in healthy elderly men and women. Additional protein supplementation $(15 \mathrm{~g} / \mathrm{d})$ does not further increase muscle mass, strength, and/or functional capacity. 


\section{Introduction}

Aging is associated with a progressive loss of skeletal muscle mass and strength. This process is referred to as sarcopenia and ultimately results in the loss of functional capacity and an increased risk of developing chronic metabolic diseases (1). The age related loss of muscle mass is facilitated by a combination of factors, including a less than optimal diet and a sedentary lifestyle. Resistance type exercise training has been well-established as an effective treatment strategy to counteract the loss of skeletal muscle mass and strength in the elderly (2-4). Because of the efficacy of resistance type exercise training to increase muscle mass and function up to a very old age $(5,6)$, many attempts have been undertaken to further augment the clinical benefits of exercise training.

Dietary protein intake forms an important requirement for muscle mass maintenance. A direct relationship between dietary protein intake and the loss of muscle mass with aging has been reported previously (7). Because dietary protein intake is a prerequisite to allow net muscle protein accretion after resistance type exercise (8), it has been suggested that dietary protein supplementation can further augment the increase in muscle mass and strength during prolonged resistance type exercise training. In agreement, dietary protein supplementation has been shown to increase muscle mass gains during more prolonged resistance type exercise training in healthy young adults $(9,10)$. In contrast, studies in the elderly do not seem to confirm the proposed benefits of dietary protein supplementation $(6,11,12)$. The apparent discrepancy between studies in the young versus elderly populations might be attributed to the reduced sensitivity of the muscle protein synthetic machinery to protein ingestion in the elderly when compared with the young $(13,14)$. In this light, it has been suggested that approximately $25 \mathrm{~g}$ of protein should be ingested with each main meal to maximally stimulate muscle protein synthesis in the elderly (15). Interestingly, we recently reported that habitual protein intake in elderly subjects is particularly low at breakfast, providing only approximately $10 \mathrm{~g}$ of protein (16). Therefore, the present study was specifically designed to increase daily protein intake at breakfast with an additional $15 \mathrm{~g}$, allowing ingestion of approximately $25 \mathrm{~g}$ of protein with each main meal. So far most intervention studies have applied relative short intervention periods lasting between 6 to 12 weeks. We speculate that a more prolonged resistance type exercise training duration is required to allow the additional benefits of protein supplementation to become evident in an elderly population.

We hypothesize that dietary protein supplementation at breakfast during prolonged resistance type exercise training will further augment the increase in muscle mass and strength in healthy elderly men and women. Therefore, we subjected a large group ( $n=60$ ) of healthy elderly men and women $(70 \pm 1$ y) to 6 months of resistance type exercise training ( 3 session per week) during which they were supplemented with dairy protein $(15 \mathrm{~g} / \mathrm{d})$ or a placebo. Before and after 3 and 6 months we determined 
muscle mass on a whole body, limb, and muscle fiber level and assessed muscle strength and functional capacity.

\section{Methods}

\section{Subjects}

A total of 29 healthy elderly women ( $70 \pm 1 \mathrm{y}$ ) and 31 healthy elderly men (70 $\pm 1 \mathrm{y}$ ) volunteered to participate in a $24 \mathrm{wk}$ resistance type exercise intervention program, with or without additional protein supplementation. Seven subjects dropped out (2 men and 5 women) during the study, one because of a heart attack that occurred at home, one because of a transient ischemic attack that occurred at home, and the other 5 subjects dropped out because they underestimated the time required to participate. Medical history of all subjects was evaluated, and an oral glucose tolerance test and resting and exercise ECG were performed before inclusion. Exclusion criteria that would preclude successful participation in the exercise program were defined, and these included (silent) cardiac or peripheral vascular disease and orthopedic limitations. Furthermore, because insulin resistance and/or type 2 diabetes have been associated with a more progressive loss of muscle mass and strength with aging (17), type 2 diabetes patients were excluded from participation based on the oral glucose tolerance test data (18). All subjects were living independently and were recreationally active (i.e., walking/cycling). None of the participants had a history of participating in any structured exercise training program designed to improve performance over the past 5 years. All subjects were informed on the nature and possible risks of the experimental procedures, before their written informed consent was obtained. This study was approved by the Medical Ethics Committee of the Maastricht University Medical Centre ${ }^{+}$.

\section{Study design}

After inclusion in this study, subjects were randomly allocated to either the protein (PRO) or the placebo (PLA) supplemented group. Before, during, and after exercise intervention, anthropometric measurements (height, body mass, waist-hip ratio, and leg volume (19)), strength assessment (1-repetition maximum), computed tomography (CT) and Dual-energy X-ray absorptiometry (DXA) scans were performed, and muscle biopsies, blood samples, 24-h urine, and dietary intake and physical activity records were collected. 


\section{Exercise intervention program}

Supervised resistance type exercise training was performed 3 times a week for a 24-wk period. Training consisted of a 5-min warm-up on a cycle ergometer, followed by 4 sets on both the leg press and leg extension machines (Technogym, Rotterdam, Netherlands) and 3 sets on the chest press and horizontal row; these four exercises were performed every training session. The vertical lat pull and abdominals were alternated with biceps curl and triceps extension between subsequent training sessions. Each session ended with a 5 min cooling-down period on the cycle ergometer. During the first 4 wk of training, the workload was increased from $60 \%$ of 1 RM (10-15 repetitions in each set) to $75 \%$ of 1 RM (8-10 repetitions). Starting at week 5,4 sets of 8 repetitions were performed at $75-80 \%$ of $1 \mathrm{RM}$ on leg press and leg extension. For the upper body exercises, 2 sets were increased to 3 sets starting in week 5 . Resting periods of 1.5 and $3 \mathrm{~min}$ were allowed between sets and exercises, respectively. Workload intensity was adjusted based on the 1 RM tests (performed at wk 4, 8, 12, 16 and 20). In addition, workload was increased when more than 8 repetitions could be performed in 3 out of 4 sets. On average, subjects attended $90 \pm 1 \%$ of the scheduled exercise sessions, with no differences between groups.

\section{Dietary protein supplementation}

Throughout the 24-wk intervention period, subjects consumed a $250 \mathrm{~mL}$ package containing either a placebo (placebo group, PLA) or protein drink (protein group, PRO) daily after breakfast. The protein beverages contained $15 \mathrm{~g}$ protein (milk protein concentrate (MPC80) DMV international, Delhi, NY, USA), $0.5 \mathrm{~g}$ fat, $7.13 \mathrm{~g}$ lactose and 0.42 g calcium, providing of a total of $389 \mathrm{~kJ}$. The milk protein consisted of $80 \%$ of casein and $20 \%$ of whey protein. The placebo beverages contained no protein or fat, only 7.13 $\mathrm{g}$ lactose and $0.42 \mathrm{~g}$ calcium, providing a total of $119 \mathrm{~kJ}$. Placebo and protein drinks were provided in a randomized, double blind manner.

\section{Dietary intake and physical activity standardization}

Standardized meals were provided to all subjects the evening before each test day. The subjects were instructed to refrain from strenuous physical activity for at least $3 \mathrm{~d}$ before testing. On all test days, subjects arrived at the laboratory by car or public transportation after an overnight fast. Subjects were encouraged to maintain their habitual dietary intake and physical activity pattern throughout the intervention program. To assess potential changes in habitual daily food intake and physical activity during the 6 month intervention period, the subjects recorded $4 \mathrm{~d}$ weighted dietary intake records and $2 \mathrm{~d}$ physical activity records. Dietary intake was recorded before and after $4,8,12,16,20$, and 24 wk of intervention. Dietary records were analyzed 
with Komeet (Komeet, 4.059 BaS Nutrition Software, Arnhem, the Netherlands). Supplements were not included in the dietary intake analysis. Habitual physical activity was recorded before and after 12 and 24 wk of intervention. For every type of activity, a MET score was assigned as previously defined (20). Energy expenditure is reported as mean MET-h/d (21).

\section{Body composition}

Body composition and bone mineral content were measured using DXA (Hologic, Discovery A, QDR Series, Bradford, MA, USA). Whole-body and regional lean mass, fat mass, and bone mineral content were determined by using the system's software package Apex (version 2.3 Wind River, Alameda, CA). Anthropometrics data were assessed using standardized procedures; bodyweight by digital scale to within 100 g; height by stadiometer to within $0.5 \mathrm{~cm}$; and circumferences to within $1 \mathrm{~mm}$ using a measuring tape, with waist mid-way between the lowest rib and the iliac crest with the subject standing at the end of gentle expiration, and hips at the greater trochanters (16).

Anatomical cross-sectional area (CSA) of the quadriceps muscle was assessed by CT scanning (Philips Brilliance 64, Philips Medical Systems, Best, The Netherlands) before and after 12 and 24 wk of intervention ( $3 \mathrm{~d}$ after strength assessment and before muscle biopsy collection). The scanning characteristics were as follows: $120 \mathrm{kV}, 300 \mathrm{~mA}$, rotation time of $0.75 \mathrm{~s}$, and a field of view of $500 \mathrm{~mm}$. Although the subjects were lying supine, legs extended and their feet secured, a $3 \mathrm{~mm}$ thick axial image was taken 15 $\mathrm{cm}$ proximal to the base of the patella. The exact scanning position was measured and marked for replication at subsequent visits. Muscle area of the right leg was selected between 0 and 100 Hounsfield units (22), after which the quadriceps muscle was selected by manual tracing using ImageJ software (version $1.45 \mathrm{~d}$, National Institute of Health, Bethesda, MD) (23). Using the described approach, we determined the coefficient of variation for repeated scans ( $1 \mathrm{wk}$ apart) to be $0.8 \%$. All analyses were performed by 2 investigators blinded to subject coding; intraclass correlation coefficients for inter- and intra- investigator reliability were 1.000 and 0.997 , respectively.

\section{Muscle biopsy sampling}

Three days prior to the onset of the intervention and after 12 and 24 wk of intervention ( $4 \mathrm{~d}$ after final strength testing), muscle biopsies were taken from the right leg of each subject, in the morning after an overnight fast. After local anesthesia was induced, percutaneous needle biopsy samples (50-80 mg) were collected from the vastus lateralis muscle, approximately $15 \mathrm{~cm}$ above the patella (24). Any visible nonmuscle tissue was removed immediately, and biopsy samples were embedded in Tissue-Tek (Sakura Finetek, Zoeterwoude, The Netherlands), frozen in liquid nitrogencooled isopentane, and stored at $-80^{\circ} \mathrm{C}$ until further analyses. 


\section{Immunohistochemistry}

From all biopsies, $5 \mu \mathrm{m}$ thick cryosections were cut at $-20^{\circ} \mathrm{C}$. Samples collected before and after 12 and $24 \mathrm{wk}$ of intervention from each subject were mounted together on uncoated glass slides. Muscle biopsies were stained for muscle fiber typing as described in detail previously (12). In short, the slides were incubated with primary antibodies against MHC-I (A4.840, Developmental Studies Hybridoma Bank, lowa City, IA) and laminin (polyclonal laminin, Sigma, Zwijndrecht, the Netherlands). After washing, appropriate secondary antibodies were applied (goat anti-mouse IgM AlexaFluor555 and goat anti-rabbit IgG AlexaFluor647, respectively; Molecular Probes, Invitrogen, Breda, the Netherlands). Images were visualized and automatically captured at 10x magnification with a fluorescent microscope equipped with an automatic stage (IX81 motorized inverted microscope, Olympus, Hamburg, Germany). Muscle fiber type (fiber\%), and fiber CSA were measured for each separate muscle fiber. As such, mean muscle fiber size was calculated for the type I and type II muscle fibers separately. As a measure of fiber circularity, form factors were calculated by using the following formula: $(4 \pi \cdot \mathrm{CSA}) /(\text { perimeter })^{2}$. All image recordings and analyses were performed by an investigator blinded to subject coding. No differences in fiber circularity were observed over time or between groups. Mean numbers of $442 \pm 24,403 \pm 21$, and $425 \pm 20$ muscle fibers were analyzed in the biopsy samples collected prior to and after 12 and 24 wk of intervention, respectively.

\section{Strength assessment}

Maximum strength was assessed by 1RM strength tests on leg press and leg extension machines (Technogym, Rotterdam, The Netherlands). During a familiarization trial, proper lifting technique was demonstrated and practiced and maximum strength was estimated using the multiple repetitions testing procedure (25). In an additional session, at least one week before muscle biopsy collection, each subject's 1RM was determined as described previously (26). 1RM testing is preferred to evaluate changes in muscle strength during resistance type exercise training (27). Therefore, 1RM tests were repeated after $4,8,12,16$ and 20 wk of intervention and 2 days after the last training session of the intervention program.

\section{Physical performance measures}

To assess lower and upper extremity physical performance, a sit-to-stand test and a hand grip test were performed before and after 12 and 24 wk of intervention. For the sit-to-stand test, the participants were instructed to fold their arms across their chest and to stand up/sit down 5 times, as fast as possible, from a seat at $0.42 \mathrm{~m}$ from the floor. Time was recorded from the initial sitting to the final standing position. The fast- 
est out of 2 attempts was used for analysis (28). Data on maximal grip strength were obtained using a JAMAR handheld dynamometer (model BK-7498, Fred Sammons, Inc., Burr Ridge, IL, USA). Grip strength was measured 3 times with each hand. The highest value in the stronger hand was reported (29).

\section{Blood samples}

Before and after 12 and 24 wk of intervention, fasting blood samples were collected to determine basal plasma glucose and insulin concentrations, lipid profiles, serum creatinine, and blood glycated hemoglobin (HbA1c) content. Blood $(10 \mathrm{~mL})$ was collected into EDTA-containing tubes and serum tubes. EDTA tubes were immediately centrifuged at $1000 \mathrm{~g}$ for $10 \mathrm{~min}$ at $4^{\circ} \mathrm{C}$ and the serum tubes were centrifuged at $1000 \mathrm{~g}$ for $15 \mathrm{~min}$ at $21^{\circ} \mathrm{C}$ after allowing the blood to clot for $90 \mathrm{~min}$ at $21^{\circ} \mathrm{C}$. Aliquots of plasma and serum were immediately frozen in liquid nitrogen and stored at $-80^{\circ} \mathrm{C}$ until further analysis. Plasma insulin concentrations were determined by using an Insulin RIA Kit (LINCO Research Inc, St Charles, MO). Plasma glucose, triglycerides, total cholesterol and HDL cholesterol were analyzed with a COBAS FARA analyzer (Uni Kit III; Roche, Basel, Switzerland) with test kits from ABX Diagnostics (Montpellier, France). Plasma free fatty acid concentrations were analyzed with the NEFA C test kit from Wako Chemicals (Neuss, Germany). As plasma triacylglycerol concentrations were below 4.5 $\mathrm{mmol} / \mathrm{L}$, plasma LDL cholesterol could be calculated by LDL cholesterol=total cholesterol - HDL cholesterol - triacylglycerol/2.2 (in $\mathrm{mmol} / \mathrm{L}$ ). Serum creatinine concentrations were determined using the Jaffe rate method on a Synchron LX Systems analyzer (Beckmann Coulter Inc., Fullerton, CA). To determine blood HbA1c content, $3 \mathrm{~mL}$ blood was collected in EDTA containing tubes and analyzed by high-performance liquid chromatography (Bio-Rad Variant II 4, Munich, Germany).

\section{4 h urine collection}

To determine urinary nitrogen and creatinine excretion, $24 \mathrm{~h}$ urine was collected over the last day of the 4-d dietary intake assessment. Urine was collected from the second voiding on day 4 until the first voiding on the day after. Nitrogen content was analyzed with an elemental analyzer (model CHN-ORAPID, Heraeus Co, Hanau, Germany). Total nitrogen excretion was calculated from total urinary nitrogen excretion and an estimated $0.031 \mathrm{~g} / \mathrm{kg}$ body mass for miscellaneous nitrogen loss (30). Nitrogen balance was calculated as the difference between nitrogen intake [protein intake (g)/6.25] and total nitrogen excretion before and after 4,12 , and 24 wk of intervention. Urinary creatinine excretion was measured as described previously. As a measure of renal function, creatinine clearance was calculated from urinary excretion and its serum concentration and corrected for body surface area, yielding the amount of blood (in $\mathrm{mL}$ ) that was cleared from creatinine per min per $1.73 \mathrm{~m}^{2}$ of total body surface area (31). 


\section{Statistics}

Data are expressed as means \pm SEM. Based on a Type I error probability of 0.05 , a power of $80 \%$, and a drop-out rate of $20 \%$, a total of 60 subjects was included in the present study to detect relevant differences in the primary outcome parameters: lean mass determined by DXA and quadriceps CSA determined by CT scan. For various reasons (not related to the study), seven subjects (12\%) dropped out during the first month of the study. Because no follow-up measurements could be performed for these subjects, they were excluded from the analysis. Baseline characteristics between groups were compared using an independent samples t-test. Pre- vs 12 wk vs postintervention data were analyzed using repeated-measures ANOVA with time as withinsubjects factor and gender and treatment as between-subjects factor. In case of significant main effects or interactions, post hoc testing with Bonferroni correction and/or separate analyses within groups were performed where appropriate. Significance was set at $P<0.05$. All calculations were performed using SPSS version 17.0 (Chicago, IL).

\section{Results}

\section{Subjects}

Subjects' characteristics are provided in Table 1. In total, 53 subjects completed the intervention program: 27 subjects in the protein group (12 women and 15 men) and 26 subjects in the placebo group (12 women and 14 men). Within gender subgroups, no differences were observed in baseline variables between PLA and PRO. No significant changes over time were observed for weight, height, waist-hip ratio and body mass index. Systolic blood pressure significantly decreased between 12 and 24 wk of intervention in both the PLA and PRO group (women: from $133 \pm 3$ to $131 \pm 5$ and $143 \pm 5$ to $136 \pm 7 \mathrm{mmHg}$, respectively; men: from $142 \pm 3$ to $133 \pm 3$ and $139 \pm 4$ to $134 \pm 3$ $\mathrm{mmHg}$, respectively; $P<0.001)$, with no differences between groups. Diastolic blood pressure decreased between 12 and 24 wk of intervention in both groups $(P<0.001)$. 
Table 1: Subjects' characteristics

\begin{tabular}{|c|c|c|c|c|}
\hline & \multicolumn{2}{|c|}{ Women } & \multicolumn{2}{|c|}{ Men } \\
\hline & Placebo $(n=12)$ & Protein $(n=12)$ & Placebo $(n=14)$ & Protein $(n=15)$ \\
\hline Age (y) & $69 \pm 1$ & $72 \pm 2$ & $70 \pm 1$ & $70 \pm 1$ \\
\hline Body weight (kg) & $67.9 \pm 1.8$ & $63.3 \pm 2.5$ & $84.3 \pm 2.4$ & $84.0 \pm 2.3$ \\
\hline Height (m) & $1.65 \pm 0.02$ & $1.62 \pm 0.02$ & $1.78 \pm 0.02$ & $1.76 \pm 0.01$ \\
\hline Waist-Hip Ratio & $0.88 \pm 0.01$ & $0.88 \pm 0.02$ & $0.98 \pm 0.01$ & $0.98 \pm 0.01$ \\
\hline $\mathrm{BMI}\left(\mathrm{kg} / \mathrm{m}^{2}\right)$ & $25.0 \pm 0.4$ & $24.2 \pm 0.7$ & $26.7 \pm 0.6$ & $27.2 \pm 0.7$ \\
\hline Basal plasma glucose (mmol/L) & $5.4 \pm 0.1$ & $5.5 \pm 0.1$ & $5.6 \pm 0.1$ & $5.6 \pm 0.1$ \\
\hline HbA1c (\%) & $5.8 \pm 0.1$ & $5.8 \pm 0.1$ & $5.5 \pm 0.1$ & $5.5 \pm 0.1$ \\
\hline Lean Mass (kg) & $43.3 \pm 1.2$ & $41.7 \pm 1.5$ & $62.4 \pm 1.5$ & $61.5 \pm 1.3$ \\
\hline Fat (\%) & $33 \pm 1$ & $31 \pm 1$ & $22 \pm 1$ & $23 \pm 1$ \\
\hline Systolic blood pressure (mmHg) & $133 \pm 4$ & $141 \pm 7$ & $140 \pm 4$ & $146 \pm 4$ \\
\hline Diastolic blood pressure (mmHg) & $73 \pm 3$ & $76 \pm 3$ & $74 \pm 3$ & $77 \pm 3$ \\
\hline
\end{tabular}

No differences between the protein and placebo group. All values represent means \pm SEM.

BMI, Body mass index; HbA1c: blood glycosylated hemoglobin.

\section{Body composition}

At baseline, no significant differences were observed between the PLA and PRO group for any of the DXA measurements. Whole-body lean mass increased throughout the intervention period in the women, from $43.3 \pm 1.2$ to $44.4 \pm 1.3$ and $41.7 \pm 1.5$ to 43.0 $\pm 1.5 \mathrm{~kg}$ in the PLA and the PRO group, respectively $(P<0.001)$. A similar increase was observed for the men, from $62.4 \pm 1.5$ to $63.4 \pm 1.6$ and $61.5 \pm 1.3$ to $62.9 \pm 1.5 \mathrm{~kg}$, respectively $(P<0.001)$. Leg lean mass had increased by $3 \pm 1 \%$ in both the women and men (Figure 1AB; $P<0.001)$. Total fat mass decreased significantly in all groups $(P<$ 0.001 ), resulting in a significant decline in body fat percentage (women: from $33.3 \pm$ 1.1 to $31.9 \pm 1.1 \%$ and $30.9 \pm 1.2$ to $29.2 \pm 1.2 \%$; men: from $22.3 \pm 1.2$ to $21.1 \pm 1.0 \%$ and $23.1 \pm 1.2$ to $21.6 \pm 1.1 \%$ in the PLA and PRO group, respectively; $(P<0.001)$ ). In accordance, leg fat mass decreased during the intervention $(P<0.01)$. No significant differences were observed for the intervention effects between treatments and/or genders for any of the DXA variables. No changes were observed in bone mineral content (data not shown).

\section{Skeletal muscle hypertrophy}

At baseline, no significant differences in quadriceps CSA were observed between the PLA and PRO group. CSA had increased by $8 \pm 1$ and $7 \pm 1 \%$ after 12 wk of intervention in the women and men, respectively (Figure 1 C-D; $P<0.001$ ), with no differences between groups. In the subsequent 12 wk of intervention no significant further increase was observed in the women (Figure 1C). In the men, a significant $2 \pm 1 \%$ in- 
crease in CSA was observed between 12 and 24 wk of intervention, with no differences between groups $(P<0.001)$.
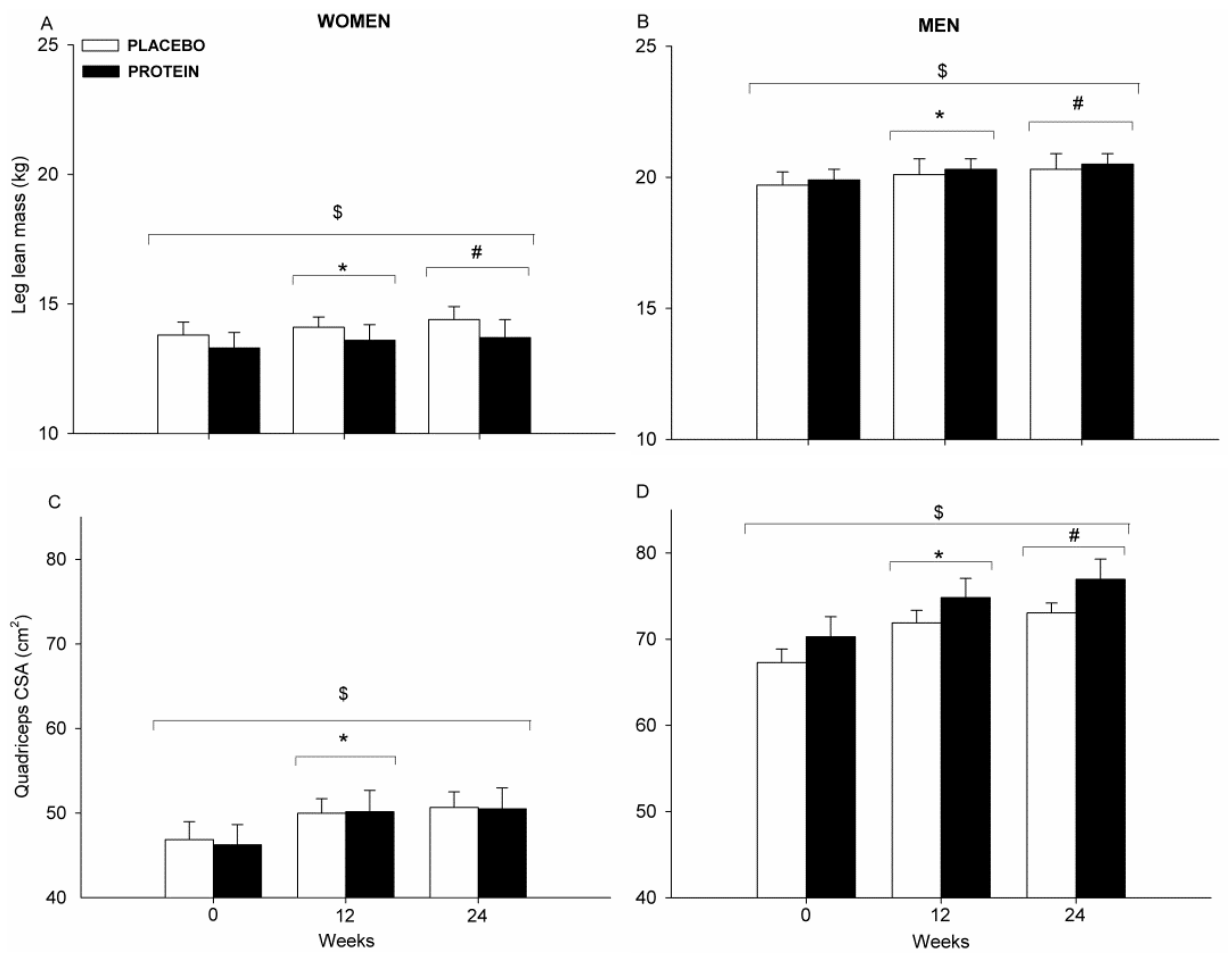

Figure 1: Mean \pm SEM leg lean mass before, after 12 and 24 wk of resistance type exercise training in elderly women (A) and men (B) with or without protein supplementation. Data were analyzed using repeated measures ANOVA with time as within-subjects factor and gender and group as between-subjects factor. No time $\mathrm{x}$ gender $\mathrm{x}$ group $(P=0.69)$, time $\mathrm{x}$ gender $(P=0.50)$, time $\mathrm{x}$ group $(P=0.61)$ interactions were observed. *Significantly different from baseline, $P<0.001$. " Significantly different from baseline and status after 12 wk of intervention, $P<0.005$. \$Significant increase over time $P<0.001$.

Mean \pm SEM quadriceps CSA before, after $12 \mathrm{wk}$ and after 24 wk of resistance type exercise training in elderly women (C) and men (D) with or without protein supplementation. Data were analyzed using repeated measures ANOVA with time as within-subjects factor and gender and group as between-subjects factor. No time $\mathrm{x}$ gender $\mathrm{x}$ group $(P=0.69)$, time $\mathrm{x}$ group $(P=0.60)$ interactions were observed. $\mathrm{A}$ time $\mathrm{x}$ gender interaction was observed $(P<0.05)$. *Significantly different from before the intervention, $P<0.001$. "Significantly different from baseline and status after $12 \mathrm{wk}$ of intervention, $P<0.001$. \$Significant increase over time $P<0.001$.

Muscle fiber type composition in the PRO (women and men $42 \pm 5$ and $46 \pm 5 \%$ type II fibers, respectively) and PLA group (women and men $42 \pm 4$ and $45 \pm 4 \%$ type II fibers, respectively) did not differ between groups. Before the intervention, type II muscle fiber size was significantly smaller than type I muscle fibers size (Figure 2A-B). For muscle fiber CSA, a significant 'time $X$ fiber type' interaction $(P<0.05)$, and a significant 'gender $X$ fiber type' interaction $(P<0.001)$ were observed. Separate analyses 
showed that type I muscle fiber CSA did not significantly change in any of the groups. In contrast, type II muscle fiber size significantly increased in all groups (Figure 2A-B; $P$ $<0.001$ ), with no differences between the PRO and PLA supplemented group. Post-hoc analyses showed the majority of the increase to occur between week 0 and 12 . As a consequence of the type II muscle fiber hypertrophy, the total area percentage occupied by type II muscle fibers had increased from $38 \pm 2 \%$ at baseline to $43 \pm 2 \%$ after 24 weeks of training, with no differences between groups.

A

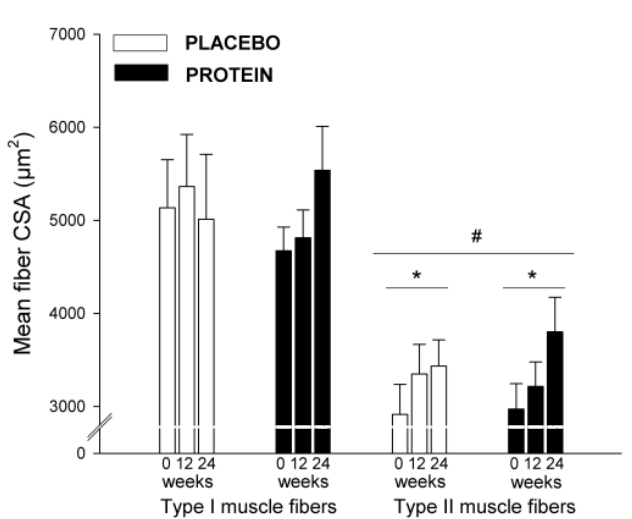

B

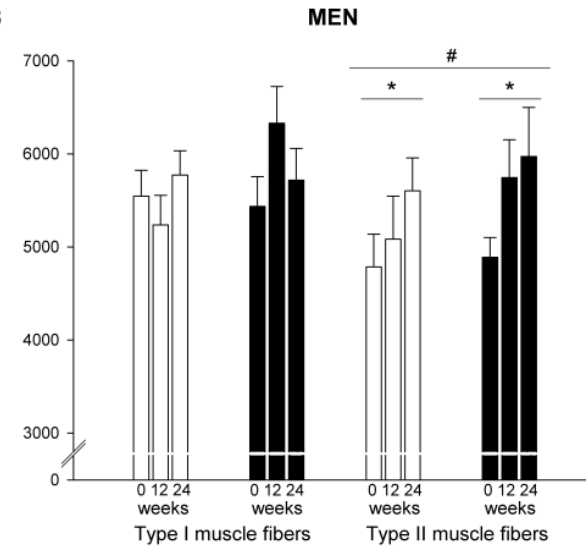

Figure 2: Mean \pm SEM muscle fiber cross-sectional area (CSA) for type II muscle fibers before, after 12 and 24 wk of resistance type exercise training in elderly women $(\mathbf{A})$ and men $(\mathbf{B})$ with or without protein supplementation. Data were analyzed using repeated measures ANOVA with time as within-subjects factor and gender and group as between-subjects factor. No time $\mathrm{x}$ gender $\mathrm{x}$ group $(P=0.57)$, time $\mathrm{x}$ group $(P=0.25)$, time $\mathrm{x}$ gender $(P=0.26)$ interactions were observed. *Significant increase over time $P<0.01$. "Significantly different from type I fibers prior to intervention, $P<0.001$

\section{Muscle strength}

At baseline, no significant differences in muscle strength (1RM) were observed between the PLA and PRO group (Figure 3A). After 12 wk of intervention, leg extension strength had increased by $22 \pm 2 \%$ in the women and $23 \pm 2 \%$ in the men $(P<0.001)$, with no differences between groups. Between 12 and 24 wk of intervention, leg extension strength increased by another $17 \pm 1 \%$ in the women and $16 \pm 1 \%$ in the men. No significant differences were observed between groups. For the leg press, similar gains in strength were observed; 1 RM leg press strength had increased by $31 \pm 3$ and $26 \pm$ $2 \%$ after 24 wk of intervention in the women and men, respectively $(P<0.001)$, with no differences between groups. 


\section{Physical performance}

At baseline, no significant differences were observed in sit-to-stand time between the PLA and PRO groups (Figure 3B). After 12 wk of intervention, sit-to-stand time had decreased by $8 \pm 2 \%$ in the women and $9 \pm 2 \%$ in the men $(P<0.001)$. Between 12 and 24 wk of intervention, sit-to-stand time decreased with another $10 \pm 2$ and $11 \pm 2 \%$, respectively $(P<0.001)$. No significant differences were observed between the PLA and PRO group. Before the exercise intervention, no differences were observed in handgrip strength between the PLA and PRO group ( $27 \pm 1$ and $25 \pm 1 \mathrm{~kg}$ in the women and $41 \pm$ 2 and $45 \pm 2 \mathrm{~kg}$ in the men, respectively). No significant changes over time were observed in either the PLA or PRO group.

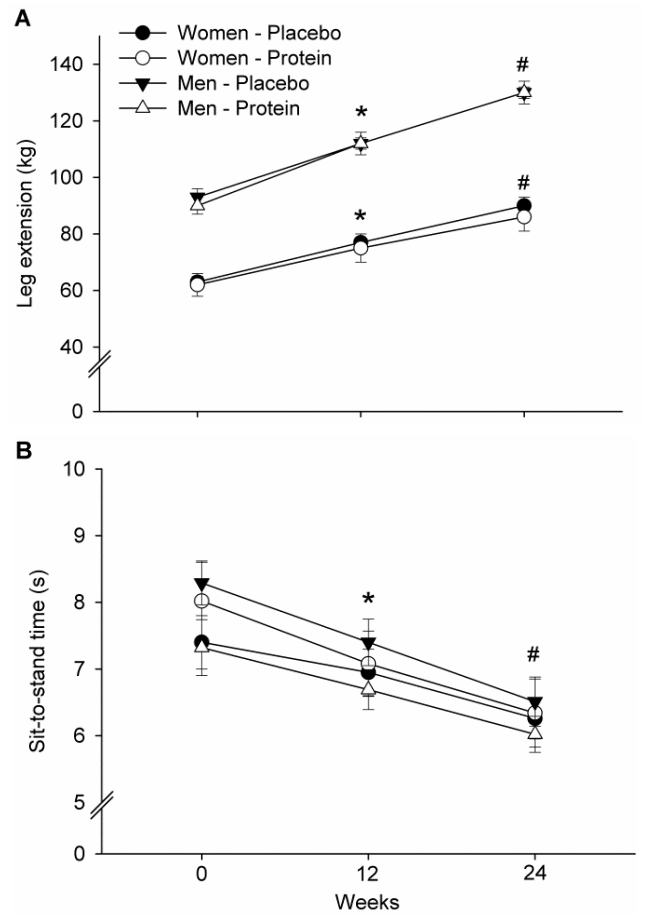

Figure 3: A: Mean \pm SEM leg extension $1 R M$ after 12 and 24 wk of resistance type exercise training in elderly women and men with or without protein supplementation. Data were analyzed by using repeated-measures ANOVA with time, as within-subjects factor and gender and group as between-subjects factor. No time $\mathrm{x}$ gender $\mathrm{x}$ group $(P=0.37)$, time $\mathrm{x}$ group $(P=0.86)$ interactions were observed. A time $\mathrm{x}$ gender interaction was observed $(P<0.001)$. *Significantly different from baseline, $P<0.001$. " Significantly different from baseline and status after $12 \mathrm{wk}$ of intervention, $P<0.001$.

B: Mean \pm SEM sit-to-stand time after 12 and 24 wk of resistance type exercise training in elderly women and men with or without protein supplementation. Data were analyzed by using repeated-measures ANOVA with time, as within-subjects factor and gender and group as between-subjects factor. No time $\mathrm{x}$ gender $\mathrm{x}$ group $(P=0.14)$, time $x$ gender $(P=0.71)$, time $x$ group $(P=0.73)$ interactions were observed. *Significantly different from baseline, $P<0.001$. "Significant improvement different from baseline and status after $12 \mathrm{wk}$ of intervention, $P<0.001$. 


\section{Dietary intake and physical activity}

Analysis of the $3 \mathrm{~d}$ dietary intake records collected prior to the exercise training regimen showed no significant differences between the PLA and the PRO group at baseline (Table 2). No changes in total energy intake or macronutrient composition of the diet were observed over time. Daily protein intake averaged $1.2 \pm 0.1 \mathrm{~g} / \mathrm{kg} / \mathrm{d}$ in the women and $1.1 \pm 0.0 \mathrm{~g} / \mathrm{kg} / \mathrm{d}$ in the men. Daily protein intake increased significantly by 0.24 $\mathrm{g} / \mathrm{kg} / \mathrm{day}$ in the women and by $0.18 \mathrm{~g} / \mathrm{kg} / \mathrm{d}$ in the men following daily protein supplementation in the PRO group. Habitual physical activity levels and mean energy expenditure at baseline did not differ between groups (Table 2). Habitual physical activity levels did not change over time.

Table 2: Food intake and habitual physical activity levels

\begin{tabular}{lccccc}
\hline & \multicolumn{2}{c}{ Women $(n=24)$} & & \multicolumn{2}{c}{ Men $(n=29)$} \\
\cline { 2 - 3 } \cline { 5 - 6 } & 0 & 24 & & 0 & 24 \\
\hline Energy Intake (MJ/d) & $8.2 \pm 0.2$ & $8.7 \pm 0.4$ & & $10.0 \pm 0.4$ & $10.1 \pm 0.4$ \\
Carbohydrate (\%) & $44 \pm 1$ & $44 \pm 1$ & & $45 \pm 1$ & $35 \pm 1$ \\
Fat (\%) & $36 \pm 1$ & $36 \pm 1$ & & $34 \pm 1$ & $35 \pm 1$ \\
Protein (\%) & $16 \pm 1$ & $15 \pm 1$ & & $15 \pm 1$ & $14 \pm 1$ \\
Alcohol (\%) & $4 \pm 1$ & $5 \pm 1$ & & $6 \pm 1$ & $6 \pm 1$ \\
Protein (g/kg/d) & $1.2 \pm 0.1$ & $1.2 \pm 0.1$ & & $1.1 \pm 0.1$ & $1.0 \pm 0.1$ \\
Mean energy expenditure & $1.44 \pm 0.15$ & $1.49 \pm 0.11$ & & $1.48 \pm 0.19$ & $1.50 \pm 0.18$ \\
(MET-h/d) & & & &
\end{tabular}

All values represent means \pm SEMs. No significant differences were observed between the protein and the placebo group prior to intervention.

No time $\mathrm{x}$ group interaction or main group effects were observed.

\section{Glycemia and lipidemia}

Measures of glycemic control did not differ between the PLA and PRO group prior to intervention (Table 3). After $24 \mathrm{wk}$ of intervention, $\mathrm{HbA1c}$ had decreased in both the PLA and PRO group. In accordance, insulin sensitivity parameters (OGIS and ISI) increased over time (Table 3 ). Fasting plasma glucose and insulin concentrations and HOMA index remained stable throughout the intervention period. No significant differences were observed between groups. At baseline, no group differences were observed in plasma lipid concentrations. Triglycerides and HDL were within the normal range $(1.2 \pm 0.1$ and $1.7 \pm 0.1 \mathrm{mmol} / \mathrm{L}$ (normal value: triglycerides $<1.7$ and $\mathrm{HDL}>1.5$ $\mathrm{mmol} / \mathrm{L})$ ) before intervention and did not change over time. No differences were observed between groups. Total cholesterol and LDL were above the normal range $6.3 \pm$ $0.2 \mathrm{mmol} / \mathrm{L}$ and $4.1 \pm 0.2 \mathrm{mmol} / \mathrm{L}$ (normal value: total cholesterol $<5.2$ and $\mathrm{LCL}<2.6$ $\mathrm{mmol} / \mathrm{L})$ ) prior to intervention. In both the PLA and the PRO group total cholesterol had decreased significantly after 12 wk of intervention $(-4 \pm 1 \%$ decrease in women 
and $-2 \pm 1 \%$ decrease in men; $P<0.001$ ). No further decrease was observed between 12 and 24 wk. In both the PLA and the PRO group, LDL had decreased from $4.46 \pm 0.18$ to $4.14 \pm 0.18 \mathrm{mmol} / \mathrm{L}$ in the women and from $3.76 \pm 0.18$ to $3.60 \pm 0.17 \mathrm{mmol} / \mathrm{L}$ in the men after $12 \mathrm{wk}$ of intervention $(P<0.001)$. Between 12 and $24 \mathrm{wk}$, LDL further decreased from $4.14 \pm 0.18$ to $3.98 \pm 0.18 \mathrm{mmol} / \mathrm{L}$ in the women and from $3.60 \pm 0.17$ to $3.53 \pm 0.17 \mathrm{mmol} / \mathrm{L}$ in the men $(P<0.05)$.

Table 3: Glycemic control

\begin{tabular}{lccccc}
\hline & \multicolumn{2}{c}{ Women $(n=24)$} & & \multicolumn{2}{c}{ Men $(n=29)$} \\
\cline { 2 - 3 } \cline { 5 - 5 } Week & 0 & 24 & & 0 & 24 \\
\hline Plasma glucose (mmol/L) & $5.4 \pm 0.1$ & $5.2 \pm 0.1$ & & $5.6 \pm 0.1$ & $5.7 \pm 0.1$ \\
Plasma insulin (mU/L) & $13.7 \pm 1.2$ & $13.2 \pm 1.3$ & & $14.5 \pm 0.9$ & $14.5 \pm 0.9$ \\
HbA1c (\%) & $5.8 \pm 0.0$ & $5.7 \pm 0.0^{*}$ & & $5.5 \pm 0.1$ & $5.4 \pm 0.1^{*}$ \\
ISI & $3.8 \pm 0.4$ & $4.2 \pm 0.3^{*}$ & & $3.1 \pm 0.3$ & $3.4 \pm 0.4^{*}$ \\
OGIS & $385 \pm 15$ & $418 \pm 14^{*}$ & & $345 \pm 15$ & $361 \pm 15^{*}$ \\
\hline
\end{tabular}

All values represent means \pm SEMs. No significant differences were observed between the protein and the placebo group before the intervention. No time $\mathrm{x}$ group interaction or main group effects were observed.

* Significantly different from wk 0.

HbA1c: blood glycosylated hemoglobin; ISI: insulin sensitivity index; OGIS: oral glucose insulin sensitivity.

\section{Creatinine and urinary nitrogen}

Serum creatinine concentrations were within the normal range ( $>60 \mu \mathrm{mol} / \mathrm{L}$ ) before the intervention. At baseline, no significant differences were observed between the PLA and PRO groups (women: $76.0 \pm 4.2$ and $77.9 \pm 3.3 \mu \mathrm{mol} / \mathrm{L}$; men: $88.9 \pm 4.5$ and $93.9 \pm 3.7 \mu \mathrm{mol} / \mathrm{L}$, respectively). No changes were observed over time in either group. Creatinine clearance was within the normal range $\left(>60 \mathrm{~mL} / \min\right.$ per $\left.1.73 \mathrm{~m}^{2}\right)$ before the intervention. At baseline, no significant differences were observed between the PLA and PRO group (women: $83.2 \pm 3.7$ and $81.3 \pm 4.9 \mathrm{~mL} / \mathrm{min}$ per $1.73 \mathrm{~m}^{2}$; men: 85.5 \pm 6.8 and $89.4 \pm 6.8 \mathrm{~mL} / \mathrm{min}$ per $1.73 \mathrm{~m}^{2}$, respectively). No changes were observed over time in either group. Before the intervention, 24-h nitrogen balance was $1.30 \pm$ $0.44 \mathrm{~g} / \mathrm{d}$ in the women and $-0.14 \pm 0.53 \mathrm{~g} / \mathrm{d}$ in the men. Nitrogen balance did not change over time in either group.

\section{Discussion}

The present study shows that prolonged resistance type exercise training increases muscle mass and strength, augments functional capacity, improves glycemia and lipidemia, and reduces blood pressure in healthy elderly men and women. Additional protein supplementation at breakfast $(15 \mathrm{~g} / \mathrm{d})$ did not further augment the increase in muscle mass, strength, and/or functional capacity in these healthy elderly subjects. 
Resistance type exercise training has been well established as an effective treatment strategy to counteract the loss of muscle mass and strength in the elderly (2-4). In the present study, we observed substantial gains in whole body lean mass of $1.2 \pm$ 0.2 and $1.3 \pm 0.4 \mathrm{~kg}$ in the women and $1.0 \pm 0.3$ and $1.4 \pm 0.4 \mathrm{~kg}$ in the men in the placebo and protein supplemented group, respectively. These findings tend to be in line with previous observations in shorter intervention studies $(4,12)$. The increase in whole-body lean mass was largely attributed to an increase in leg lean mass. The latter was also evident from the quadriceps CSA that had increased by approximately $10 \%$ after 6 months of training in both the women and men. The greater part of the increase in muscle mass occurred during the first 12 weeks of the intervention. The latter is in line with findings by Frontera et al (2), who observed a 9\% increase in quadriceps CSA following 12 weeks of resistance type exercise training in elderly men.

Apart from the changes in whole-body and leg lean mass and quadriceps CSA with aging and exercise, specific alterations likely also occur at the myocellular level. The age related loss of muscle mass is largely attributed to the specific type II muscle fiber atrophy (26). In accordance, we observed a significantly smaller type II muscle fiber size when compared with type I muscle fibers in these older women and men at baseline (Figure 2A-B). Resistance type exercise training strongly increased type II muscle fiber size with $28 \pm 7 \%$ in the women and $23 \pm 7 \%$ in the men. These findings are in line with earlier reports from Kosek et al (4), who observed an approximately $23 \%$ increase in type II muscle fiber size after $16 \mathrm{wk}$ of resistance type exercise training ( $3 \mathrm{x} / \mathrm{wk}$ ). Also in accordance with the observations of Kosek et al (4), type I muscle fiber size did not change in response to training. In agreement with muscle mass data, type II muscle fiber size had increased most during the first $12 \mathrm{wk}$ of intervention.

The increase in leg lean mass, quadriceps CSA, and muscle fiber size was accompanied by a substantial increase in leg muscle strength. Interestingly, both the increase in leg lean mass $(r=0.307 ; P<0.05)$, and quadriceps CSA $(r=0.44 ; P<0.001)$ correlated significantly with the concomitant increase in 1RM strength. Furthermore, type II muscle fiber size was strongly correlated with leg lean mass $(r=0.70 ; P<0.001)$ and quadriceps CSA ( $R=0.79 ; P<0.001)$, and also with leg press and leg extension 1RM $(r=0.79$ and $r=0.74$, respectively; $P<0.001$ ). Whereas leg press strength had increased by 25 $30 \%$ in both the men and the women, leg extension strength had increased by as much as $40 \%$ after 6 months of training. Although similar improvements in muscle strength have been reported previously after $8-16$ wk of resistance type knee extension exercise training $(4,32)$, this is the first study to assess the impact of 6 months of wholebody resistance type exercise training in elderly men and women. The observed increase in leg muscle strength was shown to be of important clinical relevance as it translated to substantial improvements in functional capacity (Figure 3 ). The sit-tostand test showed an $18 \pm 1 \%$ improvement in both the women and the men $(P<$ 0.001). This is in accordance with Capodaglio et al (33) who observed an approximately $23 \%$ improvement in chair rise time after 1 year of strength training in the elderly. The latter clearly shows the clinical relevance of increasing leg muscle strength in the elder- 
ly, which generally translates to improvements in functional capacity. Despite the whole-body resistance type exercise training, we failed to detect any changes in handgrip strength over time. In fact, handgrip strength was shown to be highly reproducible (with a CV of $0.06 \%$ ), between measurements taken at 0, 3 and 6 months and had clearly not been affected by the resistance type exercise training. Although handgrip strength has been shown to represent a useful tool to assess physical performance capacity in both healthy and compromised populations in cross-sectional studies (34, $35)$, handgrip strength should not be used as a parameter to assess changed in muscle strength and/or function over time in the individual patient when the training program does not include a specific handgrip exercise.

Our data show that prolonged resistance type exercise training represents an effective strategy to augment muscle mass and strength and improve functional performance in the elderly. It has been suggested that dietary protein supplementation can further augment the skeletal muscle adaptive response to resistance type exercise training. However, long-term nutritional intervention studies have generally failed to observe additional benefits of increasing protein intake during exercise intervention in elderly populations $(6,11,12)$. It should be noted, however, that these combined exercise and nutritional interventions in the elderly generally lasted between 6 and 12 wk $(6,11,12)$. Considering the blunted muscle protein synthetic response to protein intake in the elderly, it could be speculated that more prolonged exercise intervention periods are required for any benefits of dietary protein supplementation to become apparent. Another aspect that may well influence the benefits of additional protein intake is the timing of the supplementation (36). We have previously shown that the ingestion of a protein supplement immediately before and after each exercise session (i.e., three times per week for 12 wk) does not further augment muscle hypertrophy after resistance type exercise training in elderly men (12). Therefore, in the present study we applied a different supplementation strategy. Because it has been proposed that a sufficient amount of protein (i.e. 25-30 g) should be ingested with each main meal to allow proper muscle maintenance, we assessed normal dietary habits in various elderly subpopulations in the Netherlands (16). These data show that dietary protein intake in community-dwelling elderly is particularly low at breakfast (approximately $10 \mathrm{~g}$ ) and, as such, insufficient to allow normal postprandial stimulation of myofibrillar muscle protein synthesis (37). We speculated that provision of additional protein with breakfast during a prolonged period of resistance type exercise training would represent a more effective strategy to support net muscle protein accretion. Therefore, a drink containing $15 \mathrm{~g}$ of milk was supplemented at breakfast to ensure the ingestion of an optimal amount of protein (i.e., approximately $25 \mathrm{~g}$ ) with all main meals.

Despite substantial increases in skeletal muscle mass in both women and men, we observed no differences between the protein and placebo supplemented groups. Importantly, muscle mass, muscle strength, and muscle function continued to increase between 12 and 24 weeks of training. As such, prolonging exercise training in the elderly clearly has the capacity to induce further clinical benefits. However, daily protein 
supplementation with breakfast did not further augment the increase in muscle mass and strength during prolonged resistance type exercise training in this large group of elderly men and women. To provide an in-depth insight in the hypertrophic response to training, muscle mass was measured on a whole body (DXA), limb (CT) and myocellular level (biopsy). Furthermore, muscle strength and function were extensively assessed with both leg extension and leg press 1RM testing and with handgrip strength and sit-to-stand time. On each of these outcome parameters, we did not observe any additional benefits of protein supplementation during 6 months of resistance type exercise training in elderly women and men. These results extend on several relative short-term intervention studies that failed to observe additional benefits of protein supplementation during resistance type exercise training in the elderly $(6,11,12)$. Taken together, these data clearly indicate that there is no rationale for protein supplementation during prolonged resistance type exercise training in healthy elderly men and women.

The apparent absence of any additional benefits of protein supplementation implies that optimal dietary protein requirements to allow skeletal muscle hypertrophy to occur were already met within the habitual diet of the participants. In the present study, dietary intake remained stable throughout the intervention period. Even without additional protein supplementation, habitual protein intake averaged $1.2 \pm 0.1$ $\mathrm{g} / \mathrm{kg} / \mathrm{d}$ in the women and $1.1 \pm 0.0 \mathrm{~g} / \mathrm{kg} / \mathrm{d}$ in the men in both groups. These values are well above the current Recommended Daily Allowance of $0.8 \mathrm{~g} / \mathrm{kg} / \mathrm{d}$ (38). Hence, we conclude that protein supplementation does not modify improvements in muscle mass, strength and function during prolonged resistance type exercise training when ample protein is already ingested in the normal diet $(>1.0 \mathrm{~g} / \mathrm{kg} / \mathrm{d})$. These findings are in line with observations from Campbell and Leidy (39), who concluded that improvements in muscle mass and strength induced by resistance type exercise training are not enhanced when older people who consume adequate dietary protein (in excess of $0.8 \mathrm{~g} / \mathrm{kg} / \mathrm{d}$ ) further increase their protein intake. Apparently, a low-protein intake at breakfast does not preclude muscle hypertrophy to occur in healthy elderly men and women. However, It remains to be addressed whether dietary protein supplementation is of clinical relevance in more compromised (frail) elderly populations in which daily protein intake is likely insufficient (16).

Besides muscle mass, strength and functional capacity, we observed many other benefits of prolonged resistance type exercise training that are normally attributed to the effect of prolonged endurance type exercise. In the present study, we observed substantial improvements in glycemic control in our healthy elderly subjects. The latter was evident by both a decrease in $\mathrm{HbA1c}(0.1 \%)$ and an increase in insulin sensitivity, i.e., a $7 \pm 2 \%$ increase in OGIS, and a $6 \pm 4 \%$ increase in ISI, with no differences between the placebo and protein supplemented groups. These results extend on previous findings from several studies in middle-aged subjects $(15,40-42)$, showing that resistance type exercise training improves whole-body insulin sensitivity and improves glycemic control in elderly men and women. In addition to the improvement in glucose 
tolerance, prolonged resistance type exercise also improves blood lipid profile. We observed a decrease in total cholesterol and LDL in the men and even to a larger extent in the women. Furthermore, systolic and diastolic blood pressure was significantly reduced over the course of the intervention. These findings are in line with previous observations (43) and underline the clinical relevance of prolonged resistance type exercise training to improve metabolic health in the elderly. Because the resistance type exercise program was highly appreciated by the subjects and accompanied by excellent adherence and compliance, we suggest that exercise intervention programs for the elderly should focus on the implementation of resistance type exercise.

One of the clear advantages of the present study is the prolonged timeline and the ability to compare the adaptive response during the first 3 months with the subsequent 3 months of intervention in both older men and women. The greater increase in muscle mass and muscle strength was observed during the initial 12 wk of training, representing 85 and 53\% of the change in muscle mass and strength over the entire 6 months period. The latter clearly shows that the first few months of resistance type exercise training should be highly supervised to allow proper and safe training responses, with concomitant increases in muscle mass and strength. The subsequent period should focus on muscle mass maintenance and likely requires less effort than implemented in the present study. Clearly, future studies should establish how resistance type exercise training can be prescribed to elderly people and how we can setup an exercise regimen that will allow maintenance of the initial increase in muscle mass and strength that is obtained during the initial approximately 3 months of supervised resistance type exercise training.

We conclude that prolonged resistance type exercise training increases skeletal muscle mass and strength, augments functional capacity, improves glycemia and lipidemia, and reduces blood pressure in healthy elderly men and women. Additional protein supplementation $(15 \mathrm{~g} / \mathrm{d})$ does not further augment the gains in skeletal muscle mass, strength, and functional capacity in healthy elderly men and women. 


\section{References}

1. Evans W: Functional and metabolic consequences of sarcopenia. J Nutr 1997, 127(5 Suppl):998S-1003S.

2. Frontera WR, Meredith CN, O'Reilly KP, Knuttgen HG, Evans WJ: Strength conditioning in older men: skeletal muscle hypertrophy and improved function. J Appl Physiol 1988, 64(3):1038-1044.

3. Charette SL, McEvoy L, Pyka G, Snow-Harter C, Guido D, Wiswell RA, Marcus R: Muscle hypertrophy response to resistance training in older women. J Appl Physiol 1991, 70(5):1912-1916.

4. Kosek DJ, Kim JS, Petrella JK, Cross JM, Bamman MM: Efficacy of 3 days/wk resistance training on myofiber hypertrophy and myogenic mechanisms in young vs. older adults. J Appl Physiol 2006, 101(2):531-544.

5. Fiatarone MA, Marks EC, Ryan ND, Meredith CN, Lipsitz LA, Evans WJ: High-intensity strength training in nonagenarians. Effects on skeletal muscle. JAMA 1990, 263(22):3029-3034.

6. Fiatarone MA, O'Neill EF, Ryan ND, Clements KM, Solares GR, Nelson ME, Roberts SB, Kehayias JJ, Lipsitz LA, Evans WJ: Exercise training and nutritional supplementation for physical frailty in very elderly people. N Engl J Med 1994, 330(25):1769-1775.

7. Houston DK, Nicklas BJ, Ding J, Harris TB, Tylavsky FA, Newman AB, Lee JS, Sahyoun NR, Visser M, Kritchevsky SB: Dietary protein intake is associated with lean mass change in older, communitydwelling adults: the Health, Aging, and Body Composition (Health ABC) Study. Am J Clin Nutr 2008, 87(1):150-155.

8. Tipton KD, Ferrando AA, Phillips SM, Doyle D, Jr., Wolfe RR: Postexercise net protein synthesis in human muscle from orally administered amino acids. Am J Physiol 1999, 276(4 Pt 1):E628-634.

9. Willoughby DS, Stout JR, Wilborn CD: Effects of resistance training and protein plus amino acid supplementation on muscle anabolism, mass, and strength. Amino Acids 2007, 32(4):467-477.

10. Josse AR, Tang JE, Tarnopolsky MA, Phillips SM: Body composition and strength changes in women with milk and resistance exercise. Med Sci Sports Exerc 2010, 42(6):1122-1130.

11. Godard MP, Williamson DL, Trappe SW: Oral amino-acid provision does not affect muscle strength or size gains in older men. Med Sci Sports Exerc 2002, 34(7):1126-1131.

12. Verdijk LB, Jonkers RA, Gleeson BG, Beelen M, Meijer K, Savelberg HH, Wodzig WK, Dendale P, van Loon LJ: Protein supplementation before and after exercise does not further augment skeletal muscle hypertrophy after resistance training in elderly men. Am J Clin Nutr 2009, 89(2):608-616.

13. Cuthbertson D, Smith K, Babraj J, Leese G, Waddell T, Atherton P, Wackerhage H, Taylor PM, Rennie MJ: Anabolic signaling deficits underlie amino acid resistance of wasting, aging muscle. FASEB J 2005, 19(3):422-424.

14. Guillet C, Prod'homme M, Balage M, Gachon P, Giraudet C, Morin L, Grizard J, Boirie Y: Impaired anabolic response of muscle protein synthesis is associated with S6K1 dysregulation in elderly humans. FASEB J 2004:03-1341fje.

15. Miller JP, Pratley RE, Goldberg AP, Gordon P, Rubin M, Treuth MS, Ryan AS, Hurley BF: Strength training increases insulin action in healthy 50- to 65-yr-old men. J Appl Physiol 1994, 77(3):1122-1127.

16. Tieland M, Borgonjen-Van den Berg KJ, van Loon LJ, de Groot LC: Dietary protein intake in communitydwelling, frail, and institutionalized elderly people: scope for improvement. Eur J Nutr 2011.

17. Park SW, Goodpaster BH, Strotmeyer ES, de Rekeneire N, Harris TB, Schwartz AV, Tylavsky FA, Newman $A B$ : Decreased muscle strength and quality in older adults with type 2 diabetes: the health, aging, and body composition study. Diabetes 2006, 55(6):1813-1818.

18. Diagnosis and classification of diabetes mellitus. Diabetes care 2006, 29 Suppl 1:S43-48.

19. Jones PR, Pearson J: Anthropometric determination of leg fat and muscle plus bone volumes in young male and female adults. J Physiol 1969, 204(2):63P-66P.

20. Ainsworth BE, Haskell WL, Whitt MC, Irwin ML, Swartz AM, Strath SJ, O'Brien WL, Bassett DR, Jr., Schmitz KH, Emplaincourt PO et al: Compendium of physical activities: an update of activity codes and MET intensities. Med Sci Sports Exerc 2000, 32(9 Suppl):S498-504.

21. Zhang X, Geiss LS, Caspersen CJ, Cheng YJ, Engelgau MM, Johnson JA, Plotnikoff RC, Gregg EW: Physical activity levels and differences in the prevalence of diabetes between the United States and Canada. Prev Med 2010, 50(5-6):241-245. 
22. Goodpaster BH, Kelley DE, Thaete FL, He J, Ross R: Skeletal muscle attenuation determined by computed tomography is associated with skeletal muscle lipid content. J Appl Physiol 2000, 89(1):104-110.

23. Strandberg S, Wretling ML, Wredmark T, Shalabi A: Reliability of computed tomography measurements in assessment of thigh muscle cross-sectional area and attenuation. BMC Med Imaging 2010, 10:18.

24. Bergstrom J: Percutaneous needle biopsy of skeletal muscle in physiological and clinical research. Scand J Clin Lab Invest 1975, 35(7):609-616.

25. Mayhew JL, Prinster JL, Ware JS, Zimmer DL, Arabas JR, Bemben MG: Muscular endurance repetitions to predict bench press strength in men of different training levels. J Sports Med Phys Fitness 1995, 35(2):108-113.

26. Verdijk LB, Koopman R, Schaart G, Meijer K, Savelberg HH, van Loon LJ: Satellite cell content is specifically reduced in type II skeletal muscle fibers in the elderly. Am J Physiol Endocrinol Metab 2007, 292(1):E151-157.

27. Verdijk LB, van Loon LJC, Meijer K, Savelberg HHCM: One repetition maximum strength test represents a valid means to assess leg strength in vivo in humans. J Sport Sci, (in press).

28. Guralnik JM, Simonsick EM, Ferrucci L, Glynn RJ, Berkman LF, Blazer DG, Scherr PA, Wallace RB: A short physical performance battery assessing lower extremity function: association with self-reported disability and prediction of mortality and nursing home admission. J Gerontol 1994, 49(2):M85-94.

29. Cappola AR, Bandeen-Roche K, Wand GS, Volpato S, Fried LP: Association of IGF-I levels with muscle strength and mobility in older women. J Clin Endocrinol Metab 2001, 86(9):4139-4146.

30. Maroni BJ, Steinman TI, Mitch WE: A method for estimating nitrogen intake of patients with chronic renal failure. Kidney Int 1985, 27(1):58-65.

31. Levey AS, Bosch JP, Lewis JB, Greene T, Rogers N, Roth D: A more accurate method to estimate glomerular filtration rate from serum creatinine: a new prediction equation. Modification of Diet in Renal Disease Study Group. Ann Intern Med 1999, 130(6):461-470.

32. Martel GF, Roth SM, Ivey FM, Lemmer JT, Tracy BL, Hurlbut DE, Metter EJ, Hurley BF, Rogers MA: Age and sex affect human muscle fibre adaptations to heavy-resistance strength training. Exp Physiol 2006, 91(2):457-464.

33. Capodaglio P, Capodaglio Edda M, Facioli M, Saibene F: Long-term strength training for communitydwelling people over 75: impact on muscle function, functional ability and life style. Eur J Appl Physiol 2007, 100(5):535-542.

34. Chevalier S, Saoud F, Gray-Donald K, Morais JA: The physical functional capacity of frail elderly persons undergoing ambulatory rehabilitation is related to their nutritional status. J Nutr Health Aging 2008, 12(10):721-726.

35. Toffanello ED, Perissinotto E, Sergi G, Zambon S, Musacchio E, Maggi S, Coin A, Sartori L, Corti MC, Baggio $G$ et al: Vitamin $D$ and physical performance in elderly subjects: the Pro.V.A study. PLoS One 2012, 7(4):e34950.

36. Esmarck B, Andersen JL, Olsen S, Richter EA, Mizuno M, Kjaer M: Timing of postexercise protein intake is important for muscle hypertrophy with resistance training in elderly humans. J Physiol 2001, 535(Pt 1):301-311.

37. Paddon-Jones D, Rasmussen BB: Dietary protein recommendations and the prevention of sarcopenia. Current Opinion in Clinical Nutrition \& Metabolic Care 2009, 12(1):86-90 10.1097/MCO.1090b1013e 32831cef32838b.

38. Campbell WW, Johnson CA, McCabe GP, Carnell NS: Dietary protein requirements of younger and older adults. Am J Clin Nutr 2008, 88(5):1322-1329.

39. Campbell WW, Leidy HJ: Dietary protein and resistance training effects on muscle and body composition in older persons. J Am Coll Nutr 2007, 26(6):696S-703S.

40. Dipietro L, Yeckel CW, Dziura J: Progressive improvement in glucose tolerance following lower-intensity resistance versus moderate-intensity aerobic training in older women. J Phys Act Health 2008, 5(6):854-869.

41. Sillanpaa E, Hakkinen A, Punnonen K, Hakkinen K, Laaksonen DE: Effects of strength and endurance training on metabolic risk factors in healthy 40-65-year-old men. Scand J Med Sci Sports 2009, 19(6):885-895. 
42. Ryan AS, Pratley RE, Goldberg AP, Elahi D: Resistive training increases insulin action in postmenopausal women. J Gerontol A Biol Sci Med Sci 1996, 51(5):M199-205.

43. Martins RA, Verissimo MT, Coelho e Silva MJ, Cumming SP, Teixeira AM: Effects of aerobic and strength-based training on metabolic health indicators in older adults. Lipids Health Dis 2010, 9:76. 
CHAPTER 6

\title{
Elderly men and women benefit equally from prolonged resistance type exercise training
}

\author{
Marika Leenders \\ Lex B Verdijk \\ Letty van der Hoeven \\ Janneau van Kranenburg \\ Rachel Nilwik \\ Luc JC van Loon
}

The Journals of Gerontology. Series A, Biological Sciences and Medical Sciences 


\section{Abstract}

This study compares the effects of 6 months resistance type exercise training ( $3 x / w k)$ between healthy elderly women $(n=24 ; 71 \pm 1 y)$ and men $(n=29 ; 70 \pm 1 y)$. Muscle mass (dual-energy x-ray Absorptiometry - computed tomography), strength (1 repetition maximum), functional capacity (sit-to-stand time), muscle fiber characteristics (muscle biopsies), and metabolic profile (blood samples) were assessed. Leg lean mass ( $3 \pm 1 \%)$ and quadriceps cross-sectional area $(9 \pm 1 \%)$ increased similarly in both groups. $1 \mathrm{RM}$ leg extension strength increased by $42 \pm 3 \%$ (women) and $43 \pm 3 \%$ (men). Following training, type II muscle fiber size had increased and a type II muscle fiber specific increase in myonuclear and satellite cell content was observed with no differences between genders. Sit-to-stand time decreased similarly in both groups. Glycemic control and blood lipid profiles improved to a similar extent in both women and men. A generic resistance type exercise training program can be applied for both women and men to effectively counteract the loss of muscle mass and strength with aging. 


\section{Introduction}

Aging is accompanied by the progressive loss of muscle mass and muscle strength, referred to as sarcopenia (1). The loss of muscle mass and strength leads to a substantial decline in functional capacity, an increased risk of falls and fractures, and an increased risk of developing chronic metabolic diseases $(2,3)$. The relative loss of muscle mass and strength with age has been reported to be similar for men and women (4). However, the loss of muscle mass and strength may represent a greater health concern in women, as older women tend to suffer more from physical disabilities than older men (5). Effective interventions are required to prevent or treat the detrimental consequences of muscle mass and strength loss in both elderly women and men.

Resistance type exercise training has been well-established as an effective treatment strategy to counteract the loss of muscle mass and strength in the elderly population (6-9). Even in the very old population, substantial improvements in muscle mass, strength, and functional capacity have been observed following prolonged resistance type exercise training (10). Also at the muscle fiber level, it has been shown that both elderly men (11) and women (12) maintain the capacity to augment muscle fiber size and function. Despite the overwhelming evidence showing the efficacy of resistance type exercise training to increase muscle mass and strength in the elderly population, there is much discrepancy on the proposed benefits of resistance type exercise training in elderly women versus men. Previous work has suggested that muscle mass and strength gains following prolonged resistance type exercise training are either similar $(13,14)$, smaller $(15-17)$, or even greater $(18)$ in older women compared with older men. As it remains unclear whether women benefit to the same extent from prolonged resistance type exercise training as men, there is still no consensus on whether resistance type exercise training programs should be specifically tailored for gender.

Given the conflicting data on gender-based differences in the skeletal muscle adaptive response to prolonged resistance type exercise training, the purpose of the present study was to assess whether elderly men and women adapt differently to a generic prolonged resistance type exercise training program. In this study, we compare structural, functional, and metabolic adaptations to prolonged resistance type exercise training on a whole body, muscle, and muscle fiber level. We hypothesized that elderly men experience greater absolute but not relative gains in skeletal muscle mass and strength compared with women following 3 and 6 months of generic resistance type exercise training. As such, we speculate that a single generic resistance type exercise training program can be applied successfully in both elderly men and women. The latter would greatly facilitate the implementation of exercise training programs in the older population.

In this study, we selected 60 healthy elderly men $(n=31)$ and women $(n=29)$ to participate in a generic $24 \mathrm{wk}$ resistance type exercise training program ( 3 sessions per wk). Prior to and after 12 and 24 weeks of exercise training, we assessed skeletal muscle mass, muscle strength, functional capacity, muscle fiber characteristics, and meta- 
bolic profile. This study compares the clinical benefits of resistance type exercise training between older women and men and addresses the question whether the same generic exercise program can be used for both genders.

\section{Methods}

\section{Participants}

A total of 29 healthy, elderly women (70 \pm 1 y) and 31 healthy, elderly men (71 \pm 1 y) volunteered to participate in a $24 \mathrm{wk}$ resistance type exercise training program. Seven participants dropped out ( 2 men and 5 women) during the study, one because of a heart attack that occurred at home, one because of a transient ischemic attack that occurred at home, and the other 5 participants dropped out because of time constraints. Medical history of all participants was evaluated and an oral glucose tolerance test (OGTT) and resting electrocardiogram and submaximal electrocardiogram were performed prior to selection. Exclusion criteria were defined that would preclude successful participation in the exercise program, and included (silent) cardiac or peripheral vascular disease and orthopedic limitations. Furthermore, as insulin resistance and/or type 2 diabetes have been associated with a more progressive loss of muscle mass and strength with aging (19), type 2 diabetes patients were excluded from participation (20). All participants were living independently and had no history of participating in any structured exercise training program over the past 5 years. All participants were informed on the nature and possible risks of the experimental procedures, before their written informed consent was obtained. This study was approved by the Medical Ethics Committee of the Maastricht University Medical Centre ${ }^{+}$and is part of a greater project investigating the impact of combined dietary and exercise interventions to increase muscle mass and strength in different elderly populations (21-23).

\section{Study design}

Before, during, and after exercise intervention, anthropometric measurements (height, body mass, waist-hip ratio, leg volume)(24), strength assessment (one-repetition maximum; [1RM]), computed tomography, and dual-energy x-ray absorptiometry scans were performed, and muscle biopsies, blood samples, $24 \mathrm{~h}$ urine, and dietary intake and physical activity records were collected.

\section{Exercise intervention program}

Supervised resistance type exercise training was performed 3 times a week for a 24-wk period. Training consisted of a 5 min warm-up on a cycle ergometer, followed by 4 sets 
on both the leg press and leg extension machines (Technogym, Rotterdam, Netherlands). In addition, 3 sets were performed on the chest press and horizontal row, and (alternating) vertical lat pulldown and abdominal crunches, or biceps curl and triceps extension, followed by a 5 min cooling-down period on a cycle ergometer. During the first 4 weeks of training, the workload was increased from $60 \%$ of 1RM (10-15 repetitions in each set) to $75 \%$ of 1 RM (8-10 repetitions). Starting at week 5,4 sets of 8 repetitions were performed at $75-80 \%$ of 1 RM on leg press and leg extension. For the upper body exercises, 2 sets were increased to 3 sets starting in week 5 . Resting periods of $\sim 90 \mathrm{~s}$ between sets and $\sim 3 \mathrm{~min}$ between exercises were allowed. Workload intensity was adjusted based on the 1RM tests (performed at week 4, 8, 12, 16 and 20). In addition, workload was increased when more than 8 repetitions could be performed in 3 out of 4 sets. On average, subjects attended $90 \pm 1 \%$ of the scheduled exercise sessions in both groups.

\section{Dietary intake and physical activity standardization}

Standardized meals were provided to all subjects the evening prior to each test day. The subjects were instructed to refrain from strenuous physical activity for at least $3 \mathrm{~d}$ prior to testing. On all test days, participants arrived at the laboratory by car or public transportation following an overnight fast. To assess potential changes in habitual daily food intake and physical activity during the 6 month intervention period, the subjects recorded $4 \mathrm{~d}$ weighted dietary intake records and $2 \mathrm{~d}$ physical activity records. Dietary intake was recorded before, after $4,8,12,16,20$, and 24 weeks of intervention. Dietary records were analyzed with Komeet (Komeet, 4.059 BaS Nutrition Software, Arnhem, Netherlands). Habitual physical activity was recorded before, after 12 and 24 wk of intervention. For every type of activity, a mean equivalent task (MET) score was assigned to express the intensity of a specific activity as previously defined (25). One MET unit equals resting energy expenditure (i.e. $\sim 1 \mathrm{kcal}$ per $\mathrm{kg}$ body weight per $\mathrm{h}$ (25)). Energy expenditure was calculated as mean MET-h/d (26).

\section{Body composition}

Body composition and bone mineral content were measured with dual-energy $x$-ray absorptiometry (Hologic, Discovery A, QDR Series, Bradford, MA, USA). Whole-body and regional lean mass, fat mass, and bone mineral content were determined by using the system's software package Apex version 2.3. Anthropometrics were measured by trained observers with standard technique; weight by digital scale to within $100 \mathrm{~g}$; height by stadiometer to within $0.5 \mathrm{~cm}$; circumferences to within $1 \mathrm{~mm}$ using a measuring tape, with waist midway between the lowest rib and the iliac crest with the participant standing at the end of gentle expiration, and hips at the greater trochanters (27). All body composition measurements were assessed before, after 12 and 24 wk of the exercise program. 
Anatomical cross-sectional area (CSA) of the quadriceps muscle was assessed by computed tomography scanning (Philips Brilliance 64, Philips Medical Systems, Best, Netherlands) before, after 12 and 24 wk of the exercise intervention program ( $3 \mathrm{~d}$ after strength assessment and prior to muscle biopsy collection). The scanning characteristics were as follows: $120 \mathrm{kV}, 300 \mathrm{~mA}$, rotation time of $0.75 \mathrm{~s}$, and a field of view of $500 \mathrm{~mm}$. While the participants were lying supine, legs extended and their feet secured, a $3 \mathrm{~mm}$ thick axial image was taken $15 \mathrm{~cm}$ proximal to the base of the patella. The exact scanning position was measured and marked for replication at subsequent visits. Muscle area of the right leg was selected between 0 and 100 Hounsfield units (28), after which the quadriceps muscle was selected by manual tracing using ImageJ software (version 1.45d, National Institute of Health, Maryland, USA) (29). Using the described approach, we determined the CV for repeated scans ( 1 week apart) to be $0.8 \%$. All analyses were performed by 2 investigators blinded to participant coding; intra-class correlation coefficients for inter- and intra- investigator reliability were 1.0 and 1.0 , respectively.

\section{Muscle biopsy sampling}

Three days prior to the onset of the intervention, after $12 \mathrm{wk}$ of intervention, and immediately after cessation of the intervention ( $4 \mathrm{~d}$ after final strength testing), skeletal muscle biopsies were taken from the right leg of each subject, in the morning following an overnight fast. After local anesthesia was induced, percutaneous needle biopsy samples (50-80 mg) were collected from the vastus lateralis muscle, $\sim 15 \mathrm{~cm}$ above the patella (30). Any visible non-muscle tissue was removed immediately, and biopsy samples were embedded in Tissue-Tek (Sakura Finetek, Zoeterwoude, Netherlands), frozen in liquid nitrogen-cooled isopentane, and stored at $-80^{\circ} \mathrm{C}$ until further histological analyses.

\section{Immunohistochemistry}

From all biopsies, 5- $\mu \mathrm{m}$ thick cryosections were cut at $-20^{\circ} \mathrm{C}$. Pre, $12 \mathrm{wk}$, and $24 \mathrm{wk}$ samples from each participant were mounted together on uncoated glass slides. Care was taken to properly align the samples for cross-sectional fiber analyses. Muscle biopsies were stained for muscle fiber typing and myocellular satellite cell content as described previously (31), with slight modifications. In short, the slides were incubated with primary antibodies against MHC-I (A4.840, Developmental Studies Hybridoma Bank, lowa City, IA), CD56 (BD Biosciences, San Jose, CA), and laminin (polyclonal laminin, Sigma, Zwijndrecht, Netherlands). After washing (PBS), slides were incubated with biotinylated goat-anti-mouse IgG (Vector Laboratories, Burlingame, CA) to optimize staining results for CD56. After another wash, appropriate secondary antibodies were applied: goat anti-mouse IgM AlexaFluor555 and goat anti-rabbit IgG AlexaFluor647 (Molecular Probes, Invitrogen, Breda, Netherlands), for MHC-I and laminin, respective- 
Iy; and Streptavidin AlexaFluor488 (Vector Laboratories) for CD56. Nuclei were stained with 4,6-diamidino-2-phenylindole (DAPI, $0.238 \mu \mathrm{M}$; Molecular Probes). After a final washing step, all slides were mounted with cover glasses using Mowiol (Calbiochem, Amsterdam, the Netherlands).

Images were visualized and automatically captured at $\times 10$ magnification with a fluorescent microscope equipped with an automatic stage (IX81 motorized inverted microscope, Olympus, Hamburg, Germany). The image was centered and focused on each section, after which the microscope was programmed to automatically capture a series of images to record the entire section. All images were then pasted together to reproduce a single image file of the entire biopsy section, including all four fluorescent channels (i.e. a DAPI UV excitation filter [360-370 nm] for the nuclei, a fluorescein isothiocyanate excitation filter [470-495] for CD56, a tetramethyl rhodamine isothiocyanate excitation filter [540-570 nm] for MHC-I, and a Cy5 excitation filter [590-650 nm] for laminin). Using ImageJ software individual fibers were localized using the laminin outline, and a Region of Interest (ROI) list was created listing all individual fibers. Muscle fiber type (fiber\%), and fiber CSA were measured for each separate muscle fiber. As such, mean muscle fiber size was calculated for the type I and type II muscle fibers separately. Subsequently, the number of myonuclei, and the number of satellite cells were measured for each separate muscle fiber. Satellite cells were identified at the periphery of muscle fibers and stained positive for both CD56 and DAPI (31). For each biopsy, myonuclear and satellite cell content were calculated for the type I and type II muscle fibers separately. As a measure of fiber circularity, form factors were calculated by using the following formula: $(4 \pi \cdot \mathrm{CSA}) /$ (perimeter) ${ }^{2}$. All image recordings and analyses were performed by an investigator blinded to subject coding. No differences in fiber circularity were observed over time or between groups. Mean numbers of $442 \pm$ $24,403 \pm 21$, and $425 \pm 20$ muscle fibers were analyzed in the biopsy samples collected at baseline and after 12 and 24 wk of intervention, respectively.

\section{Strength assessment}

Maximum strength was assessed by 1RM strength tests on leg press and leg extension machines and for the upper body exercises (Technogym, Rotterdam, Netherlands). During a familiarization trial, proper lifting technique was demonstrated and practiced, and maximum strength was estimated using the multiple repetitions testing procedure (32). In an additional session, at least one week prior to muscle biopsy collection, each participant's 1RM was determined as described previously (33). 1RM testing is preferred to evaluate changes in muscle strength during resistance type exercise training (34). Therefore, 1RM tests were repeated for upper body and leg exercises after 4, 8, 12,16 and 20 wk of intervention and $2 \mathrm{~d}$ after the last training session of the intervention program. 


\section{Physical performance measures}

To assess lower and upper extremity physical performance, a sit-to-stand test and a hand grip test were performed prior to the onset of the intervention, after $12 \mathrm{wk}$ of intervention, and immediately after cessation of the intervention. For the sit-to-stand test, the participants were instructed to fold their arms across their chest and to stand up/sit down 5 times, as fast as possible, from a seat at $0.42 \mathrm{~m}$ from the floor. Time was recorded from the initial sitting to the final standing position. The fastest out of 2 rises was used for analysis (35). Data on maximal handgrip strength were obtained using a JAMAR handheld dynamometer (model BK-7498, Fred Sammons, Inc., Burr Ridge, IL, USA). Grip strength was measured 3 times with each hand. The highest value using the stronger hand is reported (36).

\section{Blood samples}

Before and after 24 wk of intervention, fasting blood samples were collected to determine basal plasma glucose and insulin concentrations, plasma amino acid and lipid profiles, serum creatinine, and blood glycated hemoglobin (HbA1c) content. Blood (10 $\mathrm{mL}$ ) was collected into EDTA-containing tubes and serum tubes. EDTA tubes were immediately centrifuged at $1,000 \mathrm{~g}$ for $10 \mathrm{~min}$ at $4^{\circ} \mathrm{C}$ and the serum tubes were centrifuged at $1,000 \mathrm{~g}$ for $15 \mathrm{~min}$ at $21^{\circ} \mathrm{C}$ after allowing the blood to clot for $90 \mathrm{~min}$ at $21^{\circ} \mathrm{C}$. Aliquots of plasma and serum were immediately frozen in liquid nitrogen and stored at $-80^{\circ} \mathrm{C}$ until further analysis. Plasma insulin concentrations were determined by using an Insulin RIA Kit (LINCO Research Inc, St Charles, MO). Reagents to determine plasma glucose, triglycerides, total cholesterol and high-density lipoprotein (HDL) cholesterol were from ABX Diagnostics (Montpellier, France). Plasma free fatty acid concentrations were analyzed with the NEFA C test kit from Wako Chemicals (Neuss, Germany). As plasma triacylglycerol concentrations were below $4.5 \mathrm{mmol} / \mathrm{L}$, plasma low-density lipoprotein (LDL) cholesterol could be calculated by LDL cholesterol=total cholesterol HDL cholesterol - triacylglycerol/2.2 (in $\mathrm{mmol} / \mathrm{L}$ ). Serum creatinine concentrations were determined using the Jaffe rate method on a Synchron LX Systems analyzer (Beckmann Coulter Inc., Fullerton, CA). To determine blood HbA1c content, $3 \mathrm{~mL}$ blood was collected in EDTA containing tubes and analyzed by high-performance liquid chromatography (Bio-Rad Variant II 4, Munich, Germany). Total serum testosterone and sex hormone-binding globulin (SHBG) concentrations were measured using reagents from Roche Diagnostics (Mannheim, Germany), and assays were run on a Modular Analytics E170 analyzer (Hitachi Data Systems, Santa Clara, CA, USA). The intraassay CVs are $2.7 \%$ to $1.8 \%$ and $1.1 \%$ to $1.7 \%$ for low to high concentrations of testosterone and SHBG, respectively. Bioavailable testosterone was calculated as non-SHBGbound testosterone using a formula described and validated previously (37). 


\section{Statistics}

Data are expressed as means \pm SEM. Baseline characteristics between groups were compared by means of an independent samples $t$ test. Training-induced changes were analyzed using repeated-measures ANOVA with time (pre, 12 wk, 24 wk) as withinsubjects factor and gender as between-participants factor. In case of significant main effects or interactions, post hoc testing with Bonferroni correction and/or separate analyses within groups was performed where appropriate. In addition to the repeatedmeasures analysis, relative changes over time were calculated and analyzed by independent $t$ test to detect potential differences between groups. Because the results for both analyses were identical, we report both absolute and relative changes but only present $P$ values for the repeated-measures analyses, unless otherwise stated. Significance was set at $P<0.05$. All calculations were performed using SPSS version 17.0 (Chicago, IL, USA).

\section{Results}

\section{Participants}

Participants' characteristics are provided in Table 1. In total, 53 subjects completed the resistance type exercise training program, 24 women (71 \pm 1 y) and 29 men (70 \pm 1 y). Men were taller and heavier with a lower body fat percentage (fat\%) and a lower $\mathrm{HbA1c}$ level when compared with the women. No significant changes in bodyweight, height, and BMI were observed over time. Systolic blood pressure significantly decreased between 12 and $24 \mathrm{wk}$ of intervention in both the women (from $138 \pm 3$ to $133 \pm 4 \mathrm{mmHg}$ ) and the men (140 \pm 2 to $134 \pm 2 \mathrm{mmHg}$ ), with no differences between genders $(P<0.0001)$. Diastolic blood pressure decreased significantly between 12 and 24 wk of intervention, with no differences between genders (from $74 \pm 2$ to $69 \pm 2$ $\mathrm{mmHg}$ in women and from $76 \pm 2$ to $70 \pm 2 \mathrm{mmHg}$ in men; $P<0.0001$ ).

\section{Body composition}

Prior to the exercise intervention, women and men differed in whole-body lean mass, leg lean mass, and bone mineral content (Table 2). The resistance training program resulted in an absolute increase in whole-body lean mass of $1.2 \pm 0.2$ and $1.2 \pm 0.3 \mathrm{~kg}$ in the women and men, respectively $(P<0.001)$, with no differences between groups $(P=0.94)$. Leg lean mass increased by $3 \pm 1 \%(0.5 \pm 0.1 \mathrm{~kg})$ and $3 \pm 1 \%(0.6 \pm 0.1 \mathrm{~kg})$ in the women and men respectively $(P<0.001)$, with no differences between groups $(P=$ 0.69 ). The increase in lean mass was accompanied by a $5 \pm 2 \%$ and $6 \pm 1 \%$ decrease in fat mass, respectively $(P<0.001)$. No significant differences were observed for the 
intervention effects between women and men for any of the DXA variables (Table 2). At baseline, bone mineral content was significantly lower in the women compared with the men $(1.9 \pm 0.1$ vs $2.8 \pm 0.1 \mathrm{~kg})$. No changes were observed in bone mineral content during the 6 month intervention (data not shown).

Table 1: Subjects' characteristics

\begin{tabular}{lcc}
\hline & Women $(n=24)$ & Men $(n=29)$ \\
\hline Age $(\mathrm{y})$ & $71 \pm 1$ & $70 \pm 1$ \\
Body weight $(\mathrm{kg})$ & $65.6 \pm 1.6$ & $84.3 \pm 1.7^{*}$ \\
Height $(\mathrm{m})$ & $1.63 \pm 0.01$ & $1.77 \pm 0.01^{*}$ \\
BMI $\left(\mathrm{kg} / \mathrm{m}^{2}\right)$ & $24.6 \pm 0.4$ & $27.0 \pm 0.5^{*}$ \\
Fat $(\%)$ & $32 \pm 1$ & $23 \pm 1^{*}$ \\
Basal plasma glucose $(\mathrm{mmol} / \mathrm{L})$ & $5.4 \pm 0.1$ & $5.6 \pm 0.1$ \\
HbA1c $(\%)$ & $5.8 \pm 0.1$ & $5.5 \pm 0.1^{*}$ \\
\hline
\end{tabular}

All values represent means \pm SEM. HbA1c: blood glycosylated hemoglobin. Data were analyzed using independent samples t-test.

* Significantly different from women $(P<0.05)$.

Table 2: Body composition

\begin{tabular}{|c|c|c|c|c|c|c|}
\hline \multirow[b]{2}{*}{ Week } & \multicolumn{3}{|c|}{ Women $(n=24)$} & \multicolumn{3}{|c|}{ Men $(n=29)$} \\
\hline & 0 & 12 & 24 & 0 & 12 & 24 \\
\hline Total mass (kg) & $65.6 \pm 1.6$ & $66.2 \pm 1.6$ & $65.9 \pm 1.6$ & $84.3 \pm 1.7$ & $84.7 \pm 1.6$ & $84.3 \pm 1.7$ \\
\hline Lean mass (kg) & $42.5 \pm 0.9$ & $43.5 \pm 0.9 *$ & $43.7 \pm 1.0^{*}$ & $62.2 \pm 1.0$ & $63.3 \pm 1.1^{*}$ & $63.4 \pm 1.0^{*}$ \\
\hline Leg lean mass (kg) & $13.6 \pm 0.4$ & $13.9 \pm 0.4^{*}$ & $14.0 \pm 0.4^{* \#}$ & $19.8 \pm 0.3$ & $20.2 \pm 0.4^{*}$ & $20.4 \pm 0.4^{* \#}$ \\
\hline Fat mass (kg) & $21.2 \pm 0.9$ & $20.7 \pm 0.9 *$ & $20.3 \pm 0.9 *^{\#}$ & $19.3 \pm 1.0$ & $18.6 \pm 0.9^{*}$ & $18.1 \pm 0.9 *^{\#}$ \\
\hline Fat (\%) & $32.1 \pm 0.8$ & $31.0 \pm 0.8^{*}$ & $30.5 \pm 0.8^{* \#}$ & $22.6 \pm 0.8$ & $21.8 \pm 0.8^{*}$ & $21.2 \pm 0.8^{* \#}$ \\
\hline
\end{tabular}

All values represent means \pm SEM. Data were analyzed using repeated-measures ANOVA with time as withinsubjects factor and gender as between-subjects factor. No time $\mathrm{x}$ gender interaction was observed.

* Significantly different from wk 0.

\# Significantly different from wk 12.

\section{Skeletal muscle hypertrophy}

At baseline, quadriceps CSA was significantly smaller in women compared with the men (46.6 vs $68.8 \mathrm{~cm}^{2}$, respectively). Following the first $12 \mathrm{wk}$ of intervention, quadriceps CSA had increased by $8 \pm 1 \%\left(3.5 \pm 0.5 \mathrm{~cm}^{2}\right)$ and $7 \pm 1 \%\left(4.6 \pm 0.5 \mathrm{~cm}^{2}\right)$ in the women and men, respectively $(P<0.001)$, with no differences between genders (Figure 1). During the subsequent period from wk 12 to wk 24, we observed a significant gender $\mathrm{x}$ training interaction $(P<0.05)$. Whereas no significant increase in quadriceps CSA was observed in the women, CSA further increased by $1.7 \pm 0.4 \mathrm{~cm}^{2}$ in the men during the last 12 wks of exercise training. Nonetheless, the percentage change in 
quadriceps CSA between 12 and 24 wk of intervention did not differ significantly between the women $(1 \pm 1 \%)$ and men $(2 \pm 1 \%)$.

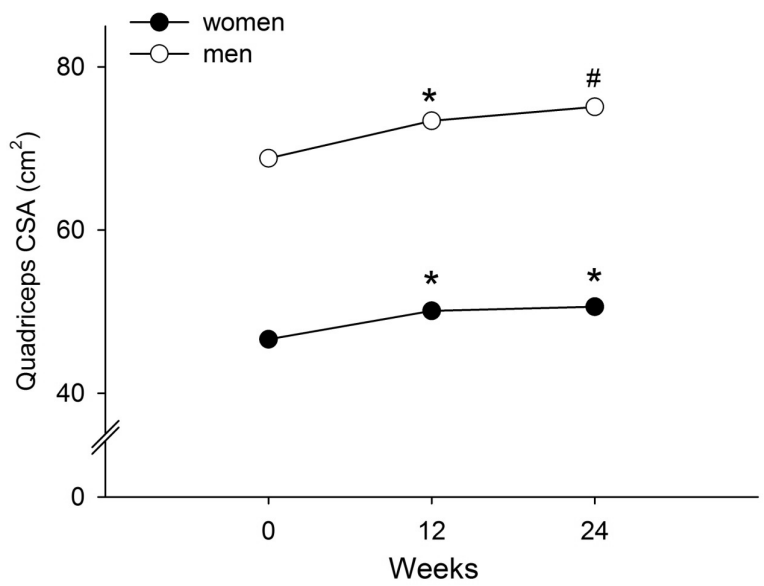

Figure 1: Mean ( \pm SEM) quadriceps CSA before, after 12 and 24 wk of resistance type exercise training in elderly women and men. Data were analyzed using repeated measures ANOVA with time as a withinsubjects factor and gender as a between-subjects factor. A significant time $x$ gender interaction was observed between 12 and 24 wk of intervention $(P<0.05)$. ${ }^{*}$ Significantly different from before the intervention, $P<0.001$. "Significantly different from wk 0 and $12, P<0.001$.

At baseline muscle fiber CSA was significantly smaller in the type II vs the type I muscle fibers in both the women $\left(3167 \pm 216\right.$ vs $\left.5103 \pm 271 \mu \mathrm{m}^{2}\right)$ and the men $(5126 \pm 193$ vs $5802 \pm 209 \mu^{2}$ ), respectively. In addition, prior to intervention type II muscle fiber CSA was significantly smaller in the women compared with the men (Figure 2A). In contrast to the type I muscle fibers, type II muscle fiber CSA significantly increased in both the women (from $3167 \pm 216$ to $3891 \pm 269 \mu \mathrm{m}^{2}$ ) and the men (from $5126 \pm 193$ to $6120 \pm 325 \mu^{2}$ ), with no differences between groups (Figure 3). Likewise, the relative increase in type II muscle fiber CSA was comparable between the women and the men ( $29 \pm 7$ vs $24 \pm 7 \%$, respectively; $P=0.68$ ). Type I and type II muscle fiber percentage did not change over the 6 months of exercise intervention. However, the specific type II muscle fiber hypertrophy resulted in an increase in type II muscle fiber area percentage in the women and the men (from $38 \pm 2$ to $43 \pm 2 \% ; P<0.05$ ). No gender differences were observed. 

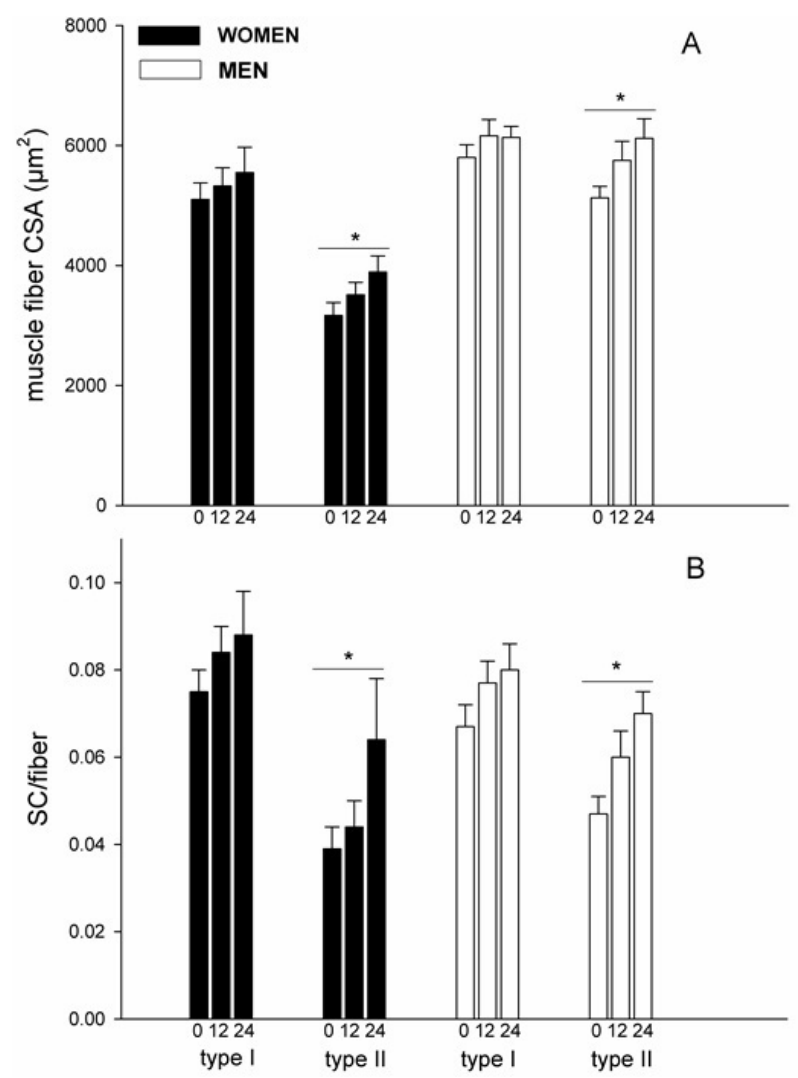

Figure 2: A: Mean ( \pm SEM) muscle fiber cross-sectional area (CSA) for type I and type II muscle fibers before, after $12 \mathrm{wk}$ and $24 \mathrm{wk}$ of resistance type exercise training in elderly women and men. Data were analyzed using repeated measures ANOVA with time as withinsubjects factor and gender as between-subjects factor. No time $x$ gender interactions were observed. ${ }^{*}$ Significant increase over time $P$ $<0.01$.

B: Mean ( \pm SEM) number of satellite cells (SC) per type I and type II muscle fiber before, after $12 \mathrm{wk}$ and $24 \mathrm{wk}$ of resistance type exercise training in elderly women and men. Data were analyzed using repeated measures ANOVA with time as within-subjects factor and gender as between-subjects factor. No time $x$ gender interactions were observed. * Significant increase over time $P<0.01$.

\section{Myonuclear and satellite cell content}

In line with the smaller type II vs type I muscle fiber size, myonuclear content was lower in the type II vs type I muscle fibers at baseline in both the women ( $2.5 \pm 0.2$ vs $3.4 \pm 0.2$ nuclei per fiber) and men ( $3.4 \pm 0.2$ vs $4.0 \pm 0.2$ nuclei per fiber) $(P<0.001)$. In addition, type II muscle fiber myonuclear content was significantly lower in the women 
compared with the men $(P<0.01)$. In contrast to the type I muscle fibers, the number of myonuclei per type II muscle fiber significantly increased in both the women (from $2.5 \pm 0.2$ to $2.7 \pm 0.2$ ) and men (from $3.4 \pm 0.2$ to $3.8 \pm 0.2)(P<0.05)$, with no differences between groups. At baseline, satellite cell content was significantly lower in the type II vs type I muscle fibers in both the women $(0.039 \pm 0.005$ vs $0.075 \pm 0.005$ satellite cells per muscle fiber) and men (0.047 \pm 0.004 vs $0.067 \pm 0.005$ satellite cells per muscle fiber) $(P<0.001)$, with no differences between genders. Whereas there was only a tendency for satellite cell content to increase in the type I muscle fibers $(P=$ $0.065)$, the number of satellite cells per type II muscle fiber significantly increased following $24 \mathrm{wk}$ of resistance type exercise training (Figure 2B; $P<0.01$ ). The increase in satellite cell content was apparent for both the women (from $0.039 \pm 0.005$ to 0.064 \pm 0.014 ) and the men (from $0.047 \pm 0.004$ to $0.070 \pm 0.005$ ), with no differences between groups.

\section{Muscle strength}

Prior to intervention, muscle strength was lower in the women when compared with the men (Figure 3). In response to training, leg press $1 \mathrm{RM}$ increased by $31 \pm 3 \%$ in the women (from $138 \pm 5$ to $179 \pm 5 \mathrm{~kg} ; P<0.001$ ) and by $26 \pm 2 \%$ in the men (from $207 \pm$ 4 to $260 \pm 2 \mathrm{~kg} ; P<0.001$ ). No significant gender $\mathrm{x}$ training interaction was observed for leg press $1 R M$. In contrast, for leg extension $1 R M$, a significant gender $x$ training interaction was observed, indicating that strength gains were larger in the men compared with the women $(P<0.002)$. However, relative strength gains for both the leg extension and leg press did not differ between the women and men ( $42 \pm 3$ vs $43 \pm 3 \%$ and $31 \pm 3$ vs $26 \pm 2 \%$, respectively). For all upper body exercises, both absolute and relative strength gains were similar for men and women (on average $42 \pm 3$ and $47 \pm$ $3 \%$, respectively).

\section{Physical performance}

Prior to the exercise intervention, no significant differences were observed in sit-tostand time between women and men $(7.7 \pm 0.3$ vs $7.8 \pm 0.3 \mathrm{~s}$, respectively). After 24 wk of intervention, sit-to-stand time had decreased significantly by $18 \pm 2$ and $19 \pm 2 \%$, respectively $(P<0.001)$. No significant differences were observed between women and men. At baseline, handgrip strength was significantly lower in the women compared with the men ( $26 \pm 1$ vs $43 \pm 2 \mathrm{~kg}$, respectively). No changes in handgrip strength were observed over time. 


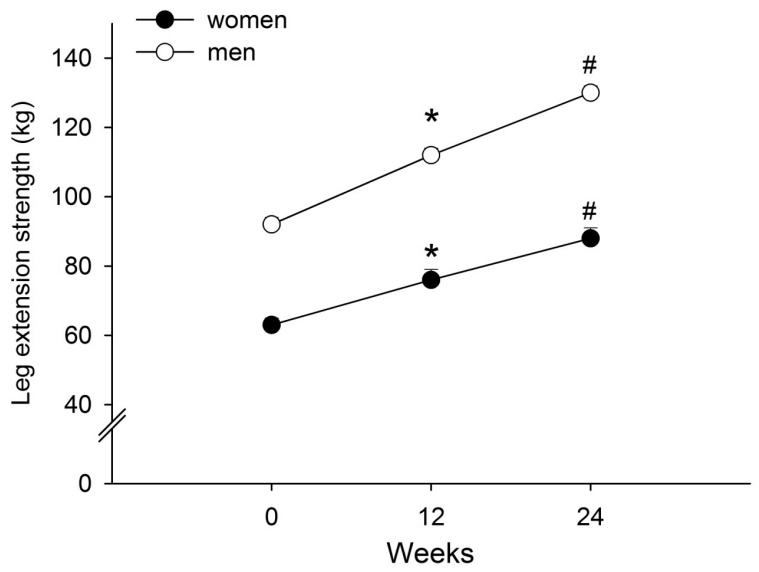

Figure 3: Mean ( \pm SEM) leg extension 1 RM before, after 12 and 24 wk of resistance type exercise training in elderly women and men. Data were analyzed using repeated measures ANOVA with time as a within-subjects factor and gender as a between-subjects factor. A significant time $x$ gender interaction was observed $(P<0.001)$. ${ }^{*}$ Significantly different from baseline, $P<0.001$.

\#Significantly different from wk 0 and $12, P<0.001$.

\section{Glycemia and lipidemia}

Prior to intervention blood HbA1c contents (5.8 \pm 0.1 vs $5.5 \pm 0.1 \%$ ) and whole-body insulin sensitivity indices (OGIS: $454 \pm 8$ vs $427 \pm 9$ ) differed significantly between the women and men, respectively $(P<0.05$; Table 3$)$. All other baseline measures of glycemic control did not differ between women and men. Over time, a significant decline in blood HbA1c content was observed in both the women and men (from $5.8 \pm 0.1$ and $5.5 \pm 0.1$ to $5.7 \pm 0.1 \%$ and $5.4 \pm 0.1 \%$, respectively; $P<0.02$ ). Accordingly, we also observed an increase in ISI and OGIS over time. For all measures no interaction was observed with gender. At baseline, plasma LDL, HDL and total cholesterol concentrations were higher in the women compared with the men (Table 3). Over time significant improvements in total cholesterol and LDL were observed in both groups with no difference between genders.

\section{Hormonal profiles}

At baseline, average serum concentrations of total testosterone, bioavailable testosterone, and sex hormone-binding globulin (SHBG) concentrations averaged $0.79 \pm 0.13$ $\mathrm{nmol} / \mathrm{L}, 0.18 \pm 0.02 \mathrm{nmol} / \mathrm{L}$ and $89.52 \pm 8.32 \mathrm{nmol} / \mathrm{L}$ in the women and $17.08 \pm 1.15$ $\mathrm{nmol} / \mathrm{L}, 6.14 \pm 0.32 \mathrm{nmol} / \mathrm{L}$ and $56.00 \pm 3.99 \mathrm{nmol} / \mathrm{L}$ in the men. Whereas obvious 
gender differences were observed for all hormones, no significant changes over time and no time $x$ gender interactions were observed.

Table 3: Glycemic control and plasma lipid concentrations

\begin{tabular}{|c|c|c|c|c|}
\hline \multirow[b]{2}{*}{ Week } & \multicolumn{2}{|c|}{ Women $(n=24)$} & \multicolumn{2}{|c|}{ Men $(n=29)$} \\
\hline & 0 & 24 & 0 & 24 \\
\hline \multicolumn{5}{|l|}{ Glycemic control } \\
\hline Plasma glucose (mmol/L) & $5.4 \pm 0.1$ & $5.2 \pm 0.1$ & $5.6 \pm 0.1$ & $5.7 \pm 0.1$ \\
\hline Plasma insulin (mU/L) & $13.7 \pm 1.2$ & $13.2 \pm 1.3$ & $14.5 \pm 0.9$ & $14.5 \pm 0.9$ \\
\hline HbA1c (\%) & $5.8 \pm 0.1$ & $5.7 \pm 0.1^{*}$ & $5.5 \pm 0.1$ & $5.4 \pm 0.1^{*}$ \\
\hline Insulin sensitivity index & $3.8 \pm 0.4$ & $4.2 \pm 0.3^{*}$ & $3.1 \pm 0.3$ & $3.4 \pm 0.4^{*}$ \\
\hline Oral glucose insulin sensitivity & $454 \pm 8$ & $475 \pm 10^{*}$ & $427 \pm 9$ & $440 \pm 8^{*}$ \\
\hline \multicolumn{5}{|l|}{ Plasma lipid concentrations } \\
\hline Free fatty acids ( $\mu \mathrm{mol} / \mathrm{L})$ & $456 \pm 34$ & $430 \pm 41$ & $450 \pm 30$ & $424 \pm 34$ \\
\hline Triglycerides (mmol/L) & $1.11 \pm 0.11$ & $1.14 \pm 0.10$ & $1.25 \pm 0.07$ & $1.20 \pm 0.09$ \\
\hline Total Cholesterol (mmol/L) & $6.84 \pm 0.19$ & $6.43 \pm 0.18^{*}$ & $5.83 \pm 0.21$ & $5.62 \pm 0.21^{*}$ \\
\hline High-density lipoprotein (mmol/L) & $1.92 \pm 0.08$ & $1.97 \pm 0.08$ & $1.55 \pm 0.08$ & $1.59 \pm 0.09$ \\
\hline Low-density lipoprotein (mmol/L) & $4.46 \pm 0.18$ & $3.98 \pm 0.18^{*}$ & $3.76 \pm 0.18$ & $3.53 \pm 0.17^{*}$ \\
\hline
\end{tabular}

All values represent means \pm SEM. HbA1c = blood glycosylated hemoglobin. Data were analyzed by using repeated-measures ANOVA with time as within-subjects factor and gender as between-subjects factor. No time $x$ gender interaction was observed.

*Significantly different from wk 0

\section{Creatinine and urinary nitrogen}

Serum creatinine concentrations were within the normal range ( $>60 \mu \mathrm{mol} / \mathrm{L})$ prior to the intervention. At baseline, women differed significantly from men (77.0 \pm 2.6 vs $91.5 \pm 2.9 \mu \mathrm{mol} / \mathrm{L}$, respectively). No changes were observed over time in either group. Creatinine clearance was within the normal range $\left(>60 \mathrm{~mL} / \mathrm{min}\right.$ per $\left.1.73 \mathrm{~m}^{2}\right)$ prior to the intervention. At baseline, no significant differences were observed between the women and men $\left(82.2 \pm 3.1\right.$ vs $87.5 \pm 4.7 \mathrm{~mL} / \mathrm{min}$ per $1.73 \mathrm{~m}^{2}$, respectively). No changes were observed over time in either group. Prior to the intervention, 24-h nitrogen balance was $1.3 \pm 0.4 \mathrm{~g} / \mathrm{d}$ in the women and $-0.1 \pm 0.5 \mathrm{~g} / \mathrm{d}$ in the men. Nitrogen balance did not change over time in either group.

\section{Discussion}

In the present study, we show that traditional, prolonged resistance type exercise training effectively increases muscle mass, strength and functional performance and improves metabolic profile in both elderly men and women. No gender differences were observed in the adaptive response to prolonged resistance type exercise training. 
Elderly men and women benefited equally from the same generic resistance type exercise training regimen.

Resistance type exercise training has been well established as an effective treatment strategy to counteract the loss of muscle mass and strength in the elderly (6-10, $31,38-43)$. Yet, whether there are gender specific differences in the adaptive response to prolonged resistance type exercise training in the elderly remains equivocal. Whereas some report gender-specific differences in the adaptation to prolonged resistance type exercise training $(15,16,18)$ others fail to detect differences in the impact of prolonged exercise training on structural, functional and/or metabolic adaptations between men and women $(14,17)$. This study is the first to assess differences in gains in muscle mass and strength, increases in functional capacity as well as metabolic adaptation following prolonged, resistance type exercise training in a large cohort elderly men and women. On the whole-body level, we show that increases in lean mass are similar between the elderly women and men (Table 2). The increase in whole-body lean mass was mainly attributed to the increase in leg lean mass which was $\sim 3 \%$ in both women and men. These data are in line with Bamman et al (15), who reported similar absolute gains in whole-body lean mass in women and men in response to 26 wk of knee extensor training. Several studies also reported a significant increase in thigh muscle cross-sectional area ranging from 2 to $9 \%$ following resistance type exercise training in men $(7,8,44)$ and women $(45,46)$. However, these studies did not make a comparison between genders to assess whether men and women respond to the same extent. By actually comparing the response to $9 \mathrm{wk}$ of (unilateral) resistance type exercise training between genders, Tracy et al (17) reported a greater absolute increase in quadriceps muscle volume in elderly men when compared with women. However, percent increases in muscle volume were similar between the women and men (17). Our study confirms these latter findings, indicating that whereas absolute increases in quadriceps CSA are greater in men compared with women (6.2 \pm 0.6 vs $4.0 \pm 0.4 \mathrm{~cm}^{2}$, respectively), the relative increase in muscle mass remains similar between men and women ( $9 \%)$.

The loss of skeletal muscle mass with aging is associated with specific type II muscle fiber atrophy $(33,47,48)$. In agreement, we observed that type II muscle fiber CSA was significantly smaller than type I fiber CSA in both the women and men (Figure 3). Comparisons with type I and II muscle fiber size of muscle tissue collected in young adults from our laboratory $(33)$ as well as others $(47,48)$, clearly shows that specific type II muscle fiber atrophy is a hallmark of senescent muscle. Furthermore, we confirm and extend on our previous findings in men (31) by showing that type II muscle fiber atrophy with aging is associated with a specific decline in type II muscle fiber satellite cell content in both elderly men and women. In line with previous observations $(9,49,50)$, type II muscle fiber CSA increased following resistance type exercise training, with no significant changes in type I muscle fiber CSA. This study extends on these data by the comparison of changes in type I and II muscle fiber size between the men and women (Figure 3A). Type II muscle fiber CSA increased by $29 \pm 7$ and $24 \pm 7 \%$ in the women 
and men, respectively after training. We detected no gender differences in muscle fiber hypertrophy following 3 and 6 months of resistance type exercise training. In accordance, we observed a type II muscle fiber specific increase in myonuclear and satellite cell content, with no differences between groups (Figure 3B). This is the first study to show that the lower type II muscle fiber size and satellite cell content with aging can be enhanced to the same extent in both elderly men and women by prolonged resistance type exercise training. This seems to be at odds with previous data by Bamman et al (15) who reported that muscle fiber hypertrophy was greater in men when compared with women. However, the latter findings were observed in a relative small group ( $n=14$, with only 5 women included) when compared to the present findings ( $n=53$, with 24 women included). Therefore, we conclude that type II muscle fiber hypertrophy is achieved in both men and women, with no apparent differences between genders. As a consequence of the training-induced gain in type II muscle fiber CSA, the relative type II muscle fiber atrophy observed prior to intervention was no longer apparent after $24 \mathrm{wk}$ of intervention in the men. In contrast, despite the substantial $29 \pm 7 \%$ type II muscle fiber hypertrophy, muscle fiber size was still significantly smaller in the type II vs type I muscle fibers after $24 \mathrm{wk}$ of intervention in the women. The latter clearly shows the relevance of effective interventions to maintain or even increase type II muscle fiber size in women, as baseline type II muscle fiber size is even more compromised in the women compared with the men. Importantly though, muscle tissue in both older women and men is still capable of inducing satellite cell proliferation, differentiation, and fusion of new myonuclei into existing muscle fibers, resulting in type II muscle fiber hypertrophy.

The loss of strength with aging is generally greater than can be predicted based on the loss of muscle mass (51). This is likely attributed to changes in muscle quality (i.e. the maximal strength per unit of muscle mass) as well as impairments in neuromuscular function (52). Goodpaster et al (28) showed that fat infiltration of the muscle is associated with lower muscle strength per CSA. As such, intermuscular adipose tissue infiltration likely represents an important contributor to the loss of muscle quality and, therefore, the loss of muscle strength and function with aging.

In line with the more pronounced decline in muscle strength versus muscle mass with aging, we observed a massive increase in muscle strength following the onset of exercise training in our volunteers. Various resistance type exercise training studies in elderly population, using different training and testing methods, have observed increases in $1 R M$ leg extension muscle strength ranging from $27 \%$ to $113 \%(7,9,10,15$, $17,45,53)$. In this study, absolute strength increases appeared to be lower in the women when compared with the men. The latter was apparent for both the leg press ( $41 \pm 3$ vs $53 \pm 3 \mathrm{~kg}$ ) and leg extension ( $26 \pm 2$ vs $38 \pm 2 \mathrm{~kg}$ ) exercises. The larger absolute increase in leg press compared to the leg extension can be explained by the different nature of the exercises; i.e., multi-joint versus isolating the quadriceps muscle (34). However, when expressed relative to pre-intervention values increases in strength were similar between women and men for the leg press (31 \pm 3 vs $26 \pm 2 \%$ ) and leg 
extension ( $42 \pm 3$ vs $43 \pm 3 \%$ ) exercise. These findings confirmed the observations by Tracy et al (17) who studied whether gender affects the increase in muscle strength due to resistance type exercise training in the elderly over a period of $9 \mathrm{wk}$. Although they showed a greater absolute increase in muscle strength for the men compared to the women, the relative changes were comparable between genders ( 27 vs $29 \%$, respectively). Bamman et al (15) also observed substantial increases in muscle strength over 26 wk of training. They confirmed that men gained more absolute strength than women. We speculate that baseline differences in muscle strength may at least partly explain previously reported differences in the increase in muscle strength between genders. This is confirmed by the positive correlation between baseline leg extension strength and the absolute increase in leg extension $(r=0.31, P<0.05)$ and the positive correlation between baseline leg press strength and the absolute increase in leg press ( $r=0.33, P<0.05)$ observed in the present study. Furthermore, when correcting for baseline strength values by calculating percentage changes, the gender differences in strength gains had completely disappeared.

It is clear that several daily tasks, such as rising from chair, climbing stairs, and walking are influenced by muscle strength, especially in older people (54). The clinical relevance of increasing muscle strength in the elderly was shown by Capodaglio et al (55) and Fiatarone et al (10), who observed improvements in functional capacity following resistance type exercise training. Nevertheless, gender comparisons of the increase in functional capacity following resistance type exercise training are lacking. In this study we also assessed functional parameters; sit-to-stand time and handgrip strength. Sit-to-stand time improved significantly in both the women and the men. Although there is a large difference in muscle strength between genders, the increase in strength due to resistance type exercise training improves sit-to-stand time to the same extent in both women and men. Notably, whereas there were large gender differences in muscle mass and strength already at baseline (even when corrected for body mass), functional capacity measured as sit-to-stand time was similar for the men and women. This supports the idea that functional capacity is not merely explained by muscle strength, but other factors such as neurological function should also be taken into account. No changes were observed over time in handgrip strength in either women or men. Though a potentially relevant marker in large cross-sectional studies (56), this study clearly shows that handgrip strength does not represent a clinically relevant and/or valid measure to assess individual changes in muscle function in response to prolonged resistance type exercise training programs.

Together with the increases in muscle mass, strength and function, we also observed significant improvements in several risk factors for metabolic disease. These improvements are normally attributed to the impact of prolonged endurance type exercise training. Glycemic control improved similarly in both the women and the men as evidenced by a $0.1 \%$ decrease in $\mathrm{HbA1c}$ as well as a significant increase in ISI and OGIS. Our findings confirm previous studies in middle aged subjects and elderly women (57-59), and extend on those findings by showing that resistance type exercise 
training improves whole body insulin sensitivity and glycemic control to the same extent in elderly women and men. The improvement in glycemic control was accompanied by an improvement in the lipid profile. In addition, we observed significant improvements in both total cholesterol and LDL in the women as well as in the men, with no differences between genders. These findings confirmed the observations of Martins et al (60), supporting a role for resistance type exercise also in the prevention and/or treatment of chronic metabolic disease in the elderly population. It should be noted that elderly women are at a greater risk of developing insulin resistance due to a further decline in muscle mass which will affect the fat mass/muscle mass ratio. This will make women even more susceptible for ectopic lipid deposition and insulin resistance.

It has been suggested that gender related differences in the hypertrophic response to resistance type exercise training may be attributed to differences in anabolic hormones, especially gender related hormones such as testosterone. Among the hormones measured in serum, we observed obvious gender differences for testosterone concentrations. However, serum concentrations did not change over time for any of the hormones, and no relations were found between serum hormone concentrations and the response to resistance type exercise training. These findings lend support to the assumption that hormonal profile may not be as important in the general response to resistance type exercise training as was previously assumed $(61,62)$.

Although previous studies have shown the efficacy of resistance type exercise training in both elderly men and women, this is the first study to compare the impact of prolonged resistance type exercise training on such an extensive range of measurements between elderly men and women. We show that despite differences in the absolute increase in muscle mass and strength, there are no differences in the relative training response between women and men. The present work clearly shows that the same generic resistance type exercise training program is applicable in both elderly women and men to counteract the loss of muscle mass and function with aging. The latter greatly facilitates the implementation of training in a practical setting, enabling generic group sessions (for both men and women) on traditional training equipment. The increase in muscle mass and strength will attenuate the risk for functional impairments, thereby improving quality of life at an advanced age. Combined with an improvement in metabolic risk profile, these findings indicate that resistance type exercise training is the best approach to counteract the negative consequences related to the loss of muscle mass and function with aging in both elderly women and men.

We conclude that gender does not affect skeletal muscle mass and strength gains or improvements in functional capacity and metabolic profile in response to prolonged resistance type exercise training in the elderly. As such, elderly women and men benefit equally from a resistance type exercise training program allowing them to prevent and treat the loss of muscle mass and function and reduce the risk of developing chronic metabolic disease. 


\section{References}

1. Rosenberg IH: Sarcopenia: origins and clinical relevance. J Nutr 1997, 127(5 Suppl):990S-991S.

2. Evans W: Functional and metabolic consequences of sarcopenia. J Nutr 1997, 127(5 Suppl):998S-1003S.

3. Forbes GB, Reina JC: Adult lean body mass declines with age: Some longitudinal observations. Metabolism 1970, 19(9):653-663.

4. Lindle RS, Metter EJ, Lynch NA, Fleg JL, Fozard JL, Tobin J, Roy TA, Hurley BF: Age and gender comparisons of muscle strength in 654 women and men aged 20-93 yr. J Appl Physiol 1997, 83(5):1581-1587.

5. Katz S, Branch LG, Branson MH, Papsidero JA, Beck JC, Greer DS: Active life expectancy. N Engl J Med 1983, 309(20):1218-1224.

6. Fiatarone MA, Marks EC, Ryan ND, Meredith CN, Lipsitz LA, Evans WJ: High-intensity strength training in nonagenarians. Effects on skeletal muscle. JAMA 1990, 263(22):3029-3034.

7. Frontera WR, Meredith CN, O'Reilly KP, Knuttgen HG, Evans WJ: Strength conditioning in older men: skeletal muscle hypertrophy and improved function. J Appl Physiol 1988, 64(3):1038-1044.

8. Verdijk LB, Jonkers RA, Gleeson BG, Beelen M, Meijer K, Savelberg HH, Wodzig WK, Dendale P, van Loon LJ: Protein supplementation before and after exercise does not further augment skeletal muscle hypertrophy after resistance training in elderly men. Am J Clin Nutr 2009, 89(2):608-616.

9. Kosek DJ, Kim JS, Petrella JK, Cross JM, Bamman MM: Efficacy of 3 days/wk resistance training on myofiber hypertrophy and myogenic mechanisms in young vs. older adults. J Appl Physiol 2006, 101(2):531-544.

10. Fiatarone MA, O'Neill EF, Ryan ND, Clements KM, Solares GR, Nelson ME, Roberts SB, Kehayias JJ, Lipsitz LA, Evans WJ: Exercise training and nutritional supplementation for physical frailty in very elderly people. N Engl J Med 1994, 330(25):1769-1775.

11. Trappe S, Williamson D, Godard M, Porter D, Rowden G, Costill D: Effect of resistance training on single muscle fiber contractile function in older men. J Appl Physiol 2000, 89(1):143-152.

12. Trappe S, Godard M, Gallagher P, Carroll C, Rowden G, Porter D: Resistance training improves single muscle fiber contractile function in older women. Am J Physiol Cell Physiol 2001, 281(2):C398-406.

13. Ivey FM, Tracy BL, Lemmer JT, NessAiver M, Metter EJ, Fozard JL, Hurley BF: Effects of strength training and detraining on muscle quality: age and gender comparisons. J Gerontol A Biol Sci Med Sci 2000, 55(3):B152-157; discussion B158-159.

14. Roth SM, Ivey FM, Martel GF, Lemmer JT, Hurlbut DE, Siegel EL, Metter EJ, Fleg JL, Fozard JL, Kostek MC et al: Muscle size responses to strength training in young and older men and women. J Am Geriatr Soc 2001, 49(11):1428-1433.

15. Bamman MM, Hill VJ, Adams GR, Haddad F, Wetzstein CJ, Gower BA, Ahmed A, Hunter GR: Gender differences in resistance-training-induced myofiber hypertrophy among older adults. $J$ Gerontol A Biol Sci Med Sci 2003, 58(2):108-116.

16. Ivey FM, Roth SM, Ferrell RE, Tracy BL, Lemmer JT, Hurlbut DE, Martel GF, Siegel EL, Fozard JL, Jeffrey Metter $E$ et al: Effects of age, gender, and myostatin genotype on the hypertrophic response to heavy resistance strength training. J Gerontol A Biol Sci Med Sci 2000, 55(11):M641-648.

17. Tracy BL, Ivey FM, Hurlbut D, Martel GF, Lemmer JT, Siegel EL, Metter EJ, Fozard JL, Fleg JL, Hurley BF: Muscle quality. II. Effects Of strength training in 65- to 75-yr-old men and women. J Appl Physiol 1999, 86(1):195-201.

18. Hakkinen K, Kallinen M, Izquierdo M, Jokelainen K, Lassila H, Malkia E, Kraemer WJ, Newton RU, Alen $\mathrm{M}$ : Changes in agonist-antagonist EMG, muscle CSA, and force during strength training in middle-aged and older people. J Appl Physiol 1998, 84(4):1341-1349.

19. Park SW, Goodpaster BH, Strotmeyer ES, de Rekeneire N, Harris TB, Schwartz AV, Tylavsky FA, Newman $A B$ : Decreased muscle strength and quality in older adults with type 2 diabetes: the health, aging, and body composition study. Diabetes 2006, 55(6):1813-1818.

20. Diagnosis and classification of diabetes mellitus. Diabetes care 2006, 29 Suppl 1:S43-48.

21. Leenders M, Verdijk LB, Hoeven LV, Kranenburg JV, Nilwik R, Wodzig WK, Senden JM, Keizer HA, Loon $\amalg$ : Protein Supplementation During Resistance-Type Exercise Training in the Elderly. Med Sci Sports Exerc 2012. 
22. Tieland M, Dirks ML, van der Zwaluw N, Verdijk LB, van de Rest O, de Groot LC, van Loon L: Protein supplementation increases muscle mass gain during prolonged resistance-type exercise training in frail elderly people: a randomized, double-blind, placebo-controlled trial. J Am Med Dir Assoc 2012, 13(8):713-719.

23. Tieland $M$, van de Rest $O$, Dirks ML, van der Zwaluw N, Mensink M, van Loon LJ, de Groot LC: Protein supplementation improves physical performance in frail elderly people: a randomized, double-blind, placebo-controlled trial. J Am Med Dir Assoc 2012, 13(8):720-726.

24. Jones PR, Pearson J: Anthropometric determination of leg fat and muscle plus bone volumes in young male and female adults. J Physiol 1969, 204(2):63P-66P.

25. Ainsworth BE, Haskell WL, Whitt MC, Irwin ML, Swartz AM, Strath SJ, O'Brien WL, Bassett DR, Jr., Schmitz KH, Emplaincourt PO et al: Compendium of physical activities: an update of activity codes and MET intensities. Med Sci Sports Exerc 2000, 32(9 Suppl):S498-504.

26. Zhang X, Geiss LS, Caspersen CJ, Cheng YJ, Engelgau MM, Johnson JA, Plotnikoff RC, Gregg EW: Physical activity levels and differences in the prevalence of diabetes between the United States and Canada. Prev Med 2010, 50(5-6):241-245.

27. WHO: Measuring obesity: classification and description of anthropometric data. Copenhagen: WHO 1989. Nutr UD, EUR/ICP/NUT 125.

28. Goodpaster BH, Kelley DE, Thaete FL, He J, Ross R: Skeletal muscle attenuation determined by computed tomography is associated with skeletal muscle lipid content. J Appl Physiol 2000, 89(1):104-110.

29. Strandberg S, Wretling ML, Wredmark T, Shalabi A: Reliability of computed tomography measurements in assessment of thigh muscle cross-sectional area and attenuation. BMC Med Imaging 2010, 10:18.

30. Bergstrom J: Percutaneous needle biopsy of skeletal muscle in physiological and clinical research. Scand J Clin Lab Invest 1975, 35(7):609-616.

31. Verdijk LB, Gleeson BG, Jonkers RA, Meijer K, Savelberg HH, Dendale P, van Loon LJ: Skeletal muscle hypertrophy following resistance training is accompanied by a fiber type-specific increase in satellite cell content in elderly men. J Gerontol A Biol Sci Med Sci 2009, 64(3):332-339.

32. Mayhew JL, Prinster JL, Ware JS, Zimmer DL, Arabas JR, Bemben MG: Muscular endurance repetitions to predict bench press strength in men of different training levels. J Sports Med Phys Fitness 1995, 35(2):108-113.

33. Verdijk LB, Koopman R, Schaart G, Meijer K, Savelberg HH, van Loon L: Satellite cell content is specifically reduced in type II skeletal muscle fibers in the elderly. Am J Physiol Endocrinol Metab 2007, 292(1):E151-157.

34. Verdijk LB, van Loon L, Meijer K, Savelberg HH: One-repetition maximum strength test represents a valid means to assess leg strength in vivo in humans. J Sports Sci 2009, 27(1):59-68.

35. Guralnik JM, Simonsick EM, Ferrucci L, Glynn RJ, Berkman LF, Blazer DG, Scherr PA, Wallace RB: A short physical performance battery assessing lower extremity function: association with self-reported disability and prediction of mortality and nursing home admission. J Gerontol 1994, 49(2):M85-94.

36. Cappola AR, Bandeen-Roche K, Wand GS, Volpato S, Fried LP: Association of IGF-I levels with muscle strength and mobility in older women. J Clin Endocrinol Metab 2001, 86(9):4139-4146.

37. Vermeulen A, Verdonck L, Kaufman JM: A critical evaluation of simple methods for the estimation of free testosterone in serum. J Clin Endocrinol Metab 1999, 84(10):3666-3672.

38. Ferri A, Scaglioni G, Pousson M, Capodaglio P, Van Hoecke J, Narici MV: Strength and power changes of the human plantar flexors and knee extensors in response to resistance training in old age. Acta Physiol Scand 2003, 177(1):69-78.

39. Frontera WR, Hughes VA, Krivickas LS, Kim SK, Foldvari M, Roubenoff R: Strength training in older women: early and late changes in whole muscle and single cells. Muscle Nerve 2003, 28(5):601-608.

40. Frontera WR, Reid KF, Phillips EM, Krivickas LS, Hughes VA, Roubenoff R, Fielding RA: Muscle fiber size and function in elderly humans: a longitudinal study. J Appl Physiol 2008, 105(2):637-642.

41. Godard MP, Williamson DL, Trappe SW: Oral amino-acid provision does not affect muscle strength or size gains in older men. Med Sci Sports Exerc 2002, 34(7):1126-1131. 
42. Lexell J, Downham DY, Larsson Y, Bruhn E, Morsing B: Heavy-resistance training in older Scandinavian men and women: short- and long-term effects on arm and leg muscles. Scand J Med Sci Sports 1995, 5(6):329-341.

43. Vincent KR, Braith RW, Feldman RA, Magyari PM, Cutler RB, Persin SA, Lennon SL, Gabr AH, Lowenthal DT: Resistance exercise and physical performance in adults aged 60 to 83. J Am Geriatr Soc 2002, 50(6):1100-1107.

44. Kraemer WJ, Hakkinen K, Newton RU, Nindl BC, Volek JS, McCormick M, Gotshalk LA, Gordon SE, Fleck SJ, Campbell WW et al: Effects of heavy-resistance training on hormonal response patterns in younger vs. older men. J Appl Physiol 1999, 87(3):982-992.

45. Hakkinen K, Pakarinen A, Kraemer WJ, Hakkinen A, Valkeinen H, Alen M: Selective muscle hypertrophy, changes in EMG and force, and serum hormones during strength training in older women. $J$ Appl Physiol 2001, 91(2):569-580.

46. Welle S, Totterman S, Thornton C: Effect of age on muscle hypertrophy induced by resistance training. J Gerontol A Biol Sci Med Sci 1996, 51(6):M270-275.

47. Larsson L, Sjodin B, Karlsson J: Histochemical and biochemical changes in human skeletal muscle with age in sedentary males, age 22--65 years. Acta Physiol Scand 1978, 103(1):31-39.

48. Lexell J, Taylor CC, Sjostrom M: What is the cause of the ageing atrophy? Total number, size and proportion of different fiber types studied in whole vastus lateralis muscle from 15- to 83-year-old men. J Neurol Sci 1988, 84(2-3):275-294.

49. Charette SL, McEvoy L, Pyka G, Snow-Harter C, Guido D, Wiswell RA, Marcus R: Muscle hypertrophy response to resistance training in older women. J Appl Physiol 1991, 70(5):1912-1916.

50. Martel GF, Roth SM, Ivey FM, Lemmer JT, Tracy BL, Hurlbut DE, Metter EJ, Hurley BF, Rogers MA: Age and sex affect human muscle fibre adaptations to heavy-resistance strength training. Exp Physiol 2006, 91(2):457-464.

51. Delmonico MJ, Harris TB, Visser M, Park SW, Conroy MB, Velasquez-Mieyer P, Boudreau R, Manini TM, Nevitt $M$, Newman $A B$ et al: Longitudinal study of muscle strength, quality, and adipose tissue infiltration. Am J Clin Nutr 2009, 90(6):1579-1585.

52. Clark BC, Manini TM: Functional consequences of sarcopenia and dynapenia in the elderly. Curr Opin Clin Nutr Metab Care 2010, 13(3):271-276.

53. Lemmer JT, Hurlbut DE, Martel GF, Tracy BL, Ivey FM, Metter EJ, Fozard JL, Fleg JL, Hurley BF: Age and gender responses to strength training and detraining. Med Sci Sports Exerc 2000, 32(8):1505-1512.

54. Doherty TJ: Invited Review: Aging and sarcopenia. J Appl Physiol 2003, 95(4):1717-1727.

55. Capodaglio P, Capodaglio Edda M, Facioli M, Saibene F: Long-term strength training for communitydwelling people over 75: impact on muscle function, functional ability and life style. Eur J Appl Physiol 2007, 100(5):535-542.

56. Chevalier S, Saoud F, Gray-Donald K, Morais JA: The physical functional capacity of frail elderly persons undergoing ambulatory rehabilitation is related to their nutritional status. J Nutr Health Aging 2008, 12(10):721-726.

57. Dipietro L, Yeckel CW, Dziura J: Progressive improvement in glucose tolerance following lower-intensity resistance versus moderate-intensity aerobic training in older women. J Phys Act Health 2008, 5(6):854-869.

58. Miller JP, Pratley RE, Goldberg AP, Gordon P, Rubin M, Treuth MS, Ryan AS, Hurley BF: Strength training increases insulin action in healthy 50- to 65-yr-old men. J Appl Physiol 1994, 77(3):1122-1127.

59. Ryan AS, Pratley RE, Goldberg AP, Elahi D: Resistive training increases insulin action in postmenopausal women. J Gerontol A Biol Sci Med Sci 1996, 51(5):M199-205.

60. Martins RA, Verissimo MT, Coelho e Silva MJ, Cumming SP, Teixeira AM: Effects of aerobic and strength-based training on metabolic health indicators in older adults. Lipids Health Dis 2010, 9:76.

61. West DW, Burd NA, Tang JE, Moore DR, Staples AW, Holwerda AM, Baker SK, Phillips SM: Elevations in ostensibly anabolic hormones with resistance exercise enhance neither training-induced muscle hypertrophy nor strength of the elbow flexors. J Appl Physiol 2010, 108(1):60-67. 
62. West DW, Kujbida GW, Moore D, Atherton PJ, Burd NA, Padzik JP, Delisio M, Tang JE, Parise G, Rennie MJ et al: Resistance exercise-induced increases in putative anabolic hormones do not enhance muscle protein synthesis or intracellular signalling in young men. J Physiol 2009. 

CHAPTER 7

General Discussion 
Sarcopenia is defined as the decrease in muscle mass, strength and functional performance with increasing age. Though sarcopenia is currently not considered to be a "disease" state, it does represent one of the major factors contributing to physical disability and frailty at an advanced age (1). Especially in the context of the global increase in the number of elderly people in our society, sarcopenia is associated with ever increasing health care expenditures for complications that are associated with decreases in functional capacity and loss of independence. In this thesis, we have focused on both nutritional and physical activity interventions to increase muscle mass, strength and functional performance in the elderly. In this final chapter, we will elaborate on some of the reported findings presented in this thesis and we will discuss them in a broader perspective. In addition, we will identify targets for health policies and define future research aims based on the findings presented in this thesis.

\section{Aging and physical activity}

Physical inactivity plays a key role in the development of sarcopenia. Evidence from immobilization and bed rest studies have shown that muscle mass and functional performance are rapidly reduced when inactivity is experimentally induced $(2,3)$. Additionally, epidemiological studies have shown that low levels of physical activity are related to an accelerated decline in muscle mass, strength and functional performance with aging $(4,5)$. These findings underline the importance of physical activity as a main target to prevent or counteract muscle loss with aging.

In general, the most effective intervention to increase muscle mass is prolonged resistance type exercise training. In chapter $\mathbf{5}$ and $\mathbf{6}$ of this thesis we show that resistance type exercise training represents a potent stimulus to increase muscle mass, muscle strength and physical performance in the elderly population, both for men and women. Peterson et al (6) have shown in a meta-analysis, that after an average of 20.5 wks of resistance type exercise training, elderly subjects gain $1.1 \mathrm{~kg}$ lean body mass. In agreement, we observed a $1.2 \mathrm{~kg}$ increase in lean mass after 24 wks of resistance type exercise training, underlining the key role that resistance type exercise plays in the preservation and even the increase in muscle mass in the aging population. In a separate meta-analysis by Peterson et al (7), an average $29 \pm 2 \%$ improvement in 1RM leg press strength and a $33 \pm 2 \%$ improvement in $1 \mathrm{RM}$ leg extension strength was calculated after an average of 18 wks of resistance type exercise training. Again, we observed quite similar increases in leg press ( $\sim 30 \%)$ and leg extension strength ( $40 \%)$. In our relatively healthy elderly subject group, the increase in muscle mass and strength translated into a decrease in sit-to-stand time by $\sim 20 \%$. This clearly shows that resistance type exercise training in the elderly leads to an improvement in physical functioning.

With the aging of our society, the incidence of physical disability will increase, and prevention and/or treatment of disability are becoming increasingly relevant to improve public health. An effective training program for elderly will improve their (health 
related) quality of life by enhancing several components, such as strength, balance, and flexibility (8). Furthermore, aging is not merely associated with a decrease in muscle mass, strength, and functional capacity but also with a decrease in cardiorespiratory fitness. Therefore, both resistance and endurance type exercise training could be of functional importance in the elderly population. Hence, in the actual prescription of a generalized training program for the elderly, both modes of exercise may be incorporated. Both modes of exercise may take into account the general principles of exercise training, such as gradual progression, variation, and due attention to recovery and stress. To augment the gains in health, strength, power and muscle mass in the elderly, the combination of resistance and endurance type exercise training is preferred. Resistance type exercise training has the ability to increase muscle mass and strength and improve functional capacity. Endurance type exercise training induces increases in $\mathrm{VO}_{2 \max }$ and submaximal endurance capacity (9). Based on the above considerations, the American College of Sports Medicine (ACSM) has developed guidelines for physical activity in healthy older adults $(10,11)$. In general, the ACSM advises older adults to perform moderate-intensity aerobic activity for a minimum of $30 \mathrm{~min}$ on five days each week or vigorous-intensity aerobic activity for a minimum of $20 \mathrm{~min}$ on three days each week. For muscle strengthening activity the ACSM recommends to perform 8 to 10 exercises on two or more non-consecutive days per week (12). However, these guidelines need to be evaluated critically, because performing exercise on a daily basis will not be achievable for everybody. Cadore et al (9) have further looked into what is needed when resistance and endurance type exercise training are combined in the elderly to improve both neuromuscular and cardiorespiratory functions. Recent evidence shows that resistance type exercise training should be performed at moderate to high intensity (i.e. $60-80 \%$ of $1 \mathrm{RM})(7,13)$ and with moderate volume ( 2 to 3 sets per exercise) (14), and endurance type exercise training needs to be performed at moderate to high intensity (i.e. $60-85 \%$ of $\mathrm{VO}_{2 \max }$ ), and moderate volume (i.e., 25 to 40 min) (9). According to Cadore et al (9) two to three sessions a week seems to be the optimal frequency to increase muscle mass, strength and cardiorespiratory fitness. To prevent endurance type exercise training from interfering with neuromuscular adaptation it may be preferred to perform the resistance type exercises first $(15,16)$. Aside from these general recommendations though, it is clear that for functional impairments in daily life of the elderly population (e.g. getting out of a chair, climbing a flight of stairs), the loss of muscle mass and strength - rather than endurance capacity - is the main determinant (9). For improvements in strength and hypertrophy in older adults the ACSM recommends to use both free-weights and machines; include multiple- and single-joint exercises; with slow to moderate lifting velocity; one to three sets per exercise with $60-80 \%$ of $1 \mathrm{RM}$ for $8-12$ repetitions; with 1-3 min of rest between sets; for 2-3 days/week (8, 10, 17-20). Recent evidence has also shown that including power training in resistance type exercise training induces greater enhancements in functional outcomes (21). 
In summary, a physically active lifestyle represents a key factor in the maintenance of muscle mass and function, and resistance type exercise training modalities are essential to augment muscle mass and increase strength in the elderly population. As such, resistance type exercise training should be placed at the forefront of any intervention strategy aiming to prevent and/or reverse the age related loss of muscle mass and function.

\section{Practical considerations when training elderly}

Though the guidelines described above already give a good overview of a general training program, there are a number of practical considerations that need to be taken into account when designing an effective training program for an elderly population. Some of the most difficult aspects in training elderly people are to convince them to start an exercise program and to ensure they will adhere to training once they have reached the desirable level, to prevent subsequent detraining $(22,23)$.

First of all, elderly people need to be aware of all the benefits that training on a regular basis has to offer. There is ample scientific evidence to support the overall health benefits of regular exercise training, and both general practitioners and health insurance companies could play a role in communicating that message towards the elderly population. With an expected decrease in disability- and dependency-related healthcare costs (24), financial incentives may even represent a cost-effective means to increase participation in exercise programs. As a second point, it needs to be taken into account that many elderly have been physically inactive for quite some time. For those individuals, who have difficulty with taking the step towards gym based exercise, a lifestyle integrated approach might be a more useful approach for a training program. Clemson et al (25) have shown that the incorporation of balance and resistance type exercise training into daily life activity effectively reduces the number of falls in older people, while simultaneously improving strength, balance, and physical functioning. Additional to these findings, Pahor et al (26) investigated the effect of a structured moderate intensity physical activity program done in a center and at home that included endurance and resistance type exercise and flexibility training activities. This structured program decreased major mobility disability over 2.6 years in elderly adults at risk of disability (26). When elderly are triggered to perform functional exercises in their daily life, the exercises are more likely to become part of the normal daily routine, which likely improves adherence to the 'program'.

A third point of attention is detraining. Based on unpublished observations we have learned that when healthy elderly returned 1 year after performing our standardized 6 month resistance type exercise training program (chapter 5) detraining takes place even in the elderly who maintained some level of unsupervised resistance type exercise training. All volunteers had lost muscle mass and muscle strength one year after the end of the intervention, with even some of the participants having muscle mass 
and strength levels similar to pre-intervention values. These observations clearly indicate the relevance of personalized supervision, ensuring progressiveness or at least maintenance of exercise intensity, and enabling regular assessment of the exercise effects in order to maintain or even further increase the positive effects of resistance type exercise training in the elderly (increase in muscle mass, strength and physical function). Furthermore, in trying to convince the elderly to start and to keep on training, we need to be aware that physical activity and psychological well-being are closely linked (27). In a recent review, Adams et al (28) suggested that a successful training program for elderly should include both the proper content and the social context of the activities. This means that performing exercise together, within an informal social setting likely represents the best stimulus to start performing exercise and to maintain a high level of motivation to keep on exercising (28). So incorporating the social aspect is of great importance when developing and setting up effective exercise routines for the elderly. In addition, it needs to be considered when a training program is developed, that any exercise program needs to be practically achievable within a reasonable time frame, both in terms of session time and number of sessions, with a suggested maximum of 3 sessions per week (29).

Apart from the 'integrated lifestyle approach', the aspects described above could all be facilitated by providing appropriate personal supervision during a training program. In general, supervision from an experienced training expert is needed to ensure proper execution of the exercise program, and maintain safety for all participants. However, supervision should also include monitoring of any improvements in strength and function, ensuring awareness of the actual benefits of the exercise that is performed, motivating all participants individually and as a group, and are important factors in maintaining compliance to the exercise program. Though supervision may be less needed throughout the later stages of a training program, we propose that some form of personal supervision is important to increase the adherence and compliance to an exercise regimen and, as such, to ensure overall success of any exercise training program.

In conclusion, with resistance type exercise representing the most effective method to increase muscle mass and muscle strength and improve functional capacity in elderly people, this population needs to be advised to engage in regular supervised resistance type exercise training. On a global level, it is of utmost importance that elderly are advised to increase physical activity. And public health strategies should be focused towards increasing and maintaining compliance to such exercise programs. Apart from increasing participation in specific resistance type exercise training programs, for specific groups of elderly, a solution may lie in incorporating resistance type exercise training in daily-life activities. Appropriate personal supervision and individualized exercise prescription need to be taken into account in order to increase both extrinsic and intrinsic motivation and, as such, increase successful participation in any exercise program. 


\section{Nutrition and exercise}

Physical activity and, more specifically, resistance type exercise, stimulates both muscle protein synthesis and (to a lesser extent) protein breakdown. However, in the absence of protein intake, net muscle protein balance remains negative in the postexercise state (30-32). The ingestion of dietary protein after resistance-type exercise increases post-exercise muscle protein synthesis rates and inhibits muscle protein breakdown, thereby allowing net muscle protein accretion during the acute postexercise recovery period $(30,31,33)$. Therefore, dietary protein supplementation may represent an effective strategy to augment the skeletal muscle adaptive response to prolonged resistance type exercise training. However, there has been significant disagreement in literature on the surplus value of protein supplementation during prolonged resistance type exercise training. In chapter $\mathbf{5}$ of this thesis we show that prolonged resistance type exercise training increases muscle mass, muscle strength and functional performance in healthy elderly. However, additional protein supplementation at breakfast $(15 \mathrm{~g} / \mathrm{d})$ did not further augment the increase in muscle mass, strength, and/or functional capacity in these healthy elderly subjects. This finding is supported by several other studies in which an additive benefit of protein supplementation on top of any training effects was not observed (34-39). Only a few studies have reported a significantly greater increase in muscle mass and strength when dietary protein was supplemented during prolonged resistance type exercise training (40-42). Although the reasons for this discrepancy in literature remain unclear, it has been suggested that for instance the population that is being studied (e.g. frail vs healthy) may impact the efficacy of additional protein supplementation to improve training effects (42). In addition, differences in habitual dietary protein intake, training status, training program, amount, type, and timing of protein supplementation likely contribute to the discrepant findings observed previously. Nonetheless, it appears paradoxical that basically all "acute studies" suggest that the combination of exercise and nutrition (specifically protein) has a synergistic effect, whereas the majority of long-term studies are unable to detect any additional benefits of protein supplementation on top of the exercise training effects $(30,31,33-37)$. In an attempt to resolve the question regarding the proposed benefits of protein supplementation on the gain in muscle mass and/or strength during a prolonged resistance type exercise training intervention, a meta-analysis was recently performed by Cermak et al (43). Interestingly, the metaanalysis showed that for both young and elderly individuals, protein supplementation during a prolonged resistance type exercise training intervention significantly augments the gains in lean body mass, muscle fiber size, and muscle strength when compared with resistance type exercise training alone. Based on the studies including elderly individuals, the meta-analysis reported that dietary protein supplementation $(50 \pm 32 \mathrm{~g} / \mathrm{d})$ increases lean mass by $38 \%$ more when compared with placebo. Likewise, an additional $33 \%$ increase in $1 \mathrm{RM}$ leg strength during $12 \mathrm{wks}$ of resistance type exercise training in elderly subjects was calculated. Overall, this meta-analysis clearly 
shows that dietary protein supplementation represents an effective strategy to further augment the gains in muscle mass and strength following a period of resistance type exercise training in both young and older healthy subjects (43). It could be speculated that the additional benefits may even be greater in more compromised elderly populations, who generally consume only a limited amount of protein in their habitual diet (44). Future work should focus on further optimizing the clinical benefits of combined exercise and nutritional interventions. This may involve tailoring the exercise regimen towards a specific (clinical) subpopulation, but also includes tailoring the nutritional strategy towards an optimal amount, type and timing of protein supplementation.

\section{Protein supplementation: what, when and how much?}

For resistance type exercise training to increase muscle mass, dietary protein intake is required to provide the building blocks for de novo muscle protein synthesis and allow net accretion of muscle mass. Moreover, as discussed above, additional protein supplementation further augments the benefits of resistance type exercise training. However, how this should be translated into a practical approach still remains a topic of intense debate. Several aspects need to be considered in defining optimal protein intake strategies. These include amongst others, the source of dietary protein, the amount of protein, and the timing of protein consumption in the elderly population.

\section{Source of protein}

Essential amino acids (EAA) have been shown to play a key role in regulating synthesis of skeletal muscle protein (45). However, the effect of food sources high in EAA on postprandial muscle protein synthesis rates differ between food sources, likely depending on the amino acid composition of the protein. Leucine seems to represent a unique amino acid in this regard. As was extensively discussed in chapter $\mathbf{2}$, leucine has the capacity to strongly stimulate postprandial rates of muscle protein synthesis in humans. A recent study from our lab (46) showed that addition of free leucine with protein improves post-prandial muscle protein accretion in elderly men, confirming previous work in this area (47). Therefore, it has been suggested that increasing the leucine content of meal may represent an effective strategy to increase muscle mass in the elderly population. However, we were unable to detect any effect of leucine supplementation on muscle mass in healthy elderly (48), nor in elderly type 2 diabetes patients after 3-6 months of daily leucine supplementation with breakfast, lunch, and dinner (chapter 3). From these studies we conclude that supplementation of a single amino acid will unlikely provide functional or clinical benefits. It is possible that a complete mixture of EAA is necessary to elicit improvements in muscle mass and/or function in the elderly. However, the long term effects of supplementation with an EAA mixture still need to be determined. Tieland et al (42) investigated the long term ef- 
fects of a combination of resistance type exercise training and milk protein supplementation, known for its high quality in terms of EAA content. They showed that combining resistance type exercise training with milk protein supplementation significantly increased lean body mass after 24 wks of training in frail elderly (42). Furthermore, the same authors (49) showed that only milk protein supplementation (i.e. without exercise training) for 24 wks can improve physical performance in frail elderly people. These findings clearly indicate the potential that dietary protein can have to increase muscle mass and/or function. Several studies have also looked into the practical dietary approach by focusing on protein-rich foods (e.g., beef, eggs) (50-53). These studies confirmed that a variety of high-quality dietary protein foods have the capacity to enhance muscle protein anabolism in both young and elderly (54).

Apart from the amino acid composition of different proteins, the rate of protein digestion and absorption can also vary substantially depending on the protein source (55). Current work in this area is aimed at further unraveling the optimal composition of dietary protein supplements, both in relation to the stimulation of protein synthesis and in maximizing the hypertrophic response to prolonged exercise and/or nutritional interventions.

\section{Amount of protein}

Another important issue to consider is that a proper amount of high-quality protein needs to be consumed on a daily basis. The current recommendations regarding protein intake for adults older than $18 \mathrm{y}$ is $0.83 \mathrm{~g} / \mathrm{kg} / \mathrm{d}(56)$. Although this amount is sufficient for healthy people, several studies have shown that meeting this recommendation does not prevent muscle loss with aging (57-61). Therefore, it has been suggested that the recommended daily allowance (RDA) for protein is not sufficient to maintain muscle mass in elderly people. Many experts now recommend that elderly people should increase their protein intake to 1.0 to $1.5 \mathrm{~g} / \mathrm{kg} / \mathrm{d}(58,60-64)$. In our studies (chapters 2 to 6) we describe an average protein intake of around $1.1 \mathrm{~g} / \mathrm{kg} / \mathrm{d}$, both in diabetic and in healthy elderly subjects aged 65 y and over. Although on average, protein intake was well above the current RDA, we therefore argue there is still ample reason to further increase protein intake in older subpopulations consuming (less than) $0.8 \mathrm{~g}$ protein $\mathrm{kg}$ per day. As discussed in a recent review by Volpi et al (65) the RDA for protein is probably sufficient for most sedentary or low-active elderly; however it may not be sufficient to maintain health and maximize muscle mass, strength and function in the elderly. Additionally it should also be considered that muscle mass is not only critical for adequate function but also for disease outcomes (65). Recent evidence supports the clinical benefits of increasing protein intake in elderly. Houston et al (66) showed that protein intake is associated with the extent of lean mass loss. Elderly subjects who had an average protein intake of around $1.2 \mathrm{~g} / \mathrm{kg} / \mathrm{d}$ lost $\sim 40 \%$ less lean mass over a period of 3 years when compared with those with an average protein intake of around $0.8 \mathrm{~g} / \mathrm{kg} / \mathrm{d}$. (66). In addition, by supplementing protein intake with 
breakfast and lunch, Tieland et al (49) increased overall protein intake in frail elderly from 1.0 to $1.4 \mathrm{~g} / \mathrm{kg} / \mathrm{d}$. Though muscle mass was not increased after 24 wks of dietary protein supplementation, a significant increase in muscle strength and improvements in functional performance were observed in the protein supplemented group vs the placebo supplemented frail elderly. Likewise, as described earlier, Cermak et al (43) recently reported that protein supplementation (on average $50 \pm 32 \mathrm{~g}$ protein/d on top of their normal diet) during prolonged resistance type exercise training (on average 3 months) induced a further $38 \%$ increase in fat free mass and a further $33 \%$ increase in 1RM strength compared to placebo (i.e. exercise only). This increase in muscle mass and strength will translate into an improvement in functional capacity. Consequently, we recommend increasing daily protein intake to $1.2-1.5 \mathrm{~g} / \mathrm{kg} / \mathrm{d}$, either by increasing habitual dietary protein or through protein supplementation, to ensure a sufficient supply of protein to the body to allow a maximal adaptive response to resistance type exercise training. In addition, this will also allow better maintenance of muscle mass and function throughout normal aging, and potentially even in specific disease states. We need to consider that during prolonged resistance type exercise training daily energy expenditure and daily energy intake will increase. Under conditions that the macronutrient composition of the diet is not changed, a greater energy intake will lead to a greater absolute protein intake without specific protein supplementation. Therefore, protein supplements are generally not required to attain such targets for daily protein intake.

\section{Timing of protein intake}

Apart from the amount of protein to be ingested daily, it is also important to consider when protein is ingested. It is generally acknowledged that a certain amount of protein is necessary to effectively stimulate post-prandial muscle protein synthesis rates (60, 67). That means that at least with each main meal, a certain amount of protein needs to be consumed (i.e., spread throughout the day). It has been suggested that at least 20-25 g of protein should be ingested with each meal to maximally stimulate muscle protein synthesis rates. Indeed, in the young, there appears to be a plateau in the muscle protein synthetic response after ingestion of 20-25 g high-quality (whey) protein $(68,69)$. However, various studies have shown that further increasing protein intake in the elderly actually leads to a further stimulation of postprandial muscle protein synthesis $(55,70-72)$. As such, it remains to be determined what the optimal amount of protein with each main meal would be in the elderly population. Nonetheless, in studying the habitual intake of various elderly subgroups, Tieland et al (44) showed that during breakfast, all elderly consume relatively little protein, and even the lower limit of $20 \mathrm{~g}$ is not reached. During lunch, protein intake is low for frail and institutionalized elderly. During these meals, protein intake needs to be increased by either consuming more food, consuming more protein dense foods, and/or by supplementing protein. This also supports the statement that the total RDA for protein should be 
increased, especially for the elderly population. Furthermore, our group (73) performed a proof-of-principle study to assess whether dietary protein administration during sleep could stimulate muscle protein synthesis and improve overnight whole body protein balance in elderly. We showed for the first time that dietary protein administration ( $40 \mathrm{~g}$ ) during sleep is followed by normal digestion and absorption kinetics, thereby stimulating overnight muscle protein synthesis (73). This approach may represent an alternative way to increase overall protein intake in the elderly and could theoretically limit the suggested negative impact of an overnight negative protein balance. Practically, this could be translated into a pre-bedtime protein meal or drink. However, more research is needed in this area to look at the optimal composition of such a pre-sleep protein bolus. Interestingly, we recently reported that protein ingestion prior to sleep increases muscle mass and strength gains during prolonged resistance type exercise training in healthy young men (74). Yet, it remains to be determined what the long-term effects of pre-sleep protein consumption are in elderly people, either with or without additional exercise interventions.

Taken together we can conclude that it is important that a sufficient amount of high quality protein is consumed and special attention needs to go out to the amount of leucine, since leucine seems to have the unique ability to strongly stimulate muscle protein synthesis rates. Also timing of intake needs to be guarded, with ample protein provision with each main meal. In general, we would advocate to increase the recommended daily allowance of protein intake in the elderly toward 1.2-1.5 g/ $/ \mathrm{kg} / \mathrm{d}$. Whenever possible, increasing protein intake should be combined with the implementation of resistance type exercise activities to elicit the synergistic effects of resistance type exercise training and (more) protein consumption. Future work should define the impact of the protein source, amount and timing of protein intake on health and performance in various elderly subpopulations.

\section{Future perspectives}

The actual health benefits of exercise in elderly people are well established, but exercise still is an underused form of health promotion. To inform the elderly about the benefits of exercise and to motivate them to change their sedentary lifestyle, physicians need to play a more active role. In combination with this a more tailored approach in getting elderly to start and to keep on exercising needs to be developed. Both General Practitioners and other physicians who come into contact with elderly and/or geriatric patients need to make their patients aware of the benefits of exercise and/or more habitual physical activity. Health insurance companies should be held responsible to facilitate this process. The work described in this thesis showcases the benefits of resistance type exercise training and evaluates the proposed surplus benefits of nutritional co-intervention to augment gains in muscle mass, strength and func- 
tion in the elderly population. Nonetheless, there are many remaining questions that should be addressed in future research. Such questions include:

- What is the optimal training program to counteract sarcopenia in various older subpopulations?

- What is the preferred type, amount, and composition of protein to support muscle accretion during prolonged resistance type exercise training in various older subpopulations?

- What is the impact of short term bed rest and immobilization on muscle mass, strength and functional capacity in both health and disease?

- Can pre-bedtime protein ingestion improve net muscle protein balance and, as such, prevent muscle mass loss during hospitalization or support muscle mass gains during resistance type exercise or rehabilitative exercise training?

- Are there specific nutritional compounds (eg. Vitamin D, creatine) that can be used as adjuvant interventions to attenuate muscle loss or gain muscle mass in both healthy and frail elderly (sub) populations?

Prevention and treatment of sarcopenia will reduce the risk of disability, loss of independence, institutionalization, hospitalization and mortality. As shown in this thesis, the most effective way to increase muscle mass, strength, and functional performance is by adherence to resistance type exercise training. With the right state of mind and proper guidance elderly people can prevent and even reverse the age related loss of muscle mass and strength. A more active older population will reduce health care costs, increase the number of elderly living independently up to a more advanced age, lower the incidence of falls and hip fractures, and improve overall well-being of our elders. We need to invest in developing a structure in which the older population can become more active, supporting healthy aging of our society. 


\section{References}

1. Ruiz JR, Sui X, Lobelo F, Morrow JR, Jr., Jackson AW, Sjostrom M, Blair SN: Association between muscular strength and mortality in men: prospective cohort study. BMJ 2008, 337:a439.

2. Kortebein P, Ferrando A, Lombeida J, Wolfe R, Evans WJ: Effect of 10 days of bed rest on skeletal muscle in healthy older adults. JAMA 2007, 297(16):1772-1774.

3. Gibson JN, Halliday D, Morrison WL, Stoward PJ, Hornsby GA, Watt PW, Murdoch G, Rennie MJ: Decrease in human quadriceps muscle protein turnover consequent upon leg immobilization. Clin Sci (Lond) 1987, 72(4):503-509.

4. Puthoff ML, Janz KF, Nielson D: The relationship between lower extremity strength and power to everday walking behaviors in older adults with functional limitations. J Geriatr Phys Ther 2008, 31(1):24-31.

5. Liu CJ, Latham NK: Progressive resistance strength training for improving physical function in older adults. Cochrane Database Syst Rev 2009, 8(3):Cd002759.

6. Peterson MD, Sen A, Gordon PM: Influence of resistance exercise on lean body mass in aging adults: a meta-analysis. Med Sci Sports Exerc 2011, 43(2):249-258.

7. Peterson MD, Rhea MR, Sen A, Gordon PM: Resistance Exercise for Muscular Strength in Older Adults: A Meta-Analysis. Ageing Res Rev 2010, 9(3):226.

8. Evans WJ: Exercise training guidelines for the elderly. Med Sci Sports Exerc 1999, 31(1):12-17.

9. Cadore EL, Pinto RS, Bottaro M, Izquierdo M: Strength and endurance training prescription in healthy and frail elderly. Aging Dis 2014, 5(3):183-195.

10. Ratamess NA, Alvar BA, Evetoch TK, Housh TJ, Kibler WB, Kraemer WJ, Triplett NT: American College of Sports Medicine position stand. Progression models in resistance training for healthy adults. Med Sci Sports Exerc 2009, 41(3):687-708.

11. Chodzko-Zajko WJ, Proctor DN, Fiatarone Singh MA, Minson CT, Nigg CR, Salem GJ, Skinner JS: American College of Sports Medicine position stand. Exercise and physical activity for older adults. Med Sci Sports Exerc 2009, 41(7):1510-1530.

12. Nelson ME, Rejeski WJ, Blair SN, Duncan PW, Judge JO, King AC, Macera CA, Castaneda-Sceppa C: Physical activity and public health in older adults: recommendation from the American College of Sports Medicine and the American Heart Association. Circulation 2007, 116(9):1094-1105.

13. Steib S, Schoene D, Pfeifer K: Dose-response relationship of resistance training in older adults: a metaanalysis. Med Sci Sports Exerc 2010, 42(5):902-914.

14. Candow DG, Burke DG: Effect of short-term equal-volume resistance training with different workout frequency on muscle mass and strength in untrained men and women. J Strength Cond Res 2007, 21(1):204-207.

15. Cadore EL, Izquierdo M, Alberton CL, Pinto RS, Conceicao M, Cunha G, Radaelli R, Bottaro M, Trindade GT, Kruel LF: Strength prior to endurance intra-session exercise sequence optimizes neuromuscular and cardiovascular gains in elderly men. Exp Gerontol 2012, 47(2):164-169.

16. Cadore EL, Izquierdo M, Pinto SS, Alberton CL, Pinto RS, Baroni BM, Vaz MA, Lanferdini FJ, Radaelli R, Gonzalez-Izal $\mathrm{M}$ et al: Neuromuscular adaptations to concurrent training in the elderly: effects of intrasession exercise sequence. Age (Dordr) 2013, 35(3):891-903.

17. Hakkinen K, Kallinen M, Izquierdo M, Jokelainen K, Lassila H, Malkia E, Kraemer WJ, Newton RU, Alen $\mathrm{M}$ : Changes in agonist-antagonist EMG, muscle CSA, and force during strength training in middle-aged and older people. J Appl Physiol 1998, 84(4):1341-1349.

18. de Vos NJ, Singh NA, Ross DA, Stavrinos TM, Orr R, Fiatarone Singh MA: Optimal load for increasing muscle power during explosive resistance training in older adults. J Gerontol A Biol Sci Med Sci 2005, 60(5):638-647.

19. Brown AB, McCartney N, Sale DG: Positive adaptations to weight-lifting training in the elderly. J App/ Physiol 1990, 69(5):1725-1733.

20. Frontera WR, Hughes VA, Lutz KJ, Evans WJ: A cross-sectional study of muscle strength and mass in 45to 78-yr-old men and women. J Appl Physiol 1991, 71(2):644-650. 
21. Correa CS, LaRoche DP, Cadore EL, Reischak-Oliveira A, Bottaro M, Kruel LF, Tartaruga MP, Radaelli R, Wilhelm EN, Lacerda FC et al: 3 Different types of strength training in older women. Int J Sports Med 2012, 33(12):962-969.

22. Hakkinen $\mathrm{K}$, Alen M, Kallinen M, Newton RU, Kraemer WJ: Neuromuscular adaptation during prolonged strength training, detraining and re-strength-training in middle-aged and elderly people. Eur J Appl Physiol 2000, 83(1):51-62.

23. Taaffe DR, Marcus R: Dynamic muscle strength alterations to detraining and retraining in elderly men. Clin Physiol 1997, 17(3):311-324.

24. Janssen I, Shepard DS, Katzmarzyk PT, Roubenoff R: The healthcare costs of sarcopenia in the United States. J Am Geriatr Soc 2004, 52(1):80-85.

25. Clemson L, Fiatarone Singh MA, Bundy A, Cumming RG, Manollaras K, O'Loughlin P, Black D: Integration of balance and strength training into daily life activity to reduce rate of falls in older people (the LiFE study): randomized parallel trial. BMJ 2012, 345:e4547.

26. Pahor M, Guralnik JM, Ambrosius WT, Blair S, Bonds DE, Church TS, Espeland MA, Fielding RA, Gill TM, Groessl EJ et al: Effect of structured physical activity on prevention of major mobility disability in older adults: the LIFE study randomized clinical trial. JAMA 2014, 311(23):2387-2396.

27. Compare A, Zarbo C, Marin E, Meloni A, Rubio-Arias JA, Berengui R, Grossi E, Shonin E, Martini G, Alcaraz PE: PAHA study: Psychological Active and Healthy Aging: psychological wellbeing, proactive attitude and happiness effects of whole-body vibration versus Multicomponent Training in aged women: study protocol for a randomized controlled trial. Trials 2014, 15(1):177.

28. Adams KB, Leibbrant S, Moon H: A critical review of the literature on social and leisure activity and wellbeing in later life. Ageing and Society 2011, 31:683-712.

29. Farinatti PT, Geraldes AA, Bottaro MF, Lima MV, Albuquerque RB, Fleck SJ: Effects of different resistance training frequencies on the muscle strength and functional performance of active women older than 60 years. J Strength Cond Res 2013, 27(8):2225-2234.

30. Biolo G, Maggi SP, Williams BD, Tipton KD, Wolfe RR: Increased rates of muscle protein turnover and amino acid transport after resistance exercise in humans. Am J Physiol 1995, 268(3 Pt 1):E514-520.

31. Phillips SM, Tipton KD, Aarsland A, Wolf SE, Wolfe RR: Mixed muscle protein synthesis and breakdown after resistance exercise in humans. Am J Physiol 1997, 273(1 Pt 1):E99-107.

32. Pitkanen HT, Nykanen T, Knuutinen J, Lahti K, Keinanen O, Alen M, Komi PV, Mero AA: Free amino acid pool and muscle protein balance after resistance exercise. Med Sci Sports Exerc 2003, 35(5):784-792.

33. Tipton KD, Ferrando AA, Phillips SM, Doyle D, Jr., Wolfe RR: Postexercise net protein synthesis in human muscle from orally administered amino acids. Am J Physiol 1999, 276(4 Pt 1):E628-634.

34. Campbell WW, Crim MC, Young VR, Joseph LJ, Evans WJ: Effects of resistance training and dietary protein intake on protein metabolism in older adults. Am J Physiol 1995, 268(6 Pt 1):E1143-1153.

35. Verdijk LB, Jonkers RA, Gleeson BG, Beelen M, Meijer K, Savelberg HH, Wodzig WK, Dendale P, van Loon LJ: Protein supplementation before and after exercise does not further augment skeletal muscle hypertrophy after resistance training in elderly men. Am J Clin Nutr 2009, 89(2):608-616.

36. Carlsson M, Littbrand H, Gustafson Y, Lundin-Olsson L, Lindelof N, Rosendahl E, Haglin L: Effects of highintensity exercise and protein supplement on muscle mass in ADL dependent older people with and without malnutrition: a randomized controlled trial. J Nutr Health Aging 2011, 15(7):554-560.

37. Rosendahl E, Lindelof N, Littbrand H, Yifter-Lindgren E, Lundin-Olsson L, Haglin L, Gustafson Y, Nyberg L: High-intensity functional exercise program and protein-enriched energy supplement for older persons dependent in activities of daily living: a randomised controlled trial. Aust J Physiother 2006, 52(2):105-113.

38. Fiatarone MA, O'Neill EF, Ryan ND, Clements KM, Solares GR, Nelson ME, Roberts SB, Kehayias JJ, Lipsitz LA, Evans WJ: Exercise training and nutritional supplementation for physical frailty in very elderly people. N Engl J Med 1994, 330(25):1769-1775.

39. Chale A, Cloutier GJ, Hau C, Phillips EM, Dallal GE, Fielding RA: Efficacy of whey protein supplementation on resistance exercise-induced changes in lean mass, muscle strength, and physical function in mobility-limited older adults. J Gerontol A Biol Sci Med Sci 2012, 68(6):682-690. 
40. Bonnefoy M, Cornu C, Normand S, Boutitie F, Bugnard F, Rahmani A, Lacour JR, Laville M: The effects of exercise and protein-energy supplements on body composition and muscle function in frail elderly individuals: a long-term controlled randomised study. Br J Nutr 2003, 89(5):731-739.

41. Josse AR, Tang JE, Tarnopolsky MA, Phillips SM: Body composition and strength changes in women with milk and resistance exercise. Med Sci Sports Exerc 2010, 42(6):1122-1130.

42. Tieland M, Dirks ML, van der Zwaluw N, Verdijk LB, van de Rest O, de Groot LC, van Loon L: Protein supplementation increases muscle mass gain during prolonged resistance-type exercise training in frail elderly people: a randomized, double-blind, placebo-controlled trial. J Am Med Dir Assoc 2012, 13(8):713-719.

43. Cermak NM, Res PT, de Groot LC, Saris WH, van Loon LJ: Protein supplementation augments the adaptive response of skeletal muscle to resistance-type exercise training: a meta-analysis. Am J Clin Nutr 2012, 96(6):1454-1464.

44. Tieland M, Borgonjen-Van den Berg KJ, van Loon LJ, de Groot LC: Dietary protein intake in communitydwelling, frail, and institutionalized elderly people: scope for improvement. Eur J Nutr 2011.

45. Volpi E, Kobayashi H, Sheffield-Moore M, Mittendorfer B, Wolfe RR: Essential amino acids are primarily responsible for the amino acid stimulation of muscle protein anabolism in healthy elderly adults. $\mathrm{Am} \mathrm{J}$ Clin Nutr 2003, 78(2):250-258.

46. Wall BT, Hamer HM, de Lange A, Kiskini A, Groen BB, Senden JM, Gijsen AP, Verdijk LB, van Loon L: Leucine co-ingestion improves post-prandial muscle protein accretion in elderly men. Clin Nutr 2013, 32(3):412-419.

47. Rieu I, Balage M, Sornet C, Giraudet C, Pujos E, Grizard J, Mosoni L, Dardevet D: Leucine supplementation improves muscle protein synthesis in elderly men independently of hyperaminoacidaemia. J Physiol 2006, 575(Pt 1):305-315.

48. Verhoeven S, Vanschoonbeek K, Verdijk LB, Koopman R, Wodzig WK, Dendale P, van Loon LJ: Longterm leucine supplementation does not increase muscle mass or strength in healthy elderly men. $\mathrm{Am} \mathrm{J}$ Clin Nutr 2009, 89(5):1468-1475.

49. Tieland M, van de Rest O, Dirks ML, van der Zwaluw N, Mensink M, van Loon L, de Groot LC: Protein supplementation improves physical performance in frail elderly people: a randomized, double-blind, placebo-controlled trial. J Am Med Dir Assoc 2012, 13(8):720-726.

50. Pennings B, Groen BB, van Dijk JW, de Lange A, Kiskini A, Kuklinski M, Senden JM, van Loon LJ: Minced beef is more rapidly digested and absorbed than beef steak, resulting in greater postprandial protein retention in older men. Am J Clin Nutr 2013, 98(1):121-128.

51. Symons TB, Schutzler SE, Cocke TL, Chinkes DL, Wolfe RR, Paddon-Jones D: Aging does not impair the anabolic response to a protein-rich meal. Am J Clin Nutr 2007, 86(2):451-456.

52. Symons TB, Sheffield-Moore M, Wolfe RR, Paddon-Jones D: A Moderate Serving of High-Quality Protein Maximally Stimulates Skeletal Muscle Protein Synthesis in Young and Elderly Subjects. Journal of the American Dietetic Association 2009, 109(9):1582-1586.

53. Asp ML, Richardson JR, Collene AL, Droll KR, Belury MA: Dietary protein and beef consumption predict for markers of muscle mass and nutrition status in older adults. J Nutr Health Aging 2012, 16(9):784-790.

54. Paddon-Jones D, Campbell WW, Jacques PF, Kritchevsky SB, Moore LL, Rodriguez NR, van Loon L: Protein and healthy aging. Am J Clin Nutr 2015, 101(Suppl):1139S-1145S.

55. Pennings B, Groen B, de Lange A, Gijsen AP, Zorenc AH, Senden JM, van Loon L: Amino acid absorption and subsequent muscle protein accretion following graded intakes of whey protein in elderly men. $A m$ J Physiol Endocrinol Metab 2012, 302(8):E992-999.

56. EFSA Panel on Dietetic Products NaA. Scientific Opinion on Dietary Reference Values for Protein. European Food Safety Authority (EFSA), Parma, Italy;. 2012.

57. Evans WJ: Protein Nutrition, Exercise and Aging. J Am Coll Nutr 2004, 23(suppl_6):601S-609.

58. Morley JE, Argiles JM, Evans WJ, Bhasin S, Cella D, Deutz NE, Doehner W, Fearon KC, Ferrucci L, Hellerstein MK et al: Nutritional recommendations for the management of sarcopenia. J Am Med Dir Assoc 2010, 11(6):391-396. 
59. Ferrando AA, Paddon-Jones D, Hays NP, Kortebein P, Ronsen O, Williams RH, McComb A, Symons TB, Wolfe RR, Evans W: EAA supplementation to increase nitrogen intake improves muscle function during bed rest in the elderly. Clin Nutr 2010, 29(1):18-23.

60. Paddon Jones D, Rasmussen BB: Dietary protein recommendations and the prevention of sarcopenia. Curr Opin Clin Nutr Metab Care 2009, 12(1):86-90.

61. Wolfe RR, Miller SL, Miller KB: Optimal protein intake in the elderly. Clinical Nutrition 2008, 27(5):675-684.

62. Landi F, Marzetti E, Bernabei R: Perspective: Protein: what kind, how much, when? J Am Med Dir Assoc 2013, 14(1):66-67.

63. Morley JE: Do frail older persons need more protein? J Am Med Dir Assoc 2012, 13(8):667-668.

64. Evans WJ, Boccardi V, Paolisso G: Perspective: Dietary protein needs of elderly people: protein supplementation as an effective strategy to counteract sarcopenia. J Am Med Dir Assoc 2013, 14(1):67-69.

65. Volpi E, Campbell WW, Dwyer JT, Johnson MA, Jensen GL, Morley JE, Wolfe RR: Is the optimal level of protein intake for older adults greater than the recommended dietary allowance? J Gerontol A Biol Sci Med Sci 2013, 68(6):677-681.

66. Houston DK, Nicklas BJ, Ding J, Harris TB, Tylavsky FA, Newman AB, Lee JS, Sahyoun NR, Visser M, Kritchevsky SB: Dietary protein intake is associated with lean mass change in older, communitydwelling adults: the Health, Aging, and Body Composition (Health ABC) Study. Am J Clin Nutr 2008, 87(1):150-155.

67. Campbell WW, Leidy HJ: Dietary protein and resistance training effects on muscle and body composition in older persons. J Am Coll Nutr 2007, 26(6):696S-703S.

68. Witard OC, Jackman SR, Breen L, Smith K, Selby A, Tipton KD: Myofibrillar muscle protein synthesis rates subsequent to a meal in response to increasing doses of whey protein at rest and after resistance exercise. Am J Clin Nutr 2014, 99(1):86-95.

69. Moore DR, Robinson MJ, Fry JL, Tang JE, Glover El, Wilkinson SB, Prior T, Tarnopolsky MA, Phillips SM: Ingested protein dose response of muscle and albumin protein synthesis after resistance exercise in young men. Am J Clin Nutr 2009, 89(1):161-168.

70. Koopman R, Crombach N, Gijsen AP, Walrand S, Fauquant J, Kies AK, Lemosquet S, Saris WH, Boirie Y, van Loon LJ: Ingestion of a protein hydrolysate is accompanied by an accelerated in vivo digestion and absorption rate when compared with its intact protein. Am J Clin Nutr 2009, 90(1):106-115.

71. Pennings B, Boirie $Y$, Senden JM, Gijsen AP, Kuipers H, van Loon LJ: Whey protein stimulates postprandial muscle protein accretion more effectively than do casein and casein hydrolysate in older men. $A m$ J Clin Nutr 2011.

72. Moore DR, Churchward-Venne TA, Witard O, Breen L, Burd NA, Tipton KD, Phillips SM: Protein ingestion to stimulate myofibrillar protein synthesis requires greater relative protein intakes in healthy older versus younger men. J Gerontol A Biol Sci Med Sci 2015, 70(1):57-62.

73. Groen BB, Res PT, Pennings B, Hertle E, Senden JM, Saris WH, van Loon LJ: Intragastric protein administration stimulates overnight muscle protein synthesis in elderly men. Am J Physiol Endocrinol Metab 2012, 302(1):E52-60.

74. Snijders T, Res PT, Smeets JS, van Vliet S, van Kranenburg J, Maase K, Kies AK, Verdijk LB, van Loon L: Protein Ingestion before Sleep Increases Muscle Mass and Strength Gains during Prolonged ResistanceType Exercise Training in Healthy Young Men. J Nutr 2015, 145(6):1178-1184. 

Summary 

Aging is associated with the progressive loss of skeletal muscle mass and strength, also known as sarcopenia. This loss of muscle mass and strength is associated with functional impairment in daily life activities and causes both physical and functional limitations, eventually resulting in the loss of independence in elderly. To counteract the decrease in muscle mass and strength and to improve functional capacity several interventions have been proposed. This thesis focusses on the advantages of resistance type exercise training, and the role of nutrition (more specifically protein supplementation) to improve muscle mass, strength and functional capacity in the community dwelling elderly population.

In chapter 2, we reviewed the literature on the amino acid leucine, with a focus on its anabolic properties. It has previously been established that amino acids play a crucial role to increase protein synthesis in the muscle. Leucine seems to represent a unique amino acid in this regard by not only acting as a building block, but also targeting anabolic pathways, thereby potentiating the anabolic effect of a given (protein) stimulus. Leucine has also been identified as a potent insulin secretagogue when administered in combination with carbohydrate and protein. Due to the combination of these functionalities, we propose that leucine could be a relevant pharmaconutrient in the prevention and treatment of sarcopenia, especially in type 2 diabetes patients.

Chapter 3 describes the first intervention study of this thesis. Building on the suggestions from chapter 2 , we investigated the effect of 6 months of leucine supplementation on muscle mass, strength and glycemic control in 60 elderly men with type 2 diabetes. During 6 months the participants were administered with leucine $(2.5 \mathrm{~g})$ or a placebo supplement with each main meal. After 6 months the amount of muscle mass in both groups remained the same. Also muscle strength and glycemic control (such as $\mathrm{HbA1c}$ and oral glucose tolerance) did not change in either group. We concluded that prolonged leucine supplementation $(7.5 \mathrm{~g} / \mathrm{d}$ ) does not represent an effective strategy to improve body composition, muscle mass, strength, glycemic control, and/or lipidemia in elderly type 2 diabetes patients who habitually consume adequate dietary protein.

In chapter 4 we investigated the impact of type 2 diabetes on muscle mass, strength and functional capacity in an older population. Muscle mass (whole body level and muscle level), muscle strength (1-repetition maximum), functional capacity (sit-tostand test and handgrip strength), and reaction time performance (computer task) were compared between 60 older men with type 2 diabetes and 32 age-matched normoglycemic controls. Leg lean mass and appendicular skeletal muscle mass were significantly lower in older men with type 2 diabetes. Additionally, leg extension strength was significantly lower in the group with type 2 diabetes. In agreement, functional performance was impaired in the men with type 2 diabetes, with longer sit-tostand time when compared with normoglycemic controls. However, muscle fiber size and reaction time performance did not differ between groups. Clearly, older patients with type 2 diabetes experienced greater impairments in leg lean mass, muscle strength, and functional capacity. Based on these findings, we argue that effective interventional strategies to counteract the loss of muscle mass and strength may be of 
even greater relevance in the older diabetic population and, as such, should be implemented at an earlier stage.

The second intervention study is described in chapter $\mathbf{5}$. In this study we investigated whether dietary protein supplementation can further augment the adaptive response to prolonged resistance type exercise training in 31 healthy elderly men and 29 healthy elderly women. During a 6 months resistance type exercise training program ( 3 times/week) the participants were randomly assigned to receive additional protein supplementation ( $15 \mathrm{~g} / \mathrm{d}$ at breakfast) or a placebo supplement. In both groups 1RM strength increased significantly, with no differences between groups. Leg muscle mass and quadriceps cross-sectional area also increased similarly in the placebo and protein groups. Likewise, type II muscle fiber size increased over time, and sit-to stand time improved in response to the training program, with no differences between the placebo and protein groups. Based on these findings, we conclude that prolonged resistance type exercise training increases skeletal muscle mass and strength, and augments functional capacity in healthy elderly men and women. However, protein supplementation $(15 \mathrm{~g} / \mathrm{d})$ does not seem to provide any benefit to further increase muscle mass, strength, and/or functional capacity.

In chapter 6 we focused on the question whether there is a difference between elderly men and women in the adaptive response to prolonged resistance type exercise training. The findings are based on the data collected during the training study (chapter 5). We show that both women and men respond similarly to $3 x$ per week of resistance type exercise training for a period of 6 months. In both groups we showed a comparable increase in muscle mass and strength and an improvement in functional capacity and metabolic health. As such, a generic resistance type exercise training program can be applied for both women and men to effectively counteract the loss of muscle mass and strength with aging.

The final chapter 7 provides a further discussion on the findings presented in this thesis. Our observations mainly point out the importance of resistance type exercise training to counteract sarcopenia in the elderly population. Within both intervention studies we did not find an effect of either leucine or protein supplementation, but we need to consider that both studies were performed in relatively healthy elderly with high habitual protein intake. This might explain the lack of additional effect in the group that received protein supplementation. With a tailored nutritional strategy towards an optimal amount, type and timing of protein supplementation, additional benefits may be expected, especially in more compromised elderly populations. Nonetheless, resistance type exercise training unarguably represents the most robust and effective intervention to increases muscle mass, strength and functional capacity in healthy elderly. We propose that with the right state of mind and proper guidance, elderly people can prevent and even reverse the age related loss of muscle mass and strength. A more active older population will reduce health care costs, increase the number of elderly living independently up to a more advanced age, and improve over- 
all well-being of our elders. We need to invest in developing a structure in which the older population can become more active, supporting healthy aging of our society. 

Samenvatting 

Veroudering gaat samen met verlies van spiermassa en spierkracht, ook wel sarcopenie genaamd. Dit verlies in spiermassa en spierkracht zorgt in het dagelijkse leven voor fysieke beperkingen en een verlies van functionele capaciteit. Sarcopenie leidt daardoor uiteindelijk tot een verminderde zelfredzaamheid. Om de afname van spiermassa en spierkracht tegen te gaan en functionele capaciteit te behouden of zelfs te verbeteren, zijn er verschillende interventies mogelijk. In dit proefschrift richten we ons voornamelijk op de positieve effecten van krachttraining en kijken we daarnaast naar de mogelijk ondersteunde rol van eiwit suppletie om spiermassa, spierkracht en functionele capaciteit bij ouderen te verbeteren.

In hoofdstuk 2 beschrijven we uitgebreid de rol die is weg gelegd voor het aminozuur leucine. Uit eerder onderzoek blijkt dat aminozuren een cruciale rol spelen bij het verhogen van de eiwitsynthese in de spieren. Met name voor leucine, welke samen met isoleucine en valine de vertakte keten aminozuren vormen, is aangetoond dat het de spiereiwitsynthese (en daarmee dus de aanmaak/opbouw van spieren) extra kan stimuleren. Bovendien stimuleert leucine ook sterk de afgifte van insuline in het lichaam wanneer het gelijktijdig wordt ingenomen met (andere) eiwitten of koolhydraten. Op basis van de gereviewde literatuur, concluderen we in dit hoofdstuk dat leucine mogelijk een pharmaceutische waarde heeft in de preventie en behandeling van sarcopenie en type 2 diabetes.

Gebaseerd op de bevindingen uit de leucine review (hoofdstuk 2), beschrijven we in hoofdstuk 3 de eerste interventiestudie uit dit proefschrift. In deze studie zijn de effecten van 6 maanden leucine suppletie op spiermassa, spierkracht en glycemische controle van 60 oudere mannen met type 2 diabetes onderzocht. De deelnemers namen gedurende 6 maanden een supplement van 2,5 gram leucine of een placebo supplement bij elke maaltijd. Na 6 maanden bleek de hoeveelheid spiermassa in beide groepen gelijk te zijn gebleven. Ook spierkracht en glycemische controle (zoals $\mathrm{HbA1c}$ en orale glucose tolerantie) veranderden niet in beide groepen. Deze studie toont duidelijk aan dat simpelweg het innemen van extra leucine voor een periode van 6 maanden $(7,5 \mathrm{~g} / \mathrm{dag})$ geen effect heeft op spiermassa, spierkracht en glycemische controle in oudere mannen met type 2 diabetes die dagelijks al voldoende eiwit consumeren.

In hoofdstuk 4 onderzochten we de invloed van type 2 diabetes op spiermassa, spierkracht en fysiek functioneren in een oudere populatie. Hiervoor hebben we 60 oudere mannen met type 2 diabetes vergeleken met 32 gezonde oudere mannen, met betrekking tot spiermassa (zowel op heel lichaamsniveau als op spierniveau), spierkracht, fysiek functioneren (snel opstaan uit een stoel en handknijp kracht) en reactietijd (met behulp van een computertaak). We zagen dat de mannen met type 2 diabetes minder spiermassa in de benen hadden, en minder spierkracht en een verminderd fysiek functioneren in vergelijking met de gezonde mannen. Voor de grootte van de spiervezels en voor reactietijd werden geen verschillen gevonden tussen beide groepen. Trainingsprogramma's voor ouderen zijn erop gericht om verminderde spiermassa en spierfunctie te vergroten. Gezien de slechtere fysieke conditie in oudere type 2 diabetes patiënten, is het voor deze populatie nog belangrijker om effectieve interven- 
tieprogramma's in een vroeg stadium te implementeren zodat de verminderde spiermassa en spierkracht worden aangepakt en het fysiek functioneren verbetert.

In hoofdstuk 5 vervolgen we met een tweede interventiestudie. In deze studie onderzochten we de invloed van 6 maanden krachttraining met of zonder eiwitsuppletie op spiermassa, spierkracht en fysiek functioneren van 31 gezonde oudere mannen en 29 gezonde oudere vrouwen. Gedurende 6 maanden lang kregen de deelnemers dagelijks bij het ontbijt een eiwitsupplement (15 g eiwit) of een placebo supplement. Alle deelnemers namen deel aan de krachttraining die 3 keer per week onder begeleiding plaatsvond. In beide groepen zagen we een significante stijging in spiermassa (op zowel heel lichaams- als spierniveau), spierkracht en fysiek functioneren. Er was echter geen verschil tussen de groep die het eiwitsupplement kreeg en de groep die het placebo kreeg. Op basis van deze bevindingen concluderen we dat langdurige krachttraining spiermassa, spierkracht en fysiek functioneren verbetert in gezonde ouderen, maar dat additionele eiwitsuppletie geen verdere verbetering teweeg brengt in gezonde ouderen die al voldoende eiwit consumeren.

In hoofdstuk 6 hebben we de data uit de trainingsstudie (hoofdstuk 5) nader geanalyseerd om te onderzoeken of geslacht een effect heeft op de trainingsrespons in gezonde ouderen. Uit ons onderzoek blijkt dat vrouwen en mannen hetzelfde reageren op $3 x$ per week krachttraining. In beide groepen zagen we dat spiermassa, spierkracht en fysiek functioneren in gelijke mate toenamen tijdens 6 maanden krachttraining. Ook de positieve effecten op (cardio)metabole gezondheid waren hetzelfde voor mannen en vrouwen. Op basis van deze data kunnen we concluderen dat een standaard krachttrainingsprogramma zowel bij vrouwen als bij mannen vergelijkbare resultaten heeft op spierkracht, spiermassa en op fysieke functioneren.

In het laatste hoofdstuk worden de onderzoeksresultaten uit dit proefschrift nader bediscussieerd. De bevindingen van dit proefschrift tonen vooral het belang van krachttraining aan om spiermassa en spierfunctie te verbeteren in gezonde ouderen. Binnen onze interventiestudies hebben we geen (extra) effect gevonden van leucine of eiwitsuppletie, maar hierbij moet wel opgemerkt worden dat de gezonde ouderen in onze studies al (meer dan) voldoende eiwit innamen in hun dagelijkse voeding. Het is mogelijk dat we daarom geen additioneel effect konden oppikken in deze groep en verder onderzoek zou zich daarom moeten richten op de meer gecompromitteerde oudere (patiënt) populaties. Daarbij zou vooral aandacht besteed moeten worden aan de optimale hoeveelheid, het type, en de timing van (extra) eiwit inname om de adaptatie aan krachttraining verder te ondersteunen. Op basis van dit proefschrift blijkt echter dat krachttraining op zichzelf de meest effectieve strategie is om zowel spiermassa, spierkracht, als het fysiek functioneren bij gezonde ouderen te verbeteren. Hieruit kunnen we concluderen dat met de juiste instelling en correcte begeleiding, krachttraining in gezonde ouderen een cruciale bijdrage kan leveren om sarcopenie tegen te gaan en misschien zelfs te voorkomen. Een actieve oudere populatie zal de gezondheidskosten verlagen, de mate van onafhankelijkheid vergroten en het algemene gevoel van welzijn verbeteren. Kortom, we moeten investeren in de ontwikkeling 
van een structuur waarin ouderen gestimuleerd worden om actiever te zijn, om het gezond ouder worden van onze gemeenschap waar te kunnen maken. 



\section{Valorization}



In current times, ever increasing scientific, socio-economic and political attention is going out to the health implications of global aging. Considering the demographic development over the past decades as well as the population projections for the upcoming period, this is hardly surprising. Between 2015 and 2050, the proportion of the world's population over 60 years will nearly double from $12 \%$ to $22 \%$. Even more striking, the number of people aged $80 \mathrm{y}$ and older is expected to more than triple, from 125 million in 2015 to 434 million by 2050 (1). Similar expectations have been reported for the Netherlands, where the growth of the total population will mainly be due to increased longevity. In line with the tripling on a global level, the number of Dutch people aged 80 y and over is expected to increase from 700,000 at present to 2 million in 2060 (2). The fact that people live longer is a positive sign in many ways, as life expectancy in itself is clearly associated with the general health of the population as well as the quality of the health care system. However, it also poses many challenges to maintain health and functional capacity in older people. This is essential to limit their social isolation, prevent the loss of independence, and ensure that quality of life is not exchanged with the extra years to live (1). Aging is generally accompanied by a decline in skeletal muscle mass, also known as sarcopenia. Loss of skeletal muscle mass may lead to a reduction in muscle strength and physical function, which increases the risk of falls and fractures. This could ultimately result in the loss of independence and an increase in nursing home admissions. Developing effective interventions to prevent or delay the onset of sarcopenia may improve the quality of life of older individuals, and simultaneously reduce the health care costs associated with impairments in physical functioning. This thesis focused on both exercise and nutritional interventions to counteract the negative consequences of age-related sarcopenia. Here, we shortly address how our findings may be relevant to define future research goals as well as how they should be implemented into intervention strategies aimed at healthy aging of our society.

This thesis provides further evidence that resistance type exercise training is one of the most potent stimuli to increase muscle mass, strength and functional capacity in the healthy elderly population. However, our findings as well as those from multiple other long term training studies need to be translated and implemented into daily practice. We need a structure in which physical activity is facilitated, supported, and encouraged. This includes both the trigger to become more physically active, and the continued stimulus to remain active. Such a process may entail the commitment of 1 ) scientists to provide the evidence showing the (health) benefits of exercise; 2 ) policy makers to provide the financial and/or (infra)structural conditions needed for implementation; 3) health professionals to convince the elderly of the need for being physically active; and 4) health insurance companies to (financially) stimulate physical activity both in terms of disease treatment and prevention. Obviously, a multidisciplinary approach is needed to create a different mindset at all these levels. Yet, there is already general awareness for the need to remain actively involved in society and to maintain inde- 
pendence throughout a lifetime. The next step is to really make this happen. There is ample evidence that lifestyle intervention programs, including both exercise and nutritional aspects, can lead to great improvements in muscle mass and functional capacity, as well as (metabolic) health. More work is needed to support these findings through large-scale efficacy studies in which the benefits may become even more evident in terms of improved quality of life and reduced health care costs. The latter may also include cost-effectiveness studies, considering the enormous health-care costs associated with specific age-related morbidity. For example, reduced fall risk due to improved muscle mass, strength and balance may lead to a reduction in the number of hip fractures, which represents a major health care cost for the elderly population, and is associated with both decreased quality of life and increased mortality. We have clearly shown that with proper guidance and supervision, resistance type exercise training represents a feasible means to improve overall physical functioning in healthy elderly men and women. In addition, recent work also suggests that even structured, moderate-intensity physical activity programs can already reduce major mobility disability among older adults at risk for disability (3). We propose that the time has come to start with the actual implementation of physical activity programs for the general older population.

Apart from the healthy elderly men and women included in the training study described in this thesis, we have also focused on elderly type 2 diabetes patients. In this population we observed a significant larger decrease in muscle mass and strength compared to healthy elderly. As such, this specific patient group likely needs specific tailored interventions. In fact, this may also be the case for other more compromised elderly subpopulations, such as more frail elderly, COPD patients, cancer patients, etc. Considering the multi-morbidity that is often evident in these subgroups, a more interdisciplinary approach between e.g., exercise physiologists, diabetes nurses, clinicians and other health care professionals should be pursued to create the leverage needed to change (clinical) practice. Previous work has already shown to some extent that (resistance type) exercise training in these populations can represent an efficient addition to their general care program. However, more work is needed to tailor intervention programs to the needs of such specific patient groups, especially when focusing on improving muscle mass and function.

For all the studies discussed in this thesis, we failed to show the additional benefits of amino acid or protein supplementation. However, in a recent meta-analysis (4), we did observe an additional benefit of protein supplementation on top of the effects of prolonged resistance type exercise training. In line with this observation, more recent work focusing on specifically tailored nutritional interventions, either alone or in combination with resistance type exercise, indeed shows improvements in muscle mass and function in the elderly following nutritional co-intervention (5-7). Current evidence indicates that optimizing dietary protein intake is of key importance for the elderly in general, and may be even of even greater relevance for those at higher risk of develop- 
ing sarcopenia and frailty. Recent position stands also refer to the need for separate protein recommendations for older people, even specifying different subcategories (8). Future work should focus on verifying these recommendations and evaluating the separate and combined effects of resistance type exercise and tailored protein supplementation in various subgroups of (more clinically compromised) elderly. These studies should build on knowledge obtained from short-term 'acute' studies, selecting those strategies that will likely induce the strongest effects. This may include differentiation in the amount, type, and composition of the protein, as well as the timing of protein intake (e.g., providing additional protein at breakfast and/or lunch, and even prior to sleep). Such knowledge is essential for adopting new recommendations on food intake in the elderly. Furthermore, it will provide ample leads for the development of specific nutritional products and/or supplements tailored towards the needs of the ever growing number of older people in our society. Overall, increased attention and awareness for the main adjustable lifestyle factors, i.e., physical activity and nutrition, should form the basis for improving muscle mass and function in the elderly, both from a healthy aging and from a clinical perspective.

In summary, counteracting or preventing muscle loss with aging is of major importance for the quality of life of the older individual, but also from an economic perspective regarding the health care costs associated with sarcopenia. In addition to the healthy aging population and elderly with diabetes, the results from this thesis can be translated into other clinical conditions where progressive skeletal muscle mass loss plays an important role in reducing physical functioning, including conditions such as cancer cachexia, chronic obstructive pulmonary disease (COPD), renal insufficiency, and cardiovascular disease. Scientific evidence showing the importance of both exercise interventions and nutritional strategies to increase protein intake in the elderly is slowly accumulating (9), and the time has now come to translate these findings into clinical practice. The (clinical) nutritional industry aims to develop new products/concepts to support healthy aging. The findings from this thesis will give direction for future research aiming at the development of novel exercise, nutritional and/or pharmaceutical interventions to combat the loss of skeletal muscle mass, strength, and functional capacity in a variety of older subpopulations.

In the next decade much of our knowledge on the impact of physical activity and nutrition on muscle mass and strength preservation will be applied in interventional strategies to support healthy aging. 


\section{References}

1. WHO. World report on ageing and health. 2015.

2. CBS. Centraal Bureau voor de Statistiek: 18,1 miljoen inwoners in 2060. Persbericht PB14-085 2014.

3. Pahor M, Guralnik JM, Ambrosius WT, Blair S, Bonds DE, Church TS, Espeland MA, Fielding RA, Gill TM, Groessl EJ, King AC, Kritchevsky SB, Manini TM, McDermott MM, Miller ME, Newman AB, Rejeski WJ, Sink KM, Williamson JD; LIFE study investigators. Effect of structured physical activity on prevention of major mobility disability in older adults: the LIFE study randomized clinical trial. JAMA 2014 Jun 18;311(23):2387-96.

4. Cermak NM, Res PT, de Groot LC, Saris WH, van Loon LJ: Protein supplementation augments the adaptive response of skeletal muscle to resistance-type exercise training: a meta-analysis. Am J Clin Nutr 2012, 96(6):1454-1464.

5. Tieland M, Dirks ML, van der Zwaluw N, Verdijk LB, van de Rest O, de Groot LC, van Loon LJ. . Protein supplementation increases muscle mass gain during prolonged resistance-type exercise training in frail elderly people; a randomized, double-blind, placebo-controlled trial. J Am Med Dir Assoc. 2012 Oct;13(8):720-6.

6. Tieland M, van de Rest O, Dirks ML, van der Zwaluw N, Mensink M, van Loon L, de Groot LC. et al. Protein supplementation improves physical performance in frail elderly people: a randomized, doubleblind, placebo-controlled trial. J Am Med Dir Assoc. 2012 Oct;13(8):720-6.

7. Bauer JM, Verlaan S, Bautmans I, Brandt K, Donini LM, Maggio M, McMurdo ME, Mets T, Seal C, Wijers SL, Ceda GP, De Vito G, Donders G, Drey M, Greig C, Holmbäck U, Narici M, McPhee J, Poggiogalle E, Power D, Scafoglieri A, Schultz R, Sieber CC, Cederholm T. Effects of a vitamin D and leucine-enriched whey protein nutritional supplement on measures of sarcopenia in older adults, the PROVIDE study: a randomized, double-blind, placebo-controlled trial. J Am Med Dir Assoc. 2015 Sep 1;16(9):740-7.

8. Bauer J, Biolo G, Cederholm T, Cesari M, Cruz-Jentoft AJ, Morley JE, Phillips S, Sieber C, Stehle P, Teta D, Visvanathan R, Volpi E, Boirie Y. Evidence-based recommendations for optimal dietary protein intake in older people: a position paper from the PROT-AGE Study Group. J Am Med Dir Assoc. 2013 Aug;14(8):542-59.

9. Morley JE. Nutritional supplementation and sarcopenia: the evidence grows. J Am Med Dir Assoc. 2015 Sep 1;16(9):717-9. 
Dankwoord 

Mijn naam staat dan wel op dit proefschrift, maar hier zijn ontzettend veel mensen bij betrokken geweest. Daarom wil ik toch even van dit stukje gebruik maken om een aantal mensen te bedanken voor hun bijdrage aan het tot stand komen van dit proefschrift.

Luc, het is voor ons allebei een uitdaging geweest om dit tot een goed einde te brengen. We waren het misschien niet altijd eens, maar ik heb ontzettend veel van je geleerd. Dank je wel voor je gedrevenheid, je passie en je toewijding voor onderzoek. Ik hoop dat je deze rol nog lang mag blijven spelen voor veel PhD studenten.

Lex, ik bewonder je geduld, je steun en je toewijding als co-promotor. Ik kon altijd bij je binnenspringen, bedankt dat je deze belangrijke rol voor me wilde spelen. Ik vond het heel waardevol en ontzettend leuk om met je samen te werken.

Letty, jij verdient hier zeker een plaatsje. Jij bent hier bijna van start to finish bij geweest en door dit mooie project zijn we vriendinnen voor het leven geworden. You rock!!! Bedankt voor al de vroege ochtenden, de analyse van al die dagboekjes en de lol met compres poppetjes $:$. Merci voor al je steun en bedankt dat je er ook tijdens mijn promotie als paranimf bij wilt zijn.

Astrid, jou heb ik echt leren kennen dankzij dit project! Ge zijt een madam met ballen en dat bewonder ik echt aan je! Merci voor al je steun, de peptalks en de leuke tripjes naar Wageningen en ook op deze manier wil ik je een dikke proficiat wensen met je zwangerschap, je gaat een super mama zijn! En wat leuk dat we met 5 dames deze promotie mogen meemaken! Thanks for having my back!

Marlou, Imre en Stefan, ik ben dan wel al een hele tijd weg op de uni maar onze tijd samen vond ik super! En Stefan wij delen nu zelfs onze promotiedatum! Ik wens jullie het allerbeste voor de toekomst! Leve het dansmatten!

Joan, Antoine, Janneau en Rachel, jullie zijn het bewijs, onderzoek doe je niet alleen! Merci voor al de analyses en Joan/Antoine voor de prikochtenden. Jullie zijn de backbone van M3!

Ook een dikke merci voor heel de M3-groep! Het was een eer om van deze groep deel uit te maken!

Alle proefpersonen die hebben meegedaan aan de onderzoeken van dit proefschrift. Bedankt voor jullie enthousiasme en de ontzettende leuke momenten die jullie me hebben bezorgd. Bedankt dat jullie hierin jullie kostbare tijd hebben willen steken. Zonder jullie was dit niet mogelijk geweest.

Al de stagiaires die mee hebben gewerkt aan mijn studies, een dikke merci! 
Mama en papa, wie had ooit gedacht dat we hier nu zouden staan, zonder jullie was dit nooit mogelijk geweest. Bedankt voor al jullie steun, voor het vertrouwen en er altijd voor me te zijn!

Thomas, mijn steun en toeverlaat... Jouw rust bewonder ik het meest en dat doet me goed. Bij jou kan ik thuiskomen en voel ik me veilig. Bedankt voor alles liefsjepiefje! Op naar onze volgende uitdagingen (verhuizen en ons gezinnetje met 4). Je maakt me super gelukkig!

Layla, mijn muis... Door jou heb ik terug geleerd wat echt belangrijk is in het leven. Je lach, je vrolijkheid en altijd zo goed gezind zijn geeft me vertrouwen en maakt me intens gelukkig! Je gaat een geweldige grote zus zijn!!!

Lieve kleine meid in de buik, wat fijn dat jij erbij gaat zijn, een extra mini paranimf! Jij en Layla betekenen de wereld voor me! 
Curriculum Vitae 

Marika Leenders was born on October 22, 1982 in Genk (Belgium). She completed secondary school at the Heilig Graf Instituut in Bilzen in 2000. Marika obtained her bachelor in General Health Sciences at Maastricht University in October 2005. Consecutively, she studied Physical Activity and Health at Maastricht University and obtained her Master's degree in August 2006. In the same year, Marika started a master's program at Edinburgh University in the UK. After an internship on core stability in rowers and dancers she obtained her second master's degree in strength and conditioning in November 2007.

While finishing her master thesis in Edinburgh, Marika worked as a Personal trainer for Virgin Active for 4 months. In September 2007 Marika was offered a position as teaching fellow in sport and exercise science at University of Abertay in Dundee. In February 2008, Marika started her PhD trajectory entitled "Dietary strategies to augment muscle mass and function in elderly people" at the Top Institute Food and Nutrition (TIFN) and the Department of Human Movement Sciences at Maastricht University under supervision of Prof. dr. Luc van Loon and Dr. Lex Verdijk. This work resulted in the present dissertation and numerous publications in scientific peer-reviewed journals. In September 2012, Marika started working as Clinical Research Specialist at Medtronic Spine and Biologics, located at the Bakken Research Center in Maastricht. In her position, she is trial manager for various clinical spine studies on a global level. 



\section{Publications}





\section{PUBLISHED MANUSCRIPTS}

van der Linden $\mathbf{N}$, Klinkenberg $L$, Leenders $\mathbf{M}$, Tieland $M$, Verdijk LB, Niens $M$, van Suijlen JD, de Groot LC, Bekers O, van Loon L, van Dieijen-Visser MP, Meex SJ. The effect of exercise training on the course of cardiac troponin T and I levels: three independent training studies. Sci Rep. 2015 Dec 16;5:18320.

Churchward-Venne TA, Tieland M, Verdijk LB, Leenders M, Dirks ML, de Groot LC, van Loon LJ. There Are No Nonresponders to Resistance-Type Exercise Training in Older Men and Women. J Am Med Dir Assoc. 2015 May 1;16(5):400-11.

Leenders M, Verdijk LB, van der Hoeven L, Adam JJ, van Kranenburg J, Nilwik R, van Loon U. Patients with type 2 diabetes show a greater decline in muscle mass, muscle strength, and functional capacity with aging. J Am Med Dir Assoc. 2013 Aug;14(8):585-92.

Nilwik R, Snijders T, Leenders M, Groen BB, van Kranenburg J, Verdijk LB, van Loon LJ. The decline in skeletal muscle mass with aging is mainly attributed to a reduction in type II muscle fiber size. Exp Gerontol. 2013 May;48(5):492-8.

Leenders M, Verdijk LB, van der Hoeven L, van Kranenburg J, Nilwik R, van Loon LJ. Elderly men and women benefit equally from prolonged resistance-type exercise training. J Gerontol A Biol Sci Med Sci. 2013 Jul;68(7):769-79.

Leenders M, Verdijk LB, van der Hoeven L, van Kranenburg J, Nilwik R, Wodzig WK, Senden JM, Keizer HA, van Loon LJ. Protein supplementation during resistance-type exercise training in the elderly. Med Sci Sports Exerc. 2013 Mar;45(3):542-52.

Leenders $\mathbf{M}$, van Loon $\mathrm{L}$. Protein supplementation during resistance-type exercise training in the elderly. Nutr Rev. 2011 Nov;69(11):675-89.

Leenders M, Verdijk LB, van der Hoeven L, van Kranenburg J, Hartgens F, Wodzig WK, Saris WH, van Loon LJ. Prolonged leucine supplementation does not augment muscle mass or affect glycemic control in elderly type 2 diabetic men. J Nutr. 2011 Jun; 141(6):1070-6..

Hansen D, Dendale P, Leenders M, Berger J, Raskin A, Vaes J, Meeusen R. Reduction of cardiovascular event rate: different effects of cardiac rehabilitation in CABG and PCI patients. Acta Cardiol. 2009 Oct;64(5):639-44. 

The studies presented in this thesis were performed within the framework of TI Food and Nutrition.

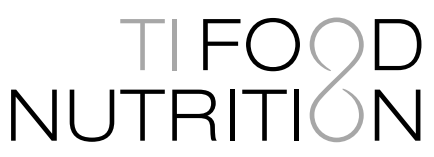

Financial support for printing of this dissertation was kindly provided by: 
